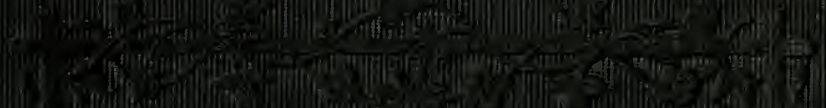
ind 
BERKELEY GENERAL LIBRARY UNIVERSITY OF CALIFORNIA

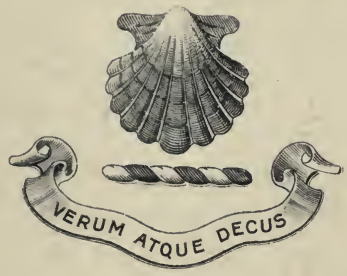

Afithur C. Hilsom- Broume.

Sultom Boldefield.

Maturistishive.

DR. GEORGE PARKER HIOLEN 122 Malean AVe. Yonkers, N. Y. 

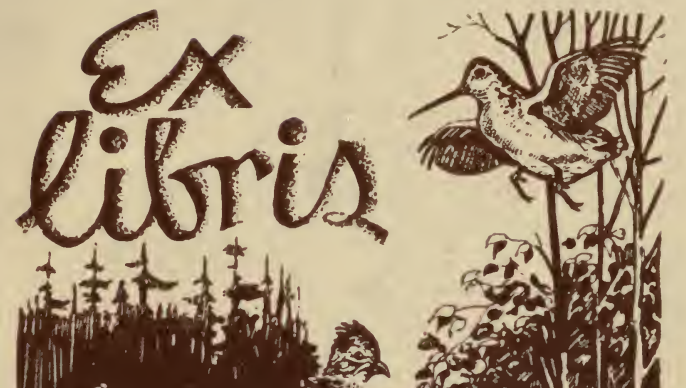

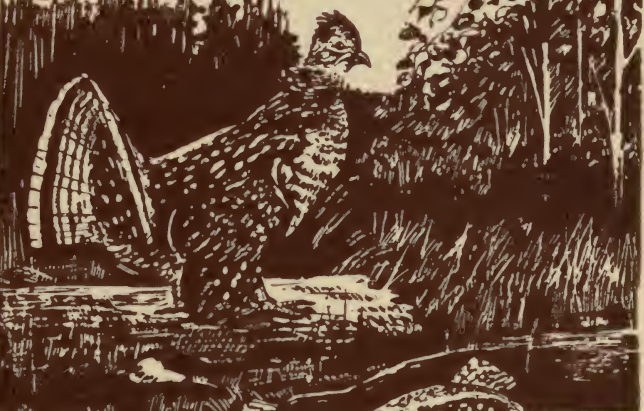

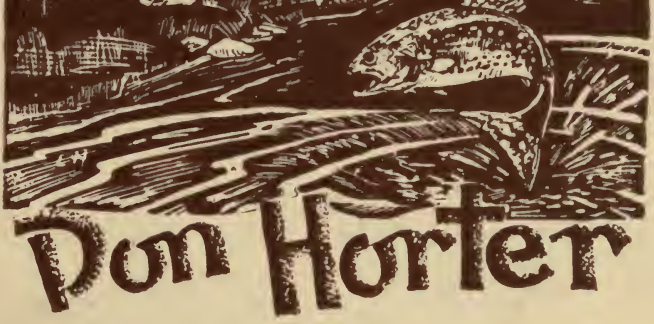





\section{HANDBOOK OF ANGLING.}




\section{LoNDON :}

Spotriswoode and Shaw, New-street-Square. 


\section{HANDBOOK OF ANGLING:}

TEACHING

FLY-FISHING，TROLLING，BOTTOM-FISHING,

AND SALMON-FISHING;

WITH THE

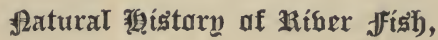

AND

THE BEST MODES OF CATCHING THEM.

B Y

\section{EPHEMERA,}

OF "BELL'S LIFE IN LONDON."

(Edrand oritgibion)

"I have been a great follower of fishing myself, and in its cheerful solitude have passed some of the happiest hours of a sufficiently happy life." - PALEY.

\section{LONDON :}

- PRINTED FOR

LONGMAN, BROWN, GREEN, AND LONGMANS,

PATERNOSTER-ROW.

1847.

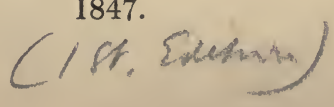


Digitized by the Internet Archive in 2007 with funding from Microsoft Corporation 


\title{
54439 757
}

TO

\section{VINCENT GEORGE DOWLING, ESQ.}

\author{
wно, \\ OF ALL HIS CONTEMPORARIES,
}

HAS BEEN ONE OF THE MOST ENERGETIC AND SUCCESSPUL

PROMOTERS OF FIELD SPORTS,

\section{Thís ฮerork,}

INTENDED TO SET FORTH THE THEORY AND PRACTICE

OF

THE GENTLE CRAFT,

IS INSCRIBED,

IN TOKEN OF THE ESTEEM AND REGARD OF

HIS FRIEND AND SERVANT,

THE AUTHOR.

A. 3 



\section{P R E F A C E.}

I HAVE been for several years before the public as a periodical writer on piscatorial matters, and during this period have received more communications than I can enumerate, from correspondents in various parts of the empire, urging me to write a plain, sensible, practical book on Angling in general.

They have one and all complained that the majority of works extant upon Angling treated only of one branch of the art; and even in those works which embraced a greater variety of the subjects the treatment was so limited as to be unsatisfactory and incomplete. They have insisted upon the necessity of a book that would teach, as far as possible, practically and fully, fly-fishing, trolling, and bottom-fishing; and they have also thought so favourably of me as to assert that they had full confidence in my ability to fill up the hiatus they lamented. Thus pressed to render a service to the angling world, I have made the attempt in the following pages.

Deeming fly-fishing the most important division of the art, I have written on it with metho- 
dical minuteness. I have shown how every part of it is to be practised, and the different sorts of gear requisite; and I have given a full list of all the artificial baits which the fly-fisher must use for the capture of salmon, trout, grayling, and some of the carp tribe. I have made this section of the book as interesting and instructive as I could.

The reader will find a short and useful chapter on fly-making. Each stage of its process is illustrated by a wood-cut, and an attempt has been made to explain each cut simply, clearly, and concisely. The different materials for fly-making are named, and the best recipes given for dyeing some of them.

In the list of artificial flies for every month of the angling season I have emphatically pointed out the most killing ones, shown several ways of making them, and stated when and where, and what fish they will take. Every fly in the list is more or less necessary; and in the text will be found my opinion of each artificial insect that deserves special notice. In composing the list, I have called to my aid the best authorities on the subject of artificial flies.

There will be found a chapter on the materials and manufacture of rods, in which those fittest for salmon and trout fishing are pointed out; and the greatest care has been taken in stating the materials of which they should be manufactured, 
the mode of making them, and the relative proportions of length and strength they should possess. I have been equally careful in designating the best kinds of trolling, spinning, and bottom-fishing rods. The chapter embodies the opinions of the best anglers and tackle-makers with whom I am acquainted.

The second division of the book is devoted to trolling and spinning. I show how they are practised; and illustrations are given of the most efficient tackle successful practice requires. This part of my subject I have simplified, and I trust the reader will say usefully.

In the next chapter I have given the fullest instructions on bottom-fishing, stating the best rods, lines, and hooks required; and giving a detailed catalogue of the most deadly baits, showing how they are to be used, preserved, and, when possible, telling how some of them are best made.

In order that certain moot points might be set at rest - I mean those which relate to the senses of fish, to their power of seeing, hearing, feeling, and tasting, - I have induced Mr. Erasmus Wilson, F.R.S., a most accomplished physiologist, to write me a chapter on the subject. He has kindly done so ; and the studious and intelligent angler cannot fail to derive much valuable information from its perusal.

The book concludes with a natural history of 
the angler's fish, and descriptions of the best modes of catching them. I have treated on the salmon much more fully than any other elementary writer on angling. The singular history and habits of that splendid fish I have detailed with considerable minuteness; nor will the reader be disposed to question the accuracy of my statements when he is told that they are founded on the authoritative data of Messrs. Shaw, Young, and Scrope. This portion of the book will probably agreeably surprise many anglers. I have not failed to mention any bait by which the salmon may be captured in a sportsman-like way. The habits of trout, grayling, pike, and of the carp family have been treated with careful brevity.

In a word, I have attempted to write what I was called upon to do, and what on deliberate reflection I think the angling community are in want of, viz., a portable and practical book from which the tyro may learn all the right theory and safe practical principles of the art, while even the old professor may find a few new hints, and have recalled to his memory some useful details that may have faded from it. Should time prove that I have succeeded in rendering a service to the brethren of the gentle craft, I shall consider myself amply rewarded for my labour, and shall be stimulated to new exertions. 


\section{O N T E N T S.}

\section{CHAPTER I.}

Angling defined.-Divided into three branches.-Each briefly described.-The superiority and merits of Flyfishing

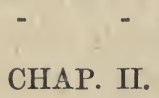

Throwing the Line and Flies - Humouring them.-Fishing a Stream.- Striking, hooking, playing, and landing a Fish

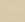

CHAP. III.

On artificial Flies

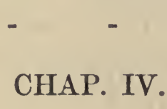

Fly-dressing -

$-$

CHAP. V.

A monthly List of Flies for the Season

CHAP. VI.

Fishing with the natural Fly, or dibbing or daping - 144

CHAP. VII.

Trolling. - Rods, Lines, Tackle, and Baits, and Methods of using them

$-162$ 


\section{CHAP. VIII.}

On Bottom-fishing. - Rods, Hooks, Lines, and Baits

Page 219

CHAP. IX.

On the proper Materials and Manufacture of Rods - 273

\section{CHAP. X.}

On Piscatorial Physiology, by Erasmus Wilson, F.R.S. 286

\section{CHAP. XI.}

The Habits of the Angler's Fish, and the best Ways of

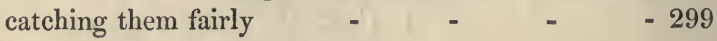




\section{A}

\section{HANDBOOK OF ANGLING.}

\section{CHAPTER I.}

ANGLING DEFINED. - DIVIDED INTO THREE BRANCHES.EACH BRIEFLY DESCRIBED. - THE SUPERIORITY AND MERITS OF FLY-FISHING.

ANGLING, or the art of taking fish with rod, line, and hook, or with line and hook only, is one of the oldest of out-door amusements and occupations. At first the modes of practising it were exceedingly rude, as they still are amongst uncivilised nations. There are tribes in existence now that fashion the human jaw bones into fishhooks. Even unto this day angling implements, amongst many of the politest people of Europe, are manufactured with imperfect roughness. The inhabitants of the British isles alone cultivate all matters pertaining to rural sports, of whatsoever kind they may be, but particularly hunting, shooting, and angling, with that persevering ardour 
which leads to perfection. In their efforts to acquire the surest, most amusing, most health-giving, and, I may say, most elegant modes of pursuing and capturing their game, be it the produce of field or flood, they call to their aid several ancillary studies, amongst which stands prominent that of the natural history of animals and of other living things, ranking not so high in the scale of creation. The hunter studies the habits of horse and $\mathrm{dog}$, and of the ferce naturce he pursues with them, the fowler of the birds of the air, and the fisherman of the fish of the water. Hence knowledge, skill, and success; hence the accomplished sportsman, rarely found except amongst the best types of Englishmen, whether of high or low degree.

Though angling has been jeered at more than any other sporting practice, still no other subject connected with field sports has been more minutely and extensively written upon. No sporting writer is so generally known as Izaak Walton, and his " Complete Angler" has earned for him an immortality which will last until the art of printing our language shall be forgotten. May that time never arrive! The subject then cannot be unworthy of a modern pen; but the pen perchance may be unworthy of the subject, and thus prove an obstacle to my design, which is to write upon angling in a plain, connected, business-like way, 
teaching its modern theory and practice, together with the recent discoveries, inventions, and improvements that have been made in the art.

The art of angling is divided into three main branches, the general principles of which being understood, an acquaintance with minute detail will follow gradually as a matter of course.

The first branch embraces angling at the surface of the water, and comprehends fly-fishing with natural or artificial insects, the latter being of more general use. The second embraces angling at mid-water, or thereabouts, and includes trolling or spinning with a live, a dead, or an artificial bait - with a small fish, mouse, frog, or their representatives. The third includes bottomfishing, which is angling at or near the bottom of the water with worms, gentles, and many sorts of inanimate baits. Bottom-fishing is the most primitive, the commonest, and easiest mode of angling; trolling is less common and more difficult; fly-fishing is the most difficult and amusing of all, and though less commonly practised than bottom-fishing, is more generally so than trolling.

Although in teaching an art it would be more regular to commence with the easiest branches of it, I begin, for several reasons, with fly-fishing, acknowledging it to be that division of the art of angling which is learned the least easily. I shall only give one reason for my irregularity, viz. that 
he who has learned the practice of fly-fishing will readily learn the two other branches of angling. If the reader should desire to be more methodical than I am, he has the power of being so, by reading this hand-book as if it were written in Hebrew. He will then find the last first, and the first last. If he wishes for slow, but sure advancement, let him reverse the order of reading, moving from the back rank to the centre, and so on to the front.

The long-continued, unbroken chain of ignorance that runs, in some instances, through the world is almost incomprehensible to the active mind. It is a miracle of visible darkness amidst the intelligence that surrounds us. "The dictionary-making pensioner," as Cobbett used to call Dr. Samuel Johnson, defined angling, as a silly thing, practised by a fool at one end of a rod and line, and a worm at the other. Many stupid people still adhere to this very stupid definition. With the practice of angling they associate nothing beyond worms, punts, patience, a nibble and tittle-bat sport. A salmon caught by angling! No-no such prodigy in their opinion ever occurred.

Let us now see what fly-fishing is - whether it is a fool at one end of a rod, and a worm at the other. The greatest names in arms, science, literature and art have been devoted to fly-fishing. Nelson's "dear, dear Merton," with its Wandle 
wandering by, offered him an attraction which he constantly revelled in, viz. fly-fishing. Sir H. Davy, Archdeacon Paley, Sir Francis Chantry, Sir Walter Scott, were enthusiastic fly-fishers. General Sir Charles Dalbiac, the Duke of Roxburghe, the Earl of Essex, and many other great names I could mention, are constant and consummate practitioners of the pleasing sport. Other field sports may be more exciting, but there is not one requiring more skill, or calling into exercise more intelligence and adroitness of mind and body. A quick eye, a ready and delicate hand, an apprehensive brain, delicacy in the senses of touch and hearing, activity of limb. physical endurance, persevering control over impatience, vigilant watchfulness, are qualifications necessary to form the fly-fisher. His amusing struggles, teeming with varying excitement, are with the strongest, the most active, the most courageous, the most beautiful and most valuable of river fish, and his instruments of victory are formed of materials so slight, and, some of them so frail, that all the delicacy and cunning resources of art are requisite to enable feebleness to overcome force. The large, vigorous, nervous salmon, of amazing strength and wonderful agility - the rapid trout of darting velocity, hardy, active, untiring, whose dying flurry shows almost indomitable resistance, are hooked, held in, wearied out, by the skilful 
and delicate management of tackle that would, if rudely handled, be bent and strained by the strength and weight of a minnow. 'Tis wonderful to see hooks of Lilliputian largeness, gut finer than hair, and a rod, some of whose wooden joints are little thicker than a crow's quill, employed in the capture of the very strongest of river fish. The marvel lies in the triumph of art over brute force. If the sporting gear of the fly-fisher were not managed with art - on the mathematical principle of leverage - he could not by its means lift from the ground more than a minute fraction of the dead weight of that living, bounding, rushing fish he tires unto death, nay, drowns in its own element. The overcoming of difficulties by the suaviter in modo forms one of the greatest charms of fly-fishing, and to my fancy is the pleasantest element of success that can be used in any pursuit. Persuade, but never drive.

The baits of the pure fly-fisher are imitations of insects in one or other of their forms. He fishes with imitations of the fly, the beetle, the grub, the caterpillar and moth. These imitations are made of divers materials, the chief whereof are feathers, fur, mohair, wool, and silk. They are affixed round hooks of various sizes, and by a process requiring the most skilful and delicate manipulation. The fly-dresser is a modeller of no mean attributes. He has to represent, by means of 
the most delicate substances of varied tissue and colour, insects, often complete atomies, and of changeable shapes and hues. Extreme neatness characterises all the paraphernalia of the fly-fisher. His sport requires the handling of nothing that will soil the best-bred hand. The composition of his bait extracts pain from no living thing; not even from the worm you tread upon. To know that his baits are good, he must to a certain extent be a naturalist. He must be acquainted with the outward appearances of several sorts of insects; he must know the divisions of the seasons in which they live and cease to be; he must know the climates and localities peculiar or otherwise to each species; he must know their names, and be able to classify them, if not scientifically, at least piscatorially; he must know those that prove the most attractive food for each kind of fish he angles for ; in fact, he must possess a fund of knowledge that will cause him to be considered an accomplished man by the members of every rational society.

To render the pleasures attendant on his pursuit complete, he is invited, if he seeks for superlative success, to practise it amongst the most picturesque panorama devised by nature. The brook that runs along the hill's side, the swift stream that dashes through the valley, the mountain waterfalls, the currents foaming between 
moss-grown rocks, or brawling over a pebbly bottom, are the scenes of the fly-fisher's triumphs. The salmon, and salmonidæ, the most frequent prizes of the fly-fisher's skill, are not to be found in the sluggish, turbid waters that flow through flats and fens, but breed in, and inhabit, in due season, those delightful streams that play over table-lands. Their food is not the offal of slime or mud, but the insects that disport on the surface of clear water. There the bounding salmon tribe seek them, and in that search they encounter the fatal artificial insect of the fly-fisher, and all the deadly resources of his craft. The shape, the colour, the flavour of the fly-fisher's fish do not mis-beseem the beauties that surround salmon, trout, and grayling streams. The plain, nutritious sheep thrives well upon Leicester pasturage lands. In their waters breed prolifically the heavy carp, chub, and tench. The heather of the Highlands is the haunt of the dainty doe and wild stag; the crystal waters of their inland cliffs produce the aristocracy of the finny race. The concordances of life, society, nature, are admirable, unerring, and tally in delightful diversity. The smooth waters of Lowland rivers and ponds afford the placid bottom-fisher his sport. The mountain torrents and lakes hold the quarry the active fly-fisher is ambitious of capturing. The broad, straight, even, thoroughfares of the 
world afford comfort and competence, acquired bit by bit by efforts, slightly but sufficiently stimulating to fresh and repeated exertion. The narrow, precipitous paths of life lead to fame, high honours, and high rank, and the ascent, rendered enchanting by the allurements of ambitious hope, is gained by daring activity, which never flags but for breath, to bound onward more and more bravely. The accessible streams that meander soothingly through soil for the sickle and scythe, yield to the industrious bottomfisher a full pannier, by a slowly and pleasantly accumulating process. The fly-fisher with haply a few casts of his artificial baits, surcharges his creel with salmon or trout, whose retreat in waters rushing by crag and fell he has attained by paths which none save the sportsman intent on high game would choose to tread.

I have now run rapidly through the salient merits of fly-fishing. Let me explain the practice of it with less precipitation. 
CHAPTER II.

THROWING THE LINE AND FLIES. - HUMOURING THEM. Fishing A STREAM. - STRIKING, HOOKING, PLAYING, AND LANDING A FISH.

Our language contains many pretty, pithy, and largely expressive figures of speech. One man says of another, "he is the best 'whip' in England." We understand by one little word that he is alleged to be the best driver and manager of horses in harness in the kingdom. So when we say, " he throws a line, or a fly better than any man we know," we mean to assert that he is the best fly-fisher of our acquaintance. The possession of the one power implies the possession of all the other necessary qualifications. Throwing well the line is an indispensable fiyfishing qualification, the first to be learned, always called into play, and without which other attributes are nearly valueless. You may hook a fish well, play a fish well, land a fish well, but you will very seldom have an opportunity of doing so unless you throw a line well. We judge of a fly-fisher by the manner in which he casts his line. If he does so with ease and elegance, and efficiently, we set him down as an adept in 
all the minutiæ of the art - if he does not, we conclude that he is a tyro. That, reader, you may not long remain in this latter category, if, indeed, you do belong to it at all, let there be during the fly-fishing season, for you, nulla dies sine lineâ.

I can see no wonderful difficulty in throwing a line well. Many certainly do not do so, by reason, chiefly, of having adopted a bad method at the outset. It is better to have no fly-fishing habit at all, than to have a bad one. Commence on the proper principle; persevere, and you must become a proficient.

How to THROw the Line aNd Flies. You are a beginner, I presume, and have never handled a rod before. Let the rod for your novitiate be eleven feet long; its play inclining rather to faulty stiffness, than to over-pliancy. Put the joints or pieces together, the rings standing in a straight line the one to the other, that your line may run evenly between them without any tortuous impediment. Put on your winch or reel with its handle towards the left side, and draw out your line through the rings, until there be about four yards of it out from beyond the last ring of the top joint. You have now quite sufficient line out to commence the practice of casting with it. Let your winch and the rings of your rod be on the under side of it when you practise casting. 
You are now ready to begin. Grasp your rod, not tightly, in your right hand, your hold being a little above the winch. Your hand must not close upon your rod with the thumb turned over your knuckles, as if you were about to strike a blow. Your fingers round the rod must simply entwine it, not squeeze it, and your thumb must lie straight with your arm on the upper part of the butt, the first joint being very slightly bent, and the fleshy or flat forepart of the thumb pressing on the rod. Hold your rod up nearly perpendicular, and pointing rather to the left side. Take the tip of the line between the fore-finger and thumb of your left hand. Poise your rod loosely and easily, and see that it balances freely in your right hand. Be devoid of that fear which begets awkwardness. What injury can you do? You are not going to explode a mine. You are merely going to throw a thin line with a thin limber rod upon the water. What if you shiver them to pieces in the attempt? The damage can be remedied.

I suppose you now on a bank above some river's surface, all ready for your first cast. Move your right wrist and fore-arm round to the right, letting go, just as it begins to get taut, the tip of the line in your left fingers, and bring round from left to right over your right shoulder the upper part of your rod, describing with the point of it 
an irregular - a horse-shoe - circle, and then cast forward with a flinging motion of the wrist and fore-arm. The motion of the wrist must predominate over that of the fore-arm and elbow joint. If you follow the above motions exactly and with freedom, from four to five feet of your line, supposing you to have between three and four yards of it out, should fall lightly upon the water. If that length do not you are wrong, and you must go on casting and casting, practising and practising, until you are right.

At first you will find, unless you are very handy and a very apt scholar indeed, that nearly all your line will fall upon the water, and that the top of your rod will come in contact with the surface of it. These are the greatest drawbacks to throwing a line well, and if not overcome the learner must never expect to become an expert fly-fisher. With might and main he must struggle to vanquish them. They are caused by letting the fore-arm fall too low whilst casting, and bending the body forward with the downward motion of the arm.

Here is the remedy. When you have made your casting movement-brought round your rod and line over the head, and propelled them forwards, the wrist must be gradually checked the instant the line is straightening itself in its onward course. The body must be upright, the chest held rather 
back, and your bust must not assume the slightest forward or stooping position. You will find, if you hold your rod properly, that the end of it nearest to you, the part between your hand and the spear or spike, will come in contact with the under part of your fore-arm just as your line is approaching the water. This contact will prevent the point of your rod following the line so low as to cause a great part of the latter to roll on to the water. Stand with your left foot a little forward, and flat on the ground, with a firm purchase; the right foot a little behind, the toes turned out, and the ball of the foot touching the ground with a slight springy pressure. Your left upper arm must hang loosely by your side; the fore part curbed from the elbow joint, will bring your left hand over and opposite to the outer ends of the right lower ribs. Your position, the limbs, \&c., arranged in the above way, will be easy and graceful, allowing free play to all the muscles required to be brought into action.

I deem you now sufficiently skilled by practice to throw four or five yards of line well, and with satisfactory ease. Double, then, the length of your line out. The right arm motion must be no longer limited to the wrist, fore-arm, and elbow joint, but must extend to the upper and shoulder joint. The os humeri and deltoid muscle must be called into requisition with fine free vigour, 
but not with so much of the latter as if you were about to strike a knock-down blow. The whole of the arm must be brought round to the right with an easy, large sweep, and the line thrown forward well from the shoulder. There must be no coachman-like jerk with the wrist backwards, as the front portion of the line is descending to the water, but the hand must follow the rod, and stop by a well-timed degree of suddenness, so that the line will fall on the water with a somewhat quick rather than a lazy floating motion.

As soon as you can throw from eight to ten yards of your reel-line with the power of making not more than a yard or two of the front portion of it fall lightly on the water, and in whatsoever direction you may choose, add to it, what is called the "foot" or "casting-line" of moderately thick silkworm gut, in length about two yards. You will now have ten yards of line, more or less, to throw with, and you must practise until you can cause the gut-line to fall upon the water before any part of the reel-line touches it. Do not be in a hurry to put on flies and fish. When you have succeeded in throwing your gut-line with freedom, with the ability of making it alight first upon the water - when you can prevent the top of your rod from descending too low - when you can prevent any part of your reel-line from making a more rapid descent than that of your casting-line, 
- you may begin to throw from left to right, with a backward twist or sweep of the wrist and arm. Hitherto you have been throwing from right to left, and that is the proper and most common way. But circumstances will arise, caused by the direction of the wind, your position with regard to the water and obstructions on and in it, in the shape of trees, roots, rocks, \&c., that will force you to cast from left to right, and sometimes underhand, as it were.

I shall say nothing of throwing with the left hand, because you will be able to do so, when you shall have learned to throw overhand and underhand with the right arm.

You have begun throwing by moving the point of your rod from left to right over your right shoulder, bringing it parallel with the right side of your head, and you have then been taught to cast straightforwards, or rather from right to left. If you have learned to do all this well, have'no fear; you must succeed in fly-fishing. But to be still more au fait in throwing the line, take the end of it in your left hand, and bringing the point of the rod to that side, move your wrist and forearm backwards to the right, turning the hand up, so that the finger-nails will point to you. Let go the line, and its point will pass first to the left of you, and then turn over and fall on the water on your right side. Although you will not be able to throw in this way so long a line, as over- 
handed from right to left, you will be able to throw it to a moderate distance easily and lightly. Take a coachman's whip in your hand, and work it right and left, making the lash crack each time, and you will acquire a freedom in the wrist that will be of service to you in handling the fly-rod. A coachman driving four-in-hand, with a long, limber whip-handle and tapering thong, makes use of the fly-fisher's motions, but does so in a manner too cramped, sudden, harsh and violent. Observe him touching playfully the heads of his leaders with the point of the lash, now the off-leader on the right side, and then the near-leader 'on the left side about the ear, and you will see how he works from right to left and from left to right. Imitate him, but most cautiously. Try and catch his ease and neatness; avoid the narrowness of the circles he describes with whip-handle and thong, and the rapidity and jerking of his wrist motions.

All you now want is to throw with precision. Let there be a mark in the water, and first try to throw a little above it, and in the next cast a little below it. Then throw right upon it, over it, beyond it, and on your own side of it. Having succeeded in throwing with accuracy where there are no obstructions, seek spots of the river where they exist - where there are overhanging branches of trees, weeds, rocks, or the ends of piles appearing 
above the surface of the water. Practise in these difficult spots until you think you can surmount the obstructions, and are able to avoid getting entangled amongst them.

Practical observation is better than any written lesson, because example is far more cogent than precept. When you see an old fly-fisher of acknowledged reputation on the water, watch his movements, and gain knowledge from what you see as well as from what you hear. You see most likely that he performs what you cannot. Observe his method, follow it, and you will overcome what had hitherto been a difficulty to you. If he permits you to accompany him during the day, do so, and if he will give you any oral instructions, be thankful to him. If they agree with those you will find in this book, practise them perseveringly. Attend always to a multitude of corroborating, intelligent and disinterested witnesses.

You have been all this while learning to cast with reel-line and casting-line without any flies on the latter. Commence with a single fly of rather large size, dressed on a full length of gut, and looped to the end of your casting-line. That fly is your tail-fly, or "stretcher." You will soon be informed of your proficiency in throwing this fly. The information will be conveyed to you in the very pleasantest way, viz., by fish rising 
at your fly. When large ones do so it is a proof that you have thrown your fly properly on the water, and you may now add a second fly, which will be your first " dropper." It should be a size smaller than your stretcher, and fastened on a yard higher up from it at one of the joinings of your casting-line. During your first season I advise you not to fish with more than two flies on your line at the same time. You may lengthen your casting-line from two yards to three, and the latter length will be found the best average one for fly-fishing with a single-handed rod. In your second year use three flies, placing them from eighteen inches to two feet apart. The length of gut to each dropper need not exceed two inches. The usual way of attaching flies is by looping them on. The only fly I loop is the stretcher to the loop at the fine end of the castingline. My droppers having a knot at the end of the gut, I fasten in between the sliding knots by which I tie together the links of gut that form the casting-line. I prefer these sliding knots to the whipped ones, because they are lighter, and enable me to attach and detach my knotted droppers more quickly than if they were looped. The knots will be found quite strong enough if you make them double; or even single, provided you do not cut off the gut too closely to them. I cannot clearly explain in writing how these sliding 
knots are made, but any fishing-tackle maker will show you.

I have now prepared you for fishing with three flies on three yards of gut casting-line. That line, as well as your reel-line and rod, should taper "fine by degrees and beautifully less." It should be thicker towards the hand, and dwindle away gradually to its end further from you. If the extreme end of your line should be the thickest part of it, common sense will tell you that when you cast it there must ensue a rapider and heavier descent upon the water than when that end of your line is the finest part of it. The gradual tapering of the line causes it to stretch out with the cast without kinking or coiling and to fall lightly and straightly on the water. Reel-lines (the best sorts are made of hair, or of two thirds hair and one third silk) are twisted in the shape of a spindle or a procupine's quill thick in the middle and tapering off in nice gradation to each end. A line so shaped has this advantage; when you have nearly worn out one end, you can have recourse to the other, which is completely fresh, having been that part wound first on the reel, and hitherto protected from the action of air and water. The used part is to be now wound next the reel. Your gut casting-line must be formed of links each finer than the other, but not with marked dis- 
proportion. The thickest link must be that next to the reel-line, and the thinnest that farthest. from it - that to which your stretcher or tail-fly is to be looped. Each of the intermediate links of gut must be finer than the other, round, and clear-coloured, before dyed, and without a flaw.

Fishing a Stream and humouring Your FLIES. - Touching the practice of angling, there are many moot points. One maintains this, another maintains that, and a third differs from both. In doing any thing there is but a right way and a wrong; but common sense has not followers enough to give the right a majority. An impartial president casting up the votes for the wrong must too often, I fear, pronounce, "The Ayes have it." Opinions are divided as to how a stream is to be fly-fished. Some say, begin at the head of a stream, and fish it downwards with the current. Others say, by no means : - commence at the tail of a stream and fish upwards to its head. Who is to decide, when adhuc sub judice lis est? Will the litigants leave it to my arbitration? If they do, my decision is, as a general rule, to be swerved from on rare contingency, first fly-fish a stream upwards from tail to head, and then, if circumstances make you think it advisable, after giving yourself and the water a rest, try down, with, if necessary, a change of fly or flies, from head to tail. By this means you 
avoid disputed extremes, and treading the best of all paths, medio tutissimus ibis.

You are approaching a stream to fish it. The wind is blowing slantingly over your right shoulder across the water. Keep as far as possible at first from the edge of the bank you stand on, and throw somewhat to your left side on that part of the water running on your side the river. Float your flies down, humouring them nattily on the surface of the water, obliquely to your left, bringing them at a civil distance below you, and close under the bank. Repeat your cast, moving one step higher up, still keeping as far as you can from the water side. When you have fished that nearer side sufficiently; approach the bank, coming down again to the tail-end of the stream, throwing as far as you can across it, humouring your flies as in the first instance, not drawing them directly across to you, but floating them lightly down the stream, until your line begins to grow taut, and the stream has a drag upon it, when you must repeat your cast, a little higher up the stream than before. Pursue this plan until you have fished the stream as widely from you as you can, and up to its head-formation.

The objections to fishing a stream in the above way are, that by so doing you expose your back and side too much to the fish above you, and you 
lose too much time and ground by this backward process. In my opinion, these objections are not fatal. If you keep a proper distance from the side of the stream, you will obviate the first objection. The second I think of little moment, for sometimes you cannot fish too carefully or too slowly, inch by inch, especially if the stream be a choice spot and fish upon the rise, whilst, under contrary circumstances, your progress may be more rapid, hurrying over chanceless parts, and fishing for luck quickly right a-head, hastening on to more favourable localities.

There is but one main objection to commencing at the head of a stream, and I do not see how it can be well got over. You hook a fish at the head of a stream, and must of course play him downwards. What is the consequence? Is it not plain, that you must disturb many fish below you, over which you have not as yet thrown your flies? I think it is evident, and if I did not think so, I should be decidedly in favour of downstream fishing, as being the most rapid and apparently the most natural way. At the head of a stream you hook a large and game fish. $\mathrm{He}$ darts across it, down it, through it in every direction, at one time plashing on the surface of the water, at another doggedly struggling beneath it, or rushing through it, as if an otter were at

$$
\text { c } 4
$$


his tail. His struggles are at any rate extraordinary, and think you not instinct tells other fish, perhaps shoal-companions, that there is something wrong? Surely they see and hear - not usual sights and sounds, but somewhat alarming ones, because they are not customary. May we not infer that they dread an enemy at hand - that they see a fellow-being in danger, and are cowed into skulking for safety, at least for a time? All anglers will acknowledge something like this ; but then, some of them argue that the effects of the disturbance are only temporary, and not so lasting as those which arise from the fish seeing you, as you fish a stream upwards. You can avoid their seeing you, but you cannot, unless you whip a fish out of the water the instant he is hooked, prevent the more or less disturbance he will cause according to his strength and unflinching struggles, his weakness or his want of game. It is argued you can remedy it, by not fishing for some time after you have been playing a fish, or by removing to some other spot, and coming back again in due time to the place you had disturbed. This plan will cause you to lose time at all events, and, may be, the very nick of it during which fish are rising freely. I have always succeeded best by fishing a stream from tail to head. Excellent anglers have told me they did best by doing the contrary. I dispute no man's word, 
but I advise the student to try both ways, and then judge for himself.

In what precise shape artificial flies floating on the water, or just beneath it, present themselves to the fish, I cannot truly tell. They certainly cannot present themselves in the exact living forms of natural insects, but their appearance must be something like them. If I were to guess, I should say that the artificial flies for the common trout and grayling present the appearance of drowning, or drowned natural flies; or of living insects struggling on, or underneath the water. I do not think this surmise fanciful. At any rate the fly-fisher should endeavour to present his artificial baits to the fish as deceptively as possible, that is, by giving them as natural an appearance as may be. He must cause them to drop lightly on the water, because the natural fly does so; he must cause them to swim down as near the surface as he can, because the natural fly moves upon the surface of the water, and he must impart motion to his flies, a species of fluttering, generally speaking, being the best. All this is comprehended by the expression "humouring" one's flies. To do it, the moment your flies alight upon the water hold up your rod, so that the drop-fly next to it may appear skimming the surface; the other two, if properly proportioned and attached to the casting-line, being ever so 
little under water. If you allow your upper dropper to be under water, all the flies below that dropper will be sunk too deeply to appear living insects to the fish, and therefore any motion you may give them will be useless. They then can only be taken by the fish for dead flies. When you keep your last dropper on the surface of the water, impart to it a slight skipping motion, by a tremulous wrist shake of the rod, and the flies that are just under water will receive the most natural motion you can give them. Never drag your flies straight across the water towards you, and never work them against the current. A small fish may, perchance, rise at them when so worked, but seldom or never a large one.

Striking AND HoOKIng a Fish. - In cricket there are fast and slow bowlers, which is a proof that one way is thought as good, if not better than another. In striking a fish there are fast and slow strikers, each of course maintaining the superiority of his own method. Well, if there was no difference of opinion, sad would be the monotony of life, after the old proverb, "tot homines, tot sententice," had become obsolete. The truth is, there are as many fish missed by striking too rapidly, as by striking too slowly, and a fault either way is bad. I think, however, that he who strikes too slowly labours under a greater disadvantage than he who strikes too quickly. 
Striking too strongly is a shocking fault, and, as it is generally joined with the defect of striking too quickly, double mischief ensues. You either miss your fish, or whip it out of the water awkwardly, or injure your tackle, if the fish be a heavy one. This strong rapid way of striking shews the absence of that delicacy of action and management without which you can never become an accomplished fly-fisher.

The moment you see or feel a rise, you must strike gently from the wrist, by a slight, sharp jerk of it backwards. As a general rule, strike sideways a little, and not straight towards you - to the right most commonly - but you must be guided by a guess as to which way the fish is about to turn on seizing your fly. If you fancy he is going to turn round to his left, you must strike at him neatly towards your right: if you think him on the turn from left to right, strike to your left. By pursuing this plan, you will avoid the probability of chucking the fly clean out of the fish's mouth, or of pricking him only, and you will very likely hook him, perhaps through and through, on either the right or left side of the mouth. A fish very frequently takes your fly under water, and then you merely feel a rise. Be in such case somewhat quick, yet strike as gently as possiblequick, lest the fish reject the fly, gentle, for he is already almost hooked. Those who are for strik- 
ing slowly, act on the notion that fish generally hook themselves, and that the slow stroke is only necessary to affix the hook firmly. Fish do sometimes hook themselves, 'tis true, but it is only by exception, and not by rule. The fly-fisher of sharp eye and quick hand will always have an advantage over the purblind and the slow. Dimness of vision and obtuseness of touch mar frequently the benefits of experience, and the young sharp eye and lively hand will successfully compete with the skill of old practitioners in whom the two attributes mentioned are fading away.

On this nice part of our subject I find some excellent advice and remarks in the late $\mathrm{Mr}$. Blaine's "Encyclopædia of Rural Sports *,"p.1178. He says," Striking the fish is to the full as important a part of the rod and line management as any. Many strike too slowly, many too quickly, and a correct few strike at the critical moment. The first lose their object, the second often lose both the object and their bait, while the third secure all. When a fish seizes the natural fly, his jaws find no resistance; he consequently keeps them closed until deglutition follows; and thus it is that in natural fly-fishing, it is not found so necessary to be instantaneous in striking; but with the artificial fly, the instant the fish seizes it, he is Row.

* Published by Messrs. Longman and Co., Paternoster 
apt to find the deception, either by its want of taste, or by feeling the point of the hook, or by discovering the unyielding nature of the material of which it is composed, and he, therefore, as soon as may be, blows it out again; and this we constantly observe,-when a timid irresolute learner has raised a fish, and hesitates in striking it, fearful of being too quick, or otherwise so paralysed with the sudden attack, - that he cannot collect himself for a second or two, and half that time is all that ought to be allowed for the seizure of the bait, and the stroke of the angler. The striking must be instantaneous to be successful; for when it is considered that the impulsive effort which is to fix the hook in the mouth of the fish, which has but that instant closed it on the bait, is first to be taken cognisance of by the angler, and then is to be acted on by him through a solid line of communication of many yards in length, it will be evident that a rapidity of action is required almost equal to the thought that willed it; for, as already observed, unless the stroke reaches the mouth of the fish before he has discovered the deception, it is generally too late. Fortunately for anglers it is not always so, as the act of ejecting the bait being at the moment of the turning round of fish for their retreat, it happens that they occasionally at the same time hook themselves. It is possible, however, to strike too quickly, and 
this is frequently done by those who are very ardent, as well as those who, having been convicted of being too slow, attempt to amend by the contrary extreme. We have fished with many young hands who have struck the instant they saw a fish rise even, and consequently, though the bait must have been risen at, the mouth had never received it, or, if it had, it had not time enough to close upon it. Striking a fish should be done with a smart, but not a violent effort. The ardent angler will often strike with such force as to tear away his hold on the fish, or to become minus by gut and fly, which snap by the sudden jerk. There is nothing better calculated to cure a young practitioner who strikes too forcibly, than to oblige him to whip for bleak, and to pay forfeit for every one he raises above the surface of the water, receiving forfeit for every one he hooks without raising it into sight. The forcible stroke that wholly misses its object often throws the bait out of the water by the violence of the effort; the moderate stroke that misses will not displace the hook more than a foot or two. The critical fishstroke is made by a very quick but very gentle wrist-motion, by which the hand is canted upwards, being displaced about two inches only. Such a stroke made instantly the fish actually reaches the fly (which is learned by habit), at the moment he has closed his mouth on it, and before he has time 
to throw it out again, is sure to secure the entrance of the hook within the substance of the mouth, without causing great alarm to the fish by any unnecessary violence; for it cannot have escaped the observant angler, that, when a trout has been harshly tugged in striking, he commences at once a more determined resistance than when the stroke has been less violent, and his alarm less sudden. Neither can we wonder that his efforts should be extreme, when he is made sensible of his situation by a stab and a drag which have half pulled him out of the water. If such critical nicety be required in striking, it may be here asked, how is it that fish are ever taken by novices? Such a question is reasonable, but may be easily explained. Many eager and hungry fish hook themselves in taking any bait without hesitation. Their seizure of the fly, their closing their mouth on it, and the passing it backwards, are all one instantaneous effort; and, on examination, such fish will be found to have partially gorged the bait. But if the number of fish so taken was arranged against the number of those lost by a defect in striking, the difference would be as five to one of small fish, and as ten to one of those of mature growth." This extract contains much of the sound rationale of striking a fish, and should be read and digested carefully.

Playing a Fish. - This is the pleasantest and 
most exciting portion of the angler's recreation. Contest and struggle have now begun. If you fail, you lose the object you have been carefully seeking for, and perhaps a line and flies you have cherished for the fatal remembrances attached to them. The fish that struggles so savagely to do them damage you see with exultation tired to death, or with chagrin you see him swim away to the bottom of the current with them. The blood in this tussle is called from the interior to the surface of the body and sent through the vessels with exhilarating rapidity, and you feel a temporary access of the pleasantest sort of intoxication, viz., that which attacks you at a sporting crisis. Playing a fish is the great crisis of angling, full of hope, full of fear, full of doubt. If he is hooked firmly, if your tackle do not fail you, if he do not get your line and flies foul, if, if, if ah, the pleasant anxiety implied by those ifs! you must kill him.

Having hooked a fish, your first business is to determine what may be his size, and whether he is hooked firmly or loosely. You can scarcely be mistaken with respect to size and strength, except when you have hooked a fish foul, that is, outside the mouth, in the fin, or in some other exterior portion of the body. Then a small fish may be taken for a large and strong one. There is a general rule for judging how a fish is hooked. 
A FISH SLIGHTLY OR FIRMLY HOOKED. 33

If slightly, the fish on being struck generally struggles for a few moments on the surface of the water before he darts off into its depths: if firmly hooked, the fish sinks rapidly and heavily towards the bottom, as if he knew that the only way of getting rid of the barb that holds him was by attrition against stump or stone, or some such thing, at the bottom of the water. You must prevent the slightly-hooked fish from struggling on the surface, by lowering the point of your rod, and you must prevent the firmly-hooked fish from sinking to the bottom, by elevating its point. These two general rules are easily practised.

I see your recently-hooked fish plashing about upon the water, endeavouring to shake off the hook, or at any rate to loosen its hold, which he will do if you allow him too much freedom. Point your rod downwards towards him, and the slackened heaviness of your line will cause him to quit the surface. The moment he does so, raise the point of your rod, so as to feel your fish and keep him in hand, gently or strongly, according to his size. If small, allow him just so much play as will deprive him of any power of straining your rod, wind up, and lift him out of the water. If large, which you will soon find out-you have found it out already, by having measured him with your eye whilst he was on the water - give him line, tightly though, as he darts through the 
water - just tightly enough to enable you to check him instantaneously as he nears some foul portion of the water. As he rushes from you, keep going with him, holding him gently " under buckle," as they say, and at each pause he makes after every rush, feel him more fully, by presenting towards him the butt-end of your rod. The lower joints of your rod will then incline backwards over your shoulder, and the upper pieces will be bent like the one half of a strained bow, the weight of the fish being thrown on every part of your tackle, and equalised according to its strength, the thickest parts of course having the severest strain upon them. If whilst the rod is in this position you find your fish still vigorous, do not press upon him by holding the butt-end of your rod too much pointed forwards, but, letting it fall into an easy perpendicular position, give a little line and move onward with your fish. The greater the length of line he drags after him through the water, the sooner will he be tired. Still you must take due care that the line be not too long to prevent you from making it taut by a turn or two of your winch at an instant's notice, or by inclining your rod backwards over the shoulder. After you have checked your fish a few times, and you find his struggles wavering to weakness, wind up and make him show himself on the top of the water. If he bears this lan- 
guidly, shorten your line to a convenient length and guide your fish, not against the water, but with it, to some easy landing spot if it can be found. Whilst you play a fish never show yourself to him if you can help it, and request any one who is with you, or who may be looking on, to keep away from the water until your fish is landed.

When a fish on being struck darts to the bottom and then away, you may be sure that the hook is firmly fixed, and then you may play him more confidently than when his first struggles are made on the surface of the water. Still be cautious, and do not play too roughly. Rough play is never necessary. It is always dangerous. Checking a fish rudely whilst he is strong, increases his obstinacy and his strength at the very time when they ought not to be exerted. If you let him go carefully when he is first struck, he will not plunge desperately, as he most certainly will if you strongly bear upon him whilst his vigour is as yet fresh. Reduce this vigour by degrees, and as it wastes away by your repeated checks, and your causing him to haul a long length of wet line after him, hold more tightly; and when you see him turn upon his side, bring his opening mouth to such contact with the surface of the water that more of that element will enter than can pass out by the gills. These safety valves having lost their natural action, something very 
like suffocation or asphyxia by drowning will ensue. Your victory is then complete.

When a fish is hooked foul, that is, on the outside of the mouth, he has his head free, and you will find great difficulty in tiring him down. A small fish so hooked will show more strength than a large one fairly hooked. You have not got the bit in his mouth, but are forced to manage him with, as it were, a halter round his neck. Give him as much line as you can, bearing upon him as heavily as the strength of your tackle will with safety admit, and having no fear that your hook will tear away, as it often does from the brittle fibrous parts of the interior of the mouth. Be prepared for several swift rushes of a fish hooked foully, and do not bring him near you until you have softened down his struggles. Use much patience, and should your line, as it not unfrequently does, get coiled round the fish's body, hold hard, and shorten line, for you will now have little more than his weight to contend with, the power of his fins being impeded. I repeat again, eschew violence. Always play with a light hand, making its strength gradually felt in the ratio of the decline of that of your fish. That is the killing rule to be observed in playing a fish. In doing so, never seize your line in either hand to shorten it, unless (and the occasion will not often occur) you cannot wind up rapidly enough 
to prevent the fish from darting into some dangerous place. Playing a fish with the line in your hand, without having recourse to your rod, is the very worst habit you can adopt. I should say, avoid it altogether, which you will be able to do if you fish with a perfect winch. The best sort of winch is a carefully London-made multiplier.

Landing a Fish. - A few lines will describe this final operation. In performing it, mark, let your person and all that pertains to it be as nearly invisible to the fish as may be. Select the clearest spot you can for landing. If you have any one with you to handle the landing-net, let him keep himself behind the fish, sink his net in the water, and as you gently bring the fish towards it, let him advance it underneath the struggler, and when right under him lift it up without a jerk, and with an easy motion, well-timed and accurate, after the fish is withinside the hoop. Never thrust the net at the fish whilst he is in voluntary motion, or touch him with it until he is fairly inside it. Where there is no bank, but a low shelving strand, you may land your fish on it without the aid of the net; but I advise you to do so rarely, as hauling the fish ashore over gravel or sand will strain your rod prejudicially, and very often injure your flies. Use the net upon all occasions, unless some casualty occurs to render it exceed- 
ingly inconvenient. When you have no one to assist you in landing a fish, and the banks are high, tire your fish out completely, and bring him in close under the bank. If you cannot reach him whilst holding your rod in either hand, wind up tightly and put the stop on your winch. Then stick the spear or spike in the ground, your rod inclining backwards from the river, and sinking your net behind the fish bring it tailwise under him and lift him out. If you frighten your exhausted fish by clumsy use of the net, showing it to him, touching him with it, or making a noise in the water with it, you may awaken in him a death flurry, fatal to some portion of your tackle and to your success. The generality of landing nets are too small. On an average they should be by one half as large every way as the largest that are commonly sold in the shops. The thread the meshes are made of should be stained of a water colour, and if frequent immersion in water should wash the dye out, they should be dyed again. I have seen many a fish break away through the dreadful vigour with which he has been inspired by the sight of a net bleached almost white by constant exposure to sun and water.

In landing large fish, salmon, very heavy trout and pike, you must use the gaff, that is, a large, well-tempered, sharp, deeply barbed hook, fastened to the end of a proper piece of wood. The best 
place to insert your gaff-hook is beneath the gills of a fish in his gasping movements. The next best place is beneath one of the pectoral fins, by a sharp stroke. When you intend to gaff your fish beneath the breast or belly, put the gaff outside and beneath him, the point upwards, and if possible towards you. Then strike sufficiently strong to make the barb penetrate beyond the skin, and then, if you cannot land him, he must be very strong, or you must be very weak, or something for angling purposes much worse. Remember this caution; never fly-fish without a landing net or gaff.

The author of the "Encyclopædia of Rural Sports" says, "Some directions with regard to the use of the landing net may be necessary to the tyro, who, when he has hooked any fish beyond one of the smallest size, should never attempt to lift it out of the water by means of the line, still less by means of the rod and line together; for although neither may break, both may be strained, or the hook may break, or the hold on the fish give way. Every one of these accidents we have seen occur through the want of a landing net. In fly-fishing, where the line is long and there is not much space to step backwards, or where the reel is clogged, it is necessary sometimes to lay hold of the line with one hand; but this should be done with great caution, and then 
only after the fish is well nigh spent, or one struggle may carry away line, hook, and fish. In all other cases avoid touching the line if possible; but having sufficiently played the fish, whether taken by bottom or by fly-fishing, bring him within reach of the landing net, and then carefully conduct or slide the net obliquely under the fore-parts of his body, which, if the fish be completely exhausted, will fall into it; but if he has still sufficient vigour, it will be prudent rather to slide him over the net, than the net under him. It must have occurred to every angler to have supposed a trout or salmon to be completely spent who, the moment he has been touched by the net, or has even caught sight of the fisher, has sprung off with most annoying violence. Against such an accident, it is prudent to be ever prepared by keeping the rod in an upright position, acting on a tightened line, but yet so disposed that it can run at liberty if required. When the head and shoulders of the fish are once fairly within the net, a slight turn of it will take in the whole body, and the net being then kept horizontally, will ensure his safety; for with the head downwards, not any efforts he can make will disengage him from the net; but if he be received tail foremost, as is sometimes done in deep waters, from overhanging banks, \&c., beware of his plunge."

In playing and landing a fish, do so with your 
winch and the rings of your rod pointing upwards. In England people throw the line, strike, play, and land a fish with winch and rings under the rod. They do wrong. When the rings point to the water as you play a fish there is too much strain upon them; taking it off the rod, wearing out the line by friction against the rings, and not letting it run freely through them, as it would along the rod if they pointed upwards. In casting only is it more convenient that the winch should appear beneath the rod. Appearance and convenience are the only advantages of that position.

The following observations of Mr. Ronalds* should be attended to:- "When a fish has just risen at a natural object, it is well for the fisherman to try to throw into the curl occasioned by the rise, and left as a mark for him; but should the undulations have nearly died away before he can throw to the spot, then he should throw, as nearly as he can judge, a yard or two above it, and allow the flies to float down to the supposed place of the fish; if a rise do not occur, it may be concluded that the fish has removed without seeing the flies; he may then try a yard or two on each side of the place where the curl appeared, when he may probably have a rise, and may pos-

" " The Fly-fisher's Entomology;" an exceedingly useful book, published by Messrs. Longman and Co. 
sibly hook the fish, provided he has the knack of striking, which knack, like all others, is acquired only by practice: it must be done by a very sudden, but not a very strong stroke - a twitch of the wrist. Having hooked him, the rod should be carefully retained in that position which will allow its greatest pliability to be exerted. For beginners to do this, it may be advisable that they should get it up over the shoulder, and present the buttend towards the fish. A gentle pull must now be kept upon the fish, and he should be led down the stream rather than up, making use of the reel as occasion may require to shorten the line. But if he runs in towards the bank upon which the fisherman stands, it will be necessary for him to approach the edge of the water as nearly as possible, holding the rod with an outstretched arm in almost an horizontal position, and if the reel is of the usual bad construction, it will be also necessary to pull in the line as quickly as possible with the left hand; this may prevent the fish from reaching his harbour: if it should not, he will most likely twist the gut round roots, \&c., and break away. To kill him, the nose must be kept up as much as possible, and should he be very importunate and resolute, he may be lent a little more line now and then, but it must be promptly retaken with tremendous interest, and got up as short as possible. After various fruitless efforts to escape, 
which exhaust his strength, the nose may be got fairly out of the water, the fish towed gently to the side, and the landing net passed under him. From the time of hooking the fish, if a large one, to the time of landing, care must be had that the line shall not be touched by the hand, excepting under the just-mentioned circumstances; all should depend upon the pliability of the rod. In case a landing net should not be at hand, the reel may be stopped from running back, the rod stuck up in the ground by the spike, and both hands being disengaged, the fisherman may stoop down, and grasp the fish firmly behind the gills. The principal differences between trout and grayling fishing are, that the latter requires a more delicate hand, a quicker eye, and the use of smaller flies upon the finest gut. The strike must be made on the instant of the rise. The fish may be sometimes seen, if he be of a good size and the water bright, a few inches before he gets up to the fly, and the fisherman must strike immediately that he does so, for his motion at the instant of seizure is too rapid to be visible. When the fisherman comes upon a favourable place for grayling, he should recollect that this fish does not follow the fly as the trout does, and should therefore allow it to float down the stream in a natural way; for should a grayling be waiting for it, and it is drawn away, "the fish will be disappointed of that 
which it was the fisherman's intention to entertain him with.' It must also be remarked here that the mouth of the grayling is much more tender than that of the trout, therefore much more care in landing is required; and a landing net is generally indispensable, especially when the banks are high, for the mouth will seldom bear his weight out of the water."

This chapter is a long and important one. Unless you carry into practice its precepts, you will never become a good angler. It teaches the great branches of the art, - throwing a line, hooking, playing, and landing a fish. When you understand them, all you require to know is, the best sort of tackle and the best baits for the several fishing months. I have quoted, and shall quote, authorities who differ from me in opinion. I respect them. Let the reader do so likewise, and if he finds by experience their opinions better than mine, let him follow them. All I desire is to place valuable opinions before him.

Nоте.-Mr. Blacker, fishing-tackle maker, of 54. Dean Street, Soho, and who is also an experienced fly-fisher, says, in a communication to me, "I will now give the angler an idea of casting the line and fly, which is a most essential point 
towards his success in hooking and catching his fish. In the first place the fly-fisher should keep as far off the stream as possible, and make it a rule, whenever he can, to angle on that bank from which the wind blows, as it will enable him to command the whole stream from side to side, and throw the flies across to the opposite bank, and draw them gently and playfully down the stream, bringing them in to his side, and moving backwards as they approach him. When lifting the flies out of the water to cast them again, he should raise them quickly out, and with a backward sweep of the arm, let the line stretch to its full length behind him so as to prevent the flies from whipping off, and then, with a sudden, but not violent, jerk of the wrist forwards, convey the line over the stream, letting the flies fall lightly on the surface without splash or ripple, and when he causes a fish to rise he must give a little time to the closing of the broken water, and then raise his hand with a gentle pull, and I warrant him success. I generally fish down the stream myself, but it is of little consequence whether the stream be fished upwards or downwards. To prevent the shadow of the rod falling on the water, fish with your face to the sun. In landing a fish, I have always found it the most convenient and sure plan to place the landing net in the water immediately under the head of the fish, and let his nose drop into it, and he is sure to fall towards the bottom headforemost when fatigued after having been well played.

"When you commence to fly-fish for salmon, you must be careful not to cast too long a line, and when you become master of throwing a short line, let it out piece by piece till you are enabled to cover the whole pool with ease, keeping the point of your rod well up, but not too high, and drawing the fly in a slanting direction down towards your own side of the bank, letting it fall gradually with the current, and when you bring it, as you suppose, immedi- 
ately over a fish, give the rod a playful shake to give apparent life to the $\mathrm{fly}$; and as you expect a rise, be always on your guard as to steadiness - not nervous, - that you may raise the rod, or strike with a gentle, long pull, just as the break of the fish closes on the surface; for sometimes a rise surprises you, and at that moment, if you strike too hastily, you are apt to pull or draw away the fly from the fish's mouth; or, if you hook him, probably snap either your hook or line. Do not let the top of your rod touch the water in throwing, or your reel-line will roll along the surface, which is injurious, as it frightens the fish that may be lying between you and the fly, and drives them away. On the contrary, when you cast the line and fly, keep the heavy rod steadily in your hands, and raise it gradually into the air, until you see the fly appear on the top of the water, and to cast again, give the rod a semicircular quick turn to the right far behind you to the line's full extent, and then, with a smart jerk of the wrist and muscles, convey the line right over the stream straightly, as if shot from a bow, and the fly will fall first on the water, and very softly too. Keep your body up, so as not to bend or fall forwards with the cast; push forwards your chest, and throw back your shoulders, as this position will keep you steady on your feet. When a salmon is rightly hooked, bend with the rod, and set yourself to work, laying such a stress on the line as you think it will bear. At this instant the fish may probably rise several times out of the water, in his surprise and fright, and in this case by no means let an inch of the line go with him; but when he begins to run fairly, do not prevent him, still, however, keeping your line taut, and if he runs back towards you or up the stream, wind up your line quickly, and when he stops short, give him the butt of the rod well, as he is now sulky, or about to lie down at the bottom, 
when he will try to rub the hook out of his mouth; and if you do permit him to get fairly to the bottom, you will find it difficult to move him or get him to run again. Try all you can to keep him on the run from the beginning, as thus you have the best chance of quickly tiring and capturing him. Some gaff a salmon by laying the point of the gaff under him, others by placing it over him; but it may be done with precision either way." 


\section{CHAPTER III.}

ON ARTIFICIAL FLIES.

OF late years a new doctrine-in my opinion a totally wrong one - has been sent forth about artificial flies. Some Scotch writers were the first promulgators of it, and they have carried it to ridiculous extravagance. They positively maintain that there is no likeness between the natural fly and the artificial one, and that when natural flies are on the water the angler will be more successful by using artificial flies as widely different from them in shape, colour, \&c., as may be. A nondescript artificial fly will succeed better, they say, than a bad resemblance, and every attempt at imitation, in their opinion, produces at the best but a bad resemblance. These angling heretics contend that fish rising at a natural fly immediately detect, by comparison of course, the bad imitation, and refuse to rise at it, whereas they will rise at some outlandish artificial that differs, more than chalk does from Cheshire cheese, from the living fly on the water. They say, that when they go fly-fishing they catch some of those flies that are on the water, and fish with artificial flies totally different from them, and invariably meet with more success than if they used so-called, as 
they name them, imitations. The majority of mankind are mad on one subject or another. Perhaps the majority of animals are similarly so. These mad fly-fishers are successful, no doubt, because they meet with mad fish, which are more readily taken with fantastic flies than with naturally coloured and shaped ones. That is the only way I can account for their heterodoxy.

My friends, do not mind what these cracked sectarians say. They are learned philosophers, writing the article "Angling" in ponderous encyclopædias, from visionary data, but we are lowly scatterers of information gathered by the waterside. We grant that there is very great difficulty in imitating, by means of feathers, fur, wool, \&c., the water-insects fish feed upon, but we maintain that a fair deceptive imitation can be made, and that it is beyond all comparison more attractive to fish than no imitation at all. We maintain that the less imperfect an imitation, the more attractive will it be found in fishing.

We said that philosophers, - naturalists with barnacles on nose, - reading insect nature through the glass-cases of museums, find, they assert, no likeness whatsoever between the natural fly and what, to the vulgar, appears the best artificial imitation ever dressed. The microscope, they cry, proves this. An unjaundiced human eye proves quite another thing. See if it does not. 
In the last week of the month of October, of last (1846) year, a young relative of mine, making drawings of the church and seat of the Earl of Gainsborough, at Exton, Rutlandshire, sent me a fly that had alighted on his paper as he was sketching out of doors. He wanted to know the name of it. When the fly arrived some boyish anglers were, with me, and I told them to find amongst my artificial flies any one that they thought resembled the natural one in shape and colour. Without more than necessary delay, and at the first guess, they picked out the right imitation. I then told them to look for the same fly in Alfred Ronalds's "Fly-fisher's Entomology." They did so ; found the drawing and the imitation, and pronounced the natural fly "the gold-eyed gauze wing." They were right, and if boyish eyes looking through nature's microscope were right, think you fish would be wrong?

Now this fly, of which I am speaking, has a green body, with a slight yellow cast in it, four transparent, shovel-pointed, reticulated wings, lying flat over the body, the two under wings being shorter than the upper, and these latter longer than the body of the fly. The head and eyes appear brightly burnished. You have seen an imitation cigar with its burning end deceive the most knowing connoisseur. You have seen a glass filled with simulated brandy and water, invitingly 
undulating, as it was offered to a most accomplished judge, and taken by him unconscious, until no smell or taste told him of the deception. You have seen man deceived by imitations, with his fine eye for shape and colour, and yet the philosophers tell you fish cannot be so deceived.

I have told you the colour and the shape of the fly I have just mentioned. I'll now tell you how it is to be imitated. Mr. Ronalds says the following is the way:-Body, very pale yellowish green floss silk, tied on with silk thread of the same colour; wings and legs, the palest blue dun hackle that can be procured. In this imitation the body only is correct; the legs partly so, but the wings are wrong. The fly should not be dressed with hackle-wings, but with wings long and lying flat. They should be made of the fibres of the wing feather of a young starling, or of any light dun feather, stained very slightly green.

Strange as it may appear, the somewhat imperfect imitation of Mr. Ronalds will be taken by fish in the autumn months, especially by grayling. The reason it will be so taken is that the colour of the body is right, and it is of more importance that the body should be a good imitation than that the wings should be. But if the fly is imitated in my way with flat, transparent wings, a bright brown head of two or three laps of silk, it will be a better imitation and a better killer. 
The eyes of birds are, I believe, pretty good. At any rate they can see at an immense distance. The philosophers will perhaps allow that the eyes of the feathered tribes are as difficult to be deceived as those of the finny tribes. I should say more so, because their eyes are sharpened by something very like an intelligent brain placed close by them. Well, birds are continually deceived by the artificial fly of the angler. Swallows, martins, swifts, goldfinches, have darted at artificial flies as the wind blew them about on the line, and have hooked themselves and been taken. It was only last year that a dunghill cock seized an artificial May-fly, attached to an angler's rod resting outside an inn at Buxton, and was caught. If birds take these imitations of water-flies, not being their natural or best food, how can it be argued that fish will not take them?

The philosophers say, attempts at imitation are of no avail, for salmon and some of the salmonidæ rise eagerly at artificial flies that resemble nothing living on earth, in air, or water. That is true, and as yet unaccountable. But dress those gaudy salmon flies, or lake trout flies, as small as you like, and the common trout and grayling will not: rise at them; neither will dace, chub, or roach, and yet they will rise freely at imitations of riverflies, caterpillars, house-flies, and flies that are bred upon trees, amongst gravel, sand, and plants. 
A QUESTION FOR THE PHILOSOPHERS. 53

I say they will rise at these imitations, and rise at them only, with very few exceptions, when the natural fly is on the water or in season.

Will the philosophers answer this question? How is it that neither trout nor grayling will during the spring, autumn, or winter months rise at an imitation of the May-fly, their especial favourite during a part of May and June? If trout, or grayling, or chub would prefer nondescripts to the imitations of flies on the water, no more attractive nondescript could be presented to them than the imitation of the handsome May-fly. But they never take it, except during the "drake season," or a little before or a little after it. In that season, viz. when the May-fly (ephemera vulgata) or green-drake is out upon the waters, fish will prefer an imitation of it to an imitation of any other fly, except indeed at mornings or evenings, when other natural flies are out, and the Mayfly is not. I will here grant, and doing so will strengthen my argument, that it is impossible to imitate well the delicate and beautiful May-fly. Still, fish will sooner take the bad imitation, I may say the worst imitation of it, than the best of any other fly not in season.

The artificial May-fly is not a killing bait except under peculiar circumstances, and when thrown upon the water amongst the real flies, fish will generally prefer the latter. Use any 
other artificial fly, as unlike the May-fly as possible, and you will prove the theory of the philosophers to be erroneous, for fish will not rise at these un-like flies at all. They will rise, however, at a bad imitation, particularly under circumstances that tend to improve that imitation. When the weather is gloomy and windy during the "drake season," and the deep waters are ruffled, and few natural May-flies are out, imitations of them will kill well. I account for it thus. During such weather the imperfections of the artificial fly are to a great measure hidden. The water is disturbed and not very clear, the plash caused by the falling line and large imitation-flies is not very great, and the appearance of the artificial fly then is like that of a natural one either drowned or drowning, or struggling against the effects of gusty weather. On a fine clear day, in pools at least, the artificial May-fly will not succeed; and still less any of the philosophers' outlandish flies, because of the impossibility of imitating the motions of the natural May-fly observed plainly and constantly by the fish through the clear and tranquil water sending up myriads of the beautiful real insect. When it first comes to the surface of the water it has to shake off the case that confines its wings, to dry them, to gain a little strength in the new atmosphere it breathes, before it can fly away to enjoy a few hours' existence. 
Whilst making these incipient preparations for ephemeral enjoyment, it is seen by the fish, and frequently checked at the outset of its career. The fly-maker cannot imitate these acts of the fly, so apparent to fish in sunny weather, and hence the little success attending the artificial green drake at such a time.

The above famous fly, so common in the rivers of the midland, the western, and the southern counties of England, is not so common in the north, is rare and even unknown in many of the best rivers of Scotland, Ireland, and Wales. It would be in vain to fish with it there, which proves again that the common trout, at any rate, will not rise at nondescript things, which instinct informs them bear no resemblance to their natural food. Gnats and midges are to be found every where throughout the kingdom, especially in summer, and hence the different sorts of dun artificials, intended to be imitations of those insects, are good general flies in every part of the empire. Artificial palmers, which are imitations of caterpillars of different sizes and colours are common to the rivers of the British isles, and are therefore good baits, perhaps the best general ones, except in those months when the living caterpillar does not exist.

After what I have now written, it will be apparent to every one that $I$ am in favour of close 
imitation. I have tried the nondescript fly, and found it fail - tried it for two seasons on the Thames without a shadow of success. Having found how difficult it was to kill large Thames trout with the ordinary artificial flies, I had some nondescript ones dressed as attractively as imagination, guessing at probabilities, could make them. During the last two seasons I used them with the utmost perseverance, for I wanted to test the discovery of the philosophers, but the Thames trout seemed determined not to afford me a single excuse for becoming a convert to the new doctrine. They would have nothing to do with my newfangled flies. In previous years I had killed Thames trout with artificial flies, and I had made others kill them with flies similar to those I had used, viz. large red, black, brown, and furnace hackles, and a very large imitation of the sandfly. Flies like these were successful last year, and I saw a trout weighing upwards of $10 \mathrm{lb}$. that had been taken with a large brown palmer at Sunbury. My gaudy flies were of no use. I had my faith slightly shaken one day, by seeing a Thames trout taken with a bad imitation of the May-fly late in July. That fly was a nondescript then. A day or two afterwards I saw several natural flies on the Thames; they were large, in shape like the May-fly, but the body was of a lighter colour, and the wings not so 
transparent. In fact, the bad imitation of the May-fly that had been taken by the Thames trout was not unlike the living fly that was then out upon the waters of that river.

If fish preferred nondescript artificial flies, I may reasonably conclude they would prefer nondescript natural fish, mice, frogs, beetles, grasshoppers, and so forth. They do not, however; and artificial fish are made as like as possible to natural minnows, bleak, gudgeons, dace, roach, and small trout. Perhaps the philosophers would contend that an artificial imitation of the red mullet, or of some other fish that would be a nondescript to salmonidæ or pike, would be taken by them with greater avidity than the bad imitation of the fish they feed upon, because, and that is the philosophers' reason, they can distinguish the badly imitated artificial minnow or gudgeon from the real ones they constantly see and feed upon, and will therefore seize by preference something that must be foreign to their instinct.

Before I conclude this chapter, I think it but fair to the philosophers to give a summary of their theory. It is the opinion of governments and of other bodies of men, that it is dangerous to publish false theories. I do not think so. Falsehood cannot stand against truth in the open day. It may creep on in private, but its publication draws after it its refutation, and the establishment of 
true knowledge into the bargain. There is great philosophy in "Oh, that mine enemy had written a book!" A modern writer ("The Angler's Souvenir") says, "Most books on fly-fishing contain long lists of flies, named after the particular insect of which it is pretended they are an imitation, but to which they bear so very distant a resemblance, that the most skilful entomologist would be completely at fault in assigning the species. Such lists, for the most part, only confuse the beginner, and give him wrong ideas of the rationale of the art, and are not of the least use to the proficient. The greatest number of trout, as is well known to every practical angler, is caught with flies which are the least like any which frequent the water. The imitation of the yellow May-fly, which is so common on many streams towards the latter end of May and the beginning of June, is scarcely worth admitting into the angler's book; for when the natural fly is most abundant, and teachers say the imitation is to be used, it is generally good for nothing, as the trout very seldom take it when the real fly is on the water; but, in direct opposition to the unfounded theory, prefer a hackle, black, red, or brown, or a dark coloured fly. Wherever fly-fishing is practised - in England, Scotland, Ireland, Wales, France, Germany, and America - it has been ascertained by experience that the best flies are not 
those which are dressed professedly in imitation of any particular insect. Red, black, and brown hackles, and flies with wings of the bittern's, mallard's, partridge's, woodcock's, grouse's, martin's, or blue hen's feathers, with dubbing of brown, yellow, or orange, occasionally blended, and hackles, red, brown, or black under the wings, are the most useful flies that an angler can use on any stream in daylight all the year through."

The above passage contains a summary of the doctrine preached by the new piscatorial philosophers. They are lazy theoretical anglers, and would be glad if there were only three general killing artificial flies, that they might not have the trouble of changing them, or observing which flies are in season. There is one truth, and one only, in the above extract; viz. that which says fish will generally in the drake season, "prefer a hackle, black, red, or brown, or a dark-coloured fly," to the imitation of the May-fly. That truth, however, does not strengthen the philosophers' reasoning. Quite the contrary. I have already explained why the artificial green-drake is not generally a successful fly. It is the most difficult of all flies to be imitated well. - Other artificial flies are better imitations of other real flies, and therefore fish prefer them to the bad imitations of the drake. Another reason why they take "black, red, brown, or a dark-coloured fly," 
is, that fish, like man, have a versatile appetite. What will the philosophers answer, when I tell them that trout at certain times of the drake season will prefer a small artificial fly, to the fine fat living fly? Unaccountable! perchance they will say. Not a whit of it. I have seen fish so much gorged and surfeited with the live May-fly that they would no longer rise at it, whilst they would rise rapidly, particularly towards evening, at an imitation of the common house-fly. What do I conclude from this? Not, certainly, that the artificial fly is a better bait than the natural fly at all times, but that it is sometimes, when palled appetite, or some other casualty, makes it so. The philosophers recommend the use of only a few flies. They recommend, however, the most general ones; that is, those whose appearance on the water is not limited to a few days in a particular month - in fact, flies which are to be found alive in one shape or other during spring, summer, and autumn. After all, they do not in reality recommend nondescripts, and are particularly minute in describing how their imitation should be dressed. If they considered, as they say they do, imitation useless, why are they so precise about appearance, about certain sorts of feathers, fur, \&c. ? I grant them that some of the flies they name are the best general ones we know of, and that they will kill when trout are rising at very different sorts of flies, better than bad imitations 
of those flies which are in season. But they kill on a principle totally different from the philosophers' doctrine, viz., because they are like some natural fly, whilst the bad imitation is not like any fly at all.

In the month of March, when the weather was open and the water in fly-fishing tune, I have seen thousands of a particular species of fly sailing with wings erect upon the surface of the water. The fly I mean is diversely called the Marchbrown, brown-drake, cob-fly, and grey caughlan. It is easier to dress an imitation of this fly than of the May-fly, and therefore such imitation will kill when a nondescript, or a fly as unlike as possible the March brown, will not. Practical anglers know this so well, that when the March-brown is on the waters, they fish with three imitations of it of different sizes attached to their foot-line at one and the same time. I have known a good imitation of the March brown thrown upon the water amongst the live insects and eagerly taken, I may say in preference to the natural fly. Did the fish confound it with the natural fly, or rise at it because it was a nondescript? That is the question. I answer without hesitation they confounded the artificial with the natural fly. At the same time I maintain that if fish did not in general make the mistake of confounding the artificial with the natural fly, 
the fly-fisher's art would be a bungle from beginning to end, and he should call it a comedy of errors, rather than a science. Of the March-brown, Mr. Bainbridge, in his "Fly-fisher's Guide," and Christopher North pronounces that gentleman to have been one of the most accomplished anglers that ever crossed the Tweed, - says, "This very excellent fly very generally appears about the middle of March, and is strongly recommended as a good killer from eleven until three o'clock. Large quantities of these beautiful insects sail down the streams in succession, and invite the trout to action. Their wings are upright on the body, and whilst they are on the water, it is almost in vain to attempt the use of any other fly. Therefore, as they vary in the shade of their body, it is advised to use three of this form, but of different sizes and colours, at the same time, which will insure success to the angler." Mr. Bainbridge is an orthodox authority acknowledged by every practical angler. $\mathrm{He}$ is perfectly right in advising the use of differently coloured Marchbrowns, because the hue of the male differs from that of the female.

Why are duns in general use? Because they are imitations of the ephemera family, the most common and most killing water insects. It is not because they are nondescripts; and he who has the best dun hackles of various hues, dressed 
in the neatest way over bodies varying in colour, as the natural flies do, according, I am justified in saying, to wind and weather, will meet with the surest success. For my own part I seldom flyfish for trout or grayling without some sort of dun on my line, and I am guided by the shape and colour of the dun-fly on the water. Some species of dun-fly is on the water throughout the fly-fishing season.

I find in "The Encyclopædia of Rural Sports," some passages so full of sound sense on the subject of natural and artificial flies, that I cannot resist the temptation of borrowing them. They deserve attentive perusal, and their author, the late Mr. Delaborde P. Blaine, was famed for his knowledge of natural history and his practically scientific attainments. He says, "The small ephemeral flies, called duns in the angler's vocabulary, are very important to his practice: the entomological outline will show that they are very numerous also. A few, as the May-fly, the March-brown, and great whirling dun, are large; most of the remainder are very small, but yet are so attractive to fish, particularly to the trout, that in the counties which are favourable to their propagation and increase, they form the sheet anchor of the trout fly-fisher's practice. It would be difficult in the extreme for the most attentive, either angler or naturalist, to designate or charac- 
terise them individually, from their numbers and varieties. The short period of their existence, limited to a few days at most, and in some to a few hours only, renders a constant succession necessary to fill up the void. They have been grouped under the comprehensive term of duns, which has become so conventional, that it would be extremely difficult to disjoin them; although whoever examines the yellow and the orange varieties, which equally pass under the same name, will find they have little of a dun hue about them. There are, however, extreme exceptions, for it is very certain that in most other varieties there is a predominating bluish grey tinge. Were it not for the successional changes which take place in their tribes, they might perhaps be conveniently and appropriately divided into brown, red, and yellow ephemera; of each of these the modifications are almost infinite.

"Of the brown ephemera, or duns, some are very dark, approaching a claret colour, which is best imitated by a dark blue, mixed with a reddish brown. These are usually found in the earliest part of the fly-fishing season, and to them usually succeed a mixture of red and coloured varieties, followed by a new series, which are gradually softened into the different hues of dun, orange, or yellowish ash. Of the tree dun ephemeral flies the variety is equally endless, from the early 
blue-dun, which may be considered as the type, through all the gradations of iron-blue, violet-blue, ashy grey, and pale blue. The yellow ephemera or duns are still more difficult to define, as there are few even of the former that do not exhibit a yellowish intermixing tinge about some parts of their little frames. Often it appears in exquisite orange bars over the abdomen; but they derive their character from the yellow being more strictly predominant. In some may be perceived a slight mixture of bright yellow with a larger of ashy dun. When both colours are bright, an elegant tint of green is produced. In others again, as the little yellow May-fly, bright yellow prevails without mixture. Of all these the series are wonderfully varied, some having orange bodies and dun wings, while in others the orange is shed over the wings, and the dun body serves as a foil to them.

"The successional change of colour which takes place in the series of ephemera, as they advance from the spring to summer, and as they retrograde again towards autumn, has not escaped the notice of anglers; and we find in most of the directions for fly-dressing the subject practically glanced at; but no systematic arrangement of the series has been attempted. All that has been hitherto noted is, that in the early spring months the predominating colour of the winged insects 
which are seen near the water, is almost black. The early duns are of a very dark olive, whose occasional varieties, as the season advances, assume a lighter brown, while others shine in a heavy blue; until at length yellow, orange, or cinnamon decks the former, and pale blue the latter, intermixed with others apparently compounded between these. With one exception, that of the blue-blow, the ephemera appear invariably to become of a lighter hue as warmth and light increase; and we see the summer duns dressed in bright yellow, orange, red, and cinnamon. From these fresh relays appear, and as the season advances, these again assume the gradatory shades of red, brown, violet, and claret colour.

"The daily appearance of the ephemera, as well as the colours they shine in, is also under the influence of times and seasons. Excess of cold, as well as of heat, is unfavourable to them: thus in the depths of winter they are not seen at all; in spring they do not show themselves until towards noon: while in the meridian splendour of the summer days, they (to avoid heat) come out in the mornings and evenings principally, and are hardly seen at mid-day. A kind and provident nature so suits the supply of her creatures, that her economy may never be disturbed. If these ephemeral flies appeared all of them at one time, the air would be vitiated, and the birds 
and the fishes which live on them would be glutted to satiety and fatal repletion at one time, and at another might want the necessary support. But we see species after species arrive in succession to fill up the breaks made by the last; and that no inconsiderable interruption may occur by variation in temperature, and changes in weather, some are destined to appear when cold and storms prevail, while others require cloudless skies and genial warmth to draw them from their seclusion. The whirling dun thus frolics in the gale, the red spinner dances in the sunny beam, and the blueblow braves the chilling day. The observant angler makes a practical use of all this, and frames his mimic art accordingly."

The intelligent reader will find, in the above extract, hints that will serve as a safe clue to much interesting and useful information. He will be inclined to think that a partial knowledge at least of entomology will be necessary to make him a perfect fly-fisher. He will find that each month produces its particular flies, with some that äre common to most months and waters, and with imitations of these he will angle. He will find that the first. spring flies are generally olive coloured, reddish and brown; that as spring advances, various duns, not as yet very light ones, come on together with larger flies of mottled wings, and yellow and dark bodies. In the last spring month, appear such 
flies, as the little and large May-fly, precursors of more gaudy ones for summer-tide, and in early autumn he will find gnats, transparent duns, cinnamon-coloured flies, ant-flies, and as the season advances the spring flies, olive and green, reappear. This information is important.

In dressing flies, colour is of more importance than exact shape. If the colour of your materials be bad, it is in vain for you to be correct in shape. You must therefore ascertain the colours of the living flies, and match them by artificial means. The fly-fisher who is the best judge of colour has an immense advantage over the bad colourist. When by and by I give my list of flies, I shall be most particular in stating the coloured materials of which they are to be made. The wings and feet of flies are almost always made of feathers, the bodies of fur, mohair, silk, wool, \&c. ; and the fly-dresser cannot be too particular in the quality of those materials and in their colours. The most general feather for wings is the wing feather of the starling, its longest or inner fibres to be used; the most general feather for legs and sometimes for body is a cock's hackle-feather; and the most general substance for dubbing the body is mohair : it is the best also. The hacklefeather is taken from the back part of the cock's neck, and that part of the bird affords feathers of various sizes and various hues. Mohair can be 
dyed any colour, it resists water well, does not cake in it, shows its colour effectually, and mixès well with fur and silk. It is a most valuable material. The hackles of cocks are of different colours. The most valuable are duns, and they are the most difficult to be obtained in perfection. The best dun feathers are to be found in the midland counties. Hackles are to be got from a variety of other birds, from the grouse, the green and golden plover, the partridge, bittern, woodcock, snipe, wren, tom-tit, \&c. ; and feathers for wings from a still greater variety of birds. The same feather that will make the wings will frequently answer best for the legs and shoulders of the fly. All that is required is judgment in the selection, and this can only be obtained by comparison.

Artificial flies are now certainly very neatly made-infinitely better, everyjudge acknowledges, than they used to be a few years ago. My own ephemeral writings in Bell's Life in London have (I have heard many say) tended much to this advance towards perfection, and so have $\mathbf{M r}$. Ronalds's "Fly-fisher's Entomology," and Mr. Blacker's "Art of Fly-making." The books of these two ingenious and practical anglers, studied in conjunction with that now in the hand of the reader, will afford most ample and correct information touching all matters connected with artificial 
fly-fishing. Mr. Ronalds gives the natural history of the angler's flies, natural and artificial representations of them, and the materials of which they are made. Mr. Blacker's book contains the flies dressed in every stage, from the whipping on of the gut to the last finish of the head. It also contains valuable instructions both for procuring and for dyeing angling materials, as well as an excellent list of trout and salmon flies for different rivers and countries.

Still we are not perfect in fly-making, nor shall we be so until some more pains-taking fly-dresser gets a collection of natural flies, examines them by means of the microscope, ascertains their precise colours and anatomy, and then by microscopic examination again of feathers, mohair, fur, and so forth, arrives at the exact imitative materials. When that is done, fly-fishing will be reduced to a sporting science exceedingly amusing and instructive. The journeyman or woman fly-dresser at present is merely acquainted with the mechanical part of the art, dresses from artificial specimens, knows little or nothing of the natural insect, and is rarely a good angler. They are copyists, and do not know whether that which they have to copy is a good likeness of the living subject or not. A fishing-tackle maker, to be a great and good one, should have an insect museum, - each fly, caterpillar, or beetle, preserved in cases, named and 
numbered, and its season noted. From these models he should dress his flies, and when he finds he has succeeded in framing perfect copies, he should note down the materials he has used in their formation, and then he will have sure guides for the fly-dressers he employs. He should pay those persons well, and engage none who do not deserve high pay; and should charge his customers a remunerative price. The generality of flies are sold at too low a price. They cannot be made well at a low price. They must be defective in every way, and hence the purchaser meets with little success, much loss of time and of money, for cheap things are always the most expensive in the end.

In trout and grayling fishing I would always have three flies on my casting-line at the same time. The tail-fly or stretcher should be the best, and when possible the largest; the first dropper, a good general fly, and the second dropper, or third fly, a most attractive hackle. The stretcher should be an imitation of the fly in season. It is the fly which ought to fall first on the water if you cast well, it floats most naturally in it, and a fish hooked by it is more easily played and killed than with either of the droppers. When you find that fish are rising at one sort of fly only, that your stretcher, or one or other of your droppers is the sole attraction, remove your 
useless flies, and fish with a triple attraction. You will often find several sorts of natural flies on the water simultaneously: observe which of them the fish are feeding upon, and produce your imitations if you can.

It is a fact that hackles and palmers are the most killing flies on many of the rivers in England, whilst in others winged flies are the best. Hackles, except a very few, do not kill well in Ireland. Winged flies are the best there. Palmers are not good flies, generally speaking, in Ireland; whilst in some parts of England they are the best general baits. In our northern streams, which are exposed to cold winds, and not well sheltered with trees, bushes, and plants, hackles and small flies are the most killing. In well-wooded rivers, in our midland, western, and southern counties, winged flies are the most attractive, and the palmer kills better than the simple hackle. The natural flies are bred larger there, and with more seasonable regularity. We have one consolation, however, that the good general fly extends its attractive qualities to all aquatic coquettes, be they English, Irish, Scotch, or Welsh salmon or salmonidæ. Experience alone can make you intimately acquainted with the great local favourites. 


\section{CHAPTER IV.}

\section{FLY-DRESSING.}

THere are hundreds of things that cannot be taught easily by means of pen and ink, but which the tongue and hand, reciprocally illustrating each other, can inculcate with very little difficulty. Fly-dressing or fly-making is one of those things. I can scarcely teach it by writing; in half an hour I could explain the whole matter with tongue and hand. However, I must on paper do the best $I$ can, and the artist in wood having lent me some assistance, I fancy I can make a short lecture on fly-making practically comprehensible.

The wood-cut on the right-hand side of this page, and marked 1., represents what fly-dressers term " the gut armed," that is, plainly speaking, the gut and hook whipped on, or tied together. It is the

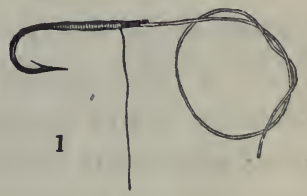
first step in fly-dressing, and is thus performed. You take the hook by the bent part, or bend, between the tips of the fore finger and thumb of the left hand, the back part of the hook being 
upwards, and the barbed part downwards, as. represented in the little plate before you. You next take a strand of fine silk, neatly waxed, and about a foot in length, and you whip it two or three times firmly round the hook at that part of it nearest your finger nails, or, generally speaking, that part of the shank which is opposite to the pointed and barbed part of the hook. You make the two or three whips in the direction of the end of the shank of the hook, that is, towards your right. Next you take a link of gut, coiled for convenience sake, as you see in the cut, and having softened between your lips, and drawn between your teeth to soften and flatten it, a small portion of the freed end of the gut, you place that end against the last whip that you have made with your silk, and you wind your silk over gut and hook up to the end of the shank, or up to that part of it from which you see in the cut a portion of the silk hanging. Wind your silk firmly, and in regular twists, and one winding will be sufficient to fasten safely your hook and gut together. If you only wind your silk as far as you see it wound on the hook before you, a very small portion of the end of the shank will be bare, and leave more room for you to make the head of the fly, and fasten off there with greater delicacy. On the other hand, if you wind your waxed silk to the end of the 
shank, and back again to the spot at which you see the silk depending, you will make a firmer foundation for the setting on of the wings, the time for performing which operation is now arrived.

Here you see the wings merely whipped on; the butts of the fibres fastened down by being whipped over in the direction of the bend of the hook, and the tips of the fibres pointing away to the right. You ask where do you get

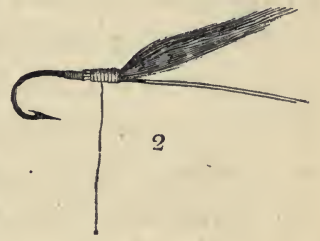
these fibres, and what are they? Simply a small parcel of feathers cut or torn from the stem of some appropriate feather, generally from that of the wing of a small bird, the most common one being the starling. These fibres are generally taken from that side of the feather lying on the inner part of the wing. They are longer, of a lighter colour, and more transparent than the fibres lying on the outer side of the wing, because the latter are more exposed to atmospheric action. Having cut or stripped your fibres in sufficient quantities to form two wings, and having made a little bundle of them, their buttends lying evenly, and not projecting the one beyond the other, fasten the butt-ends down on the top of the back of the hook, at the spot indi- 
cated in the wood-cut. Three firm whips of your silk will be sufficient to fasten them. Then cut away any of the butt-end fibres that may remain uncovered by the silk. Wind your silk down towards the bend of your hook, stopping at the spot at which you first began the arming of your gut, as described in Figure 1. You are now ready for the placing on of the tail.

Here you see it placed on and whipped over with your silk. The tail is generally made of two fibres of a feather, or of two hairs. In tying on the tail use three fibres or three

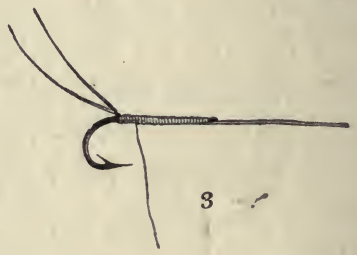
hairs, lest one should drop off or be in any way injured whilst you are dressing the other parts of the fly, and afterwards, if you have succeeded in fastening on three, you may cut away the worst of them, and allow only two to remain; the generality of angling flies having but two tails, and a few only being pachas of three. These illustrious insects have their appendages particularised in our list of killing flies. You have now, attentive learner, performed three things, - armed your gut, fastened on your fibres for wings, and fixed your tail. You now come to making the body, and attaching it round your hook. 
Here are hook and gut with a body on without wing and tail. That body is made of what is called dubbing, and dubbing is made of fur, hair, mohair, silk, and a few other sub-

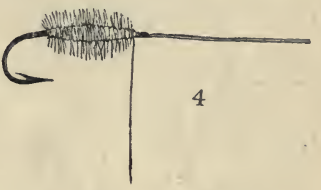
stances. You spin a little of either, the quantity to be determined by the size of the hook you use, the size of the fly determining the size of the hook, on your silk, by twirling both dubbing and silk between the fore-finger and thumb of your right hand, and you wind the whole on your hook, beginning at the tail, and working up to the setting on of the wings. The dubbing must be wound more sparingly on the silk near the tail, and increase upwards, being most plentiful close under the wings. You will easily perceive that you begin winding on the dubbing after you have tied on the tail, just where you see the silk hanging from the hook in Fig. 3., and you cease winding on when you come to the wings. It may be here necessary to warn you that in some instances you place the tail and dubbing on first, and before you whip on the wing fibres. These instances are, when you are dressing very small flies with perfectly upright wings. Then you place on the wings last, with the butts of the fibres pointing towards the end of the shank, and the top ends towards the bend of the hook. In 
fact, such wings, for such flies, are placed on in a way quite the reverse from that shown in Fig. 2.

This next cut represents an ordinary winged fly, one of the easiest of the sort you can make, in nearly a finished state. You

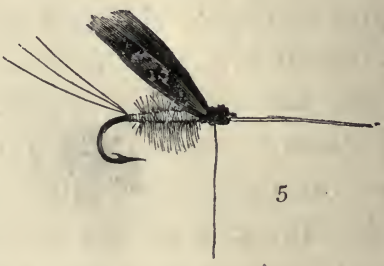
have only to cut off the silk which is left hanging at the spot at which you have finished the fly. You wonder perhaps at the position of the wings, pointing very differently from the way you left them when you first tied them on as directed in the explanation accompanying Fig. 2. I will explain to you the different operations that have caused this change of position. When you wind up your dubbing to the setting on of the wings, you fasten your dubbing there, and pinch off all of it that is superfluous. You fasten your silk with a slip-knot. You then take the wing fibres between the forefinger and thumb of your left hand, and reverse them, bending them down over the back of the body of your fly, with the tops of the fibres pointing towards the bend of your hook. Whilst so bent and held down, you pass your silk behind the wings, between them and the end of the shank of the hook, and you 
lap your silk two or three times tightly close under the wings. They will now lie nearly as represented. To make them do so completely, you divide the fibres exactly in the middle with your dubbing needle, and through the division you pass the silk, and then you wind it round the bottom of the division farthest from you, or that on the right side of the fly, and you bring back the silk, passing it again through the divided wings, and bringing it round and under the bottom of the division which is next to you. You now whip the silk behind the wings, and form the head-part of the fly. Fasten with a couple of slip-knots newly waxed, and clip off the depending silk. Your fly, consisting of tail, body, and wings, is now finished. If your wings are too long, pinch off with your finger nails the unnecessary portion of the tips of the fibres. Pick out your dubbing with your dubbing needle, and make your body taper by taking away parts of the dubbing wherever you see it superfluous. The fly here represented has three visible defects. It has three tails, one of which should have been clipped off; the head is too thick and too long, which might have been prevented by fewer laps of the silk between the wings and the end of the shank; and the wings should be more pointed and equally divided. I have purposely left the defects standing, in order to show how they are to be remedied. 
Here is a complete fly, with wings, body, tail, and hackle for legs wound under the wings, and just before them.

You see here the hackle feather whipped on for the purpose of making the legs of a winged fly or for making a plain

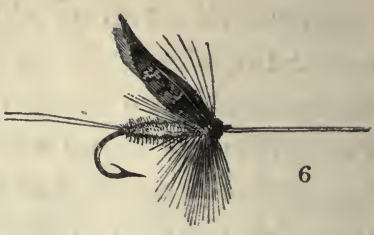
hackle or a palmer hackle. I will suppose you going to make the fly, Fig. 6. You arm your gut, as described at Fig. 1.; you fasten on your wings as shown at Fig. 2.; and you then whip on your hackle, as here represented, close by the wings. You cut away butt-ends of the hackle and wing fibres, and you whip your silk down towards the bend. Whip on your fibres or hairs for tail, and then spin on your dubbing, which you wind up to the thick ends of hackle and wing. Carry back towards the tail your silk a little, and then wind on over the body for two turns, in the same direction as your silk, your hackle-feather, which you tie down, and cutting off what remains of it unbound, bring your silk through the fibres of the hackle behind your wings, which divide, and pass your silk 
through the division, and round the bottom of each wing, finishing at the head in the way directed for fly, Fig. 5. A fly made carefully in this way is a most general and killing one, wanting only, for higher finish, to be ribbed or tipped with tinsel.

I here present you with a fly ribbed with tinsel over the body. It is a difficult fly to make, and when you can make

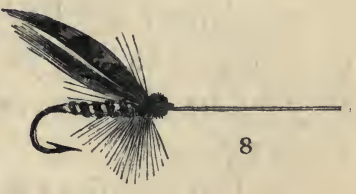
it well, you may consider yourself a proficient in the art of fly-dressing. Arm your gut, then tie on your hackle for legs, and your wings as usual. Cut away thick end of hackle and wings, and wind your silk down to the tail. Attach your tail, and then your gold or silver twist, as may be. Spin on your dubbing, which wind up carefully to the wings, fasten with a slip-knot and leave your silk depending. Go back to the tail, and take your gold or silver twist and lap it at regular intervals over the body up to the wings; fasten, and cut away the remaining parts of the twist and dubbing; then wind your hackle a coupleof turns over twist and dubbing in the direction of the tail, and fastening down the hackle cut away the point of it. Bring your silk back behind the wings; divide them, and finish in the way already taught. In the body of the fly repre- 
sented you see white and dark ribs. The white are caused by the tinsel; the dark by the portions of the dubbing which you have not covered with the twist or tinsel. In this figure there are three prominent defects. The head is too thick, the wings unequally divided, and the tail is omitted. These defects are designedly done. They will often occur to the young fly-dresser, but when they do, he must unfasten his defective fly, and begin again.

The two last flies the learner has been studying are amongst the most difficult to make. I will give him a little relaxation now by presenting to him one or two flies more easily dressed,

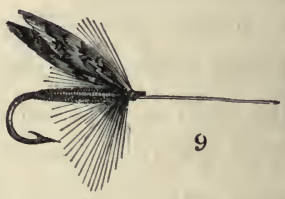
- and here is one. It is a fly with plain silk for body, wings, and legs. The making of it should be frequently practised, as that will afford greater facility in dressing the more complicated flies. There is nothing like a good foundation. Arm your gut. Suppose the body of your fly should be delicate and of an' orange colour, let the silk you use for arming be of that colour, waxed with colourless wax.* Consequently, whilst you are

* Wax colourless, as far as the effect or coloured silk goes, may be thus made: - Take two ounces of the best and lightest-coloured resin, with a drachm of bleached bee's wax ; put them into a pipkin on a slow fire, until completely 
arming your gut you are forming the body of your fly. You must make that body of the requisite length and thickness, and of the proper tapering shape by a few laps more or less of the gut. Tie on your hackle and wings, as shown. at Figs. 7. and 2. Wind on your hackle two or three laps down the body of the fly. Fasten, and clip off the point of the hackle. Bring your silk back through the fibres of the hackle to behind the wings, which divide in the usual way, and finish at the head delicately.

I now give you a simple hackle to make, which I think very easily done, though others do not. The great difficulty consists in winding the hackle feather, so that its fibres may project below and

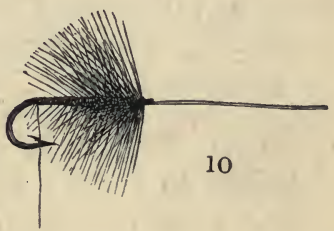
above the hook with great regularity, tapering off according to their length towards the bend of the

dissolved. Let the whole simmer for ten minutes. Then add a quarter of an ounce of white pomatum, and allow the whole, constantly stirring it, to simmer for a quarter of an hour longer. Now pour the liquid into a basin of clean, cold water, when the liquid will instantly assume a thick consistency. In this state, and while it is yet warm, work it by pulling it through the fingers until it be cold. This last operation is necessary to make the wax tough, and give it the bright silvery hue which it has when made to perfection. 
hook, and not being entangled, by some getting tied down by the others, or hitching in them uncouthly. Arm your gut, and attach your hackle, as shown at Fig. 7. Then wind your hackle to the bend of the hook, and there fasten. Cut away your silk and the point of your hackle feather. Now with your dubbing needle pick out any of the fibres that may be caught in the winding on, and clip away the points of those that project irregularly.

Before you now is a palmer-hackle, a most useful bait, representing a caterpillar. Arm your gut, and then attach your hackle feather as usual, together with some floss silk, peacock, or ostrich harl, or dubbing, to form the body. They must be attached near the end of the shank. First wind your floss silk, or harl, or other material for the body, down to the bend of the hook. Then wind your hackle for legs all down the body, and fasten at the tail. Clip away all that remains at the end of the hackle and body. Palmer hackles are frequently ribbed with gold or silver twist. When you use it, attach your hackle first, then your twist or tinsel, and lastly your harl or dubbing. Note, as a general rule, that the material you attach first, is that which is to be wound round your hook last. Having attached hackle, tinsel, 
and harl, near the shank of your hook, wind down the body of it, towards the bend; first, your harl or dubbing; secondly, your tinsel; and lastly, over all, your hackle. Fasten, and cut away the ends.

: I said before that very small flies are dressed differently from the way I have been teaching

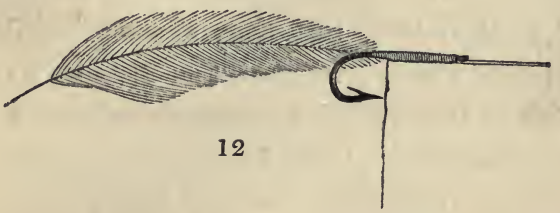

you hitherto. The chief difference consists in the wings being tied on last, instead of first, after the gut has been armed. To dress flies with the wings fastened on last, you must arm your hook as usual, then attach your hackle feather at the bend, as here represented, and then spin on your dubbing also from the bend. When you have wound up your dubbing to the shoulders, fasten it down there, and then wind up your hackle to the same spot. Clear away the ends of dubbing and of hackle. Set on your wings with the buttends towards the shank of the hook; lap your silk a couple of times round the butts of the fibres. Divide the wings, and pass your silk through the division, as directed at Fig. 5. Finish at the head carefully. Wings set on in 
this way, will sit upright, and also enable you to dress with a finer body, and composed of a great variety of materials. It may often happen that after a little use, the wings will get spoiled and the body of the fly remain uninjured. By the method taught here, you can attach a new pair of wings without interfering with the body, and that is an advantage. I think that wings tied on last generally sit better, but they cannot be tied on so firmly as the wings that are attached immediately after the arming of the gut, with the buttend fibres pointing to the bend of the hook. As many insects have their wings lying flat on the body, such wings are best imitated by feathers tied on with their roots pointing towards the shank of the hook.

The last specimen of fly-dressing $I$ intend to give is a very simple one, though not the less valuable. It is a hackle, with the wings placed on last; that is, dressed reversely

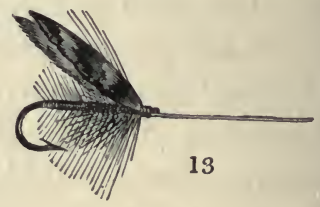
from the fly, Fig. 9. You

see that the wings sit well, and as one way is as easy as the other, you may adopt whichsoever you like. In making plain hackles, you may begin by attaching the hackle near the end of the shank, as shown at Fig. 7.; or near the bend, as 
seen in Fig. 12. 'Tis six of one, and half-a-dozen of the other.

I have now shown the reader, as clearly and concisely as I could, how to dress the usual sorts of trout and grayling flies. The cuts are rather rough ones, because the originals were designedly left in a rough state; but, if they were too much fined down, and finished, the learner, seeing that he could not easily approach their neatness, might be deterred from fly-dressing. When the learner can tie flies in this passably rough way, he must get finished models, and laying them before him, he must pick, trim, and shave his own rough insect statues until he can fashion them as delicately as the most cunning professional artist. If he confides in the sure and steady improving progress which time and perseverance invariably produce, he will become his own complete artist in flies. In arranging the heads of this chapter, I have been materially assisted by the intelligence of Mrs. Little, the wife of Mr. Little, fishing-tackle-maker, No. 15. Fetter Lane.

\section{MATERIALS USED IN FLY-DRESSING.}

The substances which the fly-dresser wants to make flies of are various, - chiefly feathers, fur, hair, and silk. The colours he requires are still more various than the materials. There is scarcely a bird 
or quadruped, particularly the smaller sorts, that does not contribute to the fly-dresser's magazine. The fly-dresser who is a good judge of colour has an immense advantage over him who is not. He will find many excellent coloured materials where the bad judge would never think of looking for them.

Feathers are obtained, remarks Mr. Blaine, from nearly every bird, from the gigantic ostrich down to the Lilliputian wren. Nothing can be commoner for making flies than the ostrich harl, or the individual fibres of some of the plumes of that bird, dyed variously. Peacock harls, or single fibres of its largest feathers, are still more common for the bodies of flies. The wings of small flies are made of the wing feathers of the starling, lark, landrail, hen pheasant, partridge, woodcock, plover, snipe, dotterel, sea-swallow, sea-gull, wild-duck, teal, water-hen, domestic hen, and many other birds. The tom-tit's tail affords an excellent blue feather for wings and hackle. Foreign birds afford an infinite variety of feathers for gaudy flies.

Hackle feathers are very valuable, and, as Mr. Blaine says, "they are generally those which deck the neck and rump of the cock. Such hackles only should be chosen as have fibres about half an inch long, and those from the game fowl are to be preferred. The principal colours are white, black, 
grizzled, grey, ginger, light red, dark red, and that variety in which the dark red is divided by a black listing. The dun or blue hackle is difficult to obtain, not only on account of the colour, but because, as it is wanted to dress minute flies (the duns), those of the dun cock are rather too long and gross, and those of the dun hen too weak." The dun hackle is seldom to be got pure. Fowls' feathers should be plucked in winter, and from full-grown birds. The feathers of male fowls are generally the best. The backs and tails of the partridge, grouse, golden plover, snipe, and some other wild fowl, afford excellent hackles. Golden pheasant's feathers are most valuable for salmon flies.

Furs can be easily got at the furriers'. Those most wanted are bear's, grey, black, brown, and dun of every shade; badger's, sable, and martin's fur, particularly the parts about the head of the former, and the yellow spotted portions under the jaws of the latter. Squirrel's fur, American and English ; also the fur of the water and house rat, field mouse, mole, seal, both dyed and natural. Skins of the black, sandy, and grey rabbit, in all their varieties, are useful; also those of the ferret, weasel, and polecat. The fur of the ears, head, and neck of the hare is most useful. Mr. Blaine advises, "that skins of all kinds when they fall in the angler's way should be looked over, and 
any striking portions preserved, every one of which may prove valuable in the hour of need."

Of hair, there is none more useful than that called " hog's down." Naturally, it is of various colours, and can be dyed artificially of any hue advantageously. It resists the water well, and when immersed in that element retains its vivid colour, whatever that may be. I have a high opinion of mohair, and it can be obtained of every colour. Worsted is well suited for the bodies of large flies. Mr. Blaine is very minute on this subject. He says, "Of hair, that of calves, colts, and cows, of every colour and from every part, should be collected. About the ears of the silkycoated spaniel, some of a very fine texture and rich colour may be always met with. The tan of the black spaniel, and the tawny, is all good and worth selecting. In long wiry-haired animals of every kind, there is at the roots of the longer hairs a fine woolly substance. This should be looked for in all skins, as it present shades very different from the general exterior hue, and often produces the richest and finest dubbing that it is possible to meet with. Cuttings from the skin of the fox, both young and old, should by all means be procured; indeed, there is no part of the body of this animal from which valuable shades of fur may not be taken. Some hairs also of the stiff kind, 
from the skins of goats, cows, monkeys, and other animals, should be saved by themselves, as those also from the beards of cats, dogs, rabbits, and badgers, and from the tails of ferrets and polecats, to make the tails and horns of certain flies."

For tying on flies the best silk is that which is the finest and strongest. Undyed silk is always the strongest, and the floss silk used for making delicate fringes, and the sewing silk employed in the finest sort of glove work, are perhaps the best. If you use them of different colours, wax them with the wax, to make which I have already given you a recipe. If you use white silk only, you must wax with wax dyed the general colour of the body of the fly you are dressing. As common shoemaker's wax is always useful, ever have a bit between a piece of leather to prevent it from sticking to your fingers. Thick floss silk and camlet of various hues are necessary for the bodies of some flies and palmers.

The instruments for fly-dressing are few. You will want a small table vice, a small spring pliers, a penknife with a file-blade, two pairs of scissors of the very best manufacture, one with long and fine blades, ending in the sharpest and finest points, another with short stout blades and large finger hooks, and as correctly pointed as the other. A large needle, with a fine point and fitted into a small handle, is necessary to divide the wings, 
to pick out the dubbing, and to free the fibres of the hackle when required.

\section{A FEW RECIPES FOR DYEING.}

Under the head of the May-fly, will be found a recipe for dyeing feathers a yellowish green. Mr. Packer, in his Dyer's Guide, dyes feathers yellow thus:-Into a saucepan three parts filled with soft water, put the feathers to be dyed, and when they are thoroughly wetted, add a small quantity of sulphate of iron. Simmer them over a moderate fire a few minutes, and the feathers will have gained the colour-base or mordant. Remove the liquor from the feathers, and put to them instead a smaller quantity of soft water, and when it is of a simmering heat, add a small quantity of powdered Aleppo galls.

The requisite shades of dun colour may be obtained by varying the quantities of the iron and galls. For a full dark dun, add sufficient quantities of the sulphate and galls. By increasing or diminishing the proportions of either of these articles, you will obtain duns of divers shades. If logwood be used instead of galls, a different tint will be the result. Madder, camwood, the bark of the alder tree, walnut peels, produce different hues. Galls, logwood, and madder should howerer be omitted when the 
colouring is intended to approach a red or brown. The light shades in all cases should be first gained, and any other deeper hue added afterwards. Hard water should not be used in dyeing. Having given to the feathers their mordant or base, as already directed, add either sulphate of iron, sulphate of alum, acetate of alum, or acetate of copper, according to the intended shade. Wash the feathers from the mordant, and put them into a strong decoction of that plant which the dyers call weld. Simmer them in this a few minutes, strengthening or weakening the welddecoction in proportion as the colour is to be more or less brilliant. A little practice, and the noting of the various results after each trial, will soon make the angler familiar with the methods of varying the colours so as to meet his wishes. These instructions, Mr. Packer states, apply to wool also, which may be tinted in the same manner.

Mr. Ronalds dyes white feathers a dun colour thus :-Make a mordant by dissolving about a quarter of an ounce of alum in a pint of water, and slightly boil the feathers in it, taking care that they shall be thoroughly soaked or saturated with the solution; then boil them in other water with fustick, shumach, and a small quantity of copperas, put into it until they have assumed the required tint. The fustick and copperas will 
produce a yellow dun tint; the shumach and copperas a blue dun tint. The greater the quantity of copperas the deeper will be the dye.

To turn red hackles brown. - Put a piece of copperas, the size of half a walnut, into a pint of water; boil it, and whilst boiling put in the red feathers. Let them remain in it until, by frequent examination, they are found to have taken the proper colour.

To stain feathers an olive dun, \&c.-Make a very strong infusion of the outside brown coating of an onion, by allowing the whole to infuse by the fire for twelve hours. If dun feathers are boiled in this dye, they will become an olive dun, and white feathers a yellow. If a small piece of copperas be added, the latter colour will become a useful muddy yellow, darker or lighter as may be required, and approaching to a yellow olive dun, according to the quantity of copperas used.

To dye feathers dark red and purple. - Hackles of various colours, boiled (without alum) in an infusion of logwood and Brazil wood dust until they are as red as they can be made by this means, may be changed to a deeper red by putting them into a mixture of muriatic acid and tin, and to a purple by a warm solution of potash. As the muriatic acid is not to be saturated with tin, the solution must be made diluted. If it burns 
your tongue much, it will burn the feathers a little.

To dye feathers various shades of red, amber, and brown. - First boil them in the alum mordant already mentioned; secondly, boil them in an infusion of fustick strong enough to bring them to a bright yellow, (about a tablespoonful to a pint of water;) then boil them in a dye of madder, peach wood, or Brazil wood. To set the colour, put a few drops of dyer's spirit, (i. e. nitrate of tin combined with a small quantity of salt,) which may be had from a silk-dyer, into the last-mentioned dye.

To stain gut the colour of weeds, water, \&c. Make an infusion of onion coatings as before directed, and when quite cold put the gut into it, and let it remain until the hue becomes as dark as required. A strong infusion of green tea will dye gut a useful colour. So will warmed writing ink: the gut to be steeped in it a few minutes, and immediately afterwards to be washed clean in spring water. You will obtain another good colour by steeping gut for three or four minutes in a pint of boiling water in which you have put a teaspoonful of alum, a bit of logwood the size of a hazel nut, and a piece of copperas the size of a pea. To make your gut a watercolour, take a teaspoonful of common red ink, add to it as much soot, and about the third of a tea- 
cupful of water; let them simmer for about ten minutes; when cool, steep your line until it be stained to your fancy. This is a very good colour for the purpose, but should be applied gradually, taking out your gut frequently to examine the depth of the tint, lest it should become too dark. 
THE FLIES FIT FOR EVERY MONTH. 97

\section{CHAP'TER V.}

A MONTHLY LIST OF FLIES Fok THE SEASON.

\section{Jar Jebruary and fatarch.}

As a general rule, it will be found that the earliest spring flies have bodies of a greenish or olive colour. The angler should never fly-fish in February without an olive-bodied fly, which will remain a good general one throughout March and April, unless those months be very fine indeed. Mixed with green and olive-bodied flies you must have brown, red, and yellow-bodied ones; and they will be found the earliest and most killing flies. In the above months artificial flies must be dressed large and full, and their general wings must be made of the longest fibres of the starling's wing-feathers. The flies that kill in February will continue good in March; and if the weather be open in the former month, March flies may be looked upon as February ones.

Olive fy. - Body of dark olive mohair; wings, a starling's wing-feather, to stand upright; tail, two whisks of a mottled mallard's feather; to be tipped with a lap of silver tinsel. This fly may be advantageously varied by mixing with the 
mohair a little yellow hare's fur, and tying on with yellow silk.

The red $f y$. - Body of the dark red part of squirrel's fur, mixed with an equal quantity of claret-coloured mohair, showing most claret colour at the tail of the fly; to be spun on, and warped with brown silk thread. Wings, from a gingerdun covert feather of the mallard's wing; legs, a claret-coloured stained hackle. Mr. Ronalds ("Fly-fisher's Entomology"), according to whose fashion the fly is dressed, observes of it, "that it appears about the middle of February, and is in season until the end of March, and may be used on fine but rather windy days, until the blue dun and other flies come in. I have taken very large grayling with it."

Blue dun. - Body of the hare's ear, dark and yellow part mixed with a little yellow mohair, the whole to be spun on yellow silk; wings, from a feather of the starling's wing, stained in onion dye; tail, two small whiskers of a rabbit; legs to be picked out of the dubbing, at the thick part near the wings.

N. B. Infuse the outer coatings of an onion in water, and macerate by the fire for a day. Dun feathers boiled in the liquid will become an olive dun, white hackles will become yellow, and the addition of a little copperas will stain them a yellow-olive dun. 
The preceding fly is sometimes called "the hare's ear and yellow," and is a first-rate general fly throughout the year, and throughout the empire on coldish, cloudy, windy days.

The red spinner. - Body, brown silk, ribbed with fine gold twist; tail, two fibres of a red cock's hackle; wings of some transparent light brown feather; legs, red cock's hackle.

The alder-fy. - Body, any dark claret-coloured fur, as that which a brindled cow yields, and that of a copperish hue, from a dark brindled pig or a brown-red spaniel's ears; upper wings, red fibres of the landrail's wing, or red tail-feather of the partridge; lower wings of the starling's wing-feather; legs, dark red hackle; horns and tail of fibres the colour of the legs, the horns or antennce to be shorter than the body of the fly, but the tail a little longer. This is an excellent general fly. Mr. Blaine erroneously calls it the coch-y-bonddu of Wales.

The furnace-fly.-Body, orange-coloured silk; wings, a fieldfare's feather ; legs, a cock's furnacehackle. A good general fly. The feather called the furnace-hackle is rather a rare one. Its outside fibres are a beautiful dark red; that portion of them next to the stem being black. It is got from a cock's neck.

Early small blackfly. - Body thin and long, of black ostrich harl, to be dressed with iron-blue 
coloured silk; wings to lie flat, of a hen blackbird's wing-feather; legs, a small dark coppercoloured hackle.

Hofland's fancy. - Body, reddish dark brown silk; wings, woodcock's wing; legs, red hackle; tail, two strands of a red hackle. Hook, No. 10. This is a good general fly for trout and dace, particularly in the rivers near London. The late Mr. Hofland, the inventor of it, says, "I have killed trout with this fly at Farningham, when the May-fly has been strong on the water, and the fish have refused any other that I could offer. It may be used after sunset with success in any part of the kingdom, and in any season."

The Chantrey. - Body, copper-coloured peacock's harl, ribbed with gold twist; legs, a black hackle. Wings, partridge's wing-feather, or hen pheasant's tail. A good fly in the rivers of Hampshire.

Red-brown Ay. - Body of dark brown mohair dubbing; wings, a starling's or dotterel's wingfeather. To be tied on with red silk. Kills best from eleven to three o'clock.

Red fly.-Body, dark red dubbing of cow's hair found in tan yards; dark red cock's hackle for legs; wings, a starling's feather, or the dun covert feather of a mallard's wing. To be dressed with orange-coloured silk. This fly will kill well until May. 
Dark fly.-Body of dark water spaniel's fur, or black rabbit's, intermixed with a little claretcoloured mohair, to give the body a tinge when held up to the light; wings, from the back of the fieldfare or hen blackbird; legs, a dusky black hackle.

Golden ostrich palmer. - Body, black-ostrich harl ribbed with gold twist ; legs, dark red cock's hackle. To be dressed with orange or puce silk. Hook, No. 3., Kendal.

The three following are good dun flies for cold weather:

Esterhazy dun.-Body, bright Esterhazy-coloured silk; legs, blue-dun hackle; wings, from the feather of a fieldfare's wing.

Dark dun. - Body of dark plum-coloured silk; legs, a blue-dun hackle feather; wings, the same as those of the preceding fly.

Another blue dun. - Body, a very small portion of the water rat's fur spun round yellow silk; legs, a blue-dun hackle; wings, starling's wingfeather.

The water-cricket. - Body, orange floss silk, tied on with black silk; legs, of a feather from the green plover's (pewit's) top-knot. A good early fly when the water is low.

An excellent dark dun.-Body, mole's or dark rabbit's fur, or water rat's mixed with dark mohair of a brown hue; legs, a small, dark, grizzled 
hackle; tail-whisks, two brown hairs. To be dressed on a No. 8 or 9 hook, with orange silk.

The cowdung-fly. - Body, yellow lamb's wool mixed with a little brown mohair; legs, gingercoloured hackle; wings, from the wing-feather of a landrail, to lie flat on the body, and be longer than it. To be dressed with orange silk. A general spring fly, but seldom killing except on windy days. Of this fly Mr. Blaine observes, "It is justly prized for its qualities, which are such as deserve the highest commendation as a standard and almost universal bait for all fly-taking fish. If the weather be open it appears very early in March, and is to be found of all sizes. This proves advantageous to the angler, for if the water be fine and low, he can use them as small as he pleases without outraging nature. It is to be observed, that as they are not aquatic, they are not often seen on the water but when blown there; and consequently they are most successfully used in blustering weather; and in the rivers of the midland counties in particular, which are usually skirted by grass fields, they are taken with great eagerness at all hours throughout the whole fishing season; but, as.might be expected, in situations where they are less indigenous, the imitation is less freely taken. As they are so valuable, it is of importance to dress them true to colour and shape. The originals may be seen in clusters on 
every cow's dropping, when it will be observed that their wings are very transparent, which should be carefully imitated by a thin, almost diaphanous feather, with a glossy reflection from it. The body should be rather full and rough, and of a tawny hue. The wings should never be upright or divided."

Peacock-fly. - Body, brown peacock's harl, dressed with mulberry-coloured silk; wings, the darkest part of the starling's wing-feather; legs, a hackle stained dark purple. Hackle-feathers may be dyed red by boiling them in an infusion of logwood and Brazil wood, and then they may be changed to purple, by putting them in a warm solution of potash.

The March-brown, or dun-drake. - This is, perhaps, the best fly that can be used from the middle of March to the middle of April, and sometimes up to May. It is a large, showy fly, and almost as great a favourite in March as the May-fly in May. It has various names, viz. the cob-fly, brown caughlan, and turkey-fly, and kills every where. In a work I edited for Mr. Shipley, of Ashbourn, I find the following note:- " On the 23d of March, 1836, we killed with this fly, from one and the same standing on the Dove, sixteen trout and one grayling. We fished with two flies of this sort on our casting-line at the same time, and we caught three times successively two 
fish at one cast. We should have caught many more, had it not been for an accident that occurred to our tackle ; for, before we could repair the damage caused by it, the rising time of the fish was over. From the middle of March to the middle of April it is decidedly the best and most killing fly that can be fished with in the trout streams of the midland counties. We recommend the angler to fish with two flies of this sort on his casting-line at the same time, one ribbed with gold twist, and the other without. The best time for fishing with this fly is between the hours of eleven and three o'clock, especially if the water is curled by a smart breeze."

Dress this famous fly as follows:- Body, orange-coloured silk, or deep straw-colour, on which wind for dubbing the fox-coloured fur taken from a hare's poll; legs, a honey-dun hackle; wings, to stand erect, of the top of the light or inner fibres of the feather of the hen pheasant's wing; tail, two fibres of the same feather. Rib with gold twist for your tail-fly, and let your dropper be without any twist. When the natural fly is out well upon the water, and fish are voraciously taking it, angle with three flies on your foot-line, varying them slightly in size and colour.

Mr. Blaine's method of dressing this fly:Wings, mottled feather from the tail of a par- 
tridge, set upright from the hook; body, light hair and red squirrel's fur; legs, a grizzled cock's hackle; tail, two reddish hairs or feather fibres. Hook, No. 6.

Mr. Ronalds's method:- - Body, fur of the hare's face, ribbed over with olive silk, and tied with brown; tail, two strands of a partridge's feather; wings, feather of the pheasant's wing, which may be found of the exact shade; legs, a feather from the back of a partridge.

$M r$. Bainbridge's way: - Wing's, the dark mottled feather from the tail of a partridge, or mottled feather from the ptarmigan in its summer plumage; body, of the fur from a hare's ear, intermixed with a small portion of yellow worsted, well dubbed together; a grizzled hackle; and, if the imitator choose to be exact, two fibres from the same feather which composed the wings will enable him to form the tail. With respect to the tail-whisks of artificial flies, Mr. Bainbridge ("Fly-fisher's Guide") says, with much of truth, "This appendage to the flies in their natural state need not be attended to in the artificial formation, as it is of little importance in aiding the success of the angler; although, if flies are dressed for sale, it improves their appearance, and renders them more showy and attractive."

$M r$. Best's way: - Wings of the pheasant's wing, which is full of fine shades, and exactly re- 
sembles the wing of the fly; body of the bright part of hare's fur, mixed with a little of the red part of squirrel's fur, ribbed with yellow silk, and a partridge's hackle wrapped over twice or thrice under the butt of the wing.

Mr. Handsard's mode:- The wings and whisks at the tail may be made from the spotted tail-feathers of a young partridge. For the body, use the dark fur which has yellow tips from a hare's ear, and tie it on with reddish-buff silk; if you are inclined to use a hackle for legs, let it be a dun cock's, or a small partridge feather. As the fly grows lighter, alter the body, and use the yellow-buff fur from a hare's ear, tied with pale yellow silk, and let the hackle be a light dun with yellow edges, or a dull ginger one.

Every angling writer praises this fly, therefore I have shown how it may be dressed in various ways. I would have a few of each variety. Fish will soon tell you which variety is best.

The great red spinner is a metamorphosis of the dun-drake, and is in season longer. It kills well on fine evenings, and may be used in conjunction with the dun-drake. It is a fine showy fly, dressed thus : - body, brown red hog's down, ribbed with gold twist and tied on with brown silk; wings, starling's wing-feather ; legs, bright amber-red hackle; tail, two fibres of the same feather. 
Blaine's blue dun. - Wings, from the tailfeather of a tom-tit; body, blue water rat's or monkey's fur ; legs, a fine, light blue hackle ; tailwhisks, two blue hairs. Hook, No. 9 or 10 . Of this fly, Mr. Blaine says, "It comes on early in March, and continues through April, when it is succeeded by a race of flies in which the bluedun tinge predominates in various proportions. It is well therefore to be prepared with the gradations of this fly, of which the ashy. dun appears the first. In favourable days, the blue dun will kill in all the fishing hours, particularly in April, but best towards mid-day. It is likewise almost universal on the British waters."

The early dark-bodied willow-fy. - Wings, the feathers of the starling, or a rich olive feather of a pheasant is preferable: to lie flat and long. Body, dark hare's fur, with claret mohair; legs, reddish dun hackle, and horns of the same colour. Hook, No. 6 or 7.

Nothing can be more true than Mr. Blaine's reasoning touching those very general and very good baits, called palmers, or palmer-hackles. He says, "As they are meant to represent the larvæ or caterpillars of flies, as well as some of the insects themselves, it is very evident that their sizes and colours may be varied to infinity. If our experience did not inform us that they are very effective in taking fish, we should be natu- 
rally led to expect it : for as every tree and every bush which overhangs the water teems with one or more varieties of larvæ, which must be constantly liable to fall into it; and as from their natural plumpness of figure they must form a delicious morsel, we need not wo nder that the fish are always ready to receive them, unless something more tempting (as when particular favourite flies are on the water) is at hand to attract their attention. As these larvæ are continually appearing in endless succession, so palmers are used to advantagie from March until the latest period of flyfishing or at least until October. In May, June, July, and August, they are however in the greatest request. When the innumerable variations in the size, form, and colour of the larvæ of insects are considered, it is evident that the directions in our angling books to confine the number of palmers to three, four, or five are limited in the extreme; but it is still more erroneous to confine their size to a No. 6. hook. On the contrary, there is such an endless number of them, each different from the other, that the dresser may vary them in any way he pleases with effect, tying them on hooks from No. 4. to No. 9., but keeping these general principles in view, that when the water is fine and low, they should be dressed small, and sober in their tone of colour; but when used on waters which are disturbed, and the day 
is dark, such as are larger and more conspicuously coloured are required."

Palmers kill better in England than in any other part of the empire. They are better suited to streams running somewhat smoothly through flat districts, than to the precipitous ones that dash through hills and mountains. I subjoin a list of them.

Black palmer-hackle. - Body, black ostrich harl, ribbed with gold twist. Black cock's hackle wound over the whole. Hook, No. 4, 5, 6, or 7.

When palmers are dressed large they may be tied on two hooks whipped lengthways on the gut.

Brown palmer-hackle. - Body, brown floss silk, or brown fur, or mohair of a deep amber, or a rich brown ostrich harl, ribbed alternately with gold and silver twist; legs, a red cock's hackle. Hook, No. 4, 5, 6, or 7 .

A plainer brown palmer. - Body, mulberrycoloured worsted, spun on brown silk thread; legs, a fiery brown cock's hackle wound over the whole of the body. These two last palmers kill well when the water is clearing after a flood.

Red palmer-hackle. - Body, dark red-coloured mohair, with a little richly-tinted red fur intermixed, to be ribbed with gold or silver twist; legs, a blood red cock's hackle. Hook, No. 4, 5, 6, or 7 .

A plainer red hackle. - Body, a peacock harl 
with a red cock's hackle wrapped over it, and tied with dark brown silk thread.

Golden palmer-hackle. - Body, peacock harl, ribbed with gold twist; legs, a bright red cock's hackle, worked with a rich green silk. Hook, No. $4,5,6$, or 7 .

Peacock primer-hackle. - Body, a rich full fibre of peacock harl, ribbed with wide silver platting. Make a head to this palmer with a bit of scarlet mohair. Legs, a dark grizzled hackle, dressed with red silk. Hook, No. 5 or 6. This hackle, dressed very large, will kill Thames trout and chub of the largest size.

The golden palmer-hackle. - The same as the last, except that it should be ribbed with gold twist, and worked with green silk, instead of silver platting and red silk; legs, a dark blood red hackle. Hook, No. 4, 5, or 6 .

A good general palmer. - Body, long and tapering, of yellow mohair; legs, a good furnace hackle wound on from tail to shoulder; head, black mohair. Hook, 4, 5, 6, or 7 .

\section{Wlies for Aprít.}

April is the best fly-fishing month for trout in the year. That fish is then getting strong and voracious. The water is generally in good tune, being neither too full, nor too low. The weather 
is often as it ought to be; wind blowing west or south, with alternate sun and clouds. The temperature is moderate. Fish are to be found in the streams, and also in deepish water ; the largest and the best conditioned in the latter. The pools are often aptly ruffled by a genial breeze, and can be fly-fished to the greatest advantage. All the good flies of March will kill in April. Add to them the following.

The oak-fly, or down-looker. - This fly is my fancy. It is generally considered as fit chiefly for the summer months, but I consider it the best English trout fly for those April days which are not too cold and windy. During the last fortnight of April the fly-fisher should never angle without this fly. It is called by some the ash-fly, cannonfly, and woodcock-fly. It is found on the trunks of trees by the river side, in a state of quietude, its wings lying close to its back, and its head looking downwards - hence one of its names. In May and June this fly is also in season, and/it will kill well in deep streams, and on pools that are ruffled by a strong but tepid wind. I shall give divers ways of dressing it, placing my own mode first, as follows:-

Body, yellow mohair, ribbed regularly with dark brown silk; legs, a honey-dun hackle wound thrice under the wings, which are to lie flat and short,"and be made of the wing-feather of a young 
partridge or hen pheasant. To be tipped with pale gold twist. Hook, 8, 9, and 10 .

Mr. Ronalds's way: - Body, orange floss silk, tied with ash-coloured silk thread, which may be shown at the tail and shoulders: wings from the wing-feather of a woodcock; legs, a furnace hackle (i.e. a red cock's hackle, with a black line up the middle, and tinged with black also at the extremities of the fibres). This should be warped all down the body, and the fibres snipped off again nearly up to where the wings are set on, leaving a sufficient quantity uncut for the legs.

Mr. Blaine's method:-Wings, partridge's mottled wing-feather, dressed of a full size, and to lie flat; body, first wrap a little dun fur, next some dark grizzle, and form the tail part of a yellowish dun; make a large head of the brown fur of the hare; legs, represented by the body-dubbing picked out.

Mr. Bainbridge's plan:-The wings are short in proportion to the body, and lie flat on the back. The colours of this fly being various and unequally mixed make the imitation difficult. The head is to be made of the fur from the hare's ear; body, under the wings, dun fur; in the middle orange and yellow, and towards the tail a brownish dun; the wings from the feather of a yellowish brown hen; or it may be made with a bittern's hackle only, without wings. It is an excellent 
fly both for dibbing in the natural state and using artificially.

Mr. Shipley's way: -Body, a black ostrich harl, wound thinly round the hook; legs, a dark red hackle, stained deeper than the natural colour; wings, from the feather of the woodcock's wing. To be dressed with orange-coloured silk.

I advise the angler to have this fly dressed different ways and of different sizes, and to angle with three of the different patterns on his castingline at the same time.

The sand-fy.-Body, bright sandy-coloured fur from the hare's neck, mixed with a very small quantity of orange-coloured mohair ; legs, a ginger hackle; wings, the sandy-coloured feather of the landrail's wing. If dressed as a hackle, the feathers from under the wings of a thrush or redwing will be found proper.

Of this fly Mr. Bainbridge observes, that " It may be considered as one of the best for affording diversion which can possibly be selected, for it may be used successfully at all hours of the day, from April to the end of September; and is equally alluring to trout and grayling." Though I have not so high an opinion of this fly, I think it one that should be tried, in conjunction with the oak-fly, in April and May. It may be used of a small size in August. I agree with Mr. Ronalds, who says, - "My own experience leads me to 
recommend the sand-fly during April and May, on days when there is no abundance of any particular insect on the water. A fly very like it is used in September and October, called the cinnamon-fly."

Mr. Ronalds's way of dressing the sand-fly.Body, of the sandy-coloured fur from the hare's neck; wings, from the landrail's wing, made full; legs, from a light ginger feather from the neck of a hen. This fly is made buzz with a feather from the under side of the wing of the throstle, wound upon the above body.

Stone-fy. - Wings, a mottled feather of the hen pheasant, or the dark grey feather of a mallard, rather inclining to red, to be dressed large, long, and flat; body, dark brown fur, or the dark part of the hare's ear, mixed with yellow camlet or mohair, so distributed in making the body of the fly that the under and hinder parts may exhibit the yellow to the fish; legs, a grizzled hackle ; horns, two dark hairs from a dog's or rabbit's whisker. Hook, No. 4, 5, or 6.

This fly is a large and tempting bait, but you must have it dressed of different sizes, since its size varies naturally according to locality. In small, sheltered, well-wooded streams, the insect grows to a very large size ; on wide, bleak waters, it is bred smaller. This is a general rule, and we must follow it. This insect is named by some the 
caddis-fly. It appears in April, and is found until July. It kills best on warm, cloudy, windy days, and the best time for using it is in the morning and evening. The live fly is an excellent one for dibbing.

Mr. Ronalds describes and dresses this important fly well. "It comes," he says, "from a water larva. It is heavy in its flight, but uses its legs with extreme activity, and is generally found amongst the stones, or close to the sides of the water. I have kept an individual alive for three weeks, during which time it drank much water. It is in season from the beginning of April until the end of May, and should be used in the rapid parts of streams, and on windy days when the water is rough. - Imitation: - Body, fur of -hare's ear mixed with yellow worsted or camlet ribbed over with yellow silk, leaving most yellow at the tail; tail, a mottled strand or two of a partridge feather; wings, feather from the pheasant's wing; legs, a hackle stained greenishbrown; horns, two rabbit's whiskers." This imitation would be very good if the yellow worsted or camlet were left out, and use made only of the blackest and brownest fur of the hare's ear. The ribbing as directed with yellow silk will render the body alternately and spirally dark and yellow.

Golden dun midge. - Body, olive floss silk ribbed 
with gold twist, and tied with dun silk thread; wings, from the palest feather of a young starling; legs, a plain dun hackle. An excellent fly.

Orange-bodied dun. - Body, hare's mixed fur, with a little orange mohair worked with silk of the same colour; legs, the dubbing picked out with a dubbing-needle at the shoulder; tail, two strands of the mallard's mottled feather.

Ashy dun. - Water rat's fur mixed with a little orange mohair; legs picked out of the dubbing; tail the same as before; wings, hen black-bird's wing-feather. These dun-flies should be dressed on hooks, No. 8,9 , or 10 , according to the state of the water.

- The grannam, or green-tail. - This fly is very well known, but, generally speaking, it is too highly spoken off. It lasts only for about ten days in April, and its chief value is that it is a morning fly, and will kill from sunrise to eleven o'clock, when the mornings and forenoons are fine, and the water moderately clear and low. Sometimes it will kill late in the afternoon. Bowlker gives the best account of this fly, the first appearance of which, he says, "is about the beginning of April, if the weather is warm, it being a very tender fly, and unable to endure the cold. When they first appear on the water, they are seen in great quantities. On bright mornings you may begin to fish with them from six o'clock till eleven; 
then you will find the browns come on, which you must use, as the fish will not touch the grannams as long as the brown flies continue. About five o'clock in the evening you may use the grannams again with success, the browns having then totally disappeared for that day. The grannam is a four-winged fly, and as it swims down the water, its wings lie flat on the back. It has a small bunch of eggs of a green colour at the tailend of the body, which gives it the name of the green-tail fly. As soon as it alights on the water, it drops its eggs. This fly is of short duration, not lasting above a week, after which it disappears for the season." It is dressed as follows:-body, dark hare's ear fur, mixed with a little blue fur; at the tail a twist of a green harl from the eye of a peacock's feather, or a lap or two of green floss silk, or a bit of green wax; wings, from the wing-feather of a partridge or hen pheasant; legs, a yellow grizzle hackle. Hook, No. 8 or 9 .

Mr. Ronalds's way :-Body, fur of hare's face left rough and spun on brown silk. A little green floss silk may be worked in at the tail to represent the bunch of eggs there; wings, feather from that of the partridge, and made very full; legss, a pale ginger hen's hackle. Made buzz with a feather from the back of a partridge's neck, wound upon the above body. 
The spider-fly, or Harry long-legs. - There are three sorts of this insect, large, middle, and smallsized, the latter being called the gravel-fly or gravel-bed. They will kill on windy days, the water being low, throughout the spring or summer months. The large fly is dressed thus:Body, a mixture of brown and dun fur, dressed long and thin on a No. 5 hook; wings, mottled feather of a partridge, long and fine; legs, two turns of a long, thin-fibred dark dun hackle. The middle-sized fly is thus dressed : - body and legs the same as the former, but shorter and thinner on a No. 6 or 7 hook; wings, hen black-bird's wingfeather, long and slight. The small spider or gravel-fly is imitated thus:-wings, the largest fibres of the snipe's wing-feather, to lie long and nearly flat; body, simply lead-coloured silk; legs, one turn of a dark dun hackle. Hook, No. 9 and 10. This last insect does not last so long as the two others; its best season being from the middle of April to the end of May.

Mr. Bainbridge observes, - "The gravel or spider fly is first seen about the middle of April, at which time the gravel in which these insects are bred is covered by incalculable numbers of them. They are extremely delicate, and not often visible on cold days; at which times, however, success is more probable with this fly than when they are to be found in such vast numbers. 
They may be used from morning until evening, and the trout are so passionately fond of them, that they gorge themselves with their favourite food, and retire to their secret haunts, thereby disappointing the most skilful endeavours of the angler. It is probably owing to the short duration of these flies, that the fish are so greedy in devouring them, as they are seldom to be found after the expiration of about three weeks from their first appearance. The wings are made of the feather from the wing of the cuckoo's mate, the goat-sucker, or, in the absence of the preceding two, from the woodcock; the body of lead-coloured silk for the lower and middle parts, and a strip of black ostrich harl for the thick part near the shoulders, round which a small dark grizzled hackle should be twisted twice, and the fly is completed."

Grẹat whirling dun. - Body, squirrel's blue and martin's yellow fur mixed, or dark mole's fur and yellow mohair; wings, pale grey fibres of a mallard's wing-feather, to stand erect; legs, grizzled hackle; tail, two fibres of the mallard's mottled feather. Hook, No. 7 and 8.

This fly may be also dubbed with fur from the bottom of a squirrel's tail, the wings being the same as the last, or it may be made a third way; viz. the wings of a pale orange colour from the wing-feather of a ruddy hen; body, squirrel's 
fur mixed with a very small portion of pale, fine hog's down; head, a couple of whips of ashcoloured silk; legs, red cock's hackle. It is a good general April fly, and in warm weather kills best of mornings and evenings. Mr. Blaine has a very high opinion of this fly, and says of it, "In cold days it will raise trout all day long, but more particularly during a brisk blustering wind, when it proves usually very killing. In our own practice, we found it in all the waters of the midland counties a most excellent fly, but less so in the northern districts. It must, however, be remarked, that we were always furnished with two or three varieties. In very cold windy days we found a large-sized imitation, in colour almost a pure dun, to be very killing. It may be observed, that the body of the natural fly varies much, but the wings are always the same."

The yellow dun.-Body, yellow mohair tinged with a small quantity of pale blue fur; wings, the light fibres of a lark's wing; legs, a small yellow dun hackle. Hook, No. 10 and 11. In genial, but cloudy days, the water being tolerably clear, this fly will kill well during the warmest hours of the day.

Dotterel hackle. - Body, yellow silk or mohair; wings and legs from the feather of the dotterel. Hook, 11 and 12. When dressed small on the hooks just mentioned, this is an excellent fly in 
the small streams of the north of England. Dressed large on a No. 6 hook it is a good lake fly for large trout.

Golden plover hackle.-Body, a mixture of yellow and green mohair, dressed fine; wings and legs of the golden plover back and neckfeather. Hook, 10 and 11. A good summer-fly when the water is low.

Carshalton cocktail._Body, light blue fur; wings, the inside feather of a teal's wing; legs, a dark dun hackle; tail, two fibres of a white hackle. Hook, No. 10 and 11. A killing fly on the Wandle, and on all clear trout streams.

Edmonson's Welsh fly.-Body, dark orange mohair ; wings, the feather of a woodcock's wing, or from the tail of a hen grouse; legs, the backfeather of the partridge. Hook, No. 8 and 9. A good general fly when the water is passably full.

\section{Jlís for Jtay.}

This month is one of the best of the season for using small duns, provided the water be clear, and particularly that period of the month which precedes the arrival of the ephemera vulgata, or the May-fly, or green drake. I shall give a list of them and other good flies, and conclude the month with its chief attraction, the beautiful insect just named. Many of the April flies will 
kill in May, and the duns of the latter month will kill in the former, provided the weather be fine and the water low.

Iron-blue dun.-Body, mole's fur ; wings, tomtit's wing-feather; legs, a small light dun hackle; tail, a couple of small fibres of the same feather. Hook, No. 10, 11, and 12. This fly must be dressed with the neatest care, finishing off at the head with a twist or two of reddish brown floss silk. Mr. Ronalds says, "It is one of the smallest flies worth the angler's notice, but not the least useful. The male has a brownish red crown or cap on his head. The female is also crowned, but her cap is too small to be easily seen. It is in season from the latter end of April until the middle of June, and is on the water chiefly on cold days." You see that this is a hardy little gentleman, and you will find by experience that he is a killer of fish in clear water when the wind blows roughly and coolly along its surface.

The jenny-spinner.-This is a pretty metamorphosis of the last fly; but it eschews cold days, and delights in summer-tide ones. It shows through clear, rather shallow water best, and most attractively to trout: and they seem to relish it most as a dessert in post-prandial hours. It is costumed in this fashion :- body, white floss silk, with a whip of brown floss silk at the head and tail; wings and legs, a very small and very 
light dun hackle; tail, two fibres of the hackle. Hook, 11 and 12. To be dressed very small and very neatly.

Hawthorn-fly. - Body, black ostrich harl; wings, dotterel's wing feathers; legs, a feather from the green plover's top-knot. Kills tolerably well on warm, gloomy days.

Bright yellow dun. - This is also called the yellow Sally and little May-fly. It precedes by a week or less the great May-fly, and though it is a beautiful little fly, it rarely does great execution. I would dress it very small as a hackle; the body of bright yellow floss silk or mohair; wings and legs of a small hackle, dyed yellow. If you tie it with wings they should be small and stand erect, and made of the mallard's feather, of the same colour as for the large May-fly. The way of dyeing the feather will be shown hereafter.

Cream-coloured dun. - Body, cream-coloured mohair, wound on orange silk, and forked with two yellow hairs; wings, light part of the landrail's feather; legs, the dubbing picked out. Hook, No. 10 and 11.

Little whirling dun. - Wings of the fibres of one of the pale short feathers which lie underneath the wing-feathers of the male teal; body, ashcoloured silk, enlivened with a little brown hair, and wound on light orange silk; legs, one or two 
turns of a light brown hackle. Hook, No. 10 and 11. This is an attractive little fly, and will kill well about the middle of the day in warm and windy weather.

Black gnat. - Body, one of the smallest feathers of the green plover's top-knot or of a black harl, to be dressed short; wings, the darkest fibres of an old starling's wing-feather. With the green plover's topping you require no legs, but with the harl you do; and they must be made of a small black hackle. Hook, No.12. Every one recommends this fly, and it is found in every angler's fly-case; yet, notwithstanding the multitude of witnesses it has in its favour, I have very seldom found it a good fly. I would only use it of a fine evening, when the water is clear, or during the day when the weather is warm and gloomy, or after a summer shower.

Turkey brown. - This is a good summer fly, on cool windy days, and should be tried when first-class favourites fail. It will kill well on pools that are ruffled by the wind. Mr. Ronalds dresses it very attractively, thus : — "Body, dark brown floss silk, ribbed with purple thread; wings, tip of the brownest feather from a partridge's tail, or a proper feather may be found on the back of the partridge; legs, a red cock's hackle stained a fiery brown; tail, a fibre or two of the same feather. Hook, No. 10. In summer 
time, when the water is clearing after a fresh, tip this fly with gold tinsel, dress it on a No. 8 or 9 hook, and it must kill well.

The dun-cut. - Body, bear's hair mixed with brown and yellow mohair; wings, yellowishgreen feather of a landrail, to lie flat and be longer than the body; legs, a turn of a small ginger hackle. Hook, 8, 9, and 10. Mr. Blaine says of this fly, "that in many cases it proves very killing, and that it regularly appears in this month, but at an uncertain period of it, and seldom lasts longer than the middle of June. It will take fish on gloomy days the whole day through, but best of all in warm sultry evenings, when its execution is often very great, particularly amongst trout, being, according to our observations, less greedily sought by grayling."

Little dark spinner (RonalDs). - This is the metamorphosis of the Turkey brown. It is a most killing fly just at the beginning of dusk. Body, mulberry-coloured floss silk, ribbed over with purple silk thread; wings, from a feather of the starling's wing; legs, a purple-stained hackle which appears black when looked down upon, but which shines with a dark tortoise-shell tint when held up between the eye and the light.

Shorn-fly, or case-winged-fly. - Upper wings, landrail's feather, to be dressed short and bending over the body; under wings, the light fibres from 
a starling's wing; body, full and short, of brilliant peacock's harl. Some persons call this fly the Marlow-buzz, and have a high opinion of it. I do not much fancy it. If it kills well any where, it will be in our southern and western streams. I think the following is the true Marlow-buzz, as well as the coch-y-bonddu of the Welsh. I fancy it an imitation of the well-known winged beetle, called the lady-bird. Tied as follows, it is a favourite general fly of mine, and I call it the furnace-hackle for the summer months. Body, short and full, of black ostrich and brilliant peacock harl twisted together and dressed with brilliant dark silk; wings and legs, a dark furnacecock's hackle of the purest black and red colour. This is a famous fly. If fish will not rise at it, you may conclude that they are not "on the feed." They either take it for a small red and black caterpillar, or for a round black and red beetle. Fine, warm, cloudy days are the best for its being successfully used.

Another alder-fly. - Body, dark mulberry floss silk; wings, the fibres of a brown hen's wingfeather; legs, a twist or two of a dark ambercoloured hackle. Hook, No. 10. This is a good summer fly in the Hertfordshire streams.

Sky-blue. - This is one of Mr. Ronalds's beauties, bred, he says, from a water nymph. I have a high opinion of its attractions when the water is 
low and clear, and the weather propitious-breezy, warm, with alternate cloud and sunshine. Let it be dressed carefully on a small hook with fine gut, and it will kill when larger flies are of no use. It is made thus:- body, pale ginger mohair mixed with light blue fur; wings, from a feather of the sea-swallow; legs, a pale yellow hackle; tail, a couple of strands of the hackle. Hook, No. 11 and 12.

Fern-fy. - This is an admirable May and summer fly. It is very showy, and will answer best on gloomy, sultry days. Towards evening I have been in my time very successful with it, particularly close under the banks. I shall direct it to be dressed two or three different ways, and then it will answer for two or three different flies with which it is confounded. The proper sized hook is No. 10., and when the water is very low, a size smaller. The body is to be made of deep brilliant-coloured orange silk, whipped sparingly with thin gold twist; wings, lying rather flat, to be made of the light, mottled fibres of a young partridge's wing-feather; legs, a turn or two of a small, fiery red hackle. I think that is the best way of dressing the fly. Mr. Ronalds dresses it without gold twist, and with wings from the darkest fibres of a starling's wing-feather. The lightest fibres would answer best. Others dress the fly buzz by winding over the body a 
furnace-hackle. The following is another variation in the way of dressing this fly:- upper wings, red partridge's tail-feather; under wings, hen blackbird's wing-feather: body, red brown mohair, dressed long; legs, two turns of a small red hackle. Hook, No. 8 or 9 .

The bluebottle. - Wings of the transparent fibres of the lark's wing, to lie flat and broad and pointing outwards; body, thick, of peacock's harl, wound on brown silk, of which form the head; legs; a fine black hackle. Hook, No. 7 and 8. Another way: - body, bright blue floss silk tied with light brown silk thread, showing the brown at the head; wings, feather of the starling's wing, to lie flat; legs, black cock's hackle wound freely round the body. When trout and grayling are gorged with the May-fly and other dayflies, they often take freely towards the evening an imitation of the house-fly and bluebottle. Such imitations kill all the summer through on dark, windy days. They are more freely taken by chub and dace than by trout.

The wasp-fy. - I have a good opinion of this fly, for its body is well coloured, and it must prove a favourite with fish. Besides, the body is large and taper, and with its alternate dark and yellow rings, fish must be ford of its appearance. I have always had the best opinion of these regularly party-coloured flies, with somewhat large 
bodies, ringed with either black and white, black and yellow, brown and yellow, or orange spiral stripes, and having large, reticulated, transparent wings, with dark heads, and darkish tails. Such are the March brown, the oak-fly, the hare's-ear-andyellow, the wasp-fly, and a few others. If these flies are tied very large they will kill salmon, the largest species of trout, and the largest chub. Tied on 9 and 10 hooks they are excellent general brook-flies for trout and grayling. The waspfly is dressed thus:- body, light orange mohair, dubbed in very thin ribs, and alternated with black ostrich harl, neatly and finely. Form the head with the orange dubbing. Legs, two turns of a light brown red hackle. Hook, No. 7, 8, and 9 , and make the wings of a partridge-hackle, or mottled mallard's feather. Dress it large, and the fly will kill well in the Thames.

There are evening and night flies which come into use towards the latter end of May, and last during the whole of the summer. They are imitations of those large moths that are seen towards nightfall flitting about the meadows in warm weather. The dark-coloured should be used early in the evening, those of a lighter colour after sunset, and those that are white after that.

The mealy-brown moth. - Body, any soft brown fur, as of the hare, brown hog's down, bear's fur, and the nearer the shade is to tan the 
better; upper wings, the dappled feather of a mallard dyed brown; under wings, the soft feather of a brown owl; legs, a brown cock's hackle, wrapped four or five times behind the wings. Hook, No. 4, 5, and 6.

The mealy-cream moth. - Body, any soft fur of a cream colour; upper wings, the creamcoloured feather of the grey owl; under wings, a softer and lighter feather of the same bird; legs, a soft ginger hackle. Hooks the same size as before.

The mealy-white moth. - Body, white rabbit's fur, or white ostrich harl, dressed full, and exhibiting a brown head; legs, a white cock's hackle, wrapped round twice under the wings. Hooks as before.

The coachman. - Body, peacock's harl, full and short; wings, fibres of any small white feather; legs, a turn or two of a red hackle. Hook, No. 6, 7, 8, and 9. This fly will kill in most rivers, from a little before till a little after twilight. It kills best in the rivers of the south, and in those within forty miles of the metropolis. Trout, chub, and large dace take it freely. Mr. Blaine goes farther, and says, - " Throughout the summer months, as an early evening-fly, and until twilight, it proves most valuable in the midland counties, and the bordering ones within eighty miles of London. On the Colne, and throughout 
its. course, in the Hampshire, Dorsetshire, and Devonshire waters, where we have been for many years in the habit of using it, in our opinion there is no fly at all to equal it."

If moth-flies are properly used, they will take the largest fish. A young angler should use but one at a time on his casting-line, which should be of stout gut, not longer than two yards. He should keep his fly on the surface of the water, and must judge of a rise more by hearing and feeling, than by sight. He must strike promptly, and play his fish with a tight hand.

The May-fly, or green drake. - This famous fly is the opprobium of fly-makers. Try how they will, they cannot in my opinion imitate it well. The wings are their greatest foil. In making the body they succeed tolerably well. Still the best imitation is defective, and except upon rare occasions the artificial May-fly is not a deadly bait. The natural fly used in dibbing far surpasses it. However, the imitation, faulty as it is, will kill when the natural fly is scarce on the water, as in cold, dark, windy days. The artificial fly kills in currents and pools that are moved to small waves and billows by a bluff west or south wind.

The general feather used for the wings of this fly is a dappled one found by the sides under the wings of the mallard, and dyed a pale green- 
yellow colour. To hit the true colour makes the great difficulty. To get over it I know not how. I must be content to cite the best authorities. First I will take Mr. Blacker, a capital judge of colours, who dyes his feathers yellow according to the following recipe:-Boil two or three handfuls of yellow wood one hour, in a quart of soft water; wash the mallard hackles, or other feathers in soap and hot water; then boil them a short time, with a large spoonful of alum and tartar, in a little pipkin, with a pint of water; take them out and immerse them in your yellow decoction, and simmer them slowly for an hour or two. The shorter the simmering the paler yellow will be the feathers; take them out and wash them in clear, hard water. When there is occasion for dyeing yellow-green, add a little blue, more or less, according to the shade of green you wish to give to the yellow. Mr. Ronalds recommends another way for dyeing mallard's feathers for the May-fly's wings. He tells us to make a mordant by dissolving about a quarter of an ounce of alum in a pint of water, and then slightly boil the feathers in it to get the grease out of them, after which boil them in an infusion of fustick to procure a yellow, and then subdue the brightness of the yellow by adding a little copperas to the infusion. Having now the wingfeathers dyed, I'll tell you how to make the fly. 
Body, bright yellow mohair, or floss silk, ribbed slightly with peacock's harl and orange silk; wings, mottled feather of the mallard dyed a pale yellow-green. They are to stand nearly erect, and to be slightly divided. Legs, a couple of turns of a red ginger hackle; tail, two hairs from the rabbit's whisker. Hook, No. 5 or 6 . Another way (BLACKeR's):-Body, yellowgreen mohair; wings, mallard's feather dyed yellow - a black head; legs, yellowish hackle; tails, three hairs from a black bear. A third way (Mr. Ronalus's):- Body, the middle part of pale straw-coloured floss silk, ribbed with silver twist; extremities (head and tail) brown peacock's harl, tied with light brown silk thread; tail, three rabbit's whiskers: wings and legs, made buzz with a mottled feather of the mallard, stained olive. To make it with wings in their state of rest, part of a feather similarly stained must be used, and a pale brown bittern's hackle must be wrapped round the same body under the wings. What is called the buzz form, is an intended imitation of the natural fly struggling and halfdrowned. A fly dressed with erect wings, and one without them, or buzz, may be used on the casting-line at the same time, the buzz imitation being the stretcher or tail-fly.

Mr. Bainbridge says of this fly; "It appears K 3 
about the 20th of May, and continues for nearly a month. The wings stand erect upon the back, and vary in the tints of yellow in different flies. The body is long, slender and taper near the tail, from the end of which spring the forked whisks, which turning upwards, like some of the drake's tail feathers, towards the back, give the name of green drake to this fly. The body is to be made of hog's down, or light bear's hair intermixed with yellow mohair, or of barber's yellow silk only, warped with pale floss silk, and a small strip of peacock's harl for the head. A bittern's hackle is acknowledged to be the best imitation of the legs and dark stripes of the body, and for the tail the long black hairs of the sable or fitchet are most appropriate.". The May-fly is dressed many other ways, but I think the above are as good as any.

During the season of the May-fly, should the weather be gloomy, with a strong, warm wind, I would angle with three flies of different sizes, and having the wings of colours slightly differing, and one made buzz without erect wings, for doing so would afford me three different chances of success.

The grey drake is said to be a metamorphosis of the green drake, or female changing to a male. Strange though such a change may appear to us, it may be true, for Nature is ever working wonders. 
This fly is seldom a good angling one, and never kills well except towards evening. Dress it thus; -Body, the middle part of white floss silk, ribbed over neatly with silver twist ; extremities, brown peacock's harl; wings and legs made buzz with a mottled feather of the mallard, stained a faint purple; legs, three rabbit's whiskers. Hook, No. 6 or 7 . Of this fly, Mr. Blaine says, "It usually shows itself on the water at a later hour in the day than the green drake, being most prevalent from 3 P.M. until sunset. When an unfavourable day has prevented the green May-fly from appearing in sufficient numbers, the grey will commit vast havoc among the trout in the evening."

During the prevalence of the May-fly, trout fatten and grow into condition. They are never so before that fly appears, and when it has disappeared they remain in good condition until the spawning season. When fish have gorged themselves with this fly, and leave off feeding towards the evening, they will be tempted by flies of very different sizes and colours. The best are for mild weather, little dun hackles of every shade, the grouse and wren hackle, house-fly, and at dusk a moth-fly. Should you want trout very badly during the drake season, try a minnow morning and evening, and your wants in one respect will be soon supplied. 


\section{FTís far $\mathfrak{3}$ ture.}

I need scarcely remind the reader that the Mayfly prevails during the greater part of this month, and that during it several of the duns mentioned for May will still catch fish. The following are considered proper June-flies.

Dark mackerel. - Body, dark mulberry floss silk ribbed with gold twist; wings, brown mottled feather of the mallard, which hangs from the back over a part of the wing; legs, a purple-dyed hackle; tail, three rabbit's whiskers. Hook, No. 9 and 10.

Ephemeral red spinner. - Body, red dubbing, ending with a rib of gold platting, and forked; wings, landrail's wing-feather, to be dressed erect. Legs, a small fine red hackle, carried three turns round the body. Hook, No. 8 or 9 . Taylor dresses this fly differently, and in a way that will be found killing in rough water, and weather of June afternoons, thus:- The wings are of the greyish feather of a drake, tinged with a kind of reddish yellow; body, gold twist with a red hackle over it. A good evening-fly during the summer months, and if dressed large will be taken by large chub.

Orl-fly.-Body, ribbed alternately with dark brown and orange dubbing, adding two horns; wings, landrail's ruddy feather, dressed long and 
rather flat; legs, a grizzle hackle. Hook, No. 7 and 8. A good fly when the water is clearing after a flood.

Hazle-fly. - Upper wings, short fibres of the landrail's wing, to lie extended; under wings, any transparent feather, and to be dressed a little longer than the upper wings; body, dark purple mohair and brown fur, to be dressed full, and a portion picked out for the legs. Hook, No. 8 and 9. Some persons call this fly the Marlowbuzz, others the lady-bird. At any rate it is intended to imitate a small-winged beetle. It kills occasionally on warm days.

The humble bee.-Wings, the fibres from the cock blackbird's wing-feather, to lie flat; body thick, the fore part to be made of black glossy mohair, the hinder part of deep orange fur; legs, a brown hackle wound full. Hook, No. 4 and 5. It is not a good trout fly, but it is taken freely by chub and large dace.

House-fy. - Body, black ostrich harl, dressed rather full; wings, a lark's wing-feather to lie flat and extended; legs, a dark dun hackle. Hook, No. 8 and 9. In autumn, on windy days, this fly is often taken greedily by trout and grayling. It is a better fly for chub and dace.

Blue gnat.-Body, blue dun mohair with a little orange-coloured mixed; wings and legs, a small dun hackle wound over the whole of the 
body. To be dressed with orange silk. Hook, No. 10, 11, and 12. An excellent fly throughout the summer and autumn, when the water is low and clear.

\section{Jlíes for $\mathfrak{J}$ uly.}

Nearly all the flies mentioned in the list for last month will kill in this, but, generally speaking, they must be dressed smaller and on finer hooks and gut.

Large black ant-fly. - Body, black ostrich harl dressed thick near the wings, then thin, and thick again at the tail, like the shape of the ant; wings, tom-tit's tail, or any light blue transparent feather ; legs, two twists of a deep brown hackle close under the wings. Hook, No. 7 and 8.

Large red ant-fly. - Body, copper-coloured peacock's harl, full near the wings and tail; wings, a lark's wing-feather; legs, red cock's hackle. Hook, No. 7 and 8. When the water is low and clear, these flies should be dressed smaller on No. 9 and 10 hooks. They will kill well in the middle parts of the day in fine warm weather. They are good autumn flies.

Blue-blow. - Body very short, of a turn or two of black ostrich harl, or a small mass of dark blue fur; legs, two turns of the green plover's topping; tail, two dun hairs. 
This last fly is to be dressed with neat wings from the tom-tit's tail upon a very small hook. When the living fly is abundant, the artificial one, used on a very fine casting line, will prove successful. It kills best about noon.

Pale dun.-Body, yellow martin's fur; wings, a lark's wing-feather, stained a light yellow; legs, a fine honey-dun hackle. To be dressed very neatly with pale straw-coloured silk on a No. 12 hook An excellent summer-fly in low and clear water.

The two following flies are very good ones, and are dressed by Mr. Ronalds thus:-

July-dun.-Body, mole's fur and pale yellow mohair mixed, and spun on yellow silk; wings, dark part of a feather from the starling's wing, stained darker in strong onion dye ; legs, dark dun hackle ; tail, the two fibres of the hackle. Hook, No. 10 and 11. Mr. Ronalds says of this fly, "It affords a great treat to the trout and grayling, and lasts until the August-dun takes its place, in the beginning of August."

Gold-eyed gauze-wing. - Body, very pale yellowish green floss silk, tied on with silk thread of the same colour; wings and legs, the palest blue dun hackle which can be procured. Hook, No. 11 and 12. In my opinion legs are scarcely necessary, and the wings should be dressed long and flat, of a lark's feather, stained of the lightest 
green hue. This fly will kill in August, and even in September, if the weather is very fine, and the water low and clear.

The wren-tail. - Mr. Blacker very properly calls this a standard summer fly, and dresses it thus :- Body, amber mohair ; wings, partridge's grey tail-feather; legs, wren's tail-feather; tail, two fibres of the mallard's mottled feather. Hook, No. 10 and 11.

Grouse-hackle. - Body, orange or bright purple floss silk; legs, grouse hackle; gold tip.

Wren-hackle. - Body, ginger-coloured fur, ribbed with gold twist; wings and legs, feather from the wren's tail. Hook, No. 11 and 12. These three last flies are general ones throughout the summer, and the angler should never be without them.

\section{Wlíts for đugust.}

Small palmer-hackles, small ant-flies will kill well this month, and in the evening the various moths. Small brown-bodied flies will kill well also, and so will the different duns and hackles recommended for July.

August-dun. - This is one of the best flies that can be used for August and September. Mr. Ronalds dresses it thus : - Body, brown floss silk ribbed with yellow silk thread; wings, feather of 
a brown hen's wing ; legs, plain red hackle stained brown; tail, two rabbit's whiskers.

Cinnamon-fy. - Body, seal's fur not dyed; wings, of a ruddy cream colour, from a feather of the landrail, to be dressed long, large, and flat; legs, a red brown hackle. Hook, 7 and 8.

Another way (BLACKER's): - Body, cinnamonbrown mohair; wings, a woodcock's wing-feather; legs, red or cinnamon hackle.

Mr. Ronalds's way : - Body, fawn-coloured floss silk, tied on with silk thread of the same colour; wings, feather of a yellow brown hen's wing, rather darker than the landrail's wing-feather; legs, a ginger hackle. Mr. Ronalds says, "It should be used in a heavy shower, and also on a windy day. In both cases very great diversion may be expected with it.

\section{Jlíes far}

Still continue the palmer-hackles, with the grouse and wren hackles, golden and dark dun, alder-fly, Hofland's fancy, the cinnamon-fly, and the following.

Emerald fy. — Body, emerald green floss silk; wings, lark's wing-feather; legs, a small red hackle; tail, two fibres of a grizzle hackle. Hook, No. 12.

Whirling dun.-Body, water rat's fur ribbed 
with yellow silk; wings, starling's wing-feather; legs, dun hackle; tail, two fibres of the same. Hook, No. 12.

The grey housewife (BLACKER). - Body, light brown mohair, mixed with hare's ear fur; wings hen pheasant's wing-feather; legs, partridge's neck-feather; tail, two fibres of the mallard's mottled feather. Hook, No. 12.

Willow-fy. - Body, mole's fur spun upon yellow silk; wings and legs, a dark dun cock's hackle, strongly tinged a copper colour. Hook, No. 10.

Little pale blue dun. - Body, very pale blue fur mixed with a very little yellow mohair; wings, feather from the sea swallow; legs, the palest blue hackle to be had. Hook, No. 10 and 11.

After the month of September no angler should fish for trout until spring returns again. In October, and during the finest hours of very fine winter days, grayling are to be caught with the artificial fly, and the best are unquestionably duns, and small spider-flies. That fish being during the above season in fine condition will be caught with the gentle, and by sinking and drawing with the artificial grasshopper. It will also rise well in October at the red palmer and house-fly.

I have now concluded a full list of flies, and every one in it will kill at the proper season in every river in the empire. I have always made 
honourable mention of the best. As a general list, it is complete and may be relied on. Local anglers have local flies, favourites with them at the fishing stations near which they reside; and when you visit those stations, and cannot catch fish with the flies I recommend, I can only help you by entrusting you to the care of the local anglers. If they will not assist you for brotherly love, they will for the amicable consideration of money. 
CHAPTER VI.

FISHING WITH THE NATURAL FLY, OR DIBBING OR DAPING.

ANGLING with the natural fly is an appropriate summer pastime, and would not be deemed too laborious by even lazzaroni. It fatigues no muscles, for all the action it requires from them is neat, gentle motion. It abhors violence, and is totally suaviter in modo. It is a pastime for ladies; for musing, listless adolescents; and for the corpulent middle-aged, whose former sharp gusto for active sports frequent pectoral lining with good capon has blunted. If it makes no calls on the big muscles, it asks activity from the eye, and watchfulness from the brain. It requires from the fingers great delicacy of touch, and from the arm the gentlest sort of action. Your object in practising it is to drop a natural fly, fixed on your hook, so gently on the water, that the descent will not differ from that of the free, living insect. The fly with the hook in it must alight as naturally as if it were one fingers had never touched. To cause it to do so is not very easy; it demands careful guiding and dropping, and sometimes the most careful casting. 
Let us see what induces us to have recourse to a sport less exciting than artificial fly-fishing and more troublesome. Necessity is the mother of substitutes. When the artificial fly becomes next to useless, it is necessary to substitute the natural one, or something else. The weather is fine, hot, and breezeless; the water placid; the May-fly, or other insects, are abundant on its surface, and fish of various sorts are stealthily rising, causing eddies, the Scylla, Charybdis, and Maelstrom of those reckless navigators, the ephemera and other water-loving tribes. You see what the fish are about. You guess that your artificial fly will not beguile them, and you therefore flee for help to the natural one, making it effective by an artificial sting you add to it. The addition of this sting requires attention. It must be so added as to harm as little as may be the living insect. The less it harms it, the more harmful it will be to fish. Besides, there are places, no matter how favourable the weather may be, so opposed to facile throwing with the artificial fly, that you must substitute dropping or dipping with the natural insect. You will see large fish rising under bushes, and branches of trees overhanging the water, from under shelving banks and rocks, and in divers difficult spots where the artificial fly cannot be safely cast, and a moment's thought 
will tell you that the best way to reach these sheltered fish will be by the cunning use of a living insect.

The first thing you have to learn, is the best way to insert your hook in the insect so as to least injure it, and impede its natural motions. There must be no roughness employed in this operation. The insect must be handled tenderly, and the hook inserted so as not to puncture any mortal part of your frail bait. If you use but one fly, insert the hook under one of its wings, bringing it out between them at the back. If you use two flies, carry the hook through the upper part of the corset beneath both wings of one fly, and then taking another with its head reversed let the hook enter under one of its wings, and come out at the back of this second insect. This double head-to-tail bait is a very good one. If you are fishing in open water, with a breeze blowing, your winch-line must be of floss silk, and your footline of about a yard of very fine gut, or of a couple of long links of horse hair. Without casting, and by keeping the breeze to your back, holding up your rod, and letting out your blow-line, you can easily manage to make the wind carry it to the spots where you see fish rising. When you dip beneath bushes your ordinary silk and hair winchline will do, with a foot-line of gut. By turning 
your rod twist as much line about it as you want, and then inserting the point of your rod through the branches, as far as it is requisite, twirl it round so as to uncoil your line and to drop your natural bait gently on the water.

You can cast or throw the natural fly, but not so well as the artificial one. Use a long, rather stiff rod, with a long, taper casting-line, long enough to use without having much of your reel-line out. Cast with a gentle motion of the fore arm, bringing round your line softly, avoiding any thing like whipping violence, and making your bait float on to the surface of the water. Where the width of the river runs nearly equal, use no winch, but attach your casting-line to the top joint of your rod, and you will be able to throw, without whipping off your bait. On this head Mr. Blaine observes, "Whipping, as a term, can only be applicable by a licence of language, to the act of whipping out a natural fly, after the manner of a short throw with an artificial one; but it is evident that the tender nature of the living insect will admit of this but in a few instances. Some of the house-flies, the bluebottle especially, and others of the middling-sized beetles, as well as the humble bees, will bear a partial or short throw, but a short one only." Notwithstanding this opinion, which is partly correct, I know that 
the accomplished artificial fly-fisher, arming himself with the proper tackle, will be able to throw a very considerable distance the natural insect, no matter what its size may be. Mr. Blaine, however, goes on to say, "Practice will convince the angler that large natural baits cannot be thrown to any distance with advantage; the fact is, that they are far more appropriate to situations close under the land, where the large fishes frequently lie, especially in ponds, waiting for what the wind may tender to them. When, however, there is a very strong wind at the back, the natural fly may be carried out to a very considerable extent; but it must be by the act of the wind itself, and then the practice proves very successful: at other times the angler must be content to fish with as much line as he can command by his situation, without tearing his fly from his hook. With a strong wind, the angler should keep his rod steady in one position, taking the wind rather slantingly behind, and allowing the breeze to carry the line, he should watch a momentary stop in the gale, when by lowering his hand he may drop the fly on the surface as gently and as naturally as possible."

The drake season, that is, the season of the Mayfly, from the middle of May to the end of June, is the best period for dibbing, and the May-fly is 
the best of all baits. We here insert a cut of an angler intent on this sort of sport.

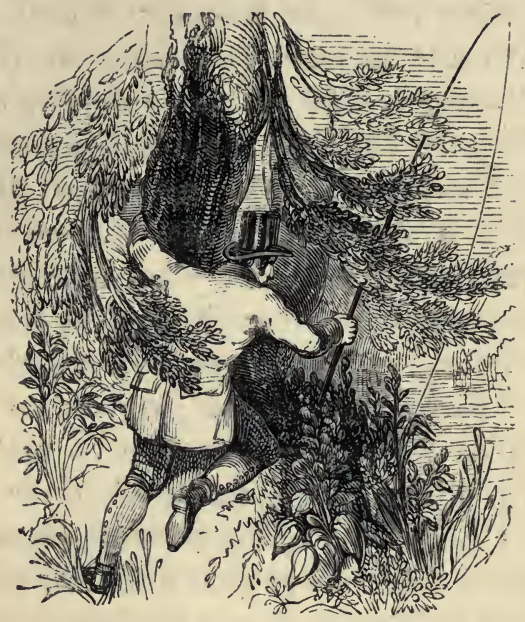

At the period just mentioned, dibbing with the May-fly is quite a rage in the midland counties. We have then seen the Dove, and other streams of Derbyshire and Staffordshire, swarming with the May-fly, and their banks thronged with anglers of all ages and sexes, dibbing with it. Trout and grayling (the latter out of season) will scarcely take any other bait. They gorge themselves with the May-fly, and thrive admirably on the nourishment it affords. At the end of the drake season trout are in perfect condition. When towards evening fish are satisfied with the May- 
fly, they will take eagerly, by way of change, house-flies and moths.

In dibbing you must keep out of sight of the fish, and cause as little disturbance as possible. You will observe that trout do not jump eagerly at the May-fly, but rise at it noiselessly, and suck it in, and swallow it; they take that fly generally as it is fluttering on the surface of the water, preparatory to flight. They take it so, but they frequently take other flies just as they drop on the water, and others as they sail along its surface. Large fish seldom jump at an insect which is on the water; they rise up to it, and inhale it, if I may use the word, through the water. Observe this operation, and just as it is being completed strike at your fish. As your rod and other tackle are strong in dibbing, do not give your fish much play, keep him on the top of the water, his head out of it if you can, and you will soon tire him.

Several sorts of insects, besides flies, are used for dibbing, such as cockchafers, beetles, bees, ants, moths, grasshoppers, \&c. Flies, however, are the best for trout. The May-fly, Marchbrown, stone-fly, oak-fly, house-flies, and moths towards evening, will be the most eagerly taken by them. The grasshopper is a most deadly bait for grayling and chub.

There is a little book, called the "North 
Country Angler," and written by a north countryman, which contains much sound information upon dibbing. The writer seems to have been a sort of poaching angler, and takes an especial delight in using the most killing baits, caring very little whether the method he adopts or recommends be sportmanlike or not. He would, no doubt, estimate his sport by the number of fish he killed, and not by the difficulty he experienced in killing them. We will take him, however, as a guide to a certain extent. $\mathrm{He}$ is a practical man, but, like the generality of local anglers, who have had no opportunity of measuring themselves with ubiquitous ones, he is full of conceit, and thinks himself an angling admirable Crichton. He says, "I generally begin fishing in the shade, or under bushes, in May, and continue it all the three following months, which we call the four hot month3. Most anglers in those months fish only in the mornings and evenings, unless the sky is cluudy, and there is a brisk wind on the pools ; for there one may have very good sport, and kill large fish. In these months, when there is no wind, and the sun is shining, from about ten o'clock in the morning, till four or five in the afternoon, is the best time for shadefishing." The author then describes the fittest rod, but on this point he is not so good a judge as Mr. Blaine, who rightly says, " $\mathrm{A}$ long and 
firm rod of twelve, thirteen, or fourteen feet, with a very stiff top (a light, long minnow-spinning rod will be a good substitute), is necessary for dibbing or daping; the length to be suited to the situation; if it be a very close and confined one, eleven or twelve feet is sufficient, but we rather recommend that the rod be of the general length, and that the reel, instead of being attached to the butt, be fastened on the second joint, when, by taking off the butt-end, the rod can be shortened as occasion suits. A reel is not thought requisite by the North Country Angler, but it is evident that in no fishing is it more wanted than in this, where it is required to lengthen and shorten the line according to circumstances; as, for instance, where; from a length of seven or eight yards, it must be reduced to one, or even less; and sometimes even to be wound up altogether, that it may be insinuated through trees and bushes; and in such cases how can it be so well done as by a reel?"

The above question the Northern Angler answers thus:- "Your line should not be above a yard long, and, where there is some difficulty in getting your rod-top through the bushes, not above half a yard, which, when baited, you may wrap loosely seven or eight times about the rodtop, and when you have thrust it beyond the bush, turn your rod round as many times, and 
let your bait drop into the water. There is a great deal of caution necessary in managing your rod and line. Some pools are shaded only here and there with a bush or two; in such places you may fish with a line a yard or more long; but you must be sure to make your approach to such open places cautiously, for the great fish lie very near the top of the water watching the fall of flies or other insects from the bushes, where they are bred or harboured; and though you do not see them, yet they will see you at your first coming, and scud away into the pool, and not return perhaps in an hour's time. I have often been agreeably amused sitting behind a bush that has hung over the water two yards or more, and observing the trout taking their rounds, and patrolling in order, according to their quality. Sometimes I have seen three or four private men coming up together under the shade, and presently an officer, or man of quality, twice as big, comes from his country seat, under a bank or great stone, and rushes among them as furiously as I once saw a young justice of the peace do to three poor anglers; and as. I cannot approve of such proceedings, I have, with some extraordinary pleasure, revenged the weaker upon the stronger, by dropping in my bait half a yard before him. With what an air of authority and grandeur have I seen the qualified - what shall I call him?- 
extend his jaws, and take in the delicious morsel, and then marching slowly off in quest of more, till stopped by a smart stroke which I have given him, though there is no occasion to do so in this way of fishing, for the great ones always hook themselves."

All this authority says generally refers to dibbing about and under bushes, and there his advice is good. Do not follow him when you dib in open water. There use a winch and blow-line, and short foot-line, and with a slight wind you will be able to convey your bait to any spot you fancy. If the weather be too still for the use of the blow-line, try and cast your insect gently, as you would your artificial stretcher when you do not wish to make any - the slightest disturbance - in low, smooth, clear water.

I must quote the North-countryman again for a few lines. He judiciously recommends, "never to let the fish get down his head, unless the angler is sure there are no roots near enough for the fish to retire amongst; but to keep him at the top of the water, where his fins and strength are of little service to him; and besides, so thrust out the rod as to reach beyond the bush, and there work the fish till he is quite tired, and lies still." He remarks justly that, "Although the shade of trees and bushes are much longer and greater on the south side of 
the river than on the north, yet on this latter side I have always found the most and the largest trout. I suppose the sun being more intense and warm on the north side, with its southern aspect, may occasion more flies, erucas, and insects of various sorts to creep upon those bushes, and consequently the more fish will frequent them. Where the trees or bushes are very close, I advise the bush-angler to take a hedging-bill or hatchet, or in want of that his sporting knife, and cut off two or three branches here and there, at proper places and distances, and so make little convenient openings, at which he may put in his rod and line; but this is to be done some time before you come to fish there. If you come to a woody place, where you have no such conveniences, and where, perhaps, there is a long pool, and no angling with the fly, or throwing the rod, there you may be sure of many, - and large fish. For that very reason I have chosen such places, though very troublesome, where I have been forced to creep under trees and bushes, dragging my rod after me, with the very top of it in my hand, to get near the water; and I have been well paid for all my trouble. Whilst you are getting in your rod throw a brandling or grub, or what you fish with, into the place, which will make the fish take your bait the more boldly."

The grasshopper is a most valuable bait for 
dibbing for grayling and chub. The former fish will take an artificial grasshopper well, by sinking it in the water and drawing it up gently to the surface. The natural insect is the best, however, for chub. Underneath is a representation of an angler intent on dibbing for chub.

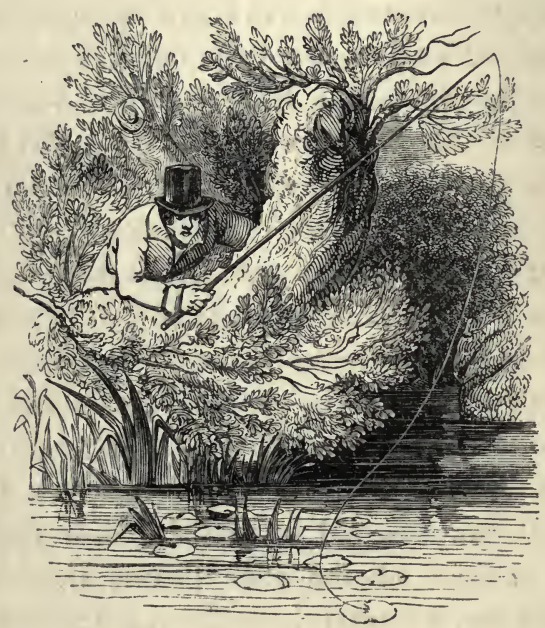

You see the angler is hiding himself as much as he can, and thinking that there are fish peering from beneath the leaves on the surface of the water, he drops his bait first on one of those leaves, and then by a sliding motion causes it to slip off, and fall on the water. The fish taking this fall as a natural one is not scared, but seizes the bait boldly. Practise a similar ruse whenever 
you can, wherever there are branches hanging on the water, rocks or other substances in it and above the surface. On them first drop your bait, and by a second motion cause it to descend on to the surface of the water. Do this, whether your baits be grasshoppers, flies, caterpillars, beetles, or any living thing liable to be blown or fall from banks, branches, leaves, rocks, roots, or piles into the water. I need not explain - it is apparent - the rationale of this practice. You will see that you are following nature. Mr. Daniel says, "Grasshoppers from June, until September, are to be met with in every pasture field or meadow, especially in a hot dry summer, but most plentifully in a kind of old, short, mossy grass. The middle sized, and the greenest are the best, and may be carried in a box with a notch cut in the edge, wide at top, and narrow at bottom, which, by lifting up the box-lid gently, leaves space just enough for the grasshoppers to creep out, which they will do separately. Some anglers take off the legs in baiting with them, but they answer better whole, if properly placed to stand on the back of the hook, which should be entered under the head and lodged in the body. This is a fine and tender bait, and is generally taken by many. kinds of fish, in clear streams, about mid-water, with a hook, No. 6, a fine gut-link, and one small shot. Grasshoppers may be preserved in fresh 
grass mixed with moss." In .fishing with the grasshopper let your hook be whipped on with green silk, on a link of fine gut stained of a light green colour.

I shall conclude this chapter with several extracts drawn from as many competent authorities. Walton says to his scholar:- "Go to the same hole in which I caught my chub, where in most hot days you will find a dozen or twenty chevins floating near the top of the water: get two or three grasshoppers as you go over the meadow, and get secretly behind the tree, and stand as free from motion as possible : then put a grasshopper on your hook, and let your hook hang a quarter of a yard short of the water, to which end you must rest your rod on some bough of the tree; but it is likely the chubs will sink down towards the bottom of the water at the first shadow of your rod, for a chub is the fearfullest of fishes, and will do so if but a bird flies over him, and makes the least shadow on the water; but they will presently rise up to the top again, and there lie soaring till some shadow affrights them again. I say, when they lie upon the top of the water, look out the best chub, which you, setting yourself in a fit place, may very easily see, and move your rod, as softly as a snail moves, to that chub, you intend to catch; let your bait fall gently upon the water three or four inches before him, and he 
will infallibly take the bait, and you will be as sure to catch him, for he is one of the leathernmouthed fishes, of which a hook scarce ever loses the hold; and, therefore, give him enough play before you offer to take him out of the water."

In dipping for trout and grayling with the May-fly or stone-fly, Cotton says, "To bait with either a stone-fly, or a green, or grey drake, put two or three on the hook together, which should be carried through the thick part of the fly's body under the wings, with their heads standing different ways: pass your hook through them under the wings, about the middle of the insect's body, and take care that your fingers are always dry when baiting, or you soon kill or spoil your bait." The following bait, though I have mentioned it elsewhere, is so good a one, that I shall do it the honour of a double insertion to imprint it more steadfastly on the reader's memory. Make a pair of wings of the feather of a landrail, and on the bend of the hook put one or two caddies. The head of the caddis should go up close to the wings. Angle with a stiff rod, about fourteen feet long, a foot-line eight feet, and a hook, No. 5. or 6. Let the bait float down the stream just below the surface, then gently draw it up again, a little irregularly, by shaking the rod, and if there be a fish in the place it will be sure to take it. If you use two caddies with the wings, put the hook in at 
the head and out at the neck of the first, and quite through the other from head to tail. Two brandlings, or small red worms, may be fished with in the same way. Walton, in recommending the above bait, adds, touching the packing of fish for presents, "Before you send trout on a journey, always have them cleaned and gutted, and let them be laid on their backs, and closely packed in a willow basket with dry straw. Packing in damp grass or rushes is apt to ferment, and therefore liable to spoil the fish."

Many are the precautions recommended to be adopted in dibbing. The chief are to keep beyond the sight of fish, and when you have hooked one to get it out of the water expeditiously with as little disturbance as possible. As dipping is not always to be practised behind the friendly shade of bushes or trees, the angler is often forced to content himself with the resources of the bank he stands on, to which he should creep on his hands and knees. In some cases, it is true, he may procure the shelter of a hurdle interwoven with boughs, or he may adopt some similar artifice; but many cases must occur, where he can trust to concealment only by prostration, or stooping low. In such situations Mr. Salter directs, that, "as much line be drawn out as . will just let the baited hook reach the surface of the water; then, with the top of the rod a little 
raised, keep the bait in motion just over and upon the surface, by gently raising and lowering the top part of the rod, and drawing it to and fro; and if you see several fish, cautiously guide your bait to the largest; play it a little, an inch or two above the water, by gently shaking the rod; then let it drop just before the fish." Mr. Blaine says, "When a fish has well taken the bait strike smartly, and to prevent its floundering from scaring away the remainder, it is advisable, if the tackle will allow of it, that the hooked fish be immediately drawn away, or even lifted out. If the angler be on the top of a high bank, or if his fish be very large, this cannot be done; but he must content himself with guiding it with his rod and line to some distance, and then landing it; which done, he had better try another spot, until the disturbed fish be again assembled."

I place this chapter immediately after those connected with artificial fly-fishing, for I consider it only as an occasional substitute, necessitated by locality and the state of the water and weather, for the other branch of our art. He who has become accomplished in the practice of that superior branch, will quickly become an adept in the gentle exercise of angling with the natural fly, and other living insects. 
CHAPTER VII.

TROLliNG. - RODS, LINES, TACKLE, AND BAITS, AND METHODS OF USING THEM.

Is England proper, trolling is practised to perfection. It is somewhat despised, because it is not well and generally understood, in Ireland, Scotland, and Wales. In those countries fly-fishing is every thing, and there it is certainly better and more generally understood than in England. The English are rapidly becoming good flyfishers. Let me hope that the Irish, Scotch, and Welch are as rapidly growing good trollers and spinners. If they follow my instructions they have nothing to fear, and will find that trolling occasionally is productive of the highest angling pleasure. When neither fly-fishing nor bottom-fishing can be practised, in consequence of certain forbidding circumstances of water and season, trolling can be resorted to as a first-rate substitute. The largest-sized river fish are killed by trolling, and I have no doubt that this mode of angling would prove very successful in the sea. A knowledge of it must be a great resource to the angler who visits foreign climes, and there dwells by large rivers and wide lakes. Numerous letters addressed to me by Englishmen sojourning by the lakes in the North of Italy, as well as on the banks of 
the lakes and rivers of several parts of Germany, in which immense trout are found, have assured me of their success by means of trolling, and particularly by practising that branch of it which is called "spinning." They have frequently killed from six to ten very large trout, as large as salmon, before noon, by spinning with the bleak, gudgeon, or some other small fish. Trolling is very successful in taking the gigantic trout of the New World. An angler finding himself without the delicate tackle necessary for fly-fishing, in some remote part of the world where fish abound, may, if he have a few hooks only and any thing to make a line with, very soon cut a rod out of the next wood, ring it, adjust his hooks into a flight of spinning tackle, and work successfully away with this rude gear. Towns are generally built by large rivers, and most of the latter, in this land of ours, breed pike, and some of them, like the Thames and Trent, very large trout. Such fish generally refuse the fly, are seldom taken by bottom-fishing, but commonly fall before the prowess of the troller. I have just mentioned a few of the inducements that ought to lead us to cultivate the art of trolling, particularly as it is not surrounded with difficulties, and as it is a smart exercise, requiring as much activity and vigour to be called into play as is conducive to hardy 
health. The fish most commonly killed by any sort of trolling in our rivers are pike, trout, and perch, the best fish they produce; and that is a sufficiently strong recommendation of it. I divide trolling into three parts, viz., sinking and roving, trolling with gorge and snap-hooks, and finally spinning.

SinkING AND ROVING is easily practised, and, at times, with capital success. It is done with a live bait: a minnow or loach for the common trout and perch; bleak, gudgeon, dace, or roach for pike or large trout. Small gudgeons are excellent for moderate sized Thames trout and perch-large gudgeons for the monster trout and pike of that royal stream. The best general bait for all sorts of trolling is the gudgeon. It will be refused sometimes, and the preference given to small trout, dace or roach, but that will not last, and pike will soon return to their favourite gudgeon-repasts.

In practising sinking and roving, I would have a strong, long bottom rod, with good winch and prepared platted silk trolling line. For foot-line about a yard and a half of the best gut. The link to which the hook is tied should be of fine gimp, if you expect pike as visitors; but gut, or threc-twisted hairs, will do for trout and perch. You must plumb your water, so as to have a good notion of the average depth, and you must put on a heavy float accordingly. If you fish 
with a live minnow, the float need not be heavy; but if you angle with a large gudgeon, your float must be sufficiently large to prevent either your gudgeon, dace, or roach from lugging it beneath the surface of the water. The float is chiefly used to prevent whatever live bait you may use from sinking deeper than you deem advisable, but neither it, nor the lead on the line, should be so heavy as to hinder your bait from swimming horizontally on any side. You lead your line also, but for a different object, viz. to keep down your bait, and to prevent it from swimming up to the surface of the water. Generally speaking, you so place your float on the foot-line that the length of the latter on the hook-side will equal half the depth of the water you are fishing in. Observe this ratio in somewhat shallow waters three feet deep, a foot more or less. In deep waters, where the largest fish roam, you must sink your bait more deeply, about two thirds or more of the whole depth.

You must angle with strong, lively baits, and put them on your hooks with as little injury as possible, that they may swim about actively and for a long time, and appear very unlike captives to the fish you wish them to captivate. Generallyspeaking, you will find a single hook answer; its size to be proportioned to the bait - small for the minnow, large for the gudgeon, and stil 
larger for the deep-breasted roach or dace; and you must insert it, by the bottom of the back fin, on the side of it towards the shoulder, between the skin and the flesh. Some insert the hook through the lips, but I do not fancy that way, as it impedes the motions of the bait, and speedily exhausts its vitality. When the bait is hooked on near the fin, it would be advisable to penetrate a slight portion of the flesh with the hook, to prevent the bait escaping by its own efforts, or to be snatched off with impunity by hasty pike or perch. Hooks used in trolling should not be coloured blue; they should be allowed to remain bright like steel as they are. They should be whipped on the hook with white silk, waxed brilliantly of the same colour.

In sinking and roving allow your bait to swim here and there, generally at mid-water, but in deep places, deeper, drawing it up gently to the surface of the water now and then, letting it sink again, and guiding it to the best-looking spots of the locality. Your float will soon inform you of a run, and you must strike pretty promptly unless when the run is that of a pike. Then you must allow your bait to be taken away and pouched before you strike. From five to seven minutes is the pouching time allowed by me, and I find it quite long enough. Some excellent anglers allow ten minutes before they strike. That length of time can be only necessary occasionally, when 
fish are not voraciously.hungry, and only playing with the bait, and even then I frequently strike in a very short time, lest the fish should not pouch the bait at all, but blow. it out of his mouth after having examined it by the sense of touch, and perceived something suspicious about it. For my own part, except in trolling with the dead-bait, I seldom allow pouching-time at all, but strike as soon as I find my hooks are within the fish's mouth. I very seldom miss, nor do I think any good striker would often fail to hook his fish by a stroke, simultaneous, but slowly so, with the bite of the pike, perch, or trout. Pike is the only fish that should be allowed time. Trout and perch should be struck immediately; stopped by a smart check as they are darting off with their prey. Their run is quicker than that of the pike, which often swims off very leisurely with the bait in his mouth to pouch it in peace in some tranquil haunt. You can therefore generally distinguish what sort of a run you have; if it be a trout-run strike quickly, if a pike-run give time. This question of time is important, and still remains doubted and discussed. I will quote a few opinions.

Mr. Blaine observes, "Be careful not to mistake the motions of the bait for those which are made by the pike or jack when seizing it. With the experienced angler there is no danger in this, 
but one less initiated might be apt to fall into the error, particularly as the mere sight of the jack will sometimes make the bait throw itself out of the water to avoid its dreaded foe. The proficient at such a time will do nothing more than gently move his bait, as though it were going to leave the spot, which alone will sometimes occasion the jack to seize it at once. The seizure of the bait by the pike is marked by the float, which is not thrown up, but, on the contrary, is drawn violently down; and the water is likewise observed to undulate, unless the bait be seized at a considerable depth. Be prepared with a free line as regards the reel; it is also a good plan to have in the left hand a yard or two of loose line to give out as the pike runs, which is infinitely preferable to allowing it to be pulled by the fish itself from the reel, which alone will cause the bait to be rejected by a pike not well upon the feed. Whatever line therefore is required in the progress of the fish to its hold or haunt, run it out by hand, and such hold is seldom far off, and the fish will, when there, probably stop to gorge the bait."

When you have a pike-run, and the fish makes away for a convenient retreat to swallow the bait in, you must allow him to move off with the least obstruction possible. You must lower the point of your rod, uncoil with your left hand 
the line from the winch, and give it out as the fish moves so that he may feel no check by a tightened line. Do nothing to disturb him whilst pouching the bait, and after you have struck him, play him according to rules already given and by some to be mentioned hereafter.

Mr. Blaine again says, "In striking let not impatience tempt you; wait until you are certain that the pike has actually gorged the bait; otherwise your slight hold on both bait and prey will tear away, and you will lose both at the same effort. The pouching time is by no means definite, but is regulated by circumstances; thus having satisfied yourself by the previous stillness of the pike or jack, that he is gorging the bait, and by his again moving out from his retreat (which signal you must look for), that he has actually done so; give your line a smart hand-stroke, which will fix the barbs into the maw beyond the power of ejection."

Captain Williamson, who is a superior authority in all that relates to trolling and pike-fishing, says, - and the reader should pay deep attention to him, - "Whatever may be the length or thickness of your line, you will always find it useful to have a swivel on it somewhere; if within a yard of your hook, the better. You should be extremely careful in your management of a jack when hooked; for he will, if possible, run into the 
most desperate situations, and try the strength of your tackle by various stratagems. Treat him tenderly, for his mouth is very hard, and frequently you will find that the hook, instead of having gone through the jaw, rests by a very slight hold of the point on some tough part, from which it is easily displaced: when such is the case, your hook is in danger of snapping at the bend.

"I consider it very hazardous to let a jack have more line than he will run off the reel when he first seizes the bait (the Captain is here in the wrong); because he will to a certainty, if there be any weeds, or other shelter at hand, go in, and lead you into difficulty; but circumstances must govern on every occasion.

"When a jack takes your bait, if the water is clear, you may see him to a great depth; at least there will be a perceptible agitation of the water, proportioned to its depth, and to the size of the fish ; for a jack generally seizes with violence, even though the bait be close to him. At all events, if you do not see any of these symptoms, you will soon feel them. If you are prepared in the snap way, strike firmly, but not with a jerk, lest you tear away through his jaw, or break your hook. If you have gorging tackle, you must let him run as far as he may please; avoiding to check him, and pointing your rod down in the direction he takes, so that there may be no hindrance, and 
he may not feel the smallest control. Give him time to swallow your bait, which he will do almost instantaneously, if he be of a good size, and not too full of other prey, as sometimes happens.

"In general a jack will lie quiet, whilst he pouches the bait; but if it be too large, or that any other jack be in sight, he will run with it until he can lie concealed, so as to turn and chuck it about according to his fancy. You should make it a constant rule to give abundance of time, and not to be sparing of line, in the first instance ; for though a large jack may bolt the bait as soon as seized, the major part of them, more particularly when they average from one to three pounds, will require some time. Let them lie a few minutes, say about four or five, and then so soon as they move, strike and manage with caution.

"If, however, after lying a minute more or less, or perhaps two minutes, the jack runs again, it may be prudent for you to strike; especially if he is intent on gaining a dangerous cover. In this you must be guided entirely by circumstances; for if the jack is obviously large, and your bait small, there can be little hesitation; since in all probability he gulped it down without difficulty; but when you have reason to think your bait is rather too large for the fish, you cannot show too much forbearance, provided you 
are in a safe water. On the whole, you will find the greatest advantage result from giving plenty of leisure for the fish to swallow the bait: you ensure the prize, because if he has pouched he cannot escape, and if he has not pouched, you ought not to disturb him. When a jack evinces his bulk, by the agitation of the water, or by rising so near the surface after your bait as to be distinctly seen, and after stopping for a few seconds, shakes your line and runs off, you may be tolerably certain that he has pouched, and is desirous to eject the bait, which, if you use a double gorge-hook, he cannot possibly do."

The following few lines, containing the opinions of more writers than one, touching the time of striking at pike, are worthy of attention. When you have a run, or in other words, when a pike or jack has seized your bait, lower the point of the rod towards the water, and at the same time draw the line gradually from the reel with your left hand, so that nothing may impede or check the progress of the fish in carrying the bait to its hole in order to pouch it. Do not strike until the pike has had possession of the bait about seven minutes, or till the line shakes or moves in the water, then wind up the slack line, and turn the rod, so that the reel may be uppermost instead of underneath, and strike, but not with violence. Mr. Taylor, in his to a certain extent useful book, says, 
"The pike will, as soon as he has seized a bait, run to his hold to pouch or swallow it: allow him therefore five minutes to do so (unless the line slackens before that time, which is a signal that he has already done it), and then strike. But if after he has run off with the bait, he makes scarcely any stay with it at his hold, but goes off with it again, you should not strike him until he has rested a second time, allowing him still about five minutes; but if he shonld run off again a third time before the five minutes are expired, draw a tight line, and strike him instantly." In fishing with snap-hooks or spinning tackle you must strike immediately the fish has taken your bait. Of these tackle I shall write more fully by and by.

There are many ways of baiting for sinking and roving, and several sorts of tackle sold for the purpose, but the following is the best. The accompanying cut, from Blaine's "Encyclopædia of Rural Sports," explains at a glance the tackle I recommend, and how, as far as baiting is concerned, it is to be used.

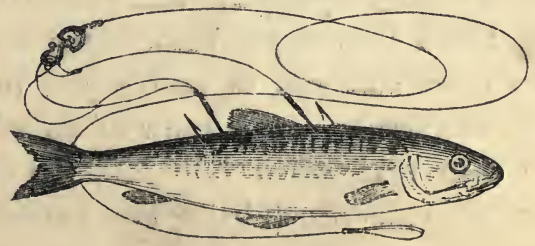


You will perceive by this illustration that two hooks are used; they are to be strong, but small according to the size of the bait. Each is to be tied to a stout piece of gut three inches long, and looped at the upper end. Their length when looped must be exactly equal, and each of the loops is to be fastened in the hook of your swivel attached to your gut foot-line. One of the hooks is to be inserted into the back of the fish just before the dorsal fin; the other hook just behind that fin. The hooks are to point different ways, and if they are properly inserted, and their gut links of equal length, the fish will hang in easy and just balance, and there will be no drag either way to prevent it from swimming freely. A live bait so hooked cannot escape by its own struggles, and neither pike, trout, or perch can snap it off with impunity.

SnaP-BaITs. - These hooks and baits are only used at seasons when pike do not feed with sufficient voracity to pouch their baits greedily. They are used to allow the troller to strike quickly, before the fastidious fish, suspecting something wrong, rejects the bait almost as soon as it is taken into the mouth. The rod used must be short and stiff to enable you to strike promptly and firmly, and I know of no rod more suitable than that which is called, the Thames punt barbel rod. Snap-baits are twofold, one 
which does not spring when you strike a fish, and the other which does. I will give you representations of each, taken from Mr. Blaine's work. The first is called the live-bait snap, figured thus:-

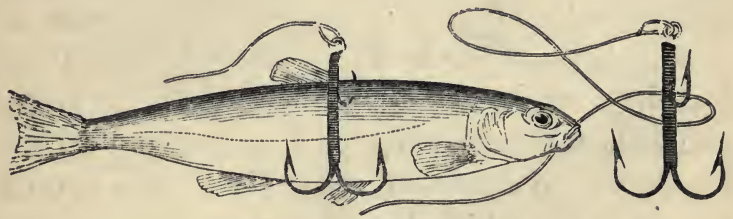

You see that it consists of three hooks, two large ones tied back to back, with their barbs pointing different ways, and one smaller hook tied on at the top of the shanks of the others, and pointing straight out from them. You can tie them yourself thus:- take two strong hooks, of size No. 3 . or 4., according to the strength of their make, as well as to the size of the bait. Tie each to about an inch and a quarter of fine twisted wire, and again tie these two wires together, including in the tie a hook, No. 8 or 9., and also eight or ten inches of gimp, which loop at the other end; but in tying, place the large hooks contrarywise, so that one may point towards the head, and the other towards the tail of the bait-fish, which will greatly increase the chance of success in using it. To use this, enter the small hook under the back fin, and allow one of the two large hooks to 
apply itself close to one side of the bait, and the other to be similarly placed on the other, but with the direction of their points reversed. A good sized roach, or dace, can conceal the snaphooks, but it is not properly applicable to a small fish.

The Spring-snap is generally used with a dead bait, because it cannot be inserted properly in a live bait without doing it disabling injury. It requires deep insertion in the bait, to allow the spring to act which it will not do without some considerable resistance. The spring-snap is figured on the opposite page.

If you examine this tackle, reader, you will perceive that the two large hooks project from one and the same shank, which is flat and split, - and which slides up and down between two perpendicular wire pillars. They are attached, as well as a small hook, to a moveable band above, and when suddenly and sharply pulled downwards below the band beneath, the elastic shank separates with a strong spring, and the result is the insertion of both hooks or at least one within the mouth of the fish that seizes it, and at which you sharply strike.

In the spring, summer, and early autumn months pike are shy, and fond of basking near the surface of the water, and if, as Mr. Blaine says, "one of them does seize a bait at these 
SNAP-HOOK SPRUNG AND UNSPRUNG. 177

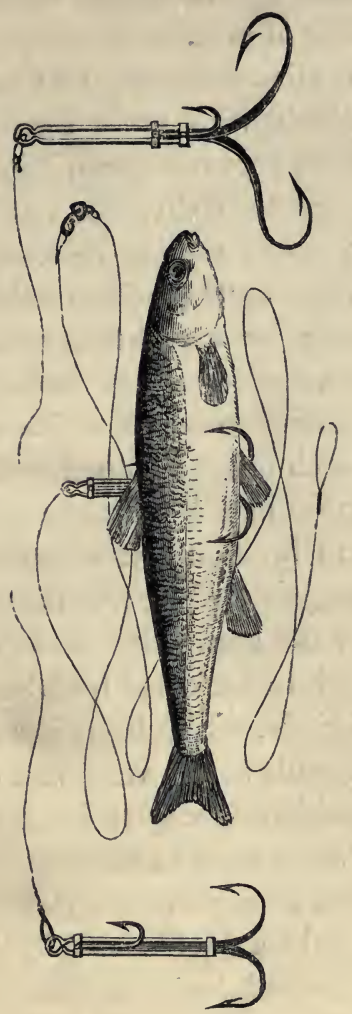

times, he is apt not to pouch or gorge it, but after roving about with it in his mouth for some time, he ejects it or blows it out, as anglers term it." Hence then the necessity of snap-hooks, to 
meet by prompt striking the snapping and not the swallowing of pike.

Captain Williamson says, "At such times they will seize a bait with great seeming eagerness, but for the most part relinquish it instantaneously. When jack are thus shy, the angler must take them at the snap; that is, he must be quick in striking so soon as the bait is seized. This requires a particular apparatus, whereby the fish rarely escapes, under proper management. The snap tackle may consist of a single hook, large and stout, which being fastened to strong gimp is inserted at the mouth of a gudgeon, or other small fish, and brought out either at the middle of its side, or just before the vent. The treble snap is by far the best, being made of three such hooks tied back to back fast together, and secured to a piece of gimp; which being inserted by means of a baiting needle at the vent, and carried out at the mouth, which is closed by a lip-hook, the three hooks being spread into different directions, it is a thousand to one but the jack is hooked."

You can make a double snap in the same way. Tie two good-sized hooks back to back; have a sliding lip-hook on your trace. With a baitingneedle carry the trace in at the vent and out at the mouth, and draw until the bend of the hooks are arrested at the vent. Fasten the lips together by inserting through them the lip-hook. This 
tackle, with the others mentioned, except the spring-snap, are very easily made, and very fit for those parts of the river in which there are obstruc-tions to the convenient practice of trolling with the gorge-hook or spinning. Where there are confined holes, waters with piles, weeds, and roots, the snap-bait with short line and rod can be easily dropped in to tempt the fish that seek refuge in such localities.

The Paternoster line is one containing several hooks, whipped on short stiff pieces of gut or stout bristles, so as to project from the foot-line horizontally into the water and to present divers baits of different sizes, and sometimes of different qualities. A plummet is fixed to the bottom of the line to sink it, and keep it steady, and the hooks and baits are placed from a foot to two feet apart, according to the depth of the water. Three or four hooks are quite sufficient for the paternosters used in most of our rivers. The hook nearest to the bottom may be baited with a worm, the one next to that with a life gudgeon or dace, and the highest hook with a live minnow. You must strike as soon as you have a bite. The paternoster is very successful in the rivers, canals, and docks near London; it is very easily used, requiring little more than close watching.

The Gorge-hook. - Until you employ this tackle you can scarcely be said to troll. The pre- 
ceding modes of taking fish with fish-baits, though I have placed them under the head of trolling, do not embrace pure trolling. To troll, you must cast your bait with a coiled line to any distance you propose, and then by drawing your line in with the left hand, a certain portion at each draw, you cause your bait to troll-generally towards you beneath the water. The rolling or rotatory motion of your bait in the water attracts fish to it; they run at it, swallow or gorge it, and then you strike, play, and kill them. Quite the contrary, however, may happen, to your great annoyance. As it is by trolling with the gorge-hook that the largest pike are killed, I must be methodical and minute on the subject. Underneath is the figure of the common gorge-hook, and above it is a hook baited, both taken from Blaine's great Sporting Encyclopædia.

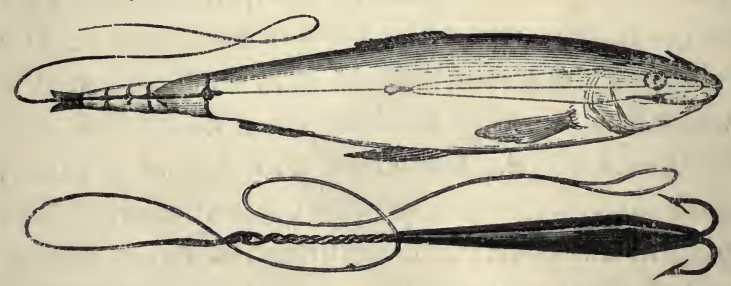

Generally the hook is formed of two single eelbooks, placed back to back, and joined together with a continuation from their shanks of a piece 
of wire, looped at the end. The shanks of the hooks, and a portion of the wire, are embedded in a piece of lead, rounded thickly at the shoulder, and tapering off towards the tail. Some persons make the lead of an octagon or quadrangular shape, which is objectionable, and not by any means so proper as lead roughly rounded, to make it steadily inherent in the interior of the bait. About a foot of gimp is to be neatly attached to the loop in the wire, and when the gorge-hook is baited, the gimp is to be fastened to the hook of the first swivel on your trace. Two good swivels are generally sufficient for your trace.

The gorge-hook is baited thus : - The loop of the gimp is placed in the eye of the baiting-. needle, which is inserted through the mouth of the bait, and the point brought out at the middle of the fork of the tail. Draw the gimp towards you until you find yourself stopped by the bends of the hooks being arrested by the mouth of the bait. The points of the hooks are to be in an upward direction, as you see in the illustrated figure. A thread of white silk, whipped round the bait close above the tail, will attach it firmly to the gimp within, and prevent the bait from having its tail part injured, by being dragged backwards during its progress towards the water.

Many persons do not allow the wire that is attached to the hooks to project beyond the fine × 3 
end of the lead, where they attach the gimp and bait, as above. They contend that gorge-hooks are too heavily wired, causing the bait when cast to sink too deeply in the water and make too large and loud a splash. The gorge-hooks, with little wire projecting beyond the lead, are very fit for trolling amongst weeds, and in foul places, but they do not act so well in wide, clean waters, as they have not the necessary stiff and firm hold on the bait, and the baits are apt to be disfigured by crumbling in the cast. For ponds and lakes the long wired gorge-hooks are the best.

Neither barb of the gorge-hook should project too widely from the sides of the mouth of the bait. If the points of the hook do project too widely the fish may perceive them, but at any rate they will be likely to get foul of obstructions in the water. Nobbs, the father of trolling, remarks : "I commonly made use of a single gorgehook, which strikes as sure as the other. The double hook hath one advantage above the other, that if it meets with such resistance in the water that it loses one side of it, the other part, with a little filing, may be still as serviceable as it was before; it is more troublesome than the single hook in the water, and more apt to stick and take hold of the weeds and roots; it is best for a great bait, for if you put a small and slender bait on a double hook, it will hang out and bear off so 
much in the bending, that a pike may not only discover the delusion, but if he takes it, it may check him in his feeding, and so hinder him from gorging it." Mr. Blaine says, "Some anglers sew up the mouth of the bait after they have introduced the gorge, which we consider as not very material: the lips certainly conceal the bends of the hook rather better when sewn up than when left open, which is all the advantage gained." The gorge-hooks should be of different sizes, according to the baits you use, and the size of the baits should be regulated according to the size of the fish probably frequenting the waters you angle in.

A rod twelve feet long is considered sufficiently lengthy for trolling with the gorge-hook. It should be strong, yet light, and made of mottled cane. The one mentioned hereafter in my list of rods, is the most appropriate for trolling with the gorgebait and for spinning. The rings should not be made of wire, but of strong brass or steel. They should be wide, far apart on the rod, and their base should be polished so as to let the line run most freely through them. Trolling rods are made to perfection by all the chief tackle manufacturers in London. The trolling line should be of stout prepared platted silk. Those of hair, or silk and hair, or of mere hemp, are bad, liable to kink, and therefore run heavily out in casting. Hemp 
lines, though oiled or varnished, will imbibe moisture, run out clumsily, and soon rot. A large London-made multiplying winch is the best to troll with.

To cast your gorge-bait you must unroll off your winch as much line as you want to reach the distance you intend to cast to. The line must fall in free coils by your feet on either side of you. Take the upper part of your line in your left hand, drawing the bait to within a yard or less of the point of your rod, which lifting, throw to your right or left just as occasion may require, and letting free the line in your left hand, the bait will be carried, the coiled portion of the line running through the rings freely, the length of the line out. The bait having entered the water, keep it at about a distance of one third the whole depth, if the water be deep, from the bottom, but genérally speaking at mid-water, and drawing your line towards you by short and gentle pulls, moving your rod in the same direction, try and give to the bait a natural and attractive motion. Do not, unless in case of emergency, lift your bait out of the water, until you have drawn in your line. Then repeat your cast, and go on casting, moving with each cast until you have left no part of the water untried. Your first cast should be into those parts of the water nearest to you, then further out, and lastly as far to the other side of 
the water as you can throw. When you have a run, let the fish move off with your bait, and strike as before directed.

Very various are the methods of handling the gorge-bait. Generally speaking they are antiquated and slovenly. The tackle I have just mentioned will answer admirably, but you may troll in wide waters with a larger rod than the one I have described. Your salmon rod will do when you have no other, and find yourself amongst the pike-lochs or lakes of our own country or amidst those of any other. Mr. Blaine on this subject says, "The plain pillar-reel is certainly the safest for very heavy fish; but, nevertheless, if the angler uses a multiplier on the best principle, it will wind up in all ordinary cases without clogging, and as fast as can be wanted. For the giving out of line it will of course answer, as the hand can readily assist it. The ground-line, however, may be used with advantage when, instead of a trolling rod, a ferruled stick is employed, of three or four feet long; and it is more useful sometimes even than a rod, in trolling from a boat, or from the high bank of any wide river. From such a height, with the trolling stick in the right hand, a quantity of loose line lying by the side, in regular coils, when baited and being passed through the ferrule or end ring, and the bait dangling on a portion of the line not more than two feet long, 
take hold of this part with the left hand, and now by means of the right hand, which upholds the trolling stick, swing the bait-fish until it has gained its momentum; then deliver it well from the hand in any direction you choose, guiding the passage of the line through the ring by the inclination of the stick, and the aid of the left hand. We have known a line carried in this way nearly forty yards, and we believe it can be projected even to fifty, whereas it would be impossible to deliver it to any such distance with the trolling rod."

Mr. Blaine here errs: the bait with a ten or twelve feet trolling rod can be thrown sixty yards or farther. But these long casts or throws are of no use generally, and in making them, as trollers do for parade sake, the bait is injured, and after it has fallen into the water it cannot be put into any thing like natural motion for some time. A shorter cast would have been more effective. Indeed, unless when you wish to reach some far off spot having some especial attraction, do not cast farther at any time than thirty yards. That distance you can handily manage by casting your bait skew-ways to it, causing it to enter the water slantingly, and gathering up your line deftly before your bait has sunk to the bottom of the water or got injured by hitching in any obstruction there. The truth is, a trolling rod can be very easily made. One of those long tapering canes, sixteen 
or eighteen feet long, specimens of which you see as signs, shooting upwards and over the streets, at fishing-tackle makers' shops, will, by adding to it half a dozen large rings, make an excellent trolling or spinning rod, by means of which you can cast any reasonable distance, and gather up your line the moment your bait enters the water. Osier and hazel nurseries will afford you long stout saplings or shoots, which, if you cut them in winter, will make useful trolling rods. However, as Mr. Blaine says, the well-made tackle-shop rod is infinitely preferable for the numerous diversities which a river presents; by its means the bait can be lifted over sedges, directed into pools, and dropped into the water-runs between reed-beds, more readily than by any other method. It also gives you the power of playing your fish according to the pleasant rules of art.

I advise the use of a moderate portion of lead only on any part of the swivel-trace. If the gorgehook is properly leaded, it will be sufficient to sink the bait without any additional weight more than that given by the swivels. The generality of trollers use too much lead, and troll with too much rapidity. The following trolling axioms are selections from good authorities.

Swivel-traces are necessary in trolling, for by their means it is that the bait revolves quickly, and answers to its character of a troll or rolling 
motion, which assists greatly to attract the notice of predaceous fish. The swivel-traces used with the gorge-hook require no leading, the hook being of itself sufficiently weighted. Some troll wholly without a swivel-trace, but we are certain that it is to the manifest injury of the spinning of the bait, and we therefore strongly recommend these traces. By means of the swivelhook a great convenience is also obtained, as the tackle becomes so readily disengaged; but it is to be noted that, in releasing it, the ardent angler sometimes is violent and snaps his swivel, which is another reason why no prudent one should be without spare traces, or indeed without duplicates of all the minor articles of fishing apparatus.

Gorge-hooks of all sizes and figures are kept in the shops. The necessity of having different sizes of the gorge apparatus is apparent, from the fact that you use it, in trolling for large and small pike, with baits from the size of the minnow to that of a roach of from two to eight ounces. Not only should gorge-hooks be kept of various sizes, but their shape, particularly the leaden part of them, should be adapted to the shape of the fish you use as a bait. The minnow and gudgeon are round enough in shape to conceal a round leaded gorge-hook, corresponding with their size, but for the bleak, and roach, and dace, which are more flat-sided, we recommend 
that the lead be somewhat flattened, and be rather of a compressed oval shape than round. Mr. Salter judiciously observes (I have already recommended a gorge-tackle of the sort for trolling amongst weeds, in narrow and foul bottomed rivers, where you need not cast far); "I generally remove about a third of the lead from the brass of those hooks which I find kept ready for sale in the fishing-tackle shops, because I have found, when the lead lies nearly the whole of the length of the bait-fish, and especially of a bleak or thin roach, that when the jack strikes it, his teeth pierce through the flesh and touch the lead; he then immediately ärops the bait. Now, by removing a part of the lead, as above directed, the angler will find the remainder to be sufficient for sinking, \&c. his bait, and that it will lie at the bottom of the bait's throat, or only a little lower; and as jack generally seize their prey by or across the middle, in such case their teeth seldom come in contact with the lead, and they then retire, without fear, to their haunts, and soon pouch the whole."

Mr. Blaine observes, "The method of holding the rod differs in the practice of different anglers; some grasp it firmly in their right hand, and depend on the strength of their arm for delivering the bait out to its extent, but we apprehend that much the better method is that of resting the 
butt against the hip, thigh, stomach, or whereever a convenient support can be obtained (we always use our hip for the purpose), by which much exertion is saved, the bait can be cast much wider, and when the angler is accustomed to the habit, he may, by this means, direct it within a few inches of the spot he aims at. The rod placed, and the bait swinging on such a length of line as can be managed, retain within the left hand a yard of it loose, which, as the bait is cast, gradually let run off the hand, directing it rather slantingly: by such means it will shoot diagonally forward, with a natural appearance, impelled by the weight of the lead. When delivered, begin to move it after the manner of the motion of a fish about mid-water, observing always to avoid removing it quickly from the water for a new throw, for both pike and jack often follow the bait and seize it at the moment it rises towards the surface, fearful it is going to throw itself out of the water to avoid the pursuit.

"In the practice of trolling, a due degree of caution must be observed throughout. Avoid alarming the fish by unnecessary noise, and keep as much concealed from view as possible; the length of the rod will assist greatly in this particular, for by it the angler can reach over the bank without approaching too near. The sides of every water should be first tried to the right 
and left ; this done, proceed somewhat further in, but avoid making either much noise or much splash in the water, by the cast of the bait. Try every spot, but do not dwell long in any; once or twice showing the bait in likely places is usually sufficient. Success in trolling depends much on the method of displaying the bait, which, of course, should represent the natural actions of the fish, and is best effected by first giving to the bait a slanting direction on its entering the water, and then drawing it towards you to make it resemble a running-away, as it were, fish, or, at any rate, a frightened one. Never allow the bait to be still, but keep it ever in moderate motion, yet never in a violent one, as some trollers improperly do; which practice, we suspect, is more detrimental to sport in trolling than is imagined, for we have had runs by trolling more slowly over the same spots which others had but just quitted without one, in consequence of having given too rapid motion to their bait. A little habit will enable the angler to vary his methods of throwing his bait, according to the extent and nature of his water. Where there are large weed-beds, intersected by open water between their waving masses, or where large aquatic plants rise up in patches, there the bait must be carefully dipped lirectly down, to avoid entanglement; and then the angler must be pre- 
pared, not to mistake the check given by the weeds for a real bite, which it often very nearly resembles. When such a check occurs, pause a second, and if all continues quiet, draw the bait gently towards you; when, if the resistance is obstinate, and yet tremulous, a jack is at it, and your moving it will most probably induce him to drop it, or otherwise gorge it. Do the same if the bait move slightly forward, with a renewed check, for there is then more certainty that something is at it; after this, if it remain a dead weight on the hand, it is probable that the jack has quitted it, and left the hooks entangled in the weeds, which is by no means uncommon in these cases: you may, therefore, now draw at it with a little more force, which will certainly inform you of the nature of the resistance, and yet allow you time to retrace your steps, if a jack be there in earnest."

Mr. Salter, and other authorities, recommend that when a large pike is struck in open water, you should give him more line, and not pull hard at any time, unless your tackle should be in danger of entangling among weeds or bushes; and when this is the case, the utmost caution is necessary, lest the rod, line, hook, or hold should break. When completely exhausted and brought to the side, take the pike up with a net, or landing-hook, or, if in want of either of these, put your thumb and 
finger into its eyes, which is the safest hold with the hand. When you have hooked a jack or pike, and played him till he is quite exhausted, and are drawing him ashore, make it a rule to float him on his side, and keep the head a little raised above the surface of the water, that the nose or gills may not hang to or catch hold of weeds, \&c., while you are thus engaged bringing your prize to the shore; for sometimes you cannot avoid drawing it over or among weeds; and we have seen a pike touch and get entangled in this way, and, before it could be disentangled, it recovered from its exhaustion or stupor, and occasioned much trouble and hazard before it could be again subdued.

I agree with Mr. Blaine in thinking that the seasons for trolling are so well laid down by Mr. Nobbs, the father of trolling, that they may be transcribed without alteration. He says, "Though the depth of winter cannot be recommended for angling, yet there are some days in December and January that a man may pick out to stand two or three hours by the river side, but the weather must be open and temperate. The great fish will be soonest enticed with the bait at that time of the year, because they lie deep, and are not so careful of their own preservation. There is another great advantage for the winter troller; the weeds are then down and rotten, which are a great hindrance, both against throwing the bait, and in 
keeping the fish from the sight of it. Though a pike delights much among the weeds, and usually makes his abode there, yet it is very difficult to take him there, except it be with the snap; for if you give him the liberty of running and playing with your bait, he winds himself so fast about the weeds, that you may be in some danger of losing both your fish and hook, if your line is not very strong. Trolling in January, even on favourable days, when the season is moderate and the water in order, which is rare in this month, is but labour well nigh lost; for if it is not a flood, yet the ditches and brooks are commonly so rank and full, that it is but indifferent fishing. February presents better prospects, and on some days these fish take a bait eagerly. March, too, is very seasonable to the troller, except the time of spawning, which usually begins about the middle of it, except the spring is very forward, and then they will be disinclined towards preying. The snap is now the most taking way; for if you fish at pouch, you may have many runs, but scarcely take one, except it be a small fish. These two months therefore will try the pike-fisher's patience, even though he be wind and weather proof. April will, however, in all probability, make him amends for his former sufferings." In the latter summer months, and on fine days in autumn, when the deeps are curled by a fine breeze, pike are to be 
| taken very pleasantly by means of the artificial fly. The best imitation is a very large one of the dragon-fly. I have seen nondescript large gaudy flies kill pike well, and Mr. Blacker, of Dean Street, Soho, is the best dresser of them I know. An imitation of the sand-martin or swallow, dressed by means of feathers on a large hook, will prove an attractive bait for pike in the seasons last mentioned. Of the season of autumn, Mr. Nobbs says, "The weather being then temperate, and the weeds, which were strong and high before, are now dying and falling to the bottom. The rivers are then generally low, which is a great advantage, because the fish are more easily found in their harbours. They leave the shallows and scowers, and lodge themselves in pits and the deepest places. A pike is now very firm and fat, having had the benefit of the summer's food; and if the weather continues open, and not extraordinarily cold, you may take in part of November, which will add much to your sport, because the weeds will be more wasted and rotten; but if a flood comes in October or the beginning of November, you may lay aside your tackling for that season, for great rivers, like great vessels, being long in filling and slowly mounting to their full height, are again long in falling and settling, so that the water will be thick and out of order, unless frost or fair weather comes to clear it. 
In small brooks and rivulets it is not so; you may fish in them again within a week or less after the flood."

\section{SPIN NING.}

Next to fly-fishing, spinning is the most amusing mode of angling. It is a dashing, killing method, and the practice of it requires considerable muscular exertion. The arms in casting, and the legs in moving on and changing ground, are continually and strongly called into requisition. Trout, pike, and perch of all sizes, but generally speaking the largest, are caught by spinning. Salmon, in my opinion, and in that of a few others, are to be taken by spinning with a real bait or an artificial one. English travellers, carrying with them into foreign lands their sporting propensities, have been very successful in the lakes of Northern Italy, and in those of Germany, in taking immense trout by means of the spinning tackle. This I know from authentic private correspondence. In America, whether in the United States or in Canada, immense trout and pike have been taken by spinning. At our own doors we know, that generally speaking, all the large Thames trout are taken with the spinning tackle. It is active angling, not of course so refined as fly-fishing, but it deserves every 
attention on the part of those who wish to become accomplished anglers.

In spinning you cast pretty much in the same way as you do in trolling with the gorge-hook. Spinning rods are magnificently manufactured in London, and I like those best that are made of mottled cane. They are strong, light, and of handsome appearance. They are generally about twelve feet in length; and with a rod of that length, ringed in the modern manner, not with wires, but with strong, hollowed out pieces of brass, and with a hard platted prepared silk line, you can throw your bait to a distance of sixty yards, a distance, however, too far to throw, except on trying occasions. For my own part I would have a spinning rod made of a single piece of this mottled cane, sixteen or eighteen feet long, well ringed, with a screw winch, requiring no winch fittings; and though it may be awkward to carry (the only sound objection that can be made to it), the advantages it would offer are very considerable. You can cast well with it, gather quickly up your line immediately your bait enters the water, strike your fish better with it, and play him when hooked in a more satisfactory and artistic manner. With a rod of this description, you can troll for salmon or large trout in the deepest and widest waters. In narrow streams you can spin with a very small portion of line out, 
and almost avoid casting, the length of your rod allowing you to drop in your bait noiselessly wherever you like, and spin it accordingly.

Your bait spins by means of swivels on your foot-trace, and by a bend given to your bait close by the tail. The spinning or revolving motion communicated to your bait as you draw it towards you, makes it, no doubt, exceedingly attractive to fish of prey. It seems then to fly madly for its life, though it has none. Predaceous animals of all sorts rush with might and main after the prey that flees with the most timid fleetness from them. The hawk darts at the frightened lark, the greyhound outstrips the wind, urged on by the fearful strides of the craven hare. I have often thought, if, contrary to instinct, hares, instead of shooting away when started, would run playfully towards the hound, fawn and jump upon him, and about him fondly, the hound might have his instinct of destruction blunted, and his ferocity softened down. I should like to see how a greyhound would act in the midst of a flock of skipping hares, not one of them running away from, but all running towards him. We have all seen a hawk nonplussed by being surrounded by an immense flock of swallows, larks, linnets, and other small birds, and seem anxious to part company from them. If one, however, leaves the flock and flies away frightened, the hawk scuds after the timid 
fugitive, his ferocious courage apparently being excited by the timidity of the weaker vessel. It happens thus, I fancy, with fish. If a mixed shoal of minnows, bleaks, gudgeons, dace, roach, and small trout were to surround daringly a pike, defy him, jump upon his back, I fancy he would look somewhat foolish, like a stripling Lothario in the midst of a couple of score mocking school girls in their teens. Let either beast of prey, however, meet with one lonely timid creature, fluttering to escape, and then see how his ardour will be excited by its efforts to get away. This, indeed, is little more than a fancy; still it makes me think that the spinning-bait is rushed after by fish the more eagerly, because they conjecture (if they can conjecture) that it is some more than usually dazzling object of prey, striving strangely to escape. Hence the more ardent they are to arrest it in its flying course.

Various indeed are the sorts of spinning tackle recommended by anglers. The great merit for which they are recommended, is generally that they spin well, that is, that you can show them in the most seductive run-away shape to the fish you wish to beguile. The second merit is, that the flight of hooks is so well placed, as to prove a deadly thorn to the gentleman that dares to pluck your rose. I can scarcely recollect exactly the varieties of spinning tackle that I have seen; 
dozens and dozens having been sent me for my examination and judgment. On the whole I have found them too intricate, the flights, as they are called, being composed of too many hooks. I will mention some of the best of them, but first describe those I think the best of all. In the subjoined engraving you will see them represented.

1.

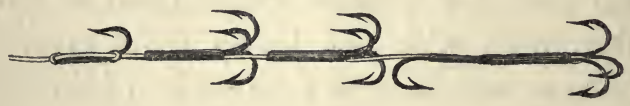

2.

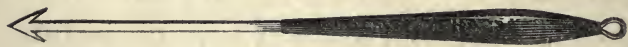

3.

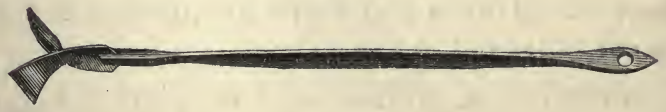

The first, you perceive, is a flight of hooks, with which, according to its or their size, you may arm or bait with minnow, bleak, gudgeon, dace, or roach. The length of your flight must be regulated by the length of the bait-fish you use. A minnow for the common trout and perch; large gudgeons, dace and roach of from four to six oz., for large trout and pike. This flight consists, 
you see, of no fewer than eleven hooks, that is to say, three treble ones, and two single ones. The first single hook on the left is a sliding one, and is called the lip-hook, because it is inserted point upwards through the lips of the bait to keep them close. The second single hook, with its barb pointing downwards, is placed next to the last treble hook on the right hand side of the page. When you use this flight of hooks without either of the additions, numbered two and three in the plate, you bait with it as follows. Insert one of the last treble hooks close to the tail of the bait, and curving that part of the bait a little, keep it on the curve, by inserting tightly the next single hook in the bait higher up from the direction of the tail. The proper insertion of this last hook will keep the tail-part of the bait bent. Next insert one of the middle treble hooks in the upper side of the bait, without any drag on, or bent, in it, in the region of the vent, and then insert one of the treble hooks (one of those next to the lip hook) in the bait by one of the sides of the back fin, and lastly finish baiting, by inserting the liphook through the lips of the bait. No part of the bait should be strained in its shape by the insertion of any of the hooks, except that single one which is used to give the bait a bend near the tail. Every other part of the bait should lie straight. A flight of hooks of this description 
should have at least two swivels on its trace, that part of it within six inches of the bait being moderately leadeci.

Now examine figure 2. in the cut. It is a piece of flat brass wire, arrow-shaped at one end, leaded and looped at the other. Give it a little sharp bend, near the arrow-head, and pass that head in at the mouth of the bait, and down through the middle of the body to the tail, but not out at it. The leaded portion of the wire, if the whole is properly placed in, and adapted to the bait, will lie in its belly, and the looped portion of the wire will project just beyond the lips of the bait. Take your flight of hooks now, and, leaving your last treble one "fly," or not inserted in the bait, but hanging by the tail, insert your downwards-pointed single hook in the side of the bait between the vent and the tail, not straining or dragging any part of your bait, and then insert one of the middle treble hooks in the neighbourhood of the vent above it, and your first treble hook on the left side of the cut, insert near the back fin, and finish by inserting the lip-hook through first one lip of the bait, then through the loop of the wire, and lastly through the other lip of the bait. A moment's consideration will show the reader the advantages of a baiting apparatus of this kind. The wire bent and passed as directed, keeps the bait stiff and sufficiently bent 
near the tail, and the leaded part of the wire renders the bait sufficiently heavy for casting and sinking it the distance and depth required. The consistence of the bait receiving additional support from the wire and lead in the interior of it, prevents it from being torn easily in the process of casting or spinning it through the water. The bait is held extended, and cannot be dragged double by the strain of the hooks, which fre-quently crumples up and spoils a bait, having no such interior support. When you use this leaded wire, you need put very little additional weight on your swivel-traces. This sort of spinning tackle I am exceedingly partial to.

The figure 3. in the cut is a new invention, and a very good one. It is a piece of wire with an artificial fish-tail affixed to it. The divisions of the tail are turned different ways, like the tail of the archimedian minnow, invented by Mr. Frederick Allies, of St. John's, Worcester. In passing through the water, a tail thus divided and inverted causes the fish to turn round as it is propelled onwards, gives it a regular rotatory, or screw motion, as you draw it through the water. It is partly an artificial and partly a natural bait. I have a good opinion of it. In using it you cut off the tail of the natural bait, and entering there the point of the wire, you pass it through the body longitudinally, and out at the mouth. The 
artificial tail now takes the place of the natural one, and the wire through the body keeps the bait-fish firm, straight, and in its natural shape. You now insert the flight of hooks exactly as I told you to do, when using the arrow-headed wire. This bait will swim and spin admirably, not be liable to tear; and if the artificial tail be made with care, it will not glaringly disagree with the natural body of the fish.

The flight of hooks I recommend as generally the best, is composed (as shown in the cut) of eleven hooks. You can have one of fourteen hooks, if you like, by adding a treble "fly" hook. You will then have three treble hooks to insert in different parts of the body from above the ventral fin to above the pectoral one, and if with a bait bristling with so many barbs you fail to hook the fish that rushes open-mouthed on such a cheval de frise, the fault lies not in your tackle, but either in your own mode of striking, or in the fish's way of seizing the bait. This augmented flight of hooks is not fit for minnow or bleak spinning. It only suits when your baits are very large gudgeons, or average-sized dace and roach. It is suitable when you spin for large fish, be they salmon, trout as large as salmon, or pike as large as either.

As I have-already said, I am not partial to those many-hooked spinning tackle, and I dislike 
them, especially for minnow-spinning, for trout weighing under two pounds. I can spin a minnow very prettily and very dangerously with a flight of only three hooks, that is, one double hook to remain at the vent, and one single lip-hook. I will use this flight with the apparatus numbered 2., or with that marked 3. in the cut. Either of the above apparatus having been passed into the body of the bait, I insert the loop of a link of gut, to which a double minnow-spinning hook is tied, in the eye of a baiting-needle, which I pass in at the vent, and through the stomach of the bait out at the mouth, drawing to the gut, until the double hook, arrested at its bend by the vent, stops there with its double barbs apart and pointing downwards. I take away the baitingneedle, and slipping down on my gut a moveable lip-hook, I pass it through the lips of the bait tightly to make taut the small portion of the gut that is in the interior of the bait, between the vent and the mouth, and I finally fix this gut-link that contains the bait thus armed to my swivel-trace. I have now a bait that swims well, with a double hook projecting on each side beneath the middle part of it, and as fish generally seize their prey by the middle, I do not see why you should not seize them with this double hook, if they once admit it within their mouths. However, as fish very often run short at the spinning- 
bait, and, as when they do, you cannot hook them by means of one double hook only at the vent, add a double fly-hook to lie along the bait towards the tail, and a little beyond it. I advise my young friends to use this latter tackls when they begin practising the art of spinning. They will find it very efficient, and it is very easily baited. The reason fly-hooks are of such general use in spinningis, that it is supposed from the run-away motion of the bait, fish of prey run after it and seize it tailways rather than middle-ways, and therefore are likely to be caught by the fly-hooks at the tail. I do not deem this reason very sound. Still let us adhere to fly-hooks as an additional, though not a very necessary weapon of success.

I have mentioned the trolling and spinning rods best suited, in my opinion, for angling for large fish. We should have an especial rod for minnow-spinning. It should not be so stout by any means as the usual trolling rods, but it should be longer. Fourteen feet is a fair average length. I would have this rod made of the best mottled cane in all its joints, except the top one, which should be of a good stiffish bit of hickory, or solid bamboo, tipped with a couple of inches of light whalebone. This rod should be ringed with moderate sized upright rings, and will answer, if well made, for bottom fishing with the worm or gentle, for dibbing or daping, and particularly for 
angling with a tripping bait, as well as for minnow or bleak spinning.

Mr. Blaine says, "The minnow-spinning rod requires length and strength, combined with lightness, which requisites appear best obtained by having it made of cane, except the last joint. It must be neither too flexible, nor too stubborn, as either extreme will impair its utility:-if too stiff, the hook or the hold will be endangered when striking; if too pliant, it will yield to the resistance of the water too much to allow a ready stroke to be made when a bite occurs, and the fish will escape ere the effect of the stroke reaches him. The first delivery of the minnow on the water should be delicately done, so as to raise no disturbance in it, either by noise or splash, which is managed by checking the impulsive swing just before the bait reaches its destination, at the same time dropping the hand as well as the point of the rod, which will thus check the bait, and lay it lightly on the water. This effected, begin to draw the bait slantingly across the stream, at various depths, with a certain degree of regularity, observing also to imitate the shootings of the living fish in its actions; and as Colonel Hawker, in the true spirit of a piscatory tactician, observes, 'if a fish comes after your minnow, never stop it, or in any way alter your pace, or he will most likely be off again directly.' More 
fish are lost by the nervous feeling, which shoots through the young angler when he perceives the first rush of a trout, or flinches from, or starts to it, than by any other course whatever. If nothing of this kind takes place, the trout sees no cause of alarm, and there need be no fear on the angler's part, but that he will himself strike the fish at the regular pace at which he attempted to overtake it; and that being done, it only remains for the fisher to fix the hook, or hooks, within its mouth by a smart stroke from the hand, if possible, in a direction contrary to the progress of the fish."

Colonel Hawker's spinning tackle, which is made by Mr. Bowness, late Chevalier, of No. 12. Bell-yard, Temple-bar, is an excellent one, having only one fault, viz. that young anglers will find it rather complicated, and difficult to place the bait neatly upon it. I can vouch for its spinning well, and killing well. Let it be made of a large size, and it will answer admirably for spinning with dace and roach for the largest species of predatory river fish. In introducing this spinning tackle the celebrated Colonel observes, "Trolling or spinning a minnow is a most general mode of trout fishing; or, I might almost say, trout poaching. It is, however, very rarely done in a proper manner, though every man, as a matter of course, upholds his own system. I, like all the rest, did 
COLONEL HAWKER'S SPINNING TACKLE. 209

the same, till after fancying for years that I could challenge any one, was beaten and laughed at by

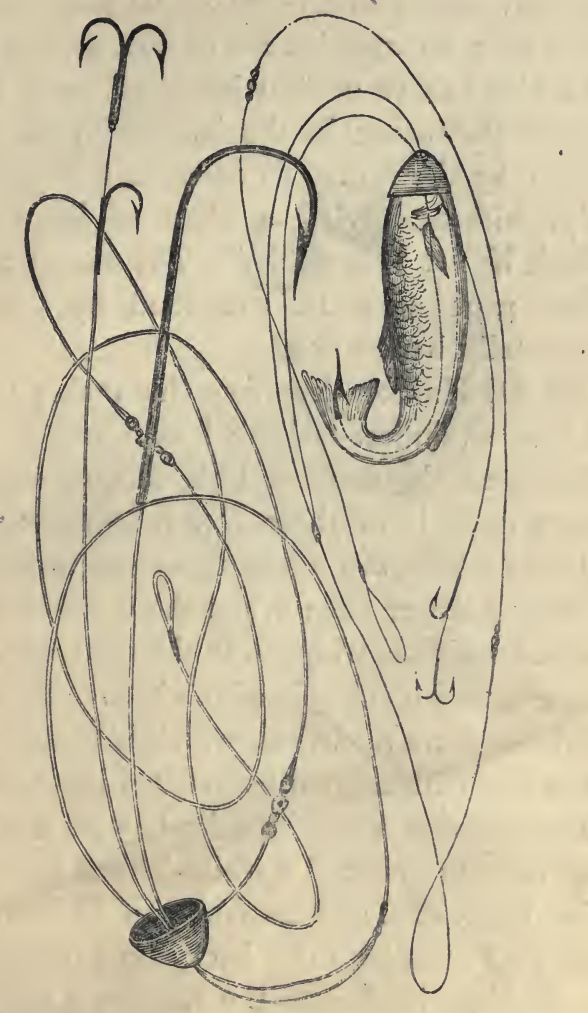

a trout-killing divine. Now, however, I have got master of his plan, against which all others that I had ever seen, read of, or heard of, had no 
chance whatever. The great advantage of it is, that it takes the trout when they run and bite short, by means of fly-hooks that play round the others on a separate branch of line, so that I have often killed three or four brace of trout without the minnow being in the least injured, or even touched by the fish. To describe the tackle properly, without giving a plate of it, would be difficult if not impossible." The cut in the preceding page must be examined by placing it horizontally before you.

Colonel Hawker describes this tackle thus:"A large minnow-trolling hook, size No. 1., is whipped to the shortest link of gut, and to the other a triangle of three No. 7. hooks, tied back to back, which are to hang about three inches below the larger one: when the minnow is on it, a second triangle, whipped to the same gut, should hang even with the side of the bait. These links altogether form a harness, which is to be attached to the line with a small box-swivel between them. The perforated snout-lead is, however, first put on. Having selected a white-bellied minnow, of rather small size, and hardening it in bran for an hour or two, first draw back the plummet, and put the large hook into the minnow's mouth and out through the right gill, taking care not to tear any part of the mouth of the bait: then draw the line three or four inches to you, so as to be able 
to get the hook back again into its mouth. Then take the minnow between the finger and thumb in the left hand, and the large hook in the right hand, and run the hook all down its back inside, close to the bone, to the very end of the fish, and let it come out about the centre of the tail-fin. Then with your right hand pull the minnow out as straight as it will lie, and press it into natural form with the finger and thumb. Afterwards, nip off the upper half of the tail-fin, in order to prevent a counter-action to the spinning of the minnow. Having done this, draw down your plummet (snout-lead) again, and see that your branch line falls smoothly by the side of your bait line; and if not, rub it with Indian rubber till it does. Your hook is then ready for action; and action, indeed it may be called, if properly done. I should observe, that new gut seldom spins the minnow so well as that which is half worn out (by reason of the stiffness which encircles the minnow's gill), therefore ten minutes' soaking in water, and sometimes a little hard friction of the gut, just above the large hook, may at first be required, besides the working of it with Indian rubber. So much for this plan: there may be many better; but all I can say is, that I have not yet seen one fit to be named with it." By studying the preceding cut and explanations of it, the 
intelligent learner will be able himself to make such a tackle and use it.

The following remarks on spinning by Captain Williamson are practically sound. He says, "The swivel-trace answers two purposes; it prevents your line from being wrenched, by the largest fish, into twists and snarls; and it causes your bait to play round, or, as it is called, to spin freely in the stream, whereby it imitates more closely the action of a live minnow, and prevents the hook, \&c. from being distinguished. The bait thus prepared, is called a spinning-bait, on account of the great rapidity with which it revolves, when properly played, especially when the current is strong. It is very tempting; and when large fish, disposed to feed are near, you may depend on success.

"If you have command of your water, and can carry your rod as you please, you should commence by casting your bait from you very gently, so as to alight in the stream without splashing more than a minnow would in one of its jumps. Then draw your rod in such direction as may cause the bait to cross the stream obliquely towards you. When near you, it should be conducted from you, in a similar manner, by an adverse tendency of the rod, carrying the bait now and then somewhat higher in the stream, and sometimes lower, so as to give ample range. The extent of your compass, in that respect, 
must be entirely subject to the breadth of the water, and to the depth at the side; whence, the length of your line being regulated, you will have fair reason to expect a bite. It is proper to remark, in this place, that the spinning-bait answers well, both in deep strong water, in which case, one or two shots above your swivel will be proper, to keep the bait down; or it will succeed in those very rapid shallows, called scours, which are to be found at the edges of all rivers in various parts, and which sometimes stretch across the beds of the rivers like banks, or what, in sea language, are termed bars.

"A good angler will make his bait spin in still water; but then the fish do not take it readily, because the line, in such cases, cannot be concealed from their view, and the perpetual, I may indeed say the violent, action it must maintain scares them. This is not the case in a strong current, which spins the bait when the line is long, and when the rod is very gradually moved, merely to direct the bait across the stream. With the spinning-bait you will catch salmon in all its varieties, trout, perch, and pike. Sometimes you will find a chub on your hook. This, however, is not the ordinary bait of that fish; but, when very hungry, it will snap at small fishes, and may, as I once experienced, be thus taken. Observe, that as all fish, in seizing a spinning-bait, direct 
their attacks towards its tail, viewing it as an object of pursuit, you need not be afraid of your trolling-hook being too long, so as to come out rather behind the vent, when it will do most execution. Many a very large trout has, however, been taken merely by the lip-hook. On such occasions . much skill is requisite. Every angler ought to make allowance for the possibility of such an attack, and to avoid all pulls and jerks, such as either might tear out the hook, or, by irritating the fish, cause him to make such efforts as would produce his liberation.

"Indeed, it is by keeping the utmost command over your own hand, and by avoiding that childish propensity, too prevalent in many, of getting an early sight, and of making the fish struggle and leap, that you will complete your purpose. In that quiet, temperate, and forbearing mode, which distinguishes the expert angler, much finer tackle may be used; whence your basket will be more readily filled, expecially with the more choice kinds of fish."

The above somewhat long extract should be carefully digested, for it contains several wholesome truths, and the last little paragraph of it embodies a valuable angling axiom or two.

It is supposed by some that large pike are caught less seldom by spinning than by trolling with the gorge--bait. If the supposition be true, 
it is because the latter bait is used more frequently than spinning in places where large pike lie, and not because the gorge-bait is the better bait on the whole. I prefer spinning even for the largest fish in wide, deep waters, clear of obstructions, for I know that by that method the largest pike are to be caught, besides the excellent chance of killing salmon, and large salmonidæ. The gorge-bait answers best in weedy waters, or in those in which there are hindrances to your spinning freely.

Be cautious how you bait your spinning-tackle. It is not an easy operation, and the portion of difficulty attached to it often deters persons from spinning. Practice will overcome partial difficulties, and even entire ones of far greater intricacy. Commence with the simplest sort of tackle, requiring but few hooks. A practical lesson from some old spinner will advance you more in the art of baiting than twenty written pages. You can spin your bait up or down stream, across or against it, in fact in any direction that the nature of the locality may render most convenient. The best way, however, is to spin against the current, for your bait moving in that direction will appear like a natural fish darting away up the stream, and trout having their heads pointed that way, when on the feed, will be 
the more inclined to rush after the bait. Generally speaking, it is not of vital importance which way you spin your bait so that you do it well. Take care not to spin too fast, by drawing in too rapidly too much line at each draw backwards of the left hand, or at each motion towards you of the rod. Spin steadily, just fast enough to make your bait revolve attractively, but not so fast as to make its speed greater than that of the fish that is pursuing it. Make it no difficult task for him to overtake your bait and seize it with facility. In spinning you must strike as soon as your bait is taken, with a short, quick, moderately strong jerk of the wrist.

The baits you use in spinning should be of the most brilliant colours. The brightest minnows, gudgeons, dace, roach you can procure. Smelts, on account of their silver brilliancy, make capital spinning baits; moderate-sized thick-set ones are the best. The hooks used in spinning should be of the bright steel-colour of the wire, not changed to the ordinary blue hue of hooks; and they should be whipped on with light-coloured silk, waxed with white wax.

The fish you intend for baits, provided you cannot keep them alive, having no bait-kettle or well in your boat to do so, should be killed immediately they are caught, and not be allowed to 
lie about any where until they die. If you suffer them so to lie about, they will lose a portion of their scales, and become less brilliant than they ought to be. Dead bait boxes are made something like sandwich-boxes, some not divided in the inside, and others divided into little compartments, to keep the baits separate, and so prevent speedy decomposition. If baits are put into bran the moment they are caught, they will soon die, preserve their scales and colour, and last good for two or three days. Baits may be kept longer by means of salt or sugar, but you must not have recourse to this mode of preservation unless on some extraordinary emergency.

Artificial Spinning-baits. - The tackle-shops are inundated with varieties of them. The most brilliant are the best. They will all kill fish more or less successfully; but the very best of them are inferior to the natural bait. When you cannot get that, you must make shift with the artificial substitute. The large brilliant ones will kill in deep lakes, the smaller ones in streams, and I fancy they are most useful when the water is beginning to clear after a flood. The archimedian minnow of Mr. F. Allies, of Worcester, is deservedly coming into repute, and, in my opinion, ought to rank first amongst artificial minnows. 
Let him make his archimedians larger (longer and deeper in the body), and if, when of an increased size, they spin as well as the smaller ones do now, I suspect that they may be found seductive of salmon, lake trout, and pike. Artificial fish-baits may be used successfully in sea-angling along shore. 


\section{CHAPTER VIII.}

ON BOTTOM-FISHING. - RODS, HOOKS, LINES, AND BAITS.

THE English are without doubt the best bottomfishers in the world, and the London anglers the most accomplished of all. We can account for this easily. English rivers are better stored than those of any other division of the empire, with the various sorts of fish which seek their food rather at the bottom than at the surface of the water. In the neighbourhood of London such rivers abound with their numerous angling clubs, subscription and preserved waters, and the easily-pleased (only perhaps with respect to his sports) character of the Saxon, be he of the country or city, leads him to indulge with infinite patience and pleasure in all the slow minutiæ of bottom-angling, when the inconvenience of distance renders fly-fishing out of the question. Even the fly-fisher from Ireland, Scotland, or Wales, settled in London, stoops from his high art, and, being a lover of nature in her water-side charms, betakes himself to bottomfishing, and partakes of its amusement in company with the joyous, good-hearted, and really philosophic cockney. In bottom-fishing, the persevering 
character of the Saxon is developed. He pursues it with that intensity of purpose, that guides him in his greater actions, and renders him capable of performing the highest. He prepares himself for a bottom-fishing campaign as carefully as if he were starting on a voyage of discovery. He neglects nothing that may tend to his success. The foxhunter and fowler laugh at the bottom-fisher, little suspecting that that very bottom-fisher watching his float so anxiously from his punt may be a firstrate horseman or shot, and that he has the wisdom of being satisfied with amusement at hand, waiting for that which at the present time is not. To be amused with harmless trifles in proper season is the acmé of practical happiness -

"When we cannot make love to the lips that we love, We can always make love to the lips that are near."

The fly-fisher will very readily become an expert bottom-fisher. He understands already the use of rod, line, winch, and hook in the most trying situations. He has a quick eye and a quick and light hand, and will easily apprehend all the arcana of bait-fishing. All he requires to know is the baits he must use, and a hint or two respecting the best manner of using them. He knows already the habits of the salmon family, he will soon learn the monotonous ones of the carp tribe, 
the different varieties of which form the principal prey the bait-fisher pursues.

The bottom-fisher's rod must be strong and light, not by any means so springy as that of the fly-fisher. It must taper stiffly, not be top heavy, and have just elasticity enough to strike his fish quickly without the delay too much elasticity in the top pieces would cause. It must be supple, so that pressure will equalise itself from top to butt. Though its pieces be not so fine or so limber as those of the fly-rod, it must taper with equal precision. The lengths of bottom-fishing rods differ very widely. Those that are used for bankfishing in wide rivers are sometimes twenty-four feet long; whilst those for angling from punts are frequently as short as ten feet. They also vary in strength according to the fish one angles for. The average length of a bank-rod should be seventeen feet, that of a punt or boat-rod twelve. In concluding the subject of bottom-fishing, I shall give a precise list of all the rods necessary for it, and for other modes of angling. With a good. general rod, having several tops, which you may shorten or lengthen as occasion requires, you may successfully bottom-angle for any species of river fish, roach, perhaps, excepted, which require a specific rod, to be described hereafter.

The bottom-lines for bait-fishing should be made of good gut, as fine as is consistent with 
strength, and it cannot be too fine for roach fishing. Roach lines, at least that portion of them next to the hook, are often made of single horse hair, but gut is better and can be had fully as fine. Foot-lines should be of the colour of the water, sometimes of a sandy hue for angling after a flood, but generally speaking a very light, transparent green is the best. They should be attached to good, prepared platted reel-lines, and should be knotted and leaded as neatly as possible to avoid catching in weeds or straws that may be swimming down with the current. Grains of shot of different sizes are commonly used for leading lines. I prefer thin strips of sheet-lead beaten to the thinness of writing paper. You can wind these thin, narrow bits of lead neatly round one or two of the last links of your foot-line, just above the knots or joinings, and it will be far less clumsy and less likely to entangle than when weighted with several shots. You can put on or undo the slips of lead more promptly and easily than shot, and you can carry them more conveniently. Always use a winch in bottom-fishing. It will prevent unequal strain upon your rod, enable you to play a fish properly, and you can shorten or lengthen your line with it according to your judgment with facility. It will enable you besides to angle with the shortest and finest footline possible. 
Hooks for bottom-fishing with worms should be long in the shank and perfectly round in the bend, with the barb and point not inclining inwards. On such hooks you can easily put your worms without injuring them. If your hooks are sneckbent you will feel a difficulty in threading your worm, and as you force it up you will often find the point of your bent hook penetrating through its sides, spoiling the bait in more ways than one, rendering it less lively, and liable to break even by the motion of the water. Hooks for gentles, greaves, paste and so forth, may be short in the shank, and sneck-bent, for they are more readily covered by the bait and will not let it slip off so easily as the straightly rounded hooks. All bait hooks should be whipped on as delicately as possible, with silk the colour of the bait you use, and waxed with almost colourless wax, at least not colour-giving, like shoe-maker's wax so very generally and improperly used. Hooks should be whipped on from towards the bend, and the whipping should be terminated by a couple of almost imperceptible slip-knots, leaving a little of the end of the shank bare. If the beginning of your whipping be rudely done, showing a commencement glaringly thicker than the wire of your hook, an obstruction will exist fatal to putting on your bait easily, and without injuring it, particularly if it be a worm. Allowing the slightest por- 
tion of the end of the shank to be exposed will prevent your bait from slipping below it and so exposing the whipping of your hook. In general hooks are whipped on too clumsily, with too many coils of the silk, and with the silk too fatly waxed. Bait hooks have commonly a few nicks made with a file or otherwise towards the ends of the shanks. The whipping need hardly extend beyond them at either end. The gut should be softened and thinned by drawing between the front teeth. I mean the small portion of it that is to be whipped on to the shank of the hook.

Floats should be of moderate size. There are thousands made ever so much too large and too heavy. I cannot fancy the use of them. Heavy floats may be used in barbel fishing, but are not absolutely necessary except when sinking and roving with a live bait for pike. In general I prefer cork floats to quill floats. The latter I never use except for roach fishing. A neat, smallsized cork float is handy, sits well in the water, and is sufficiently light to give you instantaneous information of a bite. For my own part I frequently fish without a float at all, with a lightly leaded line, and seldom miss striking at a bite. The best bottom-fishers fish for trout, grayling, perch, dace, and even for roach, with a tripping bait without a float. They are quick and sensitive enough to see and feel a bite without the 
eaves-dropping of a float. A float, however, is a safe appendage and to be surely relied upon. Notwithstanding, I advise the learner to angle frequently without one, and to depend on the sharpness of his eye and the sensitiveness of his hand. If he does, he will be always áble to angle with a very light float - an immense advantage and to distinguish the slightest fish-pull upon it. Never allow your float to drag in the water. It should sit perpendicularly in it, and the line should rise straight up from it to the point of the rod, which should hang, whenever it is possible, right over it. The advice in the last sentence is important. Neglect it, and you will seldom strike successfully. I have been in the habit of seeing persons angling with their floats slanting in the water, or lying loosely upon it, with the line slack or coiled, and of course I used to see them miss seven out of every ten fish they struck at. Their baits would be frequently nibbled off without their being conscious of it at the time.

In bottom-fishing you must strike promptly with a sharp jerk of the wrist towards you, inclining your hand generally a little to the right. If you miss your fish and find that in striking you have jerked your bait out of the water, conclude that you have struck with unnecessary force, injuring and loosening thereby the bait on your hook, and causing more pother in the water than 
fish are used to. Moderate your dangerous strength, and strike so as to lift the bait upwards only a few inches. You need not be a bit afraid, if your stroke is quick enough, that it is too weak to hold your fish firmly. Striking strongly is a great defect, a displeasing one, except to fishing-tackle makers, who thereby get an increase of business in making and repairing. Rods are broken through it, lines and hooks carried away, and fish lost and uselessly tormented and rendered shy.

Your rods and lines for bottom-fishing being less delicate than those used in fly-fishing, you may frequently after a very short struggle lift your fish out of the water. In many instances, particularly when you alight upon a shoal of small-sized fish, you should give as little play as possible, bringing your fish at once to the surface of the water and out of it with all dispatch. Barbel and large chub should be allowed to sink and run moderately, and should not be pulled at fiercely at first, under a pretty tight bearingrein, just sufficiently so to prevent them carrying their noses whithersoever they fancy, and when you feel their obstinacy becoming lax, present the butt-end of your rod to them, and try their strength under a shortened and taut line. If you feel there is danger in bearing so hard, relax the strain on your tackle, and indulge your captive with a 
short swim or two. The weight of the line he will have to drag will clog his movements, and as soon as you begin to bear on him again you will see him turn his head round towards you, beating the water with languid fins that are fast losing their propelling powers. Thus exhausted, bring his head above water, and down into your landing net with proper economy of time. In fishing with a single hair-line you must always cautiously play your fish, very small though he may be. But when with such a line you hook a monster fish, giant barbel, or chub or carp or perch, you must play him with all the careful address and ingenuity of the fly-fisher. An event of this sort will fill you with excitement, charged to the brim with doubt, pleasant suspense and fear; and if by the suaviter in modo you succeed, and you cannot succeed on any other tack, you can commemorate your success with a finny mummy in a glass case with this glorious inscription: "Barbel, weight $12 \mathrm{lbs}$, caught with a roach single hair-line, at Sunbury, July, 1847, by . . . . . ." Some sceptic may doubt the truth of this immortalising label, but I should not, knowing well what immense weights art can pull up, and what immense strength it can pull down. In fishing for perch your tackle should be strong, for he is a bold biter, and not to be scared away by a stout gut-line; hence playing him will not be very advisable. You should 
raise him on land promptly, and not allow him to dart about under water like a mad thing, else he will give the word to his mates, and cause them to disperse as diversely and as rapidly as the seizure of one out of the gang of young pickpockets by the police causes the dispersion of the remainder of the shoal.

If you fish with a float you must exactly plumb the depth of the water, in order that you may know on what part of your line you are to fix the float. For barbel, terich, and gudgeons, you must fish close to the bottom; and for the generality of other fish of the carp tribe, from three to six inches from it. When the plummet sinks the float so that the upper tip is even with the surface of the water, you have the exact depth. Withdraw your plummet, and move the float downwards on your line, as many inches as you wish your hook and bait should be from the bottom of the water. Fasten your float properly by the usual means, and see that it stands in the water clear of any obstruction to its yielding to the slightest nibble. Green, dark yellow, or brown are the best colours for floats.

BotTom-Fishing BAIts. - Worms are the most general baits, and, except at certain seasons, the best of all. No river fish will refuse them. They are decidedly the best baits in spring, and at all times when the waters are clearing after a 
fall of rain. I will classify them for the purposes of angling.

The dew or lob-worm is the largest used by anglers, and the best bottom bait for large river fish. Salmon, trout, barbel, chub, tench, perch, and eels take it freely. It is sometimes found weighing about an ounce, and extending itself nearly twelve inches. The middle-sized are, however, the best, and two of the smaller-sized placed on the hook at the same time form a most attractive bait. Mr. Blaine says, "The hinder extremity tapers more than the fore, except in that variety called the squirrel-tail, when it expands into a flattened surface, and is marked by a red stripe. The colour is a dusky red, the head more intensely red. The enlarged rings or knobs, observed in some, are not symptoms of age, as has been supposed, but are sometimes occasioned by wounds, or by accidental stoppages of the circulating juices, and may be always brought on by suffering them to become unhealthy. In some places the squirrel-tailed variety is preferred for angling, and the vicinity of the Thames is an instance, where they are eagerly sought after as baits for barbel." Dew-worms come out in pairs by thousands, in fields and meadows after sunset, when there is a fall of rain or heavy dew, and disappear into their holes about sunrise, when the dew is dried up by the coming heat of day. 
The early bird catches the worm, and so does the early angler. By night they are sought after by the light of a lantern. They may be dug out of moist mould, and out of the moist bottoms of ditches. In dry weather their retreat is deep, and you must dig deeply for them. If you place a quantity of wet straw on the surface of the ground, they will come out in a day or two. It is said that water in which walnuts, or their green shells, have been steeped, poured upon the ground, will immediately bring the worms to the surface. Digging for them, and getting them by night, by means of a lantern, or early in the morning by the light of one's own eyes, is the best and most natural way. With respect to the preservation of dew-worms Captain Williamson truly says, "It is much the same as that of other worms, namely, to be kept in moist moss, changed every three or four days, and set by in unglazed earthern pots, in a cool place during hot weather. That kind of moss is best which is found on commons, and which is crisp, and of a greenish white colour. It cannot be too soft and elastic, but should be carefully searched whilst washing, before it is put to the worms, so that all thorns and rough substances may be removed, else the worms will not thrive so well. Those who can supply a little cream every day, to be mixed in or thrown upon the surface of the moss-pans, will obtain a 
decided superiority in the condition of their baits, which will purge from all impurity, and become beautifully bright and pellucid. The pan should be large, or the worms will not live, whereas, when they have good room, clean, moist moss, and delicate handling, they will go on from year to year." Not so long, in my opinion, without a layer of nice moist earth at the bottom of the pan or wooden tub. The worms should be frequently examined, and the weak and sickly ones extracted and thrown away.

The following remarks touching worms by Mr. Blaine are interesting and important. Take notice that he advises that the substances you place them in for preservation should not be too moist, and he gives you excellent reasons. He says, "All earth-worms are found to be more alluring to fish after they have undergone an artificial method of treatment, the knowledge of which, therefore, becomes important to the angler. In large and much-fished rivers (and what large English rivers are not much fished in these days?) the inhabitants, like those of cultivated and luxurious cities, become satiated with common food. In the Thames, the Lea, the Severn, and the Wye, \&c., but particularly the two former, waggon loads of bait are annually added to the usual alimentary products of the river; thus the well-fed fish require to have their appetites pam- 
pered as much as the accomplished epicure, who looks with apathy on the meat of the shambles, but brightens at the prospect of turtle and venison; so the oft-fed fish require that the worm be cleansed of all dross, and that its dyes be heightened by artificial scourings, thus proving, that although the voracious cod, to allay the cravings of his stomach, will swallow the plumb-lead instead of the bait, yet that in matters of mere taste fish are not without a decided preference as to the nature and state of their food. Worms are extremely voracious, and consume vast quantities of both animal and vegetable substances; for they, like ourselves, are omnivorous. Vegetable matter they gain from the surface of the earth; animal matter is received by taking in earth itself, which is saturated with animal matter, living and dead. When worms are first taken they are usually gross with intestinal matter, and soft by the increased secretions of their bodies. By purging them from the earth they contain they are rendered more bright, and on being cleansed from all fæculances they prove much more palatable to the fish. As this process of cleansing promotes absorption of superfluous moisture, they also become thereby firm, or, as it is termed, tough, which is of much consequence to the fisherman, since in this state they are more readily put on the hook and retained on it. 
"The process of worm-scouring is somewhat mechanical. It must be obvious that by insinuating themselves, in their attempts to escape, between the fibrous parts of hard vegetable substances, they compress all excrementitious matter out of their bodies. Sound moss is the best scourer, as being a matter that is in a state midway between dry and moist. If the scouring matter, whatever it is, be too moist, their breathing pores are stopped up; and if too dry, the same effect follows from the orifices losing their dilatibility.

" Having carefully freed a quantity of such moss from grass, \&c., but particularly from thorns, moisten it, and put in a sufficient quantity with the worms, which, in three or four days, will be properly scoured, appearing then bright and more active than when first taken. They should, during their scouring, be examined daily, and those which are injured and diseased ought to be carefully separated from the rest, or all will participate in such injury or disease. Some anglers hastily scour their lob-worms by plunging them into water for a few hours, and placing them in moss afterwards.

"To preserve worms for use. - Shred some hard fat, without a particle of salt in it, suet is the best, and mutton kidney suet best of all. Having chopped it into small pieces, and 
thrown it into a saucepan containing about a quart of water, let it boil slowly, until the suet is dissolved; and then having ready some wellwashed hempen sacking or wrapper, that has not enveloped any thing noxious, dip it into the liquor. When well soaked in it, and having become cold, then mix some fresh mould with the worms, and put the whole into a deep earthen vessel, or tub, the latter is preferable. Into this pour in a good stock of lob or marsh worms, or any sort of red earth worms, and over the top tie a linen cloth that will admit air, and yet prevent their escaping. Place them in a cool situation, and the worms will feed and cleanse themselves, and keep lively and fit for use for many months. We would observe, however, that if the angler have different species of worms, let him keep them in separate vessels, so that at any time he may select the sort and quantity necessary, to be placed in moss preparatory to his using them."

The blue-head is a worm that I have found to be scarce in England. I found one this day (Nov. 18. 1846) in one of the paths in the Green Park, small-sized, but lively and of a most tempting colour. In my opinion it is the best of all worms for the salmon tribe, and would be taken freely by the larger species of the carp tribe. It is sometimes four inches long, but frequently found much shorter. The head is of a shining blue, the rest 
of the body, but particularly the under part, is of a light cream-colour, transparent almost to the tail. It is without knobs, and the skin on the belly side feels sharply rough to the fingers. It readily scours in moss, becomes tough, lively, and long-lived. It is one of the most lasting worms in the water I know of. When the water is discoloured by a flood, it is the best of all trout baits, and should be used on a tripping line without a float. Spun in clear water by means of a swivel or two on the foot-line, few fish will pass it by. It is to be found in rich garden mould, about the roots of esculent plants. It is not to be found, like the lob-worm, in heavy, damp soils. I strongly recommend it.

Brandlings are capital worms, perhaps the best of all for fish under a pound weight. They require very little scouring, and are almost without it tough and lively. They do not run large, and I advise two at a time on the hook if you wish to catch good-sized fish. Captain Williamson's opinion of this worm is correct. "It is," he says, " with most fish the object of choice. They are to be found in various places, more or less, but in greatest abundance among rotten tan, or in heaps of manure composed chiefly of sweepings from cow-houses and swine's muck. They rarely exceed three inches in length, and may be readily distinguished by their annular appearance, they being 
marked in very narrow rings of strong red and yellow, alternately, for their whole length. They, besides, seem to be of a distinct class, as they do not, when pressed, void an earthy substance; but, when wounded, exude a very strongly scented yellowish liquor. Nor does the circumstance of keeping them in moss create any change, except that of rendering them beautifully transparent and, if any thing, more lively. They are an admirable bait, and may be used without any preparation or scouring." Other authors do not praise them so highly ; but I think Captain Williamson's praise is deserved.

Blood or red worms. - These worms run very small, and are to be found in dung heaps of long standing where the dung and soil meet. Those found in tan heaps are the best, because they are the toughest and liveliest and require least scouring. They are also found in the sides of ditches, and in most light and moist soils. They are a delicate worm, and require light handling. Being small, the hook must be small-sized and very light in the wire. They are a good bait for carp and small perch, and the best of all baits for gudgeons.

Marsh-worms are very well known in London, and far too highly prized. They cannot be well preserved, require a deal of cleansing, and are, after all, a brittle, and, when but a short time in the water, a lifeless bait. In truth, they are only 
fit for ground-bait, and should never be used on the hook when any of the foregoing worms can be procured.

The tag-tail, called by some the turnip-worm, is a small-sized one, red about the head, and yellow towards the tail. Generally speaking, it is not a good worm. It answers best in spring, and when the water is a little discoloured by rain. They are easily found about turnips, potatoes, cabbages, and in any strong, clayey cultivated soil. They may be used as soon as found, and that is their chief recommendation.

The water-worm is a good general bait. Captain Williamson speaks very favourably of it, saying, "It is an admirable bait, and is ready for use as soon as taken, being beautifully clear, lively, and of an excellent medium size for most kinds of fishes. It is of a clear bluish white, or, occasionally; of a very light purple, growing more red about the head. By turning up the long slimy moss which grows on weirs, \&c., over which the water does not always run, especially when the mill is going, and which is rarely covered more than one or two inches deep by the passing water, this kind of worm may often be found in great numbers Fish seize it with avidity; no doubt, from being more habituated to it, by the quantity which, when the rivers are much raised by rains, \&rc., is washed out of the moss into the falls 
below, where generally the largest and boldest fish are to be found." This worm deteriorates by being kept in moss or in any other substance.

There are many other sorts of worms recommended by angling authorities, but I recommend none of them, except as a pis-aller. Some anglers use white slugs, and the black ones so cut as to show their white insides, and say they are good baits for barbel, chub, and eels. Never use them when you can get worms.

Having now described the best worms for angling, I must tell how they are best put upon the hook. Make the points of your fore-fingers and thumb rough by dipping them in sand, bran, or rubbing between them some dry earth, and you will obtain a light and firm hold of the worm, which will prevent it from slipping through your fingers as you bait your hook with it. With wet or moist slippery fingers you can never put on your hook properly, and in attempting so to do it you lose much time and injure the bait.

In baiting with a single worm, insert the point of your hook just beneath the flat part of the head, and work the worm lightly up the shank of the hook and beyond it up your line, until not more than a quarter of an inch of the tail, or at most half an inch, when the worm and hook are large, projects or hangs beyond the point of the hook. When you use well-scoured and tough 
worms, if they are large lob or blue-heads, you may leave a third part of the worm beyond the point of the hook, as you will thus afford it more room to wriggle and appear more lively in the water. The tails of small worms should scarcely project beyond the point of your hook. In putting on the worm hold the hook, its point downwards, between the up-lifted ends of your left fore-finger and thumb, and take the worm by the back of the neck, as it were, by the same fingers of the right hand, and when you have got the. head of the bait up the shank beyond the bend of the hook you may draw it gently further with the left fingers, pushing the worm on at the same time with the right hand fingers. Take care not to perforate, after the first perforation, the body of the worm with the point or barb of the hook. Never try to get the worm on by, so to speak, stitches. Endeavour as much as you can to make the tail of the worm fall inside the barb of the hook, and not on the outside of the point. If it hangs on the outside the hook will soon penetrate the upper part of it, and the point being exposed the fish will either refuse the bait altogether, or nibble off the part that is hanging partly dissevered and clear of the hook. In fishing for carp, dace, and gudgeons, use a small showy, lively worm, drawn up on the hook, the tail almost to the very point. 
When worms are small, say of the average size of brandlings, I prefer two on the hook at the same time, a larger and a smaller one. I put on the larger one first, and when I have got it half on my hook, I pass the point and barb through it, and draw it delicately up the shank on to my gut or hair. I then take the lesser worm, one just of such size that when I bring its head to the end of the shank of the hook the tail may hang but very little, more or less according to size, beyond the hook's point. I next draw down the upper worm until the perforated part of it comes in contact with the lower worm, and I allow the tails of both to meet, and, if possible, to entwine withinside the bend of the hook. Worms put on well in this way are most attractive baits, and, believe me, that salmon and large trout will greedily take two large blue-heads well scoured and adjusted on the hook in the way just described. Let such a bait roll along the stream about a foot from the bottom, and, provided salmon or trout be there, you will find it stopped by one or other of them.

Some authorities put on the double worm differently. The larger or upper worm they put on as I advise, but the smaller or lower worm in another way, viz., with its head towards the point of the hook, and its tail upwards to meet that of the larger worm. I really cannot see any material 
distinction-it is six to one and half a dozen to the other.

As I like to give the opinions of others on important parts of angling, whether they agree with my own or not, in order that the reader may have a choice, I shall here cite, with respect to putting worms on hooks, two experienced authorities. The first is Mr. Blaine, who says, "When one worm only is used, enter the point of the hook at the top of its head, and carefully draw or squeeze its body round the bend, and over the whipping, by means of the finger and thumb of one hand, while the fore-finger and thumb of the other are employed in pressing the hook onwards, until less than half an inch only of the tail part is left, which should be directed within the curve of the bend. If too much of the worm be left unattached it entices the fish to suck at that, and teases the angler with continual nibbles; till at length, on raising his hook, he finds this portion gone, and the point of the hook exposed. To the careless angler this happens continually. If too little be left, there does not remain enough to attract the fish by the motion in the worm. It had always been our own practice to attempt to direct the projecting portion of the worm within the bend, and one of our first lessons in wormfishing was never to let the tail project outwards from the point of the hook, that the fish might 
not rip the bait away, so as to bare the hook down to the bottom of the bend.

"To bait with two worms is the most alluring practice of any for the voracious tribes, as trout, perch, and eels; whilst one worm, on the contrary, well put on the hook, unless the worms be very small, is perhaps best for roach, dace, and gudgeon. In baiting with two worms, proceed to place the first as already directed, but allow it to remain above the arming until the second worm is penetrated by the hook, not at the head but near the tail, threading it up, and turning a small portion only of its head within the bend of the hook. Lastly, draw down the first worm to meet the second."

I beg the reader's attention to the following paragraph from "The Encyclopædia of Rural Sports." The author, Mr. Blaine, says, "In baiting with the dew or lob-worm, enter the point of the hook a very little below the head, and carry it to within half an inch of the tail, burying the whole of the hook within the worm. We have, when the worm has been unusually large (which is a very tempting bait either for salmon or large barbel), passed out the hook a little short of the centre of its length, and have again entered it about an inch below, and carried it along the remainder of the hook, leaving the folded portion pendent. Though the barbel has by no means a 
large mouth, yet by sucking it can take in a very large worm, and we believe that the general result of barbel-fishing shows that they are particularly enticed by a large bait; perhaps we may also include the salmon with the barbel in this respect. A very long worm is not, however, a desirable bait for any other fish, unless it be very thin, when it may be put on as directed above. In all other cases a worm whose length exceeds the linear measurement of the whole hook rather more than one half, is the most convenient for baiting, and the best for expedition. For, as in our opinion, fish never willingly take dead worms, so when one is exhibited to them crumpled up and wrinkled, or torn or crushed, we suspect it is refused because it is dead. It ought, therefore, to be the aim of every worm-fisher to show his worm lively, by allowing it some motion, and to exhibit it as healthy also, by avoiding to tear or unnécessarily pierce it; yet it should be kept so compact to the hook, that the fish shall not take any of the former without taking also the whole of the latter."

In order strongly to impress the young angler with the necessity of baiting his hook carefully, Captain Williamson observes: "I have frequently remarked the effects of doubt and of apprehension in fishes of various descriptions, when any part of my hook has been bare. They have come to it 
in a balancing manner, and either shied off or retreated, tail foremost, or they appeared to be smelling to the bait, and throwing up bubbles of air to the surface. This may be a thousand times witnessed in clear waters, where all their motions are perceptible. I have in general found it to be a very bad omen. Fishes rarely discharge air in this manner, except when in fear, or in difficulty, or when in the humour not to bite. If the worm is properly threaded on the hook, so as completely to envelope it, and to have the tail about an inch pendent, lapping over into the bend, few hungry fish will reject it. In this mode of putting on the bait, less opportunity is given for tugging at any part, while it is greatly in favour of hooking any fish that may bite fairly. As a single worm is the more certain bait, so is a double bait, consisting of two worms, more alluring, especially to all the ravenous tribe; therefore, for such it is particularly eligible. It is applied thus: put the hook into the mouth of the largest of two worms, and thread it for about a third its length; then bring out the point of the hook, and slide the worm up, so as to be kept above the bend, and with its tail hanging down in a line with the shank. Then thread the smaller worm, which should be particularly clear and high coloured, until its head comes up the shank a little above the turn of the bend, and is overlapped by the 
tail of the first worm, so that no part of the hook can be seen. Be sure to bring the second worm well on, and before you throw in (which should always be done as gently as possible, letting your line down quietly into the water up to the float), turn its tail in, so as to hang down between the point and the shank."

I have been minute in pointing out the best angling worms, and how they are to be put upon hooks, and I have quoted authorities partly for and partly against my own judgment, in order that the learner may have an opportunity of "trying conclusions," as Papa Walton says, and want no sort of information touching wormfishing, which upon the whole is the best and most general way of angling at or near the bottom, and frequently answers well at midwater, and at night even on the surface. Worms of some kind or other are taken by fish in every clime, in fresh water and in salt water, and they afford the angler a never-failing resource. $\mathrm{He}$ who knows how to angle with them has a sporting relaxation ever at hand, and he who can bait a hook with a worm for a gudgeon, can bait one with other baits, be they pieces of fish, of meat, small animals, or any other likely lure, for herrings, mackerel, whiting, cod, or monster shark. By river or sea-side he can amuse himself, and he can break in upon the monotony of an ocean 
voyage by angling from the ship's stern for those fish which swim in its wake.

On days when the salmon tribe will refuse the artificial $\mathrm{fly}$, they will act differently towards the worm, but you must angle for that species of fish with careful neatness, with a fine gut-line, delicately leaded, and without the incumbrance of a float. A lively worm dropped in rapids, eddies, mill-tails, worked artistically with the water, and ever and anon spinning it against it by means of a swivel-trace will rarely fail in affording diversion. After nightfall in summer, worms, trolled upon the surface of the water, will be taken by large trout.

Gentles, or maggots, come next after worms as a good bottom-bait. They suit the summer and autumn months best, and most fish will take them. They are bad baits for gudgeon, perch, pike, eels, and, indeed, for most sorts of fish that prey upon other fish. I have observed that in some parts of the Thames they are not so good a bait as worms, and that in other parts of that river they are better. Wherever the puntmen ground-bait constantly with worms, there the worm will prove the best bait. On the contrary, where gentles are the constant ground-bait used, they will be found the best angling bait. Fish become habituated to either of these baits, according to the frequency of their finding them in 
the water. For instance, the puntmen at Sunbury on Thames usually throw in worms as their ground-bait for barbel, and in consequence that fish takes the worm there more freely than it does the gentle. At Teddington the fishermen ground-bait with gentles, and therefore angle most successfully with them. In fishing for large barbel with gentles, you should put as many on your hook at a time as you possibly can. Half a dozen would not be too many. For small fish t.wo gentles at once on the hook are sufficient. Mr. Blaine says, "Unless the hook be very small, two, or even three gentles, are requisite on it at one time. With three insert the point of the hook into one gentle close to the head, or more bulbous end, and bring it out near the tail : now take a thin green gentle, and pass the point directly across the body, and then put on the third exactly as the first, except that, having just shown the point of the hook through the skin of the gentle, retract it again. For the latter hint we are indebted to Mr. Salter, and a very good one it is ; for, as he justly observes, the skin of the gentle being somewhat tough (especially in cold weather), by piercing the skin in the first instance an opening is made, by which the finest stroke (when a bite does occur) will enter the hook sufficiently into the fish to secure it, and you do not risk breaking your line or the top of 
your rod, by striking too hard. One gentle on a No. 10 or 11 hook will often succeed when more are refused, and the fish shy."

In angling with two gentles, insert the point of the hook by the head of one, and pass it out near the tail. Insert the point of the hook near the tail of the second gentle, and push it up the hook to meet the tail of the other gentle. The hook should be inserted as close inside the skins of the gentles as possible. The point of the hook is to meet the skin of the second gentle close inside its head. Gentle hooks should be made of very fine wire.

Towards the middle of the day when fish are rising at insects on the surface of the water, a gentle placed on the point and bend of a hook on which a red-winged artificial fly is dressed will be found a killing bait, especially for chub, dace, and roach. The straw-bait used in the same way will kill trout and grayling well. Mr. Blaine observes, - "The angler will sometimes find, while he is roach and dace fishing, that as the day advances towards its meridian, the roach and dace he may have been hitherto taking with success, will gradually leave off biting, and from the bottom will show themselves above, the dace at mid-water, and the roach but a little below the surface. This circumstance will afford him an amusing opportunity of varying his practice by mounting on a 
gentle-hook, No. 8, or 9., a pair of wings. A very slight ginger hackle-feather is the best for the purpose. After it is on, cover the remainder of the hook with a tough, well-scoured gentle. Whip with this, but not violently, and the dace will rise eagerly at it. It is more than probable that the roach will take it best when it is sunk some inches, or even a foot or more below the surface."

The above bait can be well imitated artificially. Tie on delicately a pair of wings from the landrail's reddest feather, and imitate the gentle by a body made of a little strip of bright yellow very fine wash leather. This bait will last as long as any artificial fly, and may be cast upon the water in the same way, using it as a stretcher in conjunction with two drop flies. If dressed large it will kill large chub, and towards evening in the summer season may tempt large Thames trout.

Gentles are a summer and autumn bait. The bottom-line in fishing with them should be fine, and they should be handled delicately. On fine mild winter month days they are a good bait for roach and grayling.

Gentles in London can be cheaply procured at the fishing-tackle shops, elsewhere, and by other means. You can get them of large size, and in great abundance at the manufactories of tallowchandlers and fell-mongers. You can even produce them for yourself. " Hang," says Captain 
Williamson, "a piece of ox-liver on a hook in a shady place, cut it deeply across and across in various places on both sides; then cover it over lightly with small boughs, cabbage leaves, or any thing that will shelter the flies, whilst they visit it to feed and to lay their eggs. In a few days innumerable fly-blows will be seen among the scarifications, when the liver should be taken down, and laid in an earthen pan, about half filled with sand and bran in equal quantities, somewhat moistened. As the gentles acquire strength, they will quit the liver, and bury themselves in the sand, from which they may be taken as occasion requires, when they will have scoured themselves, and be fit to handle. The same liver will produce several stocks, or successions of gentles, if properly managed. The largest will proceed from the bluebottle and gad-flies which attack livers with great eagerness. From a dead cat, and indeed from a rat, I have had such quantities of large gentles, as kept me in stock for full six weeks." A sheep's head, an old fowl, and the useless bodies of several small animals kept in a moist, sultry place, will soon produce gentles. Gentles are scoured and rendered tough by keeping them for three or four days in a mixture of sand, bran, and meal.

When you have procured gentles, you must endeavour to prevent them from turning or changing into the chrysalis state. You will do so 
best by keeping them in a cool place in a roomy vessel furnished with wet sand. Exposure to the sun's heat soon spoils them. Mr. Blaine says, "6 When the angler takes gentles with him for several days' use, he should inclose them in a wide tin with wet sand, and place them with every advantage of being kept as cool as possible; if he can lower the vessel down a well, to within a few yards of the water, his end will be fully gained. Some of the gentles may be previously separated from the rest, and placed in bran, or in oatmeal, for immediate use. When a pretty long expedition is meditated, as one of two or three weeks, the gentles selected should be of two sorts, some fully evolved, and others green, as it is termed, that is, hardly full grown: two days' keeping in bran in a warm situation is sufficient scouring for the former? to the latter a thin slice of beef or mutton, or a small fish, may be put in the moistened sand. The ressel in which these are kept should, of course, be placed in a cool but not in such an intensely cold situation as the well; as the gentles from this store become full and plump, they may be removed to the other for scouring."

It is a common and well-founded opinion that barbel and chub prefer green gentles. Roach, dace, and bream like ripe well-scoured gentles best. Mr. Daniel, in his "Rural Sports," cau- 
tions anglers not to throw away gentles that are on the turn from one state to another. Dace and roach, he says, often prefer a turned and a fresh gentle put on the hook together. Gentles used in grayling fishing should be large, fresh, and well scoured.

Preserving gentles for the winter months.-On this subject Mr. Blaine writes with his usual sound sense, remarking that "in the neighbourhood of still and deep rivers the angler's winter roach fishing chiefly depends on gentles; and in the bends and deeps of the more rapid rivers which afford grayling, he is equally indebted to them for his principal sport and his largest fish. In September or October, the later the better, so that the parent fly is yet abroad, which will much depend on the season, (we have seen the flesh-fly active in the early part of November, allow either the carcass of a fowl or rabbit; a sheep's head, or a portion of liver, to be well blown. Procure a butter tub, or, in preference, a stout long elm box (our own was one foot wide, one foot and a half deep, and three feet long); into some such vessel put sifted mould moistened and mixed with dried and pulverised cow-dung. With this mixture half fill the box, and press it down very lightly. Put the carcass and the blown gentles together into it, strewing them over with some of the same compost: as the mass sinks, fill it up with the same, and press it at 
last moderately, as the gentles will sink to the bottom. This box may be then placed in any outdoor cool situation, and the mould at times be slightly moistened; or it may be buried a foot or two in the earth, if convenient, and will then require no moistening. The advantages we derived from a long box were, that we could turn up the earth in it at one end to procure the gentles we wanted, without admitting air or disturbing the whole mass. It is, of course, some trouble to uncover the box when buried, but in this case the trouble is amply repaid by the cleanliness of the process, for the earth prevents any effluvia from annoying the angler in removing the gentles, and once a fortnight will be sufficient to effect this. During the early winter months fresh supplies may be added to them, as they may be obtained from the holes and corners of fell-mongers' yards, the melting-houses of tallow-chandlers, or the killing-houses of the knackers in London, and at collar makers, huntsmen's lodges, \&c. in the country. All this trouble is only necessary for the country angler, as London anglers can usually supply themselves the year through with gentles from fishing-tackle shops, and also from the knacker's or horse-killer's, where some of the finest may be procured, although a prejudice exists against them when thus obtained, which is fostered by the regular venders, who affirm that 
they are only fit for ground-bait. This idea is indeed groundless, for when duly prepared these will be found for barbel singularly attractive, and for all other fish also they appear nearly, if not quite, equal to those procured from any other source. Of the value of gentles as a bait but one opinion we believe exists, or we should not have dwelt so long on them; neither are they a mere local bait. In all the districts we have travelled through they are highly prized for all wintertaking fish, roach, dace, and grayling especially."

The gentles got at the knackers' are generally called carrion gentles, and their proper use is for ground-bait. They are nasty things to handle, and are never so good for hook-baits as the gentles produced by putrefying liver. When used for ground-bait they attract fish to the locality, but fish easily distinguish the nice, clear, well scoured gentle on your hook from them, and will take it in preference. They are a great nuiśance to carry, as they will eat their way through the stoutest bags, and crawl about in every direction. A bag of them in a railway carriage will furnish very pleasant travelling companions.

The caddis, or straw-bait. - I have a better opinion of this bait than the generality of anglers have. I have killed a great many trout with it, particularly by placing it on the hook in conjunction with an artificial fly. Though the gentle 
may be a better bait in large rivers for coarse fish of the carp tribe, it is not so good a bait in the gentle streams and pools of small trout and grayling rivers as the cad or straw-bait. These baits are the grubs or larvæ of several of the angler's best flies. No angling authority writes about them more sensibly than Captain Williamson, who says, "They are very fine baits for several kinds of river fish. The angler must have seen in shallow places, chiefly on stony or slimy bottoms, short pieces of stick, or of straw, \&c., which, if observed attentively, will all appear to be animated. Generally, they consist of a short piece of straw, coated over with a brown crust, and fixed to a small piece of twig. Within the tube of straw is a maggot, of a dun colour, with a dark hear, which it protrudes from under its little dwelling, and, by means of four short stiff legs, fixed close under its neck, is enabled to crawl about the bottom, carrying,' like the snail, its house on its back. Where the water is too deep to reach the caddies with the hand, recourse should be had to a tin basting-ladle, which will scoop them out admirably, allowing the water to strain through the holes in its half cover. In some places caddies are prodigiously numerous, often covering the bottoms of the shallows, either in pools or at the edges of great waters, and clinging to growing or dead rushes, reeds, twigs, \&c. Although they 
may be used quite fresh, it is not, however, advisable to employ them until they may have been kept about ten days, or even a fortnight, in an old worsted stocking, or in a woollen bag, which should be dipped daily once or twice into water. At the expiration of such period, the generality of the caddies will have quitted their tubes, and have become tough, having changed into a rich yellow colour, in which state they are a very alluring bait. If kept too long, they all turn to various kinds of water-flies. In applying this bait, the point of the hook should enter close under the head, and be brought out at its other end if two are used. When a very small hook is used one caddis may answer, and then the hook must not be brought out at its end, but the point must rest just inside the end of the bait. In general two will be found best; it being indispensably necessary to cover every part of the hook. In the latter case the first caddis should be carried round, so as to conceal all the shank, while the other fills the bend, and conceals the point. Caddies are in season only during the summer months; they generally make their first appearance in May, and by the end of June are most numerous." I think the best straw-baits are to be found under stones in running streams. Mr. Blaine, after examining several authorities respecting the merits or demerits of this bait, 
says, "We may sum up these contradictory accounts, by adding the result of our own experience, which is, that in some small rivers with little run they will kill every kind of worm-taking fish at bottom. In large, rapid streams, particularly such as. run over limestone, they are but indifferent substitutes for gentles or worms. In the Trent they prove singularly attractive to fish [it must, then, be in the upper part of it, before it reaches Nottingham], as well as in all the streams of a similar size, which flow through clay and gravel around the metropolis. The regular caddisfishing commences in May and continues until June; after which time, however, other caddies continue to present themselves, but they are small."

An artificial caddis, very attractive on warm windy days, may be very easily made. Wings, full, and slanting a little over the body, to be made of any brown-red feather; body, long and tapering, of light yellow kid leather, with a few twists of brown silk over it, thicker at the shoulders and head.

Caterpillars as baits are too highly praised. Fish, it is true, will take them, but they are more trouble than they are worth. If you do not take the greatest caution in putting them on your hook, you will spoil them either by puncturing them too deeply, or by pressing them too hard. 
Either of these accidents will cause their internal matter to exude, and so spoil them. The best way of baiting with the caterpillar is that recommended by Mr. Blaine, who says, "In putting caterpillars on the hook some nicety is required. A bristled hook (a hook with a bit of hog's bristle projecting upwards from the shank to prevent the bait from flipping down) also is necessary, of No. 5, 6, or 7 size, according to circumstances, on which the caterpillar should be threaded, passing it up from the shoulders, leaving half an inch of the tail pendent : pass or thread another contrarywise, taking care to have the barb completely covered. Inspect the bait very frequently, and change it often. We have also daped successfully with a pair of brown wings on a hook No. 5, and with one caterpillar passed up the hook to meet the wings, where a retaining bristle dressed on the hook with them should be placed." Artificial palmers, well dressed, are much more handy, and very often kill better than the real caterpillar. The green caterpillar, or cabbage-grub, is a good bait for grayling.

Pastes have divided the opinions of the angling world, very uselessly in my opinion. Perfumed and variously coloured pastes, as a general rule, should be rejected by the wise angler. The simpler the paste the better: - sometimes made of nothing more than moistened bread-crumb, worked 
between clean fingers, coloured sometimes with a little vermilion, and for sharp running streams having a little raw cotton worked up with it to prevent its washing off the hook. This paste, variẹd as above, is the best general one, and when fish will not take it, wish them a good morning, or try the gentle or worm. In order that the learner may not be deprived of any chance resource, I will give him a list of several sorts of pastes.

Common bread paste is made either of new or stale bread, according to circumstances; and as those, in the opinion of the best bottom-fishers, are somewhat important to the success of different anglings, I shall detail them separately. New bread paste is made by intimately kneading together in the hands for a few minutes three fourths of new with one fourth of stale bread, without dipping in water. This working will bring it into a very glutinous adhesive paste. It is particularly fitted, therefore, for angling in strong eddies and powerful streams; but it does not apply so well to the finer fishings of roach and dace in moderate streams and still deeps, since it will not separate so readily from the hook in striking as the paste made from stale bread; and this peculiar property of separating to allow the easiest egress for the point of the hook when the 
angler strikes at a fish, the experienced roachfisher considers to be essential. In chub-fishing, on the contrary, it forms a valuable property in this paste, as a larger piece will adhere to a larger hook without being washed off as the brittle stale bread paste would be. It is also more useful than the latter paste for taking dace in the Thames, as well as the streamy parts of all other dace rivers. This paste is convenient from the quickness with which it is made at home, or by the river side.

Stale bread paste is made of bread one day, or at most only two days' old. In the latter case the bread should be taken from the centre of the loaf. First dip it momentarily in clean water, and instantly squeeze it as dry as possible; then placing it in the palm of one hand, bruise it with the knuckles and tops of the fingers of the other for about twenty minutes, when it will have arrived at the fitting consistence. It is well to observe, that as all bread pastes have a tendency to become quickly sour, particularly if wetted, it is advisable, should the angler have far to travel, that he carry the bread with him and make the paste by the river side, in order to prevent it from becoming hard or sour. This paste is the best winter bait for roach, and the best of pastes at all times for that fish, since you can fix it on the smallest sized hook, and its very little tenacity scarcely 
offers any obstruction to the point of the hook penetrating through it to the fish's mouth.

$A$ good coloured paste in imitation of salmon roe. - Knead flour and water well together, then wash both in a pailful of cold water, working them well in a mass without dividing it, until the fine parts of the flour are completely washed away; this may be known by its eeasing to whiten the water. What remains will be nearly gluten, and very viscous. Take a little vermilion in fine powder (the size of a large pea will colour a teacupful of the gluten), and rub the whole well together on a slab with a muller or flat knife. This paste will not be affected by the water, and may be preserved many weeks if kept immersed in cold water. If left exposed to the air, it dries rapidly; when taken out for use, it should be put into a wet bag.

This last paste is from a receipt of Captain Williamson, who remarks, like a true practical angler, "As to all other pastes made with oils, essences, \&c., they are useless; and the recipes for making them are mere catchpennies, inserted in various mean publications to swell their volume, and to give an air of mystery and science, that misleads and occasions disappointment." Very true: and those who allege that they possess secret baits, and angling nostrums, are as arrant quacks as any in the world. 
Sweet paste is made by working the crumb of bread with honey to a proper consistence. This is certainly a good paste, but I doubt very much that it is so on account of its sweetness. I have heard hundreds of anglers talk of the gusto with which fish have swallowed this paste, yet I have my doubts, as I do not think highly of the delicacy of piscine palates. The paste is very easily made, and should therefore be tried, especially as it is spoken favourably of by Blaine and Salter, who say, "that it is a most killing bait for carp during the months of July and August, and indeed as long afterwards as the fishing season lasts. As regards carp, this bait has a very peculiar claim on those anglers who cannot be at their posts early and late, where the carp-fisher ought to be in most cases. This paste obviates in some measure that necessity, as it is one of the few baits which carp will take in favourable weather even at mid-day. Chub may be taken by it sometimes very well, and roach will seldom refuse it."

In angling with this paste ground-bait with the meal ground-bait, which is the best of all in deep waters for carp, chub, roach, and dace. To make this ground-bait, cut a few thick slices of bread, and put them in a pan without the crust. Saturate well with water, and then squeeze the fluid out. Knead with equal quantities of fine bran and oatmeal, and work into tough balls. Drop one of 
these in from time to time near your float, and it will attract the above fish if any thing else will.

Adhesive paste may be made by boiling slowly for a considerable time the shavings and parings of white glove leather. In the glutinous fluid so produced knead as much stale bread crumb as is required to make a given quantity of tenacious paste. This composition will suit rapid waters.

Barbel paste, of a very tempting kind, may be made by soaking bread in the liquor from which greaves have been taken after macerating therein. The introduction of wool into the mass will be found useful, to prevent the current washing the paste away. By putting a small morsel of white greaves on the point of the hook, you will prevent its exposure whilst angling with this paste.

Salmon roe preserved, and salmon roe paste.Both these baits have a terrible reputation, so bad indeed, as to give him who uses them a poaching character. Fame is mendacious even in this instance. Salmon roe is sometimes a deadly bait, but is very far from being invariably so. Taking one month with another, the worm will beat it. I have myself, in previous writings, spoken too murderously of it. Longer experience causes me not to think it so very slaughtering. An angler, named Barker, more ancient than Walton, is the first authenticated discoverer of this bait, though it must have been known before his time 
that nearly all fresh-water fish devoured greedily the spawn of other fish, and very likely, under peculiar circumstances, their own ova. Barker's letter announcing his discovery to some noble patron of his is still extant. Being curious and instructive, I shall quote it: - "Noble Lord, - I have found an experience of late, which you may angle with and take great store of fish. First, it is the best bait for a trout that I have seen in all my time; and will take great store, and not fail if they be there. Secondly, it is a special bait for dace or dare, good for chubs or bottlin, or grayling. The bait is the roe of a salmon or trout: if it be a large trout, that the spawns be any thing great, you must angle for the trout with this as you angle with the brandling, taking a pair of scissors, and cut so much as a large hazel-hut, and bait your hook, so fall to your sport; there is no doubt of pleasure. If I had known it but twenty years ago, I would have gained a hundred pounds only with that bait. I am bound in duty to divulge it to your honour, and not to carry it to my grave with me. I do desire that men of quality should have it, that delight in that pleasure. The greedy angler will murmur at me, but for that I care not. For the angling for the scale-fish, they must angle either with cork or quill, plumbing their ground, and with feeding with the same bait, taking them asunder, that they may spread abroad, that the 
fish may feed and come to your place: there is no doubt of pleasure, angling with fine tackles or single hair-lines, at least five or six lengths long, a small hook with two or three spawns on. The bait will hold one week; if you keep it on any longer, you must hang it up to dry a little. When you go to your pleasure again, put the bait in a little water, it will come in kind again." From this letter we learn that salmon roe may be used as a bait by cutting it, whilst fresh, into wormshaped slips, which are to be threaded on the hook, and the place you fish at ground-baited by throwing in separated ova. Barker's method of preserving it is very simple, and will answer only for roe that is to be kept a short time. Whether you angle with fresh or preserved salmon roe, always ground-bait with a little of either. Salmon roe is a natural bait for trout and other fish that frequent the waters salmon breedin. In the depositing of the ova many are swept away by the current, and so become the natural prey of the other fish, inhabitants of the stream.

It is not easy to preserve salmon roe so as to keep the substance of which it is composed in a proper state of hardness or softness. Generally, with all our pains, it turns out too soft; rarely it becomes, except by gross blundering, too hard. When too soft, it melts away when used, and is then only fit to mix with bread crumb to make into paste. 
When too hard, some good still remains, for it can be softened by immersion in water, and, at any rate, will answer for ground-bait. The best roe for preservation is that which is the largest and got from the fish two or three weeks before spawning time. Roe that is smaller or not so near the season of depositing is only good for paste. Some persons preserve salmon roe by slowly drying it, without any salt at all. They pick away the membranous covering with great care, taking great pains not to cause any of the eggs to burst; they then press it between two boards, and preserve it by keeping it for some days between layers of cotton, or wadding for dresses, in a state of pressure. This would be a very good plan if a little fine salt and nitre were scattered over the roe at first. Sprinkling sugar over it has been recommended, and will, no doubt, preserve the spawn.

The following (Mr. Blaine's) is the modern method:- A pound of good large spawn is immersed in water as hot as the hands can bear it, and is then cleared of membranous films, \&c. It is now to be rinsed with cold water, and hung up to drain for twenty-four hours; after which put to it two ounces of rock or bay salt, and a quarter of an ounce of saltpetre, and again hang it up for twenty-four hours longer. Now spread it on a dish and gently dry it before the fire or in the sun, and, when it becomes stiff, pot it down. We 
should, however, recommend that the potting be not in one mass, but that it be divided into small jelly-pots, pouring on the surface some melted suet, by which plan a pot can be opened when wanted, instead of disturbing the general store. Each little pot should have for external covering a lid of moist bladder.

Captain Williamson preserves salmon roe in the following way. He first parboils it, and then steeps it in strong brine for a day or two. Having allowed it to drain well, he lays it thinly between alternate layers of clean soft wool, puts it in a jar, the mouth of which he covers with a bladder, and keeps it in a moderately cool place. If he observes it getting mouldy or tainted, he scalds it for a minute in boiling water, drains it, and replaces it in fresh layers of wool. Roe simply parboiled will last without any further preparation for a few days, and is a good bait.

In baiting with salmon roe, the hook should be covered with it, and as many grains put in the bend as possible. The most perfect grain should cover the barb and point of the hook. Some persons with a fine needle thread necklace-fashion some fine pink silk thread with the grains of roe, and then tie a sufficient number neatly about the shank and bend of the hook, shielding the point with one of them.

When your preserved salmon roe is too soft to 
thread it in single grains on the hook, mix a little adhesive bread paste with it, and use it as salmon roe paste. Though salmon roe will kill all the year round, it is most deadly in spring and in the autumn and winter spawning months.

Cheese paste is made with either new or old cheese, by mixing stale bread with new cheese, and new bread with old cheese. The substances must be kneaded together to adhesiveness. New bread and old cheese for chub; the other mixture for roach. They are both good autumn and winter baits.

When pastes are used, the hooks should be short in the shanks, of fine wire, and sneck-bent. They should be whipped on with silk the colour of the paste, very delicately waxed with transparent white wax.

Ground-baits. - These are essential to extensive success, and should be used abundantly, thrown in for days and nights previously at the spots you intend to angle in. They should be thrown in, at all events, the night before you begin to fish. They should be of the same sort as, generally speaking, but of inferior quality to, the baits you are about to use. The more carefully and the longer you ground-bait any locality, the greater number of fish you will find there. Naturally they will congregate to those places at which they find most food. Mr. Blaine explains the rationale of 
ground-baiting thus:- " Fishes naturally congregate where they have been led by any singularity of appearance in the waters they inhabit; thus they are on the alert, and take every kind of bait eagerly when a flood is coming down. Conscious that food of different kinds is forced along by the sweeping current, they are on the look out to receive it; and thus, also, when ground-bait is thrown down, it attracts their attention and draws fish together and detains them; and, although their naturally roving disposition may carry them away again, fresh supplies render their absence short, and they instinctively return to the scene of former plenty. It is the principle of ground-bait to attract fish without glutting them; and thus, although edible matters enter into the composition of groundbaits, yet they are, or ought to be, always inferior to the hook-baits offered at the same time, by which fish may be tempted to leave the groundbait for the more delicate morsel on the hook."

In rapid streams your ground-bait should be heavy and adhesive, mixed with clay, and having sometimes a large round pebble within the groundbait ball. In rivers that are constantly groundbaited the very noise or splash, caused in the water by the fall of the ground-bait cast in, attracts fish to the spot. They are used to it, and know the consequence. Large worms, mixed with balls of clay, attract barbel, chub, perch, and trout. Offal 
attracts jack and eels. Bran, pollard, meal, malt, grains, attractroach, dace, chub, and bream. Greaves and pieces of cheese attract barbel and chub. Raking with an iron rake the bottom of the stream, or mudding it by going into the water and stirring up the bottom with your strong soled shoes or boots, will bring fish into the wake of the discoloured water, and they will eagerly take worms dropped in before them. The best ground-baits are the following. I have mentioned the meal ground-bait already, and it is the best of all when angling with bread pastes.

Bran and clay ground-bait is very simple, and much used for roach and dace. It is made of a mixture of adhesive clay and bran well worked together, and pieces about the size of a small egg are thrown where you fish. If you are angling in a current, throw in the balls above you so that their particles may be washed down to the spot where your hook and bait are.

A good general ground-bait for such rivers as the Thames, Trent, \&c., in which there are many kinds of fish. - Mix clay, bran, and meal together into a firm adhesive mass, which divide into round pieces about the size of cricket balls. In the middle of them place as many worms and gentles as you can; as they creep out they are taken by the fish with impunity, which will encourage them to take your bait whether it be a gentle or 
a worm. Nearly all sorts of river fish, the coarser kinds especially, are attracted by this ground-bait, which is especially good in deeps where heavy fish abound.

Other ground-baits are made of soaked greaves and clay, good, when thrown in largely, for barbel, and angling at the same time with prepared greaves; others for still water, such as ponds, are made of mixtures of sand, clay, and scalded barley or wheat; others are made of chopped worms, gentles, pieces of greaves, and cheese; and others of a mixture of wet sand and carrion gentles. Experience will soon teach the angler the proper use of ground-baits. One thing he must cautiously prevent, viz., the washing away of his groundbait by the strength of the current to a distance too far from him to fish at. His hook-bait must always drop in at the exact spot on which his ground-bait rests.

In winter many anglers fish with prepared greaves, bullock's brains and pith, that is, portions of the spinal chord. A salmon was caught in the Trent with bullock's pith last winter. Greaves are prepared by soaking pieces in water until they become sufficiently soft, clean, and white. If wrapped in leaves and kept cool, the preparation will hold good for a week or longer.

I have now in one chapter, a rather long one certainly, stated all that is necessary to enable the 
learner to bottom-fish. I might have thrown out many other suggestions, amusing and speculative rather than positively instructive, -but I have refrained, because I know the reader will by and by sufficiently speculate for himself. I have laid down the right principles for him to build on, and if he keeps them in view in all his angling-castlebuilding, his visions may be pleasantly realised, even on a sandy foundation.

Much of the information embodied in this chapter has been re-written from Blaine's "Encyclopædia of Rural Sports," and Williamson's " Angler's Vade-Mecum." The latter little work is full of good practical points on bait-fishing and trolling. 


\section{CHAPTER IX.}

ON THE PROPER MANUFACTURE OF RODS.

I HAVE consulted three living authorities touching the qualities of salmon and trout fly-rods, and I will give the result of my consultations in the words, with scarcely any alterations, of my different learned angling counsel.

The first a gentleman, and celebrated angler, and general sportsman of Wales, writes to me :"As I have fly-fished through this season with a salmon rod of eighteen feet, made by one of the London topping artists, in their best style, with ferrules, I shall lay down, sans céremonie, all its good and bad points. It is of hickory at butt and centre, top joint made of lance wood with cane or bamboo. I have no fault to find with this rod as regards its throwing, for I am of opinion that a ferruled rod will throw better and farther than the spliced one, since, if we consider what a long slender affair the eighteen or twenty foot fly-rod is, that it requires here and there some support, to give it strength and action, we will conclude that the aid of ferrules is necessary. To any sort of fly-rod I should never have more than 
three joints. The butt should be of ash, hickory, red deal, or lance wood, and all the remaining joints of lance wood. Let me here remark that, as in all other things, our rod should be suited to our strength, height, age, \&c., and whatever strength the rod gains by quality of wood, it is at the expense of additional weight. If we are young and strong we should have a rod entirely of lance wood; if not, hickory, which is lighter, will do nearly as well. It is a good plan to have our butt double-ringed, by which means we can turn and change our middle joint and top alternately, which keeps the rod straight from warping, but this requires a groove or furrow, or winch fitting, on both sides of the butt, to enable us to shift the reel to either side. The butt end should be finished off with a round piece of horn, which is preferable to brass for the hand. Many use round the butt leather, or waxed string, similar to that on the handles of cricket bats, to prevent the hands from slipping, and give better purchase in throwing. It would be a good plan if the ends of the ferrules of salmon-rods were vandyked, and the wrapping to be wound over the vandyked parts, as I think it would prevent the wood from snapping off short at the joints. A slight groove in the wood to receive the vandyked ferrules would look neat and not weaken the wood. With the usual centre joints I have no fault to 
find, but as to the top joint, I think the common plan of five or six separate pieces, spliced together, very bad; indeed nothing can be worse, and of this I can speak to a certainty, for, as every splice is glued together, and then wrapped over with silk, the first fish you play, or the first tree or bush you get foul of, strains your splice, and then crack goes your varnish, and your stupidly over-fine wrapping silk, which becomes completely rotten in two months after the rod is made. The consequence of this many-spliced top, so weakly glued and tied with varnished silk, is that you have a rickety, treacherous joint, scarcely strong enough to strike your fish, and far less so to play and kill him. Now I will tell you in a very few words what a fly-top should be. It should be made of one entire bit of wellseasoned lance wood, with two or three inches of ivory at the extreme point, finished off with a small brass ferrule, over which the reel-line will run and glide freely from injury. The upper part of the lower ferrule of the top joint should be vandyked and whipped strongly with silk, and as this is the most valuable and weakest part of the whole rod, let there be half-a-dozen turns of silk wrapping round the wood at the centre between each ring. This will give much additional strength to the rod, as well as much more action, as it shortens the leverage, and stops any incli- 
nation to breaking of the top. If any one doubts what I say respecting the paltry, over-fine wrapping of his London rod, let him undo a small portion of the ring or splice silk, and see if it be strong or weak. Be it remembered that the tighter the silk wrapping is wound on the rod, the more action and life it will have. Now, sir, if you would persuade the London school to put on all their rods good sound coarse sadler's silk, well waxed with cobler's wax, and then some water-proof dressing that will strengthen the silk, instead of the destroying varnish they now use, we should have an efficient, perfect fly-rod, that would last for years. Every thing, I am speaking generally, in London rods is sacrificed to neatness, any little weak trash doing for trout rods, reels, lines, flies, gut, \&c.; and this has led to the error of making salmon-rods and other salmon-fishing gear so defective. The rings on the top joints are generally too large; and since reel-lines are now more perfect, I would recommend rather small rings, except the two on the butt joint."

My correspondent is a gentleman of great experience, and very ingenious withal, and his suggestions I consider very valuable. He has a high opinion of the Dublin salmon and trout flyrods, made by Martin Kelly of that city. He thinks them stronger, more durable, and more 
effective than London rods, but by no means so well finished. For my own part I know, that if a fair price is paid, there are London makers who will turn out rods as well, indeed I think I am justified in saying better, than any makers in the world.

Having consulted Mr. Blacker, of 54. Dean Street, London, who is a first-rate tackle-maker, and a most expert fly-fisher, he writes to me thus:- "For a trout rod to have a good balance from the butt to the extreme top, it is essentially necessary that the wood should be well-seasoned, and straight in the grain, free from knots and imperfections. The rod should consist of either three or four joints. The butt to be made of ash, the centre piece hickory, and the top bamboo. The length to be twelve feet. This length is what I deem most useful to convey a clear line with facility on to the surface of the stream with one hand. The butt should not be made either too thin or too clumsy, but sufficiently strong to bear up the middle piece and top. The middle piece or joint should be made light and stiff to carry the top, and the top should be made so as not to run too fine towards the extreme point. The whole.weight should not exceed one pound: If such a rod is made by a man who understands fly-fishing, the angler will have great comfort in his innocent pursuit, and not be tired during a 
long summer's day. I approve of double brazing, as this prevents trouble and danger in breaking the tongue in the socket, when taking the rod to pieces, and the brazings should fit air tight. With such a rod the reel-line should be either thirty or forty yards long, with what we term a contracted reel, as the line will be found to run off much more easily from its lying close together. The casting line should be three yards long, and composed of gut of fineness in proportion to the size of the flies you fish with. The salmon-rod should consist of four joints. The butt should be of the best-grained solid ash; the second and third joints should be of well-seasoned hickory without a flaw, and the top joint should be made of bamboo, and, in my opinion, the whole length of the rod should not exceed eighteen feet. The butt and middle piece to be very powerful, to prevent it from being top-heavy. The joints to be double-brazed, having large and strong rings from butt to top, that the reel-line may run through them with ease. Proper rings besides prevent the line from prematurely wearing out. Prepared silk, and silk and hair lines are undoubtedly the best for casting. The former are more lasting; but the latter will be found the best for throwing a line straight and far."

My third authority consulted on rods is Mr. Little, of 15. Fetter Lane, rod-maker to His 
Royal Highness Prince Albert. Mr. Little is himself a maker, having worked at the bench as an apprentice, and until master as a journeyman, and I hold him thoroughly competent to pass an opinion of great value on the making and materials of rods of all kinds. He writes to me thus:- "I consider the salmon-rod, carefully made, and only spliced fairly in the middle, consisting of two pieces, the most perfect rod; but the objection is that such a rod, made of two pieces each nine feet six inches in length, will not be conveniently portable, and will be only suitable for the angler resident almost by the river side. The next best rod should be eighteen feet long, and consist of three joints, with one ferrule fitting only for the butt and second joint, the top joint being spliced to the second, and not requiring a ferrule, which increases weight at the top, and injures the correct play of the rod. The top and middle joints are to be made from the stoutest pieces of bamboo cane, called "jungle," and brought from India. The pieces should be large and straight, so that you can rend them well through knots and all. Each joint should consist of three rent pieces, split like the foot of a portable garden chair, and afterwards glued together; not knot opposite to knot, or imperfect grain opposite to imperfect grain, but the best part opposite to that which may be knotty or 
imperfect, so as to equalise defectiveness and goodness. The natural badness of the cane you counteract by art, and none save a clever workman can do it. The butt of a salmon-rod should be made of plank ash or ground ash, though many good judges prefer willow or red deal, as being much lighter, and where lightness is required, the whole rod may be made of cane. The few makers that have as yet attempted solid cane or glued up rods, have generally placed the bark or hardest part of the cane inside in gluing, and then reduced the joints down on the outside to the usual tapering shape. Give me, however, the workman who glues the splices with the bark outside, and then gives his rod a true and correct action, allowing the three different barks to be seen visibly on the outside after he has rounded the whole. If the pieces are skilfully glued together, they will require no reducing, except at the corners, to bring the rod from the three square to the round shape. I am prepared to prove that there are not more than three men in London capable of making perfectly rods of solid cane, rent, glued, and then correctly finished with the bark lying on the outside.

"The ordinary London salmon rods generally consist of ash butts, hickory middle pieces, and bamboo tops. The Irish and Scotch commonly use lance wood, which is much heavier than hickory, 
and more likely to break suddenly. Good hickory is not easily procured, but, when it is really good it is as strong as lance wood, not so heavy, more pliant, and less easily broken. Though lance wood may be used for the thick joints, I, as a maker, disapprove of it in toto for the tops of any rods. Burnt or mottled East Indian cane will make a good salmon-rod, and one of my customers tells me that a rod he has of this cane is the best he has ever had.

Double-handed trout fly-rods are generally from fourteen to sixteen feet long, and will kill middle-sized salmon, grilse, and large trout. The rent and glued bamboo cane ones are the best. The other woods I have already recommended for large salmon-rods, will suit these smaller ones, thickness and tapering of course to be proportioned to length.

Single-handed fly-rods are made generally twelve feet long, though there are some as short as eleven and ten feet. The best average length is thirteen feet. The wood should be the same as for the other rods just described. Screw fittings are bad. They are far too heavy, and soon get deranged by hard work. Tongue fittings are the best for all fly-rods, and they will not work out of place if made to fit exactly. Whenever a fitting works out, or whenever by shaking the rod you hear a rattling noise at the ferrules, they are not 
properly fitted, and you must send the rod back to the maker for alteration. If ferrules are finished in a workman-like way they will require little or no whipping with waxed silk."

My readers will now expect my opinion on the rods above recommended by competent judges. They are all good in their way. In my opinion rods made entirely of lance wood are the worst; and those made entirely of rent and glued jungle cane are the best. They must be most carefully fashioned, and no maker can turn them out well without charging a high price. I am also of opinion that they will last longer than any other sort of rod, and are far less liable to warping. I have a high opinion of their elasticity, and $\mathrm{Mr}$. Bowness, fishing-tackle maker, of No. 12. Bellyard, Temple Bar, showed me once a trout flyrod, made in this, my favourite way, that had been for many years in use, and was still as straight as a wand. I never saw a better singlehanded rod. Mr. Bowness is an ingenious, respectable tradesman, and judicious angler, and I conscientiously and cordially recommend his fishing gear to the attentive notice of the public.

The best trolling and bottom rods are thus described by Mr. Little:-

The best spinning rod is to be made of beautifully mottled East Indian cane. It will be then handsome to look upon, and work lightly and well. 
Some prefer hickory because of its alleged superior strength over cane. Good cane is equally as strong, and so much lighter that you may use a very long rod made of it - much longer than if made of hickory. The rings must be large and upright, and to render the rod portable can be made to take off and on. The trolling rod should be made of the same material, but stouter and stiffer, as a good spinning rod should play down towards the hand.

A general rod of hickory is useful for its portability. It should be fifteen feet in length and have on an average four or five tops. By means of these tops you are enabled to form a fly-rod, a trolling one, and different sorts of bait-rods. The butt of course is to be hollow, and willow or ash for that part of the rod is the best material. A general rod of South Carolina cane, eighteen feet long, is that commonly used by London bottomfishers. It has tops for roach, perch, barbel, and indeed for every sort of bottom-angling.

The white cane roach rod is made of Spanish reed, but the generality of them sold in London are too long. Eighteen feet in length is sufficient for any purpose, is more easily handled, and strikes more surely. The London makers do not recommend roach-rods made of this cane, on account of the difficulty in procuring it good. It is the best 
material however, and no true roach-fisher should be without one made of it.

The Thames rod is usually employed in punt angling. It is from ten to eleven feet long, and the best are made of hickory. That wood must be good to bear the weight of the large Thames barbel it frequently has to play and kill, and not unfrequently pike and trout, for if made well it can be used in spinning and trolling.

Walking cane rods may be made, as far as the butt goes, of divers materials. A walking stick fly-rod, very useful for small streams, is formed of four pieces, three of which enter your walking stick, hollowed out of course, and which serves as a case for them and a handle for your landing net. The fourth piece is the butt, twelve inches long', with winch fittings, \&c., in the usual way, and which you carry in your pocket. In pedestrian excursions this is a very convenient article. A good walking stick bottom-fishing rod, has three good joints, inserted into a handsome hollowed piece of ground ash with the bark on. It is a rustic looking affair, but an amateur in walking sticks may have one and a fishing rod to boot made, at least, the walking part of it, of the handsomest Malacca.

The great rod and tackle-makers of London are, Alfred, of Coleman Street, City; Bernard, Church Place, Piccadilly; Blacker, of Dean Street, 
Soho; Bond, of Cannon Street, City; the three Messrs. Bowness, father and two sons, of Bell Yard, Temple Bar; Cheek, Oxford Street; Eaton, Crooked Lane, King William Street, City; Farlow, Crooked Lane, King William Street, City ; Farlow, Strand, near Temple Bar; Holmes, Fetter Lane; Holmes, Sidney Alley, Leicester Square; Jones, Jermyn Street, St. James's ; Little, Fetter Lane.

This list, I have given alphabetically; so that the last name in it may be as good as the first.

The best tackle-makers in Ireland are, Martin Kelly, of Dublin ; the successor of Shaughenessy, Limerick; Hackett, Great Georges Street, Cork. In Scotland, - Dougall, Glasgow; Douglas, Edinburgh. 
CHAP'TER X.

ON PISCATORIAL PHYSIOLOGY.

IN order to clear up for angling purposes how far fish see, hear, smell, taste, and generally feel, I solicited one of my best friends, Erasmus Wilson, F.R.S., a well-known and accomplished anatomist and physiologist, to write me briefly his opinions on the subject. He obligingly complied, and the following is the useful result.

From the humble position of the fish in the animal kingdom, namely, at the very foot of the scale of the vertebrate series, in other words, the lowliest of that large group of animals distinguished by the possession of a spine, it may naturally be inferred that those higher attributes of animals, which depend on the presence of nerves, and of a nervous system, present a corresponding degree of inferiority. Such an inference would be strictly true; for, whatever element of their construction we examine, whether their bones, muscles, vessels, nerves, or organs of nutrition, sense, or reproduction, all suggest alike the idea of inferiority as contrasted with the higher animals and man, but of exquisite beauty as compared 
with each other, and considered in relation to the part in the great drama of life which they are called on to perform. The naturalist, however, would repudiate the term " inferiority" as applied to the structure and organisation of the fish, - a sentiment in which we feel sure that the disciple of Walton would heartily concur; it is, in truth, simplicity, so far as the rest of the animal kingdom is concerned, perfection, in relation to its own position in the grand scheme of animated nature.

The faculties of the fish which depend on the nervous system are, Intellect, Sensation, Motion, and the special senses of Sight, Hearing, Smell, Taste. Each of these faculties is presided over by a known part of the nervous system, such part being the material instrument by which the power is generated and directed. Hence a pretty correct inference with regard to amount of faculty may be deduced from structure alone, that is, from an examination of the size and qualities of the instrument; but, when to the information thus obtained we add the further knowledge which observation of the habits and instincts of these animals contributes, we find ourselves in possession of ample evidence whereon to frame a correct and sufficient judgment.

The Intellect of animals resides in the brain, in a part of the brain termed the hemispheres; and these organs always bear an exact proportion 
to the degree of manifestation of the intellectual faculties. Now, the brain of fishes is remarkable for its small size; and of the various parts of which it is composed, the hemispheres are the least. Hence we have good reason for assuming that, as intellectual beings, fishes do not merit a higher position than that in which they have been placed by the naturalist. A few instances are recorded which seem to exhibit a power of association of ideas on the part of the fish; for example, their approach to the margin of a stream or pool to be fed; but this can only be regarded as one of the humblest of the mental manifestations; and they would be as likely to advance towards an enemy as a friend if the position of the stranger corresponded with that of their accustomed feeder.

Sensation, like intellect, resides in the hemispheres of the brain, and the inference deduced from the smallness of these organs appears to be just with regard to the faculty in question. Fishes are as deficient in sensation as they are abounding in motion; but the two faculties have no necessary connection with each other; few of the motions of the fish are due to sensation, and almost as few to the will; therefore, motion alone cannot be taken as an index of sensation.

The mobility of fish is an obvious quality of these animals, and the instrument by which motion is effected the largest in their whole economy. 
This faculty draws upon the brain only for the stimulus derived from sensation and will, both of which are, as we have seen, of insignificant strength. The apparatus of motion includes the spinal marrow, and the greater part of the large and numerous nerves which proceed therefrom; and, in addition to this commanding power resident in the nervous system, a host of inferior agents, the muscles, by which the immediate phenomena of motion are accomplished.

The organs of special sense, namely, of sight, hearing, smell, and taste, are each provided with a vital and a mechanical apparatus. The mechanical apparatus of sight, the eye, or, as it is popularly termed, the eye-ball, or apple of the eye, is an optical instrument of great perfection. In man and in the higher animals, the eye-ball is very nearly globular, the deviation from the perfectly spherical shape being in favour of a greater convexity of the transparent front of the organ. In fishes, on the contrary, the breadth of the eye greatly exceeds its depth, and it is flattened in front to a remarkable degree, presenting, in fact, the form of a segment of a sphere in place of a perfect globe. It is obvious that this peculiarity of shape is less easily maintained than that of an entire sphere; hence, it is no uncommon thing to find the circumference of the eye-ball strengthened by a thin cup of gristle, and, in some instances, 
of bone. There is another remarkable difference between the eye of terrestrial animals and fishesa difference which has reference to the nature of the medium in which the creature lives. For example, the density of water is so much greater than that of air, that it is employed in the construction of the eye-ball of man, and the rest of the air-breathing terrestrial animals, as a means of directing the rays of light towards the bottom of the eye, upon which the spotless curtain is spread which receives the picture of external nature. But in fishes it is evident that water, as a medium of refraction of the rays of light, would be perfectly useless, since the medium is aqueous, through which all the rays reach the transparent window of the organ of vision. The chambers of the eye of the fish, which in other animals contain water, are consequently those which are most easily spared; and it is the reduction of capacity in them that gives rise to the flatness of the front of the eye. The proper refracting apparatus of the eye-ball of the fish is a transparent globe of considerable density and size, termed the lens. In terrestrial animals the lens is small, it is scarcely more convex that a common magnifying glass, and it is soft in its texture. That of the fish, however, is a much more powerful agent in the refraction of the rays of light, and approaches in some of its characters to the finest glass. By it the 
rays of light which pass through the transparent window (cornea) in the front of the eye are immediately received, and are as suddenly concentrated on the smooth expanse of the optic nerve, to be transferred by the latter to the vital apparatus. As is usual in optical instruments, there is a thin partition pierced with a circular aperture (the pupil), interposed between the transparent membrane of the front of the eye and the lens. This membrane is intended to regulate the admission of the luminous rays. In some fishes there are two apertures, or pupils, in place of one in this partition, a curious modification, while in some others, as in the common skate, a broad curtain with a vandyked border, is suspended immediately behind the pupil at its upper part, and serves to veil the interior of the eye against the vertical rays which would otherwise interfere with vision. The enumeration of all the modifications in the construction of the eye of the fish with which the naturalist is acquainted, would form of itself an interesting chapter, but the subject is too comprehensive to be more than glanced at in this brief sketch. In most of the fresh-water fishes, the eyeball plays in a bony niche, which is specially destined for its use; while in other fishes in which the bony niche is absent the eye is jointed to a movable bony stalk, and moves on the extremity of that stalk as upon a ball and socket hinge. 
The vital apparatus of vision, situated in the brain, is one of the largest parts of the latter organ, being more considerable in size than the hemispheres which are destined to the control of the threefold faculty of Intellect, Sensation, and Will. The nerve or conductor which passes between the vital and the mechanical apparatus of vision, is also of large size, and is curious in its structure; in external form it has the appearance of a cylindrical rod, but when opened the cylinder is found to be a mere sheath, containing a thin, white membrane, plaited like a fan. When the nerve reaches the eye-ball this membrane unfolds, and is spread out upon the inner surface of the back part of the eye, constituting the sentient part of that organ. This white and spotless membrane, upon which the rich picture of external nature is received, and by which it is subsequently transferred for perception to the brain, is the retina.

Whether, therefore, we regard the mechanical or the vital apparatus of the organ of vision, or whether we pursue the inquiry by anatomical investigation, or by observation of the habits of the animals, we have the clearest evidence before us, that the faculty of sight in fishes is one of their highest sentient endowments.

In examining the structure of the organ of vision we are struck by the absence of the out- 
works of defence to the eye, namely, the eyebrows and eyelids, which are met with among terrestrial animals. It is clear that these appendages are rendered unnecessary by the nature of the medium in which the creatures reside. The same observation applies with even stronger force to the organ of hearing: there is nothing on the exterior of the head of the fish to indicate that it is provided with an ear. In the higher animals the mechanical apparatus of hearing consists of an external and an internal portion; in fishes the internal portion alone exists, and is hardly inferior in perfection of form and structure to that of creatures placed higher in the animal scale. The nerres distributed to the organ of hearing are of large size, and the vital apparatus or portion of brain, from which the latter proceed, is also considerable. There exists, however, this important difference between the organ of hearing of terrestrial animals and fishes, namely, that the ear in the former is organised for the reception of the more delicate vibrations of the atmosphere, while in the latter, it is adapted to the rude oscillations of a denser element. We may make this difference apparent by the following simple illustration. The impulse occasioned to the air by the ticking of a watch is so weak, as to be indistinctly heard when the watch is brought close to the ear, but if we บ 3 
convey the watch to a greater distance from the ear and press it against the teeth, or if we rest one end of a rod of wood against the watch and the other against our head, we hear the ticking with remarkable distinctness. In the language of science, solid and dense bodies vibrate with greater intensity than lighter media, such as the atmosphere. When the watch is held nigh to the ear the atmosphere is the conductor; when the watch is connected with the ear, by the intervention of a rod of wood, or the solid parts of the head, these are the conductors. Now the apparatus of hearing of the fish presents conditions of the latter kind; water, a denser body than air, is the conducting medium; and the solid mass of the head, and, in fact, of the entire body, completes the conduction to the vital apparatus. Hence in fishes, a humble contrivance is capable of effecting the same end as the high-toned instrument of terrestrial animals. Fishes must, therefore, hear with moderate acuteness, particularly such sounds as occasion a vibration of the element in which they reside, for example, an approaching footstep ; while the sounds which proceed from musical instruments, being less easily conveyed, are probably unknown to them; certainly this is the case with regard to tone. Those curious porcelainlike bodies, which are found in the head of the fish, and which must be known to every investi- 
gator of the gastronomical merits of his game, form part of the mechanical apparatus of hearing.

The external or mechanical apparatus of the organ of smell is a pair of small cavities or chambers, communicating with the aqueous element by means of four apertures, and situated near the extremity of the snout. The two openings of each olfactory chamber are intended to permit a free ingress and egress to the water in which the odorant principles are dissolved. But there exists no contrivance, so far as we know, for maintaining a constant current through the chambers. In this particular, the organ of smell of fishes is greatly inferior to that of higher animals; for in the latter, the olfactory chambers give passage to the greater part of the air which enters the lungs, and are thus enabled to test the quality of all the air received into the chest for respiration. In fishes this power is less requisite, and hence the inferiority of construction. The olfactory chambers are lined by a soft membrane, technically a mucous membrane, which is richly supplied with blood-vessels, and is brought into connection with the vital organ by means of a moderately large conducting nerve. The arrangement of this membrane evinces one of those beautiful contrivances which are so frequently met with in the animal machine, and which are intended to provide a large surface within a limited space. In order to 
increase the extent of this membrane as much as possible, it is thrown into a multitude of minute plaits which radiate from a central point and have a very elegant appearance. From the back of the olfactory chambers there proceed, as we have already stated, two nervous cords, which conduct the impressions received by the mucous membrane to the brain.

The vital apparatus of smell, like that of sight, consists of two round masses or lobes of nervous substance, which occupy the front of the brain, and preside over the manifestation of the faculty. They are inferior in size to the optic lobes, though often as large as the hemispheres of the brain. We are thus supplied with conclusive evidence of the possession by fishes of a power of smell. The mechanical and the vital portions of the apparatus, with the conducting nerve from the former to the latter, are complete; the only question which requires solution is the degree of the sentient power. The vital apparatus being large would be an argument in favour of a vividness of perception, but the small mechanical portion, and especially the absence of a stream of water through the olfactory chambers, leave the organ imperfect. On these grounds, we should be inclined to give the faculty of smell a position next in order to that of hearing, and greatly inferior to sight.

Taste is at all times, and in all animals, a modi. 
fication of common sensation, or the simple sense of touch. Its seat in fishes is probably the whole interior of the mouth, the tongue of these creatures, being as is well known, very small and very imperfectly developed. The observations which we have previously made with regard to sensation and to the vital organs of that faculty - the hemispheres, are applicable here. We cannot give the fish credit for any refinement of taste, and taste, with touch and feeling, must be content to occupy the lowest rank of the nervous senses.

It is impossible to regard the distribution of the higher faculties of the fish, which is here pourtrayed, without a sentiment of admiration of the wisdom and goodness of Providence, that has thus restricted the sensations of a large group of creatures, living in an element of danger and destined to be the prey of the more powerful of their own kind as well as of the other classes of animals. They have the eye to see, the ear to apprehend, and the muscular system to escape danger. They have also a power of smell to discriminate the qualities of the stream which it is their pleasure to seek. While the absence of nicety of taste renders them unheedful of the savour of their food, and an imperfect sensation saves them from the pangs which they otherwise must feel in the grasp of their destroyer.

The angler who studies these observations, and 
would avail himself of the lesson which they convey, will judge how far it is necessary to keep out of the sight of fish, and refrain from making a noise, - to what extent fish suffer torment from the hook, and how far it is useful to employ scented baits to please their palates. 


\section{CHAPTER XI.}

THE HABITS OF THE ANGLER'S FISH, AND THE BEST WAYS OF CATCHING THEM FAIRLY.

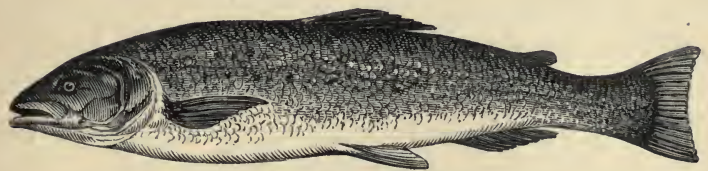

The Salmon. - Salmo Salar.

THE natural history of this splendid fish, the pride and profit of the great rivers of the British Isles, was not known until about ten years ago. The greatest natural historians, from the French Lacépède down to our own observant Yarrel, were ignorant of some of the main features of its existence. Until the period alluded to we were nearly all in error with respect to its growth, and we thought the parr a distinct species. We have now ascertained its growth, and know positively that the parr is a young salmon of the first and second year - a fact the knowledge of which is of importance with respect to the preservation of the fish. The day may come when the killing of parr will be made universally a penal offence. 
We also know that up to its second year the growth of salmon is exceedingly slow; that afterwards it is wonderfully rapid, but in salt water only. Once a grilse or a salmon, fresh water is fatal to its growth.

I shall, before I enter into detail, give in a very few words the salient points of the salmon's natural history. The female salmon, viz. the fish with what is commonly called the "hard roe," deposits its eggs, spawn, or ova, in gravel beds, in the winter months, sometimes earlier; sometimes later. Simultaneously with being deposited, the ova are impregnated by the spawn (the milt) of the male fish, or "soft-roe," being exuded over them. That is the active process of procreation. The deposited eggs or ova are hatched on an average in from ninety to one hundred and twenty days; duration of time depending on the temperature of the water. The warmer the water the more rapid is the work of incubation. In a few days after expulsion from the ova the incubated matter assumes the fish shape. This embryo salmon grows slowly, and remains for the first and second year the diminutive parr or fingerling. On completing its second year it changes its coat, and indeed its shape. The parr or samlet marks and spots disappear, and it becomes the silvergrey smolt, salmon fry, or lastspring. Its second year or thereabouts being completed, it migrates for 
the first time to the sea, and in two or three months or more returns to its parent river a gilse or grilse, having increased a pound more or less during every month it has tarried in sea water. At the end of its third year or the beginning of its fourth (I am speaking of the female fish, for the puerile parr will breed, horresco referens, with its great grand-dam) it breeds, and soon after migrates for the second time to the sea. A sojourn there of a few months changes its name, size, and shape, and immigrating again into its native stream it becomes a salmon. To deserve that name it must have made two voyages to sea, and entered the fourth year of its existence. Afterwards, as long as it lives, it visits the sea annually, and annually revisits the streams of its birth, in which it gives birth to thousands of its tribe. Become an adult, the longer it remains at sea the more rapid is its growth. In fresh water it no longer thrives, and seems to seek the pure element for no other purpose than the important one of propagating its species. I have now in a very few lines traced the grand outlines of salmon life. I shall now confine myself to some minute details, omitting those that I do not think it necessary for the mere angler to know.

Mr. John Shaw of Drumlanrig, and Mr. John Young of Sutherlandshire, the former the manager 
of the Duke of Buccleuch's salmon fisheries, the latter of those of the Duke of Sutherland, were the first to prove publicly some of the facts above glanced at. I am glad however to state that an accomplished angler and sportsman, Mr. W. Scrope, F.L.S., the celebrated author of "The Art of Deer Stalking," and of "Days and Nights of Salmon Fishing," knew, though he did not make it public, so far back as the year 1825, that the parr was the young of salmon. In that year he communicated this information in a letter to Mr. Kennedy, M. P., and maintained the point in discussion against the contrary opinions of the Ettrick Shepherd and other supposed competent authorities. To him, therefore, I give the honour of the discovery, and to Messrs. Shaw and Young that of having published it and of following it up by other important discoveries.

Mr. Scrope, in his interesting "Days and Nights of Salmon Fishing," a work which every angler who desires to become accomplished should consult, embodies Messrs. Shaw and Young's remarks on salmon with his own; and all that is left for me to do is to give the substance of their joint observations.

Salmon begin spawning in some rivers as early as September, and continue doing so through the 
winter months; the chief ones being December, January, and February. A few remain on the spawning grounds, and Mr. Scrope says he has caught full roeners, as they are called, in the month of May in the Tweed. The spawn of salmon remains in the gravel beds from ninety to one hundred days before it vivifies, and even remains there some weeks after its exclusion from the eggs. According to Mr. Shaw, the latter period is fifteen days, at the end of which the portion of the egg remaining attached for the purpose of nutrition to the abdomen of the fishfotus contracts and disappears. The fin or tadpole-like fringe divides itself into the dorsal, adipose, and anal fins, the little transverse bars, which for a period of two years characterise it as a parr, also make their appearance, so that a period of at least one hundred and forty days is required to perfect this little fish, which even then measures little more than one inch in length.

Mr. Shaw, to prove his facts, made the following experiments. He made three ponds, so constructed that the young fish could not escape, or any other sort of fish have access to them. He then (the 4th January, 1837,) proceeded to the river Nith, and discovered a pair of adult salmon engaged in depositing their spawn. He captured the pair, and pressed with the hand the ova from 
the body of the female, from the male in the same way he expressed the milt, and with it impregnated the ova, which he transferred to one of his prepared ponds. On the 28th of April following, one hundred and fourteen days after impregnation, the young salmon were excluded from the eggs, but were not so on the day preceding. On the 24th of May, twenty-seven days after being hatched, the young fish had consumed the yolk, which remains attached to the lower part of the body for the purpose of nourishment, and the characteristic bars of the parr had become distinctly visible. An accidental deposit of mud destroyed these fry. In the same year on the 27 th of January, he made a duplicate of the above experiment, and found on the 21st of March (fifty-four days after impregnation) that the embryo fish were visible to the naked eye. On the 7 th of May (one hundred and one days after impregnation) they had burst the envelope, and were to be found amongst the shingle of the stream. The temperature of the water was at the time $43^{\circ}$, and of the atmosphere $45^{\circ}$; and this brood Mr. Shaw had an opportunity of watching continuously for a length of time, for more than the entire period which was required to elapse from their exclusion from the egg, until their assumption of those characters which dis- 
tinguish the undoubted salmon fry. He instances one of those of two years old, when it had assumed its migratory dress, and measured about six and a half inches, the average size of the brood. Touching this fact Mr. Scrope exclaims, "Two years, - mark this, — and only six inches and a half long! It then goes to the sea, the first floods in May (two years or more after incubation), and returns in two or three months, as it may happen, when it is called a gilse, and is increased to the size of from four to seven pounds, and indeed very considerably more, being larger or smaller in proportion to the time it has remained in the sea. A second visit to the sea gives it another increase, when it returns to the river as a salmon. This appears so wonderful and extraordinary a departure from the general laws of nature, that it is no wonder that the most scientific men have been misled." A gilse may be larger than a salmon, by one fish remaining a longer period in the sea during its first visit, than another during its first and second.

Another experiment is more curious and conclusive if possible than the above, for it shows that the male parr will impregnate the ova of the female salmon, and that the male parrs, the offspring of this impregnation, will breed with other salmon, and therefore are not hybrids. "In January, 1837," says Mr. Shaw, "I took a female 
salmon weighing fourteen pounds from the spawning bed, from which I also took a male parr weighing one ounce and a half, with the milt of which I impregnated a quantity of her ova, and placed the whole in a private pond; when, to my great astonishment, the process succeeded in every respect, as it had done with the ova which had been impregnated by the adult male salmon, and exhibited, from the first visible appearance of the embryo fish up to their assuming their migratory dress, the utmost health and vigour." Mr. Scrope says, "On the 4th of January, 1837, a male parr, itself the produce of a male parr and female adult salmon, was made by expression of the milt to impregnate the eggs of a salmon weighing twelve pounds; and for the better security of the whole it was placed in a wooden trough, over which a sheet of fine upper wire-gauze was fixed. The trough was then placed in a stream of water previously prepared for its reception, and the results were precisely of a corresponding nature to those already detailed. Now, if the parr and salmon were distinct species, their produce would be hybrids, and would not, therefore, breed again, according to the rules of nature established to prevent the confusion of different species by a conservative law; but this last and most important experiment has proved that the produce from the male parr and female adult salmon will breed 
again with the old salmon, and therefore that such produce are not mules, but of the same species with their parents." Mr. Shaw also proves that the milt of the common river trout will impregnate the ova of the female salmon. It remains hereafter to be seen whether the bull trout, or salmo eriox, is or is not the produce of that impregnation. It appears that the sea trout is not, but is a distinct species.

Generally in May, the parr having become smolts, or salmon fry, being about two years old, and seven inches in length, migrate for the first time to the sea. If they return in about a month they weigh from a pound to two pounds each, are long and thin, and much forked in the tail. "They keep on," says Mr. Scrope, " ascending the river during the summer months, the newcomers increasing afterwards about a pound and a half a month on an average, but much less in their very young state. The most plentiful season in the Tweed, if there is a flood, is about the 18th of July, at which period they weigh from four to six pounds; and those which leave the salt for the fresh water at the end of September, and during the month of October, sometimes come up the river of the weight of ten and eleven pounds, and even more. All these fish are known in the north by the name of gilses, but by the London fishmongers are generally, I believe, 
called salmon-peel. Some of them are much larger than small salmon; but by the term gilse I mean young salmon that have been only once to sea. They are easily distinguished from salmon by their countenance, and less plump appearance, and particularly by the diminished size of the part of the body next the tail, which also is more forked than that of the salmon. They remain in fresh water all the autumn and winter, and spawn at the same time with the salmon. They return also to sea in the spring with the salmon."

Growth of the parr or salmon fry. - At two months old they are one inch and a quarter long, at four months, two inches and a half, at six months, three inches and a quarter. At eighteen months old the fry measures six inches in length, and the milt of the male is matured, and can be made to flow from the body by the slightest pressure; but the females of a similar age do not exhibit a corresponding appearance as to the maturity of the roe. The male is at this time in the autumn of his second year, and lies about and in the spawning beds of the large salmon, where he impregnates the ova. The following spring he is about seven inches and a half long, when beautiful silver scales grow over the spots and bars which have characterised him up to this period; and the majority of the breed then congregate, 
and go to sea with the first floods in May. The following table shows the growth of gilse into salmon :-

\begin{tabular}{|c|c|c|c|c|c|}
\hline \multicolumn{2}{|c|}{ When marked. } & \multicolumn{2}{|c|}{ When retaken. } & \multirow{2}{*}{$\begin{array}{c}\begin{array}{c}\text { Weight of } \\
\text { Gilse. }\end{array} \\
\text { lbs. }\end{array}$} & \multirow{2}{*}{$\begin{array}{c}\begin{array}{c}\text { Weight of } \\
\text { Salmon. }\end{array} \\
\begin{array}{c}\text { lbs. } \\
9\end{array}\end{array}$} \\
\hline Fohrupry & & & & & \\
\hline thitaly & 18 & & 25 & 4 & 11 \\
\hline & 18 & & 25 & 4 & 9 \\
\hline & 18 & & 25 & 4 & 10 \\
\hline & 18 & & 27 & 4 & 13 \\
\hline & 18 & & 28 & 4 & 10 \\
\hline March & 4 & July & 1 & 4 & 12 \\
\hline & 4 & & 1 & 4 & 14 \\
\hline & 4 & & 10 & 12 & 18 \\
\hline & 4 & & 27 & 4 & 12 \\
\hline
\end{tabular}

Mr. Scrope says, "The above disparity of growth is easily accounted for, since it is not probable that these fish, which were caught, marked, and returned to the river in February, went down to the sea before March, if, indeed, so early: of course they would not increase in growth in fresh water, though they would mend somewhat in weight, after their weak spawning state. Setting these, therefore, aside, it appears that the growth of the last four fish averaged two pounds each per month when they were at sea; and if they remained in the river after the 4 th of March, as it is reasonable to suppose they did, then their growth must have been proportionably greater." 
I fancy the reader must now be convinced that the parr is the young salmon, and he also must know something of the growth of this fish. I will go back again to before spawning time, and trace the habits of the salmon up to that time. Salmon enter rivers from the sea as early as February and March, for the sole purpose, it is supposed, of spawning, but it must have some other object in view as well, since at the earliest the spawning process does not commence until September. It cannot be for nourishment, because it is well known that salmon lose in weight and condition every day they remain in fresh water. Mr. Scrope goes on to remark, "Some think it is to get rid of the sea-louse; but this supposition must be set aside, when it is known that this insect adheres only to some of the newly run fish, which are the best in condition. I think it more probable that they are driven from the coasts, near the river, by the numerous enemies they encounter there, such as porpoises and seals which alarm them in great quantities. However this may be, they remain in the fresh water till the spawning months commence. On the first arrival of the spring salmon from the sea, they are apt to take up their seats in the rear of a scull of kelts, and at this early period they are brown in the back, fat, and in high condition. In the cold months they lie in the deep and easy water; and as the season ad- 
vances they draw into the principal rough streams, always lying in places where they can be least easily discovered. They are very fond of a stream above a deep pool, into which they can fall back in case of disturbance. They prefer lying upon even rock, or behind large blocks of stone, parti-. cularly such as are of a colour approaching that of themselves. At every swell of the river, unless it is a very trifling one, the fish move upwards nearer the spawning places; so that no one can reckon upon preserving his particular part of the river, which is the chief reason of the universal destruction of these valuable animals. Previous to a flood, the fish frequently leap out of the water, either for the purpose of filling their airbladders to make them more buovant for travelling, or from excitement, or, perhaps, to exercise their powers of ascending heights and cataracts in the course of their journey upwards."

Historians used to gravely tell us that salmon, in order to jump high, were in the habit of placing their tails in their mouths, and then bending themselves like a bow, bound out of the water to a considerable distance, from twelve to twenty feet. Mr. Scrope calculates that six feet in height is more than the average spring of salmon, though he conceives that very large fish, in deep water, could leap much higher. He says, "Large fish can spring much higher than small ones; but their 
powers are limited or augmented according to the depth of water they spring from: in shallow water, they have little power of ascension; in deep, they have the most considerable. They rise rapidly from the very bottom to the surface of the water by means of rowing and sculling, as it were, with their fins and tail; and this powerful impetus bears them upwards in the air, on the same principle that a few tugs of the oar make a boat shoot onwards after one has ceased to row."

The spawning process is thus accurately described by Mr. Scrope : - "Salmon are led by instinct to select such places for depositing their spawn as are the least likely to be affected by the floods. These are the broad parts of the river, where the water runs swift and shallow, and has a free passage over an even bed. - Here they either select an old spawning place, a sort of trough left in the channel, or form a fresh one. The spawning bed is made by the female. Some have fancied that the elongation of the lower jaw in the male, which is somewhat in the form of a crook, is designed by nature to enable him to excavate the spawning trough. Certainly it is difficult to divine what may be the true use of this very ugly excrescence; but observation has proved that this idea is a fallacy, and that the male never assists in making the spawning-place; and, indeed, if he did so, he would not possibly 
make use of the elongation in question for that purpose, which springs from the lower jaw, and bends inwards towards the throat. When the female first commences making her spawningbed, she generally comes after sunset, and goes off in the morning: she works up the gravel with her snout, her head pointing against the stream, and she arranges the position of the loose gravel with her tail. When this is done, the male makes his appearance in the evenings, according to the usage of the female: he then remains close by her, on the side on which the water is deepest. When the female is in the act of emitting her ova, she turns upon her side, with her face to the male, who never moves. The female runs her snout into the gravel, and forces herself under it as much as she possibly can, when an attentive observer may see the red spawn coming from her. The male in his turn lets his milt go over the spawn; and this process goes on for some days, more or less, according to the size of the fish and consequent quantity of the eggs. During this time trout and other fish will collect below to devour the spawn that floats down the river."

Mr. Frederick Allies, of St. John's, Worcester, informs me that in the river Teme the spawn is not only eaten by divers sorts of fish, but also by aquatic fowls and other birds and animals. Mr. Scrope remarks, "When the female has done 
spawning, she sets off, and leaves the place. The male remains waiting for another female; and if none comes in twenty-four hours, he goes away in search of another spawning place. In the spawning beds on the Tweed, (Mr. Scrope might have said in all our rivers,) great injury is done with the leister and rake hooks; and the fishermen (poachers), who know how to profit by their cruel slaughter, are in the habit of spearing the male that first comes to the female, leaving the latter as a decoy fish, and killing the other males in succession as they arrive to consort with her. By this barbarous and poaching practice all the largest spawning fish are destroyed, to the great destruction of the river."

In angling for salmon, Mr. Scrope, than whom no better authority can be found, as he has salmonfished for upwards of twenty years, recommends a salmon-rod of eighteen or twenty feet long according to the width of the river you fish in. The longer the rod, the greater command you will have over your fish; for being enabled to keep the line more perpendicular, you can lead him with more ease and security amongst rocks and eddies; whereas with a short rod you cannot keep enough of your line clear of the water to prevent danger in such places. Your reel-line should be thick in the middle, and taper towards 
each end, and should be from 100 to 120 yards long. Your casting line should be of single gut, clear and round. The colour of your casting line should depend on the state of the river. If the water be moss-stained, your gut may be very faintly tinged of the same colour, very faintly indeed, as all dyes are over-done, but if the river be clear, do not, on any account, stain your gut at all. Whatever you do, have nothing to say to multiplying reels; they are apt to betray you in the hour of need. A large London made plain stop reel, with a thick winding cylinder, is the best.

With respect to salmon-flies, Mr. Scrope truly says, - "Now, as there is no month in the year when salmon-flies are made by nature, so no distinction of species need be observed. My rule has been to adapt my fly, both as to colour and size, to the state of the water; a large fly, with sober colours, for deep and clear water, and a smaller one, equally unassuming, where it is shallower; in the throat of the cast, (head of the stream, and as long as it continues rough, a large fly also; at the tail of it, where the water runs more quietly and evenly, a smaller fly serves the purpose best. Thus you should change your fly in every stream once or twice. A large and rather gaudy fly is preferable when the river is full and discoloured, that the salmon, which lie 
at great depths, may see it; but I never had any great success with my gaudy flies, either in the Tweed or elsewhere, in clear and low waters." Although gaudy flies are in great request in Ireland and Norway, I am confident that they only suit deep and somewhat turbid waters, and I am certain that Mr. Scrope's rules for the size and colour of salmon-flies will be found practical general ones for every salmon river in the world.

Mr. Scrope says, "I do not mean to assert that all flies are equally successful, for there must obviously be a preference, however slight; but I mean merely to say that a failure oftener occurs from atmospheric variations than from the colour of the fly. Yet an occasional change, is always advisable, particularly if you have had any offers (rises); since the fish in so rising, having, perhaps, discovered the deception, will not be solicitous to renew their acquaintance with a detected scamp. After all, the great thing is to give the appearance and motion of a living animal. If your fish misses the fly in making his offer, wait awhile before you throw a second time; and if he rerises at all, he will come more eagerly for this delay. But if you keep lashing away at him immediately, as I have seen many fishermen do,and practical hands to, - he will probably treat you with contempt, and will have no intercourse with your gay deluders for the rest of the day." 
"Casting the fly is a knack," says Mr. Scrope, " and cannot well be taught but by experience. The spring of the rod should do the chief work, and not the labour of your arm. To effect this, you should lay the stress as near the hand as possible, and make the wood undulate from that point, which is done by keeping your elbow in advance, and doing something with your wrist, which is not very easy to explain. Thus the exertion should be chiefly from the elbows and wrists, and not from the shoulders. You should throw clear beyond the spot where the salmon lie, so that they may not see the fly light upon the water; then you should bring the said fly round the stream, describing the segment of a circle, taking one step in advance at every throw. In this manner the fish see your fly only, and not the line. It is customary to give short jerks with the fly as you bring it round, something in the manner of minnow-spinning, but in a more gentle and easy way; and I think this manner is the most seducing you can adopt; it sets the wings in a state of alternate expansion and contraction that is extremely captivating."

How you are to fish a stream. - Salmon will often take your fly on one side of the river when they will not touch it on the other. In high water, the channel side, as a general rule, is the best, and at the cheek of the current; and you 
should not be in a hurry to pull your fly into the more bare and still parts of the channel, where the fish will come more cautiously and lazily. In low water it is best to throw over the channel from the rocky side, drawing at first rather quickly, that your fish may take your fly in the current, which is material. ' In very low water, indeed, where the fish may be said to give over rising, you may try your luck in the rapids by hanging your fly on them; indeed, you should always let your fly dwell on this sort of water, or the fish will either lose sight of it, or not choose to follow where you may wish him.

In hooking a rising fish, Mr. Scrope properly observes, "It is best to strike a little sideways, that the hook may fasten in the fleshy part of the mouth; whereas, if you pull straight up, you are apt to encounter the upper or bony part; or if the fish has not closed his jaws, and fairly turned off, you may pull the fly away from him too soon, to the disappointment of both parties. Sometimes, however, when a salmon is clean run, and in high glee, you can scarcely miss him, strike which way you will. In low water you must be somewhat dilatory in striking; you often see the heave of the water and a break before the fish has actually seized your fly. Give him time to turn his head in his way back to his seat, to 
which a salmon always returns after rising at the fly."

Salmon never take well when the weather is about to change; it is therefore useless to go out when the mercury remains at the changeable point. When it first sets in for a continuance of dry weather, the fish will rise about your hook, and only break the surface of the water; but before a flood they will spring clear out of it, for the purpose, perhaps, of filling their air-bladders before travelling. Salmon do not rise well during a fresh, and when the water is turbid after a flood you must not fish in strong streams, but in milder running ones near the bank, and at the tails of easy streams. When the horizon is charged with large, lazy, fleecy clouds, you will kill very few salmon.

Mr. Scrope gives a list of six killing salmonflies. They are as follow :-Kinmont Willie; wings, mottled feather from under the wings of a male teal, head, yellow wool; body, fur of the hare's ear; end of body, red wool; tail, yellow wool ; round the body black cock's hackle.

The lady of Mertoun; wings, the same as before; head, crimson wool; body, water-rat's fur; end of body, crimson wool; tail, yellow wool; round the body, black cock's hackle; end of body, a little red hackle. These flies should be dressed somewhat small. 
Toppy; wings, black feather from a turkey's tail, tipped with white; head, crimson wool; body, black bullock's hair; end of body, crimson wool; tail, yellow wool; body, black cock's hackle; end of body, small piece of red cock's hackle.

Michael Scott; wings, mottled feather from the back of a drake; head, yellow wool, with a little hare's fur next to it; body, black wool; end of the body, fur from the hare's ear; next to the hare's ear crimson wool; tail, yellow wool; round the body, black cock's hackle; end of the body, red cock's hackle; round the body, gold twist spirally. These two last flies should be dressed of a moderate size. The latter one Mr. Scrope calls "' a most killing wizard."

Meg with the muckle mouth. - Wings, from the tail of a brown turkey; head, crimson wool; body, yellow silk; end of body, crimson wool; tail; yellow or orange wool ; round the tail, red cock's hackle; round the body, gold twist, and over it hackle mixed with colour as above.

Meg in her braws. - Wings, light-brown from the wing of a bittern; head, yellow wool; next the head, mottled blue feather from a jay's wing ; body, brown wool mixed with bullock's hair; towards the end of the body, green wool, and next to that crimson wool; tail, yellow wool; round the body, gold twist; over that a large furnacehackle. These two last flies should be dressed 
very large, and then they will kill in deep and in rough water.

Mr. Scrope observes, " Concerning these flies I will note one thing, which is, that if you rise a fish with the Lady of Mertoun, and he does not touch her, give him a rest, and come over him with the Toppy, and you have him to a certainty, and vice versâ. This I hold to be an invaluable secret, and is the only change that during my long practice I have found eminently successful."

The following is a list of twelve general flies, all good ones, forwarded to me by Mr. Blacker.

No. 1. Body, claret pig's hair, claret hackle, and gold tinsel; wings, brown mallard's feather; black head; golden pheasant topping for tail; hook, No. 9. Limerick.

No. 2. Body, orange floss-silk or pig's hair, orănge hackle and gold tinsel; golden pheasant. topping for tail, and jay's feather at the shoulder; wings, to be made of brown mallard's and golden pheasant's neck feathers mixed; neck, black ostrich harl. Hook, No. 8 or 9. Limerick.

No. 3. Body, fiery-brown pig's-hair or mohair, with same coloured hackle, and gold twist wound over it ; topping for tail ; wings, mallard's feather mixed with golden pheasant's tail-feather. Hook, the same as before.

No.4. Body, peacock's harl, gold tinsel, and claret hackle; golden pheasant's topping for tail ; 
and brown turkey tail-feather for wings. Hook, No. 9.

No. 5. Body, purple pig's hair or floss silk, with black hackle and silver tinsel wound over it; wings, black spotted turkey tail-feather; black head. Hook as before.

No. 6. Blue body, blue hackle and silver tinsel; blue jay's feather at the shoulders; topping for tail; mixed gaudy wings. Hook, No. 8, and 9.

No. 7. Body, crimson mohair, red hackle, and gold tinsel ; brown turkey feather for wings; blue hackle at the head, and brown mallard's fibres at the tail. Hook as before.

No. 8. Cinnamon-brown body, same coloured hackle; gold twist ; mallard's wing.

No. 9. Red body, red hackle and gold twist; brown turkey tail or mallard's feather for wings; jay's feather at the shoulder, and topping for tail. Hook, No. 9.

No. 10. Black body, tipped with yellow 'pig's hair at tail; silver tinsel and black hackle; spotted turkey tail-feather for wings, and short topping for tail. Hook, No. 8, or 9 .

No. 11. Body, half orange, half purple, the orange next the tail; dark purple or blue hackle; orange hackle at the shoulder; topping for tail, and a mixed gaudy wing. Hook, No. 9 .

No. 12. Body, dun monkey's fur, dun hackle and silver tinsel; topping for tail ; bustard's wing- 
feather for wings, with topping in the centre; blue jay's feather at the shoulder, and black ostrich harl or blue mohair for head. Hook, No. 9.

Of these flies Mr. Blacker observes, "They may be varied as to size to suit all waters, and better cannot be used with respect to the proportions of colours. They have killed well in Great Britain and Ireland."

\section{SALMON FLIES FOR NORWAY.}

No. 1. Body, orange with claret hackle; wings, mottled-yellow turkey feather; red tail. Hook, No. 8.

No. 2. Body, orange with brown-red hackle and gold tinsel; mallard wings; topping for tail. Hook, 7, 8, or 9 .

No. 3. Scarlet body, with black-red hackle and gold tinsel; wings, brown turkey's tail-feather; topping for tail. Hook, No. 8.

No. 4. Body, brown pig's hair; fiery brown hackle rolled from the tail up; wings, brown mallard's feather; topping for tail. Very large hook, No. 7.

No. 6. Body, deep gold-coloured pig's hair, with gold tinsel and scarlet at the shoulder; legs, a bright olive hackle; wings, cream-coloured spotted turkey tail or peacock's feather.

No.7. Body, the same as before, with gold 
tinsel and red hackle; a tag of red mohair at the head; brown mallard's feather for wings. Vary the bodies with scarlet, yellow, or orange, retaining the same wings and hackles.

Sir Hyde Parker has been very successful in Norway with these two last flies.

Having given a good list of salmon flies, I will simply add, that salmon may be taken with the worm, or by spinning the minnow, or any small bright-coloured fish. If you fish with a worm, use a swivel-trace well leaded, and casting your bait across the stream, draw it gently towards you through the water, as if you were spinning. When a salmon takes it, do not strike him instantly, but give him a few seconds' law, and he will gorge the bait. Some anglers fish with the worm in Ireland when the water is discoloured, but the best time is in fine, fresh open weather, when the water is low and clear. As London anglers are in general very good spinners, they will find no difficulty in killing salmon in Scotland and elsewhere by spinning, - less difficulty than in catching Thames trout. On this subject Mr. Scrope makes a few valuable remarks:"Salmon do not take the minnow or the parr's tail so well in the 'Tweed as they do in the Tay, nor so well in the upper parts of the Tweed as they do in the lower. The minnow, in low water, is preferable to the parr's tail ; and it should be worked 
in the same manner as in trout-fishing, only not with so quick a motion. It is not necessary to use more than two hooks, namely, the large hook that passes through the minnow, and the lip-hook. Shot should be put on the casting-line, about a foot and a half from the bait, fewer or more, according to the strength of the stream. What is called the parr's tail is a pretty liberal allowance of the said little fish, consisting of a diagonal cut from the shoulder to the anal fin, so that, in fact, you have all the firm part of the fish, discarding the head and the stomach. In full water I think this bait is preferable to the minnow; and it has the advantage of a much firmer hold of the hook, not breaking like the soft parts of the minnow. Clean salmon will take this bait whenever the river is in order for the fly, or perhaps a little before it is so, even when the water is slightly discoloured. But foul fish, including kelts, never take it well in the upper parts of the Tweed, unless the water is clear, though they will take it in a drumly (slightly discoloured) water in the Tay; nor can any sport be expected with it in very warm weather. The best state of the water and the most convenient time, is between the fly and bait fishing, that is, when it is rather too low for the one, but not low enough for the other. The best weather is a fresh day, with wind to act upon the surface of deep pools. In summer the 
proper hour is early in the morning. After a night's burning, salmon take the minnow, small parr, or parr's tail, particularly well in the streams." I am confident that salmon would take many of our artificial fish, particularly Mr. Allies' Archimedian minnow. 


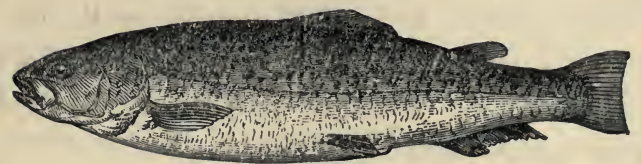

The common Trout. - Salmo fario.

THE common trout is unquestionably the handsomest and most delicately flavoured of our river fish, and, after the salmon, the best game the angler can pursue. It grows large or small, differently marked, coloured and shaped according to the qualities of the water it inhabits. The Thames trout is often caught as large as the middle-sized salmon, and is superior in flavour. In the small streams of Wales and Scotland the common trout are remarkably small. In the rivers of the midland counties the trout averages a pound in weight, and throughout the trout streams of the empire, more trout are caught under that weight than above it. A common trout in full season, weighing four pounds, is a royal fish; and a trout caught in the Dove during the drakeseason, and weighing from one pound to two, is a princely one. If you want to see a very handsome dish of trout, you will see it every day of the year at Chatsworth, in Landseer's "Bolton Abbey in the Olden Time." Trout should never be taken by 
the angler from September to March. In the intervening months they are either spawning or out of condition. I never saw a trout in prime season before May. In June trout are in their best condition.

In the spring months trout are found in the shallows and rough streams; in the summer months they seek deeper water, and the best fish are then caught in pools with the fly or worm, on gloomy breezy days when the water's surface is strongly ruffled. They are also found in whirlpools and holes into which sharps and shallows fall, and near to locks, flood-gates, rocks, large stones, weirs, under bridges, or between two streams running from under their arches, and likewise in the returns of streams where the water seems to boil, and in the decline of summer they are to be found near mill-tails. In September they run up to the shallow parts of streams, and enter brooks and even ditches to spawn. As food they are now, except in a few late rivers, good for nothing, and are so weak that they afford the angler no sport. In the early spring months trout will take the worm all day long, but in the summer months, with the usual weather, the artificial fly is the best bait during the day hours. In the morning and evening the worm and minnow will kill well. Spinning the minnow in the way described in the chapter on trolling is by far the best way of using that bait for trout. In fishing 
with a worm for trout do not use a float, but allow your worm to roll along the bottom of the water, your bottom-line being shotted so as to prevent your bait from being carried away by the stream. Sometimes spin your worm slowly against the stream, by means of a swivel on your foot-line, which should be of the finest and best gut. As a general rule, your tackle cannot be too fine for trout-fishing. Keep away from the banks, make as little noise as possible, and angle with every sort of caution and delicate handling for trout, otherwise you will not meet with success.

When angling for trout with any tripping or running baits, be they worms, caddies, gentles, or salmon roe, it is necessary to have as many shot on the line, ahout nine inches from the hook, as will readily sink the bait; because, if the stream be rapid, the bait is carried away without touching the ground, and consequently few trout will take it. While thus fishing with the running line, keep as far from the water, as you can, and let the bait be carried down into the trout haunts, and when a fish begins to bite, do not strike the first time you feel a slight tug, but rather slacken the line, and when you feel one or more sharp tugs together, then strike smartly. If it is a heavy fish, do not be too eager to land it. To these directions it may be added, that when a lob-worm is used as a tripping bait, lead is not 
necessary on the line, the weight of the worm being sufficient, and the absence of shot or lead advantageous. Allow the worm to roll of itself over the ground, which it will do in a natural manner if unencumbered with lead, and where there are large trout this bait well managed proves irresistible. As a general rule, lob-worms are most adapted for deeps, and for coloured or thick waters, and red worms or brandlings are best for brighter waters and not so profound. It will be found an excellent plan, when a bank overhangs a supposed trout hole, to cast a worm over the edge of it without approaching near. The line should not be shotted, the worm should roll naturally off the bank into the water, when if a trout be there, your bait will be taken almost to a certainty. Trout are to be taken in bright water and weather, with the worm, when they will not touch either minnow or fly, and there is certainly more art and sportmanship in fishing with a worm, than some people imagine. When to bright weather are added clear and shallow streams, much artifice must be employed. Your tackle must be very fine, your hooks small, and your worms well scoured and lively. A winch will enable you to vary the length of your line as occasion dictates, and though in general it must be as long as, or longer than your rod, yet where there are trees and other obstructions you may by 
shortening it get at the holes, and still contrive to keep out of sight, which you must do whether you kneel, stoop, or stand, and then if you can neatly and slightly drop in a lively brandling near the likely holds or haunts in a strong stream, especially near the top of it, let the sun shine ever so bright, be the wind rough or calm, and the water ever so clear, you will kill trout when they are not to be caught with any other bait.

Thames trout are to be caught best by spinning the gudgeon, dace, and bleak. In the summer months they will take large artificial flies. The best are very large red and furnace hackles, with winged flies made of a reddish feather, and red, brown, and yellow bodies. In the evening like nearly all the salmonidx, they will take artificial moths.

The salmon trout, bull trout, and white trout or sewin, are all to be taken with small salmon flies or lake flies. They may be caught also with the worm or by spinning a small natural or artificial fish. A very large coch-y-bonddu is a capital bait for the white trout or sewin. 


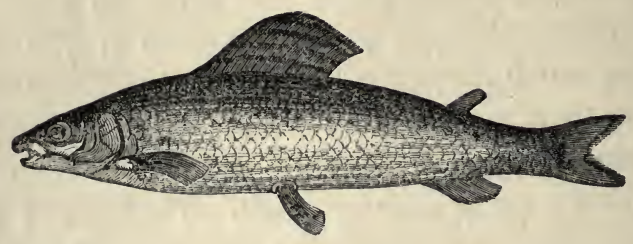

The Grayling. - Salmo Thymallus.

THE grayling is one of the most gracefully-shaped of the salmonidx. It is a favourite fish of mine, takes a fly boldly, but does not show much boldness after having taken it and been hooked. It is a gamesome fish, but not a game one. The grayling very rarely exceeds three pounds in weight, and a greater number are caught under twelve ounces in weight than above it. They are not, like the trout, indigenous to this country; and very probably, on account of their being in season in the winter, when trout are not, and being an excellent gastronomic substitute for that fish, were brought from the continent to this country by the monks or some other good judges of good things, that they might not be without a fresh -water delicacy during the most festive part of the year. The rivers of the midland counties are more celebrated for grayling than those of any other part of the empire. The grayling is not to be found in Ireland or Scotland. Though some fancy 
they emit a smell of thyme, I think they do not. They smell rather of cucumber than of any other vegetable. Mr. Blaine says, "The name of umbra which this fish bears has a far better derivation than that of thymallus, for it is so swift a swimmer as to disappear like a passing shadow. Graylings are in great esteem, and their flesh is white and palatable nearly all the year. They are in season from September to January, (some say they are best in October, others in December,) and they cannot be dressed too soon after they are caught. They lurk close all the winter, and begin to be very active and to spawn in April, or early in May; at which time, and during the surnmer, near the sides and at the tails of sharp streams, they will take all the flies that trout are fond of. They rise better than the trout, and if missed several times, will still pursue; yet, although they are so sportive after the $\mathrm{fl}_{\mathrm{y}}$, they are an inanimate fish when hooked, and the sides of the mouth are so very tender, that unless nicely treated, when struck, the hold will frequently be broken. In September they retire in shoals to the lower end of still holes."

I have lately received a very good account of the grayling from Mr. Henry George, of Worcester, the very efficient secretary of an association established in that city for the preservation of the fish of the Severn and its tributaries, and I here. 
willingly insert it, regretting that $\mathrm{I}$ have not space to make use of his remarks touching the trout and salmon of the Teme. Mr. George says, "Of all rivers running through 'merry England,' I think none produce such fine grayling as the Teme. Probably a few larger fish may be taken in one or two other rivers which are better protected, but for perfection in shape, colour, and flavour none can compete with Teme grayling. They are in season from September to Candlemas, and even later, but the months of October and September, if the weather be favourable, are the best for the fly-fisher. A Teme grayling in the height of condition in October or November, when first taken out of the water, is one of the handsomest and most symmetrical fish that rise at the fly in our beautiful streams, and if laid upon the hand, and looked at horizontally, presents the most beautiful purple or violet hue from snout to tail. The snout is sharp, and the eye lozenge-shaped; this fish is hog-hacked, and the back is of a dark purple colour, with small black square spots on the sides. The mouth (the under part of the lower jaw) and belly touch the ground together; the latter is brilliantly white, with a narrow edge or lacing of gold, extending along each side from the pectoral towards the ventral fin, and the tail, and pectoral, and ventral fins are of a beautiful purple. The 
dorsal fin, being very large, and standing up like that of the perch, is a perfect picture, covered with scarlet waves and spots intermingled with purple. The little velvet (adipose) fin on the back near the tail is also dark purple, and the fish smells like a cucumber. At the season I am speaking of grayling rise freely at the fly, but it requires some experience and judgment to suit their tastes. The heads and tails of fords with a gravelly or sandy bottom are their favourite haunts. They prefer rather deep water to shallow. The grayling takes a maggot very eagerly, and is, I think, a much more gamesome fish at the fly than the trout. I have frequently had them rise at my flies a dozen times in as many successive casts. They are not so easily alarmed as the trout, and many a time have I made half a dozen changes in my flies, and cast them all kinds of ways over a fine grayling, which kept continuously rising all the time, before I could induce him to look at them. They are rarely ever taken with the minnow. The grasshopper, when the water has been for some time low and fine, is an xcellent bait; and I find the artificial grasshopper much more killing than the natural one, perhaps from the greater facility with which it can be used. A little red worm is also a good bait for grayling when the water is a little disturbed. The spawning time of the grayling is the montl 
of April, sometimes a little earlier, at which season they come on the fords, and are then easily taken with the fly, though, of course, at such time, they ought to be strictly protected. After spawning they retire into the deeps, and the angler sees very little of them for a long time, and for this reason they are supposed to be a considerable time recovering, though I have never found them rendered so much out of season by spawning as some other fish. The grayling does not grow very fast. Those spawned in spring are three or four inches long in autumn, and in the following autumn about four or five ounces in weight; and in the-autumn after that, when about two and a half years old, they weigh from eight to twelve ounces. Grayling have been caught in the Teme, near Ludlow, weighing four pounds a piece, though one half that weight is rarely captured in this river now."

Sir Humphrey Davy says grayling grow much faster, stating that those hatched in May or June become in the following September and October nine or ten inches long, and weigh from five ounces to half a pound. The next year he says they arrive at from twelve to fifteen inches in length, and weigh from three quarters to a pound. I think Sir Humphrey wrong, and Mr. George. right. I should even think their growth is slower than that stated by Mr. George. Gray- 
ling require water of a milder temperature than trout do; water of the mean temperature of the atmosphere. They do not thrive in mountainous streams, and could never stem their rapid torrents or surmount their natural obstacles as salmon do. They cannot bound out of the water, and never jump at a bait after the manner of trout. "The grayling rises, however," says Mr. Ronalds, "with great velocity, and almost perpendicularly to seize his prey, at the top of the water, and descends as quickly after making a summerset, for the performance of which feat, the figure of his body, and the great dorsal fin seem well adapted." The following just remarks of Sir Humphrey Davy should be attended to by the angler : - "Besides temperature," he says, "Grayling require a peculiar character in the disposition of the water of rivers. They do not dwell, like trout, in rapid shallow torrents; nor, like char or chub, in deep pools or lakes. They require a combination of stream and pool; they like a deep and still pool for rest, and a rapid stream above, and gradually declining shallow below, and a bottom where marl and loam are mixed with gravel; and they are not found abundant except in rivers that have these characters." The largest grayling I have ever caught I found in the somewhat deep, rapid, and smoothly running tails of pools just before the formation of some rough 
stream, and in swift sheets of water just before rushing over the heads of rivers. I have killed more grayling with the fly early in April than in any other month. The flies they like best are duns and palmers, tipped with tinsel, and when the water is clear and smooth they will take dun midges by sinking them on a very fine casting line beneath the water, and allowing them to float with the current. I have killed grayling in the heart of winter, with frost and snow on the ground, when the water was not tinged with " snow broth," but ran low and clear. The time was from twelve to two o'clock, with the sun out, and the atmosphere tolerably temperate. The best autumn baits for grayling are gentles, and grasshoppers. The latter is the most deadly bait, and the way of using it has been already mentioned in the chapter on baits. 


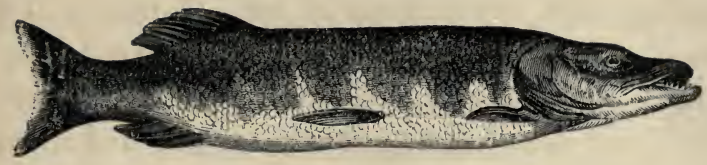

The Pike. - Esox Lucius.

The pike, commonly called jack when under three or four pounds in weight, is a well-known fish; like many of us, better known than trusted or treated. He is a greedy, unsociable, tyrannising savage, and is hated like a Blue Beard. Every body girds at him with spear, gaff, hook, net, snare, and even with powder and shot. He has not a friend in the world. The horrible gorge hook is specially invented for the torment of his maw. Notwithstanding, he fights his way vigoroúsly, grows into immense strength, despite his many enemies, and lives longer than his greatest foe, man. His voracity is unbounded; and, like the most accomplished corporate officers, he is nearly omnivorous, his palate giving the preference, however, to fish, flesh, and fowl. Dyspepsia never interferes with his digestion; and he possesses a quality that would have been valuable at La Trappe, - he can fast without inconvenience for a se'nnight. He can gorge himself then to beyond the gills without the slightest derangement of the stomach. He is shark and ostrich combined. 
His body is comely to look at; and if he could hide his head-by no means a diminished one-his green and silver vesture would attract many admirers. His intemperate habits, however, render him an object of disgust and dread. He devours his own children; but, strange to say, likes better (for eating) the children of his neighbours. Heat spoils his appetite, cold sharpens it; and this very day (30th December, 1846) a friend has sent me a gormandising specimen, caught by an armed gudgeon, amidst the ice and snow of the Thames, near Marlow. I envy his constitution.

Jack and pike spawn either in March or April, according to the mildness of the season and the temperature of the water. They retire for the purpose of procreation in pairs from the rivers, into creeks and ditches, and there, amongst aquatic plants, the female deposits her ova. The male of course accompanies the female, and when his milt has fecundated the ova, the pair return to deep water for the benefit of their own health, and quite regardless of the eggs, which they have left to be hatched by time and tide. Young pike grow rapidly, and it is said by the end of the first year attain a weight of two pounds. I doubt it, and am persuaded that afterwards pike do not each add every year a pound to its weight. They may do so for a few years, but the time comes when their growth is stationary, size varying only ac- 
cording to their good or bad condition, which is regulated by food and the season of the year.

The largest pike I ever saw weighed thirty-four pounds, but I have seen several each weighing between twenty and thirty pounds. The largest pike recorded to have been killed in the British Islands was one taken in the Shannon, and weighing ninety-two pounds. The head of one weighing seventy-two pounds, and which was caught with an artificial fly, is still to be seen at Kenmore castle. The celebrated Colonel Thornton asserts that he killed a pike in Loch Alva, Scotland, that weighed fifty pounds within two ounces. I should consider that the largest pike in the empire are to be found in the lakes and lochs of Ireland and Scotland; and that the greatest numbers are to be found in the meres and ponds of England. The anecdotes of pike are more numerous and astonishing than those of any other of our river fish. I do not credit many of them. I believe that pike digest their food in a few minutes, and that in consequence their voracity is prodigious. I will recount two or three reported instances. In 1801, a hook baited with a roach was set in the manor pond at Toddington, Bedfordshire; the next morning a large pike was caught, which with difficulty was got out. It appeared that a pike of three and a half pounds weight was first caught, 
which was afterwards swallowed by another, weighing thirteen pounds and a half, and both were taken. This story is barely probable, for I do not see how the hook that caught the lesser pike, should afterwards hook the larger one. It is recorded that a large pike put into a canal full of fish destroyed them all within twelve months, except one carp, weighing nearly ten pounds, which, though too large for the pike to swallow, showed by its scars that he had attempted to do so. I readily believe this anecdote. A pike caught in the Isis was found to contain a barbel of six pounds, and a chub of more than three. These nine pounds of food formed nearly a third of his own proper weight, which was thirty-one pounds and a half. I believe this, for I once caught in a net a pike weighing about four pounds, from whose mouth the tail of a trout weighing a pound was projecting. The pike had been caught in the purse of a drag-net with several trout, and whilst with them in the net had, no doubt, seized the one which was found sticking in his throat.

Pike are to be found in ponds, bog holes, ditches, canals, and weedy rivers. Their best haunts are in still, shady, and unfrequented waters, having a sandy, clayey, or chalky bottom. They grow larger in ponds and pools than in open, sharp running rivers. From May to October they are usually found near or amongst 
flags, bulrushes, and water docks, and under the renunculus aquaticus, when that plant is in flower. They are seldom found where the stream is rapid, but a retreat in the vicinity of a whirlpool or sharp bend is a favourite locality for them. From March to the end of May they resort to back waters, that have direct communication with the main stream. As winter approaches, they retire into the deeps, under clay banks, or where bushes impend over the water, and where stumps and roots of trees offer them a strong hold. How they are to be best caught I have taught in the chapter on trolling. They may be taken with various artificial baits, fish, frogs, mice; but the best of all artificial baits is a large gaudy artificial fly, or a colossal imitation of the dragon-fly.

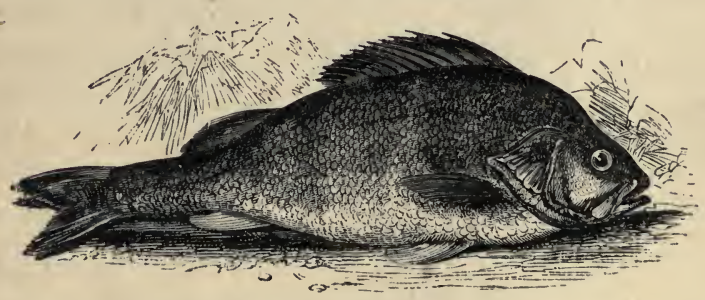

The Perch. - Perca fluviatalis.

The perch is an excellent river fish, bites boldly, and when hooked fights to the last. Though somewhat misshapen, his dress is handsome; but 
he seldom dresses better than in the Dutch oven or frying pan. Perch generally spawn in March. They are gregarious, which is remarkable, since fish of their marked predatory character are generally solitary. They grow to a goodly size. I have seen them weigh four or five pounds a piece, and it is said that one caught in the Serpentine, Hyde Park, weighed nine pounds. A perch that weighs two pounds may be considered anything but a contemptible fish. Very fine perch are caught in the Thames from Richmond upwards, the largest being caught by spinning a minnow or gudgeon. That part of the Thames which lies between Richmond and Staines, and which is under the useful surveillance of the Thames Angling Preservation Society, affords capital perch fishing. The deep streamy parts are the best. Minnows, gudgeons, and worms are the best baits for perch. They will also take gentles, and, in docks and tideways, shrimps. On the whole, however, a good lively red worm is the best general bait for perch. You may angle for them from February to November, during which time nearly any sort of weather, except sunny and bright, is favourable. They bite well on gloomy, windy days. If you light upon a shoal of them and catch one, you may catch them all if you do not frighten them by rough handling. 
HAUNTS OF, AND BAITS FOR, PERCH. 345

Some say that, as regards time, the perch bites best in the latter part of the spring from seven to eleven in the forenoon, and from two to six in the afternoon, except in hot and bright weather, and then from sunrise to six in the morning, and in the evening from six to sunset. In tide rivers, however, and the waters immediately connected with them, as docks, sluices, \&c., these general rules as to biting times do not apply; for it is there during the flow and ebb, when the natural food is principally on the stir, that the fish are most certainly on the look-out for it, let the time be what it may. Perch lie about bridges and mill pools ; in and near locks; about shipping, barges, and floats of timber, in navigable rivers, canals, and in wet docks; in the still part of rivers, in back waters, in deep gentle eddies; in ponds about sluices, and the mouths of outlets and floodgates, liking best sandy and gravelly bottoms. In deep waters and in docks, I recommend the paternoster line. If you angle in docks, deep and subject to the tide, use four hooks on your paternoster, baiting the lowest one with a minnow, roach, or gudgeon; the next with a worm, the third with a shrimp, and the fourth or upper hook with a gentle. In fresh water a shrimp should not be used. Perch have been lately caught with large gaudy lake trout flies, sunk beneath the surface of the water. Fish for perch with strong tackle, 
and get your prey out of the water as quietly and with as little disturbance as possible.

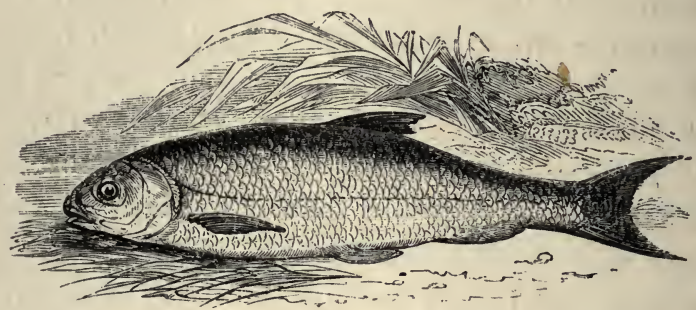

The Dace. - Cyprinus Leuciscus.

This little yellow silvery carp serves as a practical primer to the young angler. $\mathrm{He}$ is a reckless little fellow, and will snap at your worm, gentle, or paste near the bottom of the water, or jump at your fly on the surface with equal avidity. Dace are the best fish in the world to break in the young fly-fisher. They spawn in April, and are in condition again in May. They prefer the sides and tails of streams to still water, and are common to most of the large and small-rivers of England. They thrive best in moderate sized rivers. The dace of the Lea and Colne are larger than those of the Thames. In bottom fishing for dace the best baits are gentles and paste, and you must use very fine tackle. The best artificial flies for dace are red and black hackles, and small ant-flies. A gentle placed on the bend of the 
hook will often render the artificial fly more attractive. Dace may be caught by dibbing for them with the live house-fly, the flesh-fly, and natural ant-flies. Generally speaking, dace delight in rapid currents, scowers, and eddies. The point of junction between two streams is a favourite resort for them, and they are seldom absent from mill-tails. In hot weather they retire into the deeps, and seek for shelter beneath aquatic plants and the boughs of trees. Near London the largest dace are to be caught in the Colne, where they take the artificial fly well, and afford good sport, if trout are not on the rise. The scowers at Richmond, Thames Ditton, Hampton, Sunbury, Walton, Weybridge, and Laleham, are full of dace, and the localities well adapted for the use of the artificial fly.

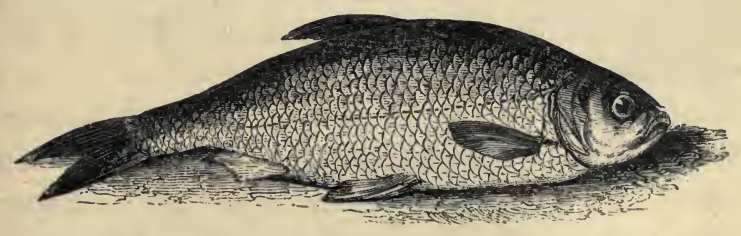

The Roach. - Cyprinus Rutilus.

This very pretty species of carp is a great favourite with London anglers, and by their skill in catching it they prove their superiority as 
bottom fishers. Roach spawn in May, and do not get into good condition again before the autumn months, which are the best months for angling for them. They do not like rough streams, and are generally found in easy swims, moderately deep, with a fine gravelly and sandy bottom. The best general baits for them are paste and gentles, though they will take small worms, and very frequently small artificial flies. It is impossible to bottom fish for roach with tackle too fine. All of it must be light and delicate, and of the best material, — rod, line, float, and hook. The foot-line should be made of single hairs, or at any rate of the very finest silk-worm gut. The rod of cane, light and long, just stiff enough to strike promptly and delicately. Some of the London rods are too long, being from twenty to twentyfour feet in length. A rod from sixteen to eighteen feet is quite long enough for bank fishing; and one of twelve feet is sufficiently long for punt fishing.

Mr. Blaine pays a high compliment to the roach, saying, "Roach angling offers much interest to the piscatory zealots, who are shut out from the high pursuits of fly-fishing. The roach is an elegant fish when taken, and it requires considerable skill to deceive it, whilst its game qualities are such that it contests the matter with the angler to the last, so as to yield no small 
triumph when landed. We have seen a roach of a pound in weight in a strong current in the Thames, raise the blood in the face of an angler of fair fame. They also, when in condition, bite freely; but we consider the principal hold they have, or ought to have, on the angler, is their great plenty, the numerous methods that may be employed to take them, to which may be added the time of the year that sport may be obtained with them, which is when few other fish yield any. From the very bottom of the water, every inch of the way up to the surface, they may be fished for in various manners; and when they are sunning themselves at the top they will take a fly with the best. No fish whatever exerts the capabilities of the angler so extensively as this; even the grayling (whose versatility in yielding sport is great also) must nevertheless give place to the roach, a precedence which we think will always rank him as a distinguished member in the piscatory list." For my own part, I think that if the roach could be caught with stout tackle, there would be an end to the rage for fishing for him. To be obliged to catch him with a single hair line is the chief cause of all the excitement felt by the roachfisher.

In the autumn and winter months you should use a very small hook, and very short in the shank. A line very lightly shotted, and the shots to be 
placed far from the bait. The link to which the hook is whipped should be of a single long horse hair of a good colour, and the upper part of the line may be of two twisted hairs, or very fine gut. Use a neat quill float, or a very small and light cork one. From your float to the point of your rod, let there be as little line out as possible, eighteen inches or two feet, and keep the point of your rod perpendicularly over your float in the water. Doing so will enable you to perceive the feeblest bite, and to strike with effect. Do not fish too close to the bottom, and ever and anon draw your bait up to the surface of the water, and let it sink gently again. Ground-bait moderately with the meal ground-bait recommended in the chapter on baits, particularly if you are angling with paste. With whatever bait you angle, ground-bait with a similar substance. Captain Williamson says, "You will find it proper to bait the place where you fish, with oatmeal a little browned over the fire, and then made up into balls with a small quantity of treacle. This draws them together far better than any other ground-bait I ever heard of. Throw a piece of it about the size of a marble, now and then, where your hook lies. It will gradually be dissolved, and attract numbers."

Roach will take artificial flies, but not so well as the dace. They like them best when tipped 
with a gentle, and sunk a few inches beneath the surface of the water. Salmon-roe is a capital bait for roach in still waters. In the spring months small red worms are the best baits. Then caddies, larvæ, and lobs and grubs of all sorts. In autumn and winter, gentles and pastes. I will conclude with an excellent extract from Captain Williamson:- "When the roach lie in the tide way, you must only expect them to bite when the flood comes in; especially at the first of it, when they commonly are very keen. If there is a fish in the water, they will bite during the latter part of the ebb. At such times they lie chiefly on the flat gravel sands, on the sides of streams, especially below bridges. In the evenings of very sultry weather, when a slight shower has fallen, they will take the common house fly, either on the surface, or at some depth. On the whole, I think that, next to the salmon roe, you will have best success with gentles, cad-baits, and blood-worms. But, above all things, have fine tackle; that is, a small hook, on a well chosen piece of superfine gut." In striking at roach, never use any other motion than that of the wrist; a slight, smart, side motion or jerk of which will be sufficient to cause your hook to penetrate, the barb of which should be finely pointed, and the whole made of the best and slightest steel wire. 


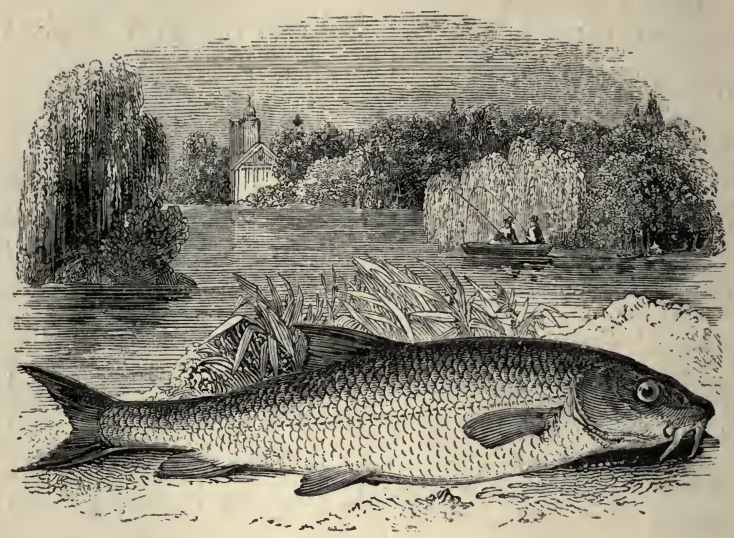

The BarbeL. - Cyprinus barbus.

This bluish-white carp is a lazy, wallowing gentleman, and the Launcelot Gobbo of the subaqueous pantries and cellars. The sound of the smacking of his lips tell you how fond he is of a good morsel. He acknowledges its receipt by the best music he can make, and yet what a shame it is that food should be thrown away upon this rather fine, though somewhat lubberly-looking, animal! So it is, however, and let him swallow good things ever so swiftly; let him be worm or gentlecrammed, his flesh is never the better for it, and his muscular tissues remain so flaccid and all his fibres so flabby, even whilst rioting in the midst of abundance, that, if incontinently afterwards 
caught and slain, a coroner's jury should judge the cause of death on view of the body, they would pronounce it to be inanition or the want of the common necessaries of life. He is one of those ungrateful creatures that always shame their nurses. His great angling value is his obstinacy, which gives him strength, notwithstanding the morbid appearances of the muscles, and he will resist your efforts to tow him out of the water with exciting energy. His large fins give him great power in the water, and he works heavily with them to get away when hooked, making them tread and beat the water like the paddles of a slow steamer.

Barbel spawn about midsummer, and are soon again as well as ever. July, August, and September are the best months to angle for them. Their general haunts are the deep parts of rapid rivers. They very seldom seek the shallow streams. They are generally in company, and, wherever you catch one, you may expect to catch two or more. They lurk under the shelter of overhanging banks, and, by their great power in stemming the stream, they are able to place themselves in the best positions for seizing displaced insects or small fish; for, though they will not, it is supposed, seize on live fish or other animals, they are considered greedily carnivorous, dead carcasses of all sorts being devoured, by them. They delight in deeps, 
weed-beds, in hollows surrounded by shelving sides, in the strong, deep currents of bridges; and piles, weirs, and locks are favourite resorts of theirs. They are on the feed during. the night, and you cannot, in fine summer weather, angle too early or too late for them.

The lob-worm is the best bait for barbel ; next gentles, prepared greaves, and cheese and bullocks' brains and pith. The latter are autumn and early winter baits. The most amusing and successful way of angling for barbel in the best rivers for them, such as the Thames and the Trent, is with the leger-line. The leger-lead should not be a perforated, flat piece of lead, but a perforated bullet, placed between two knots on the bottomline, about two feet from the hook. The knots should be an inch or two apart, and the piece of line between them should be of strong gimp, which will resist better than gut the attrition of the constantly moving bullet. The bullet enables you to cast your bait to any reasonable distance, and, when it sinks to the bottom, it keeps rocking there to the motion of the water, and the hole in it allows the worm to work away a little and wreath itself about, so that the bait is continually in attractive action. When the barbel takes it and moves off with it, he gets checked by the resistance of the bullet to the upper knob on the line; you feel the check; - strike sharply, and you cannot well fail in striking the leather-mouthed 
fish. Play him with moderate force, according to his size and the strength of your tackle, and, as soon as circumstances will permit you to get his head out of water do so. That deadens the play of his fins, and enables you to bring him over and into the landing net. If you wish to catch puntwells of barbel, ground-bait plentifully the spots you angle at for three or four nights previously. If you angle with worms, ground-bait with worms; if with gentles, ground-bait with them.

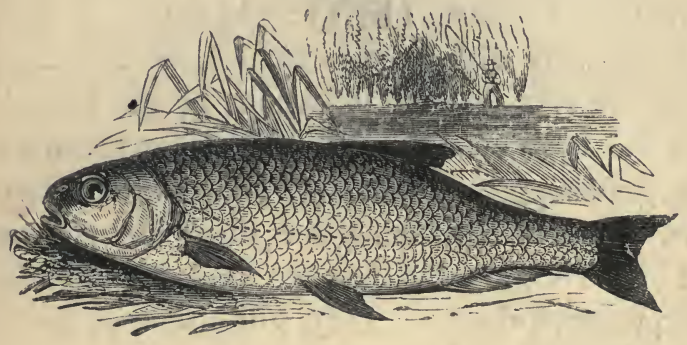

The Chub. - Cyprinus Cephalus.

This silvery bluish carp is an exceedingly fine, splendid-looking fish; but in him is fully realised the proverb, "All is not gold that glitters." His burnished gold outside hides a miserable interior. $\mathrm{He}$ is neither fish, flesh, nor good red herring. He is, to all intents and purposes, save in appearance, 
what the French call him, un villain, that is, a downright chaw-bacon or clod-hopper. Though M. A. Soyer, of the Reform Club, should condescend to dress him, I doubt whether he would make him fit to appear at any dinner table.

This fair outside and foul inside beauty spawns in April, and is soon in its usual condition. In the summer and autumn months it will take very wantonly artificial flies, large red hackles, and large palmers of different colours. In the evening it can be readily seduced by artificial moths. Its angling value rests in its occasional fondness for artificial insects. I have caught dozens of them in a few hours with large red and furnace hackles. They are very fond of imitations of the humble bee, and large blow-fly. In dibbing for them, use the grasshopper, cockchafer, and small butterflies. In bottom-fishing for them use worms; but in the hot months they are fondest of gentles and prepared cheese. They will also take pastes and salmon roe with great gusto. They are an exceedingly wary fish, therefore never let them see you or anything belonging to you through the water, - veluti in speculum. They are a cowardly fish, and after a rolling round or two give in. 


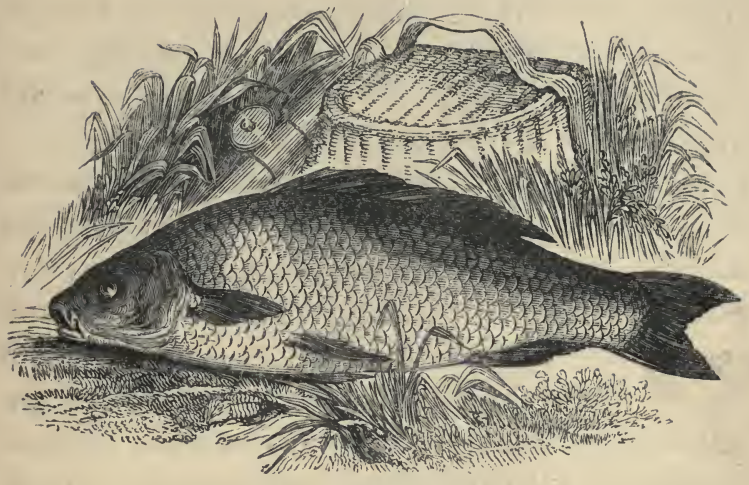

The CARP, - Cyprinus Carpio.

The yellowish olive carp stands at the head of a very numerous family, giving in my opinion no very honourable name to them. They are just as bad a race as the salmon tribe are excellent. If they are of Saxon descent, they are very inferior to 'our worst Celtic Salmonida. They happily eschew the mountain streams of the Gael, Celt, and ancient Briton. The Dutch waters of our low lands suit their burly bodies best. Neither I nor any one else can tell you how to catch with the angle the pater familias of the carp, he is so sly, and nibbles in such a namby-pamby way, that he strips the hook of its bait mouse-like. The angler that can catch large carp, Captain Williamson 
says, "must possess several qualifications extremely valuable to the angler, and bids fair by general practice to be, according to the old saying, able to teach his master." All I can tell you is, that you must fish for the carp proper with as fine tackle as you use for the roach, and at the same time it must be stronger, for carp grow to salmon size. The baits are worms, larva, grain, pastes, green gentles, and green peas. A sweet paste is perhaps the best: The angling season for carp is from February to October. In stagnant waters they are found in the deepest parts during the spring and autumn, particularly near flood-gates through which water is received and let off. In summer they frequent weed-beds and aquatic plants, and in rivers they are generally found in the still deeps having oozy bottoms, with rushes, reeds, and so forth. Worms are the best baits in spring; gentles and pastes in the spring and autumn. A Huntingdonshire correspondent once wrote to me, that he had a pond well stored with very large carp, and that after seven years' patience with rod, line, and hook, he could not catch one of them. He asked my advice. I told him that it lay in a net. 


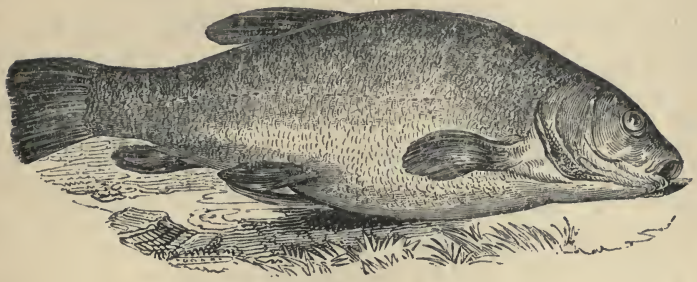

The Tench. - Cyprinus Tinca.

This mucous blackish olive carp inhabits waters stagnant on a loamy, clayey soil, with a soft muddy bottom. The best baits for tench are red worms, gentles, pastes, caddies, larvæ of all kinds, such as flag-worms, wasp-grubs, and caterpillars. They will also take water and garden snails. Fish close to the bottom, but not on it, particularly if it is a soft, muddy one. Captain Williamson says, "Tench do not swallow a bait very quickly, sometimes holding it in their mouths for a while; therefore give them good time, and let them either keep the float down, or, as is often the case, let them rise with the bait, so as to lay your float on the water. This is an excellent sign, and warrants your striking, but rather gently, lest the fish be only sucking the bait, for he will seldom return after it is drawn from his mouth." The best time for angling for tench is 
early and late of mornings and evenings, but they bite freely and all day long during the fall of mild rain in warm weather. The tench is said to be an aquatic apothecary, - a leech that cures with his slime the wounds of other fish. The pike in consequence respects this submarine Machaon. Gratitude therefore is the pike's one virtue linked with a thousand crimes.

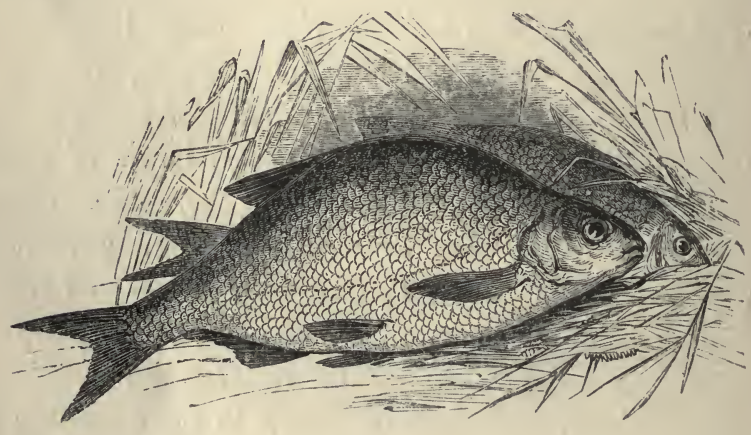

The Bream. - Cyprinus Brama.

This broad olivaceous carp grows to a very large size in such rivers as the Ouse and the Oundle. Bream are an exceedingly coarse fish, but they bite freely in warm, gloomy, windy weather, and a warm, drizzling rain sharpens their appetites. A small red worm is the best bait for 
them in the spring; in summer gentles and salmon roe. They rise freely at natural flies, particularly the house-fly, bluebottle, and stone-fly, and in the evening at the various sorts of moths. You must dib for them as cautiously as for chub, keeping carefully out of sight. In bottom-fishing your success will be augmented by ground-baiting with lumps of clay mixed with clotted bullock's blood.

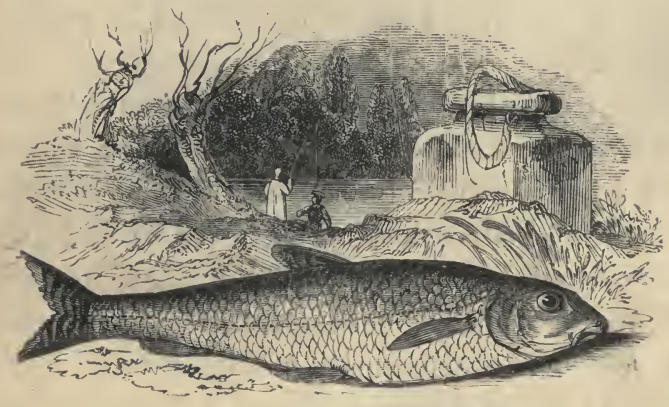

The Gudgen.

This is a good, game, little fish, and the best to initiate the young angler into the art. of bottom-fishing. The best bait is a very small red worm or a part of one. Hundreds of them are to be caught in the moderately shallow streams of the Thames, and indeed in the shal-

B B 
lows of all our mixed rivers. By a mixed river I mean one that is not confined to the production of the salmon tribe, but which produces the carp family and other coarse fish. If you can mud the bottom, that is, cause an artificial discoloration in the water by means of an iron rake, or any other way, you will draw to the spot most of the gudgeon in the immediate vicinity, and very probably kill the majority of them. You must then move to another spot and repeat the artificial discolouration of the water as before. Mudding the water is the grand secret of success in gudgeon angling.

One word of advice in this penultimate page to the reader. Let him follow one maxim, which I wish I had always followed, viz., that repetition is the soul of instruction. Whenever he finds, on a first perusal, any passage of the preceding pages obscure, let him re-peruse it attentively, and I flatter myself the obscurity will disappear. If it dö not, let him try a third time, and if then a difficulty remain, the fault most probably will be mine. Still the reader will have done well, for having persevered. In like manner, should any thing I teach seem at first difficult to be practised well, let reiterated attempts be made towards the attainment of perfection, and I am confident that the result of repetition will be surprise that a thing, found after some little patient practice of such 
easy accomplishment, should ever have been considered otherwise.

This light labour of mine is on the point of ceasing. I may now write-finis coronat opus, whether with a triumphant thought or not, none, save myself, can know. I have finished with the gudgeon, though, in angling regularity, I ought to have concluded with the salmon. But a moral may be drawn from my proceeding. What man begins with he ends with - childishness. The childish passion of gudgeon-angling may return to the true angler when he has "fallen into the lean and slippered pantaloon," and it will do so, if it be true that " the ruling passion is strong in death." 
LONDON :

SPotTiswoode and SHaw, New-street-Square. 
A CATALOGUE OF

\section{NEW WORKS AND NEW EDITIONS}

PRINTED FOR

MESSRS. LONGMAN, BROWN, GREEN, AND LONGMANS, LONDON.

\section{CLASSIFIED INDEX.}

AGRICULTURE \& RURAL AFFAIRS.

Pages Bray's Essay on Agrieulture, etc. - - $\quad 7$ Crocker's Land Surveying - . - - 9 Davy's Agricultural Chemistry - - . Jolinson's Farmer's Encyclopædia - . 16 Loudon's Encyclopadia of Agriculture - 18

, Self-Instruction for Farmers, ete. 18 (Mrs.)Lady's Country Companion 18 L,ow"s Breeds of the Domesticated Animals 19 , Elements of Agriculture - - 19

, On Landed Property - - - 19

"On the Domesticated Animals - 19 Pänell on Roads - - _ - - 23 Thomson on Fattening Cattle, etc. - $\quad-29$ Topham's Agricultural Chemistry - 30 Whitley's Agricultural Geology - _ 32

\section{ARTS, MANUFACTURES, AND} ARCHITECTURE.

Brande's Dictionary of Science, etc.

Bray's Essay on Manufactures, etc.

Buckler's St. Alban's Abbey

Budge's Miner's Guide

Cartoons (The Prize)

Cresy's Encycl, of Civil Eugineering

De Burtin on the Kuowledge of Pictures

Dresden Gallery

Gwilt's Fncyclopmdia of Architecture - 10

Haydon's Lectures on Painting \& Design 13

Holland's Manufactures in Metal - 14

Lerebours On Photography - - $\quad$ - 17

I.oudon's Rural Architecture - _ _ - 18

Moseley's Engineering and Architecture $\quad 22$

Parnell on Roads

Porter's Manufacture of Silk - _ - 24

" " Porcelain \& Glass 24 St Warming and Ventilating 25 Ure's Dictionary of Arts, etc. - - 31 Wilkinson's Engines of War - _ - $\quad 32$

\section{BIOGRAPHY,}

Aikin's Life of Addison Bell's Lives of the British Poets - : 6 Dover's Life of the King of Prussia - $\quad 1_{0}$ Dunham's Farly Writers of Britain - $1_{0}$ , Lives of the British Dramatists $1_{0}$ Forster's Statesmen of the Commonwealth $1_{1}$ Life of Jebb - - _ - I1 Gleig's British Military Commanders - 12 Grant (Mrs.) Memoir and Correspondence 12 James's Life of the Black Prince - $\quad 15$ Eminent Foreign Statesmen - 15 Lál's (M.) Life of Dost Mohammed - - 21 Leslie's Life of Constable - - - 17 Mackintosh's Life of Sir T. More - - 19 Maunder's Biographical Treasury - $\quad$ - 21 Roscoe's Lives of Eminent British Lawyers 26 Russell's Bedford Correspondence
Shelley's Literary Men of Italy, etc. Pages Fminent French Writers - $\quad 27$ Southey's Jives of the British Admirals - 28 " Life of Wesley - - - - 28 Townsend's Twelve eminent Judges - 30 Waterton's Autobiography and Essays - 31

BOOKS OF GENERAL UTILITY.

Acton's (Eliza) Cookery Book - $\quad 5$ Black's Treatise on Brewing - _ - 6 Collegian's Guide - - • - - 8

Donovan's Domestic Economy - - 10

Hand-Book of Taste - _ _ - 13

Ilints on Etiquette - $-\bullet_{-} \cdot{ }_{-}$

Hudson's Parent's Hand-Book : - 15

, Fixecutor's Guide - : : 15

On Making Wills - : - 15

Loudon's Self Instruction - - - 18

", (Mrs.) Amateur Gardener - 18 Mnunder's Treasury of Knowledge .

, Scientific and Literary Treasury 21

, Treasury of History - - 21

"Bographical Treasury : : 21

Parkes's Domestic Duties • • - 23

Pycroft's Course of English Reading - 24

Reader's Time Tables - - - - 25

Riddle's Eng.-I,at. and Lat,-Eng. Dict. - 25

Robinson's Art of Curing, Pickling, etc. 26

Rowton's Debater - - _ _ - 26

Short Whist - - - - - : $2 \overline{7}$

Thomson's Management of Sick Room - 30 Interest Tables - - : 30

Tomlins'Law Dictionary : - : :

Walker's Dictionary, by Smart - $\quad 31$

Webster's Eucycl. of Domestic F.conomy 32

BOTANY AND GARDENING. Abercrombie's Practical Gardener - • 5 Callcot's and Main's Gardener - 5 Conversationsture Herbal - - - 8 Drummond's First Steps to Botany - : 10 Henslow's Botany - - 13 Hoare On the Grupe Vine on Open Walls 14 , On the Roots of Vines - : - 14 Hooker's British Flora : : : : 14 Jackson's Pictorial Flors - : - - 15 Lindley's Theory of Horticulture : $\quad 17$

, Orchard and Kitchen Garden : 17

"Introduction to Botany - : 17

Flora Medica

$\because \quad$ Synopsis of British Flora : : 17

Loudon's Hortus Britannicus - : : 18

,H Hortus Lignosus Londinensis - 18

", Encyclopædia of Trees \& Shrubs 18

,", Gardening - 18

", Plants ". 18

"Suburban Gardener - - - 18

". Self-Instruction for Gardeuers 18 ". (Mr.) Amateur Gardener - : 18 Repton's Landscape Gardening, $\mathrm{etc.} \quad 25$

London: Printed by M. Mason, Ivy Lane, Paternoster Row. 

Roberts on the Vine - - Rogers's Vegretable Cultivator - : - $\quad 26$ Schleideu's Scientific Botany - _ - $\quad 26$ Smith's Introduction to Botany - - 27

Smith's Euglish Flora - - - - $\quad 27$ , Compendium of English Flora - 27

\section{CHRONOLOGY.}

Blair's Chronological Tables .

Nicolas's Chronology of History

Tate's Horatius Restitutus - - - 29

\section{CONIMERCE AND MERCANTILE AFFAIRS.}

Baylis's Arithmetic of Annuities - - 6 Gilbart On Banking M'Culloch's Dictionary of Coinmerce : 20 Reader's Time Tables - $\quad-\quad-25$ Steel's Shipmaster's Assistant - : - 28 Thomson's Tables of Interest - - - 30 Walford's Customs' Laws _ _ . 31

GEOGRAPHY AND ATLASES.

Butler's Ancient and Modern Geography Atlas of Modern Geography ", ," Ancient Geography ", General Geography Cooley's World Surveyed Forster's Historical Geography of Arabia 11 Hall's Large Geueral Atlas - - - 13 M'Culloch's Geographical Dictionary - 20 M'Leod's Sacred Geography - : - 20 Murray's Encyclopiedia of Geography - 22 Ordnance Maps, and Publications of the Geological Society

Parrot's Ascent of Mount Ararat - - 8

\section{HISTORY AND CRITICISM.}

Adair's (Sir R.) Mission to Vienna - $\quad 5$ " Constantinople - - - - 5

Bell's History of Russia - - - - 6

Blair's Chron, and Historical Tables - 6 Bloomfield's Translation of Thucydides Cooley's Maritime and Inland Discovery 8 Crowe's History of France - De Sismoudi's Fall of the Roman Empire 10 "Italian Republics - - 10 Dunham's History of Spain and Portugal 10 , Europe in the Middle Ages - 10 " History of the German Kinpire 10 ", Denmark, Sweden, and Norway 10 ". History of Poland - : - 10

Dunilop's History of Fiction - - 10 Eecleston's English Antiquities : : 10 Fergus's United States of America - 11 Grant (Mrs.) Memoir and Corespondence 12 Grattan's History of Netherlands - 12 Grimblot's William III. and Louis XIV. 12 Guicciardini's Hist. Maxims - - o 13 Haisted's Life of Richard III. _ _ $\quad$ - 13 Haydon's Lectures on Painting and Design 13 Historical Pictures of the Middle Ages - 14 Horsley's (Bp.) Biblical Criticism : - 14 Jeffrey's (Lord) Contributions - - 16 Keightley's Outlines of History : : 16 Laine's Kings of Nurway - - - 16 Lemprière's Classical Dictionary : : 17 Macaulay's Essays - : : 19 Mackinnon's History of Civilisation : 19 Mackintosh's History of England - : 19 Miscellaneous Works - 19 M'Culloch's Dictionary, Historical, Geo. graphical, and Statistical

Maunder's 'Treasury of History
Maury's Statesmen of America

Milner's Church History -

Moore's History of Ireland

Mosheim's Ecclesiastical History

Nicolas's Chronology of History

Ranke's History of the Reformation

Rome, History of

Russell's Bedford Correspoudence -

Scott's History of Scotland -

Sinnett's By ways of History

Stebbing's History of the Christian Church 28 , History of the Reformation - 28

,. Church History - - - 21

Switzerland, History of - : - - 28

Sydney Smith's Works - : - : 28

Thirlwall's History of Greece - - : 29

Tooke's History of Prices - - - 30

Turier's History of England - : - 30

Tytler's Elements of General History - 31

Zumpt's Latin Grammar - : - : 32

\section{JUVENILE BOOKS.}

Amy Herbert - - - - : : 5

Gertrude - - : 11

Gower's Scientific Phenomena - - 12

Hawes's Tales of the N. American Indians 13

Howitt's Boy's Country Book - - - 15

Laneton Parsonage - - - - - 16

Mackintosh's Life of Sir T. More : 19

Marcet's Conversutions-

On the History of Fingland

On Chemistry - : - 20

On Natural Philosophy - : - 20

On Political Economy $\quad$ : $\quad 20$

On Vegetable Physiology - - - 20

On Land and Water - - _ - 20

On Language - $-\quad-\quad-20$

Marryat's Musterman Ready - - $\quad 20$ " Privateer's-Mail - - - 20

" Settlers in Canada - - - 20

"Mission; or, Scenes in Africa 20

Pycroft's Course of English Reading - 24

MEDICINE.

Bull's Hints to Mothers -

Management of Children

'”

Elliotson's Human Physiology - : 11

Esdaile's Mesmerism In India - - - 11

Holland's Medical Notes - _ - : 14

Lane's Water Cure at Malvern - - 16

Pereira On Food and Diet : - : 23

Reece's Medical Guide - - - - $\quad 25$

Thomson on Food - $\quad-\quad$ - $\quad$ - 29

\section{MISCELLANEOUS.}

Adsliead on Prisons - • $\quad$ • $\quad 5$

Bray's Philosophy of Necessity - :

, Social Systems - - - $\quad-7$

Cartoons (The Prize) - - - -8

Clavers's Forest I,ife - - - - 8

Cocks's Bordeaux, its Wines, etc. - - 8

Collegian's Guide - - - - $\quad 8$

Colton's Lacon - - - - - - 8

De Burtin On the Knowledge of Pictures 9

De Morgan On Probabilities - _ - 9

De Strzelecki's New South Wales - $\quad 10$

Dresden Gallery - - _ - - 10

Dunlop's History of Fiction - - - 10

Good's Book of Nature - - - - - 12

Gower's Scientific Phenomena - - 12

Graham's English - - - - : 12

Grant's Ietters from the Mountains -12

Guest's Mabinogion - - - - : 12

Hand-Book of Taste : : - : $: 13$

Higgins's Anacalypsis - : : : 
Hobbes's (Thos.) complete Works Pages

Howitt's Rural Life of England _ - 14 , Visits to Remarkable Places - 14 , Student Life of Germany - 15

"Rurul and Social Life of Germany 15

" Colonisation and Christianity - 15 Jaenisch on Chess Openings - - : 15 Jeffrey's (Lord) Coutributions _ - 16 King's (Col.) Argentine Republic - - 16 Lane's Lifc at the Water Cure - . 16 Loudou's (Mrs.) Lady's Country Companion 18 Macaulay's Critical and Historical Essays 19 Mackintosh's (Sir J.) Miscellaneous Works 19 Maitland's Church in Catacombs - $\quad-20$ Michelet's Priests, Women, and Families 21 "The People - - - 21 Necker De Saussure's on Fducation - 23 Perry On German University Education - 24 Peter Plymley's Letters - _ _ - 24 Plunkett on the Navy - _ _ _ - 24 Pycroft's English Course of Reading - $\$ 4$ Roget's Economic Chess board - - 26 Rowton's Debater - - _ - $\quad 26$ Sandford's Parochialia - _ - - -26 Seaward's Narrative of his Shipwreck - 26 Southey's Common-Place Book - - 28 , The Doctor, etc. Vol. VI. - 28 Sydney Smith's Works - - . - 28 Thomson on Food of Animals, etc. - . 29 Walker's Chess Studies - _ _ - 31 Willoughby's (Lady) Diary _ _ - 32 Zumpt's Latin Grammar - - . - 32

\section{NATURAL HISTORY IN GENERAL.}

Catlow's Popular Conchologr - - 8 Doubleday's Butterfies and Moths - 10 Drummond's Letters to a Naturalist - 10 Gray's Figures of Molluscous Avimals - 12 ," and Mitchell's Ornithology - - 12 K'́rby and Spence's Entomology - $\quad-12$ Lee's Taxidermy - • - . 17 " Elements of Natural History - - 17 Newell's Zoology of the English Poets - 23 Stephens' British Coleoptera - - - 28 Swainson on the Study of Natural History 29

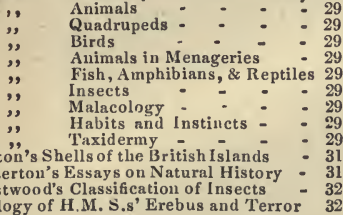

NOVELS AND WORKS OF FICTION. Bray's (Mrs.) Novels - : : $\quad: 7$
Dunlop's History of Fiction : $\quad-10$ Fuwn of Serturius - - - - - 11 Marryat's Masterman Ready - - - 20 " Privateer's-Man - $\quad-\quad 20$

", Settlers in Canada - - - 20 cricles, A Tale of Athens Southey's, The Doctor, etc. Vol, VI. : 28 Willis's (N.P.) Dashes at Jife - - 32

\section{ONE VOLUME ENCYCLOPAEDIAS AND DICTIONARIES.}

Blaine's, of Rural Sports - - - - 6 Brande's, of Science, Literature, and Art 7
Copland's, of Medicine

Pages

Cresy's, of Civil Fingineering - : : 9

Gwilt's, of Architecture - : : - 13

Johnson's Farmer - - - - - 16

Loudon's, of Trees and Shrubs : - 18

, of Gardening - _ - -

" of Agriculture - - _ : 18

" of Plauts - _ - - - 18

M'C'ulloch's Geographical Dictionary -18

" Dictionary of Commerce : 20

Murray's Encyclopadia of Geography - 22

Ure's Arts, Manufactures, and Mines : 31

Webster's Domestic Economy - - 31

\section{POETRY AND THE DRAMA.}

Aikin's (Dr.) British Poets - • - 26

Bürger's Leonora, by Cameron - - 7

Chalenor's Walter Gray - - - - 8

Collier's Roxburghe Ballads - - 8

Costello's Persian Rose Garden - $\quad-9$

Gray's Elegy, illuminated - - - -

Gutch's Robin Hode : : : : 13

Horace, by Tate - - _ - : 29

Howitt's (Mary) Ballads : -

L. E. L.'s Poetical Works - : : 17

Linwood's Anthologia Oxoniensis : : 18

Macaulay's Lays of Ancient Rome : : 19

Mackay's Enulish Lakes - : : 19

Montgomery's Poetical Works : - 22

Moore's Poetical Works - : : 22

"Lalla Rookh - _ - : 22

Moral of Flowers

Poets'Pleasaunce - - - - : - $\quad-24$

Pope's Works - : : : : - :

Reymard the Fox : : : : $: 25$

Shakspeare, by Bowdler : : : : 27

Sheldon's Minstrelsy - : : : : 27

Sophocles, by Linwood : : : : $\quad$ : 28

Southey's Poetical Works : : : 28

Spiri' British Poets - - - $\quad 26$

Spirit of the Woods - - - - 28

Thomson's Seasons - $\quad-\quad-29$

Watts's (A.A.) Lyrics of the Heart - 31

\section{POLITICAL ECONOMY AND STATISTICS.}

Gilbart on Banking - $-\overline{-} \quad-\quad-12$ M'Culloch's Geographical, Strtistical, and

Historical Dictionary

M.Culloch's Dictionary of Commerce - 20 Literature of Polit. Economy 19 Ou Tuxation and Funding - 19

", Statisties of the British Empire 19 Marcet's Conversatious on Polit. Economy 20 Symonds' Merchant Seamen's Law _ 29 Thornton on Over population - - $\quad 30$ Tooke's History of Prices - - - 30

\section{RELIGIOUS AND MORAL WORKS, ETC.}

Amy Herbert, edited by Rev W. Sewell Barrett's Old Testament Criticisms - Bloomfield's Greek Testament - :

" College and School ditto - 6 $\begin{array}{ll}\text { College and School dicto } & 6 \\ \text { Lexicon to Greek Testanent } & 6\end{array}$ Burder's Oriental Customs - - - 7 Burus's Christian Philosophy - - 7 Call'cott's Scripture Herbal $\quad-\quad-\quad \div 8$ Cooper's Sermons - - - - - $\quad-9$ Dale's Domestic Liturgy - $\quad$ - $\quad 9$ Dibdin's Sunday Library - • : : 10 Doddridge's Family Expositor : : 10 
Englishman's Hebrow Concordance - 11 Greek Concordance - $\quad 11$

Ftheridye's Syrian Churches - - II

Fitzrey's (Lady) Scripture Conversations 11

Forster's Historical Geography of Arabia 11 Life of Bishop Jebl - - - 11

From" Oxford to Rome - - - - 11

Gertrude, edited by the Rev. W. Sewell - 11

Hook's (Dr.) Lectures on Passion Week 14

Horne's Introduction to the Seriptures - 14

"Compendium of ditto - - 14

Horsley's (B p.) Biblical Criticism - - 14

Jeb', Psalms - - - - 14

Jebb's Correspondence with Kuox - - 15

Translation of the Psalms - $\quad-15$

Kin's Christmas in Rome - - • - 16

Knox's (Alexander) Remains - - - 16

Laing's Notes on the German Schism - 16

Laneton Parsonage - - - - - 16

Letters to my Unknown Frieuds - - 17

Maitland's Church in the Catacombs - 20

Margaret Percival - - - - - - $_{0}$

Michelet's Priests, Women, and Families 21 " and Quinet's Jesuits - - 21 Milner's Church History - - - - 21

Moore on the Power of the Soul - $\quad 22$ ", on the Use of the Body - $\quad$ - 22 Mosheim's Ecclesiastical History - $\quad 22$

My Youthful Companions - - - 22

Parables - - _ - - - - 23

Parkes's Domestic Duties - - - 23

Pearsou's Prayers for Fanilies.

Peter Plymley's Letters - _ _ - 24

Pitman's Sermons on the Psalms - - 24

Quinet's Christianity - - - - 25

Riddle's Letters from a Godfather - $\quad-25$

Sandford On Female Improvement - : 26

"On Woman - - - - 26

", 's Parochialia - : : -

Sermon on the Mount (The) - - - 27

Shepherd's Horæ Apostolicæ - - 27

Smith's Female Disciple - _ _ - $\quad-27$

, (G.) Perilous Tines - - - -27

"B Religion of Ancient Britain 27

Stebbing's Church Historg - : - - 28

Steepleton -

Sydney Smith's Sermons - : - 28

Tate's History of St. Paul _ - - 29

Tayler's (Rev.C.B.) Margaret ; or, the Pearl 29

,", Sermons - $\quad 29$

" " " Dora Melder - $\quad$ - 29

"' Lady Mary : : 29

Taylor's (Jeremy) Works - - - 29

Tomline's Introduction to the Bible $\quad-30$

Trevor; or the New St. Francis - - 30

Trollope's Analecta Theologica - - 30

Turner's Sacred History - - - 30

Wardlaw On Socinian Controversy - 31

Weil's Bible, Koran, and Talmud - $\quad 32$

Wilberforce's View of Christianity - 32

Wilkinson's Catechisms of Church History 32

Willoughby's (Lady) Diary - - - 32

Woodward's Essays, Sermons, etc. $\quad-32$

\section{RURAL SPORTS.}

Blaine's Dictionary of Sports - _ -

Ephemera on Angling - - - - ]

Hansard's Fishing in Wales : - - 13

Hawker's Instructions to Sportsmen -

Loudon's (Mrs.) Lady's Country Companion 18

Stable Talk and Table Talk? 28

\section{THE SCIENCES IN GENERAL,} AND MATHEMATICS.

Bakewell's Introduction to Geology

Balmain's Lessons on Chemistry

Brande's Dictionary of Science, etc.

Brewster's Optics

De la Beche on the Geology of Cornwall, etc. 9

Donovan's Cliemistry - _ - 10

Farey on the Steam Engine - _ - 11

Fosbroke on the Arts of the Ancients - 11

Gower's Scientific Phenomena - - 12

Greener on the Guil - - - - 12

Herschel's Natural Philosophy - - 13

"' Astronomy - - - - 13

Holland's Manufactures in Metal -
Humboldt's Cosmos

Hunt's Researches on Light - : : 15

Kater and Lardner's Mechanies - - 16

La Place's System of the World - - 16

Lardner's Cabinet Cyclopædia _ _ 16

, Hydrostatics and Pneumatics - 17

," and Walker's Electricity - 17

, Arithmetic - - _ - 16

" Geometry - - - - 17

'Treatise on Heat - - -17

Thotography - - - $-1 \bar{c}$

Memoirs of the Geological Survey - -21

Moseley's Practical Mechanics - $\quad 22$

Nengineering and Architecture 22

Owen's Lectures On Comparative Anatomy 23

Pearson's Practical Astronomy - - 23

Peschel's Physics - - - - - 24

Phillips's Palæozoic Fossilso Cornwall, etc. 24

"Guide to Geology - - - 24

", Treatise on Geology - - $\quad$ - 24

Poisson's Mechanics - - _ - 24

Portlock's Geology of Londonderry - 24

Powell's Natural Philosophy - - - 24

Quarterly Jourual of the Geolog ical Society 24

Ritchie (Robert) on Railways - $\quad 25$

Topham's Agricultural Chemistry - $\quad-30$

Whitley's Agricultural Geology - $\quad$ - 32

\section{TRAVELS.}

Allan's Mediterranean - - - -5

Cooley's World Surveyed - - $\quad$ - 8

Costello's (Miss) North Wales - $\quad$ - 9

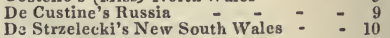

Erman's Travels through siberia - - 8

Harris's Highlands of Ethiopla - $\quad-13$

King's (Col.) Argentine Republic - • 16

Kip's Holyduys in Rome - $\quad$ - 16

Laing's Tour in Sweden - $\quad-\quad$ - 16

Mackay's English Lakes $\quad-\quad-\quad-19$

Montauban's IV anderings $\quad$ - $\quad$ - $\quad 22$

Parrot's Ascent of Mount Ararat - $\quad-8$

Paton's (A.A.) Servia - - - $\quad-23$

Pedestrian Remodern Syrians - $\quad 23$

Seaward's Narrative of his Shipwreck -26

Tischendorf's 'Travels in Russia - : 30

Von Orlich's Travels in India _ _ 31

VETERINARY NEDICINE

Miles On the Horse's Foot _ _ _ 21 Stable Talk and Table Talk - - - 28

Thomson on Fattening Cattle
Winter On the Horse 


\section{NEW WORKS AND NEW EDITIONS.}

ABERCROMBIE.-ABERCROMBIE'S PRACTICAL GARDENER, AND IMPROVED SYSTEM OF MODERN HORTICULTURE, alphabetically arranged. 4th Edition, with an Introductory 'Treatise on Vegetable Physiology, and Plates by W. Salisbury. 12mo. 6s. boards.

\section{ABERCROMBIE AND MAIN.-THE PRACTICAL GARDENER'S COM-} PANION; Or, Horticultural Calendar: to which is added, the Garden-Seed and Plant Estimate. Edited, from a MS. of J.Abercrombie, by J. Main. 8th Edition. 32mo.2s. fd. sewed.

\section{ACTON (MISS).-MODERN COOKERY,}

In all its Branches, reduced to a System of Easy Practice. For the use of Private Families. In a Series of Practical Receipts, all of which have been strictly tested, and are given with the most minute exactness. By Eliza Acton. New Edition, to which are added, Directions for Carving. Foolscap 8vo, with Plates and Woodcuts, 7s, 6d. cloth.

ADAIR (SIR ROBERT).-AN HISTORICAL MEMOIR OF A MISSION TO THE COURT OF VIENNA IN 1806. By the Right Honorable Sir Robert Adair, G.C.B. With a Selection from his Despatches, published by permission of the proper Authorities. 8vo. 18s. eloth.

ADAIR (SIR ROBERT) - THE NEGOTIATIONS FOR THE PEACE OF THE DARDANELLES, in 1808-9; with Despatches and Official Documents. By the Right Honorable Sir Robert Adair, G.C.B. Being a Sequel to the Memoir of his Mission to Vienna in 1806. 2 vols, $8 \mathrm{vo}$. 28s. cloth.

\section{ADSHEAD.-PRISONS AND PRISONERS.} By Joseph Adshead. Sro, with Illustrations, 7s. 6d. cloth.

AIKIN.-THE LIFE OF JOSEPH ADDISON.

Illustrated by many of his Letters and Private Papers never before published. By Lucy Aikin. 2 vols. post 8vo. with Portrait from Sir Godfrey Kneller's Picture, 18s. cloth.

ALLAN (J. H.)-A PICTORIAL TOUR IN THE MEDITERRANEAN; Comprising Malta, Dalmatia, Turkey, Asia Minor, Grecian Archipelago, Egypt, Nubia, Greece, Sicily, Italy, and Spain. J.H. Allan, 2d Edition. Imperial 4to, with upwards of 40 lithographed Drawings, and 70 Wood Engravings, $3 l$. $3 s$. cloth.

AMY HERBERT.

By a Lady. Edited by the Rev. William Sewell, B.D. of Exeter College, Oxford. New Edition. 2 vols. foolscap 8 vo. 9 s. eloth.

ARTISAN CLUB (THE).-A TREATISE ON THE STEAM ENCINE. In its application to Mines, Mills, Steam Navigation, and Railways. By the Artisan Club. Edited by John Bourne, C.E. 4to. with 30 steel Plates, etc., and about 350 Wood En: gravings, 27s. cloth.

\section{BAKEWELL.-AN INTRODUCTION TO GEOLOGY.}

Intended to convey Practical Knowledge of the Science, and comprising the most important recent Discoveries; with Explanations of the Facts and Phenomena which serve to confirm or invalidate various Geological Theories. By Robert Bakewell. Fifth Edition, considerably enlarged. 8vo. with numerous Plates and Woodcuts, 21s. cloth.

\section{BALMAIN.-LESSONS ON CHEMISTRY,}

For the Use of Pupils in Schnols, Junior Students in Universities, and Readers who wish to learn the fundamental Principles and leading Facts: with Questions for Examination, Glossaries of Chemical Terms and Chemical Symbols, and an Index. By IVilliain H. Balmain. With numcrous Woodcuts, illustrative of the Decompositions. Foolscap 8vo. 6s. cloth. 


\section{BARRETT.-A SYNOPSIS OF CRITICISMS}

Upon those Passages of the Old Testament in which Modern Commentators have differed from the Authorized Version: together with an Fxplanation of various Difficulties in the Hebrew and English Texts. By the Rev. Richard Barrett, M.A. Fellow of King's College, Cambridge. Vols. I \& II. 8vo.

[lu January.

\section{BAYLDON.-THE ART OF VALUING RENTS AND TILLAGES,}

And the Tenant's Right of Entering and Quitting Farms, explained by several specimens of Valuations; and Remarks on the Cultivation pursued on Soils in different Situations. Adapted to the Use of Landlords, Land-Agents, Appraisers, Farmers, and Tenants. By J.S. Bayldon. 6th Edition, corrected and revised by John Donaldson. 8vo. 10s.6d. cloth.

\section{BAYLIS.-THE ARITHNETIC OF ANNUITIES AND LIFE ASSURANCE;} Or. Compound Interest Simplified: explaining the value of Annuities, certain or contingent, on one or two Lives, and the values of Assurances in Single and Annual Payments; and comprehending the values of Leases, Pensions, Freeholds, and Reversionary Sums, in possession or expectation, immediate, deferred, or temporary. Illustrated with practical and familiar Examples. By Edward Baylis. 8vo.5s. cloth.

BFDFORD CORRESPONDENCE. - CORRESPONDENCE OF JOHN, FOURTH DUKE OF BEDFURD, selected from the Originals at Woburn Abbey, (1742-70). With Introductions by Lord John Russell. 3 vols 8 vo. 438 . cloth.

** Vol. I. (1742-48), 18s,; Vol. II. (1749-60), 17s.; Fol. III., (1761-70), $15 s$.

BELL.-LIVES OF THE MOST EMINENT ENGLISH POETS.

By Robert Bell, Esq. 2 vols. foolscap 8vo. with Vignette 'Titles, 12s. cloth.

BELL. - THE HISTORY OF RUSSIA,

From the Earliest Period to the Treaty of Tilsit. By R. Bell, Esq. 3 vols.fools cap 8vo.18s.

BLACK.-A PRACTICAL TREATISE ON BREWING.

Based on Chemical and Economical Principles: with Formulie for Public Brewers, and Instructions for Private Families. By William Black. Third Edition, revised and corrected, with considerable Additions. Svo.10s.6d. cloth.-Also,

SUPPLEMEN'T, of REMARKS on BAVARIAN BEER, Loudon Porter, the Influence of Electricity on Fermentation, and other Subjects. By William Black. 8v0.2s.6d. sewed.

\section{BLAINE.-AN ENCYCLOPFDIA OF RURAL SPORTS ;}

Or, a complete Account, Historical, Practical, and Descriptive, of Hunting, Shooting, Fishing, Racing, and other Field Sports and Athletic Amusements of the present day. By Delabere P. Blaine, Esq., author of "Canine Pathology," etc. etc. With nearly 600 Engravings ou Wood, by R. Branston, from Drawings by Alken, T. Landseer, Dickes, etc. 8vo. 50s. cloth.

BLAIR'S CHRONOLOGICAL AND HISTORICAL TABLES,

From the Creation to the present Time: with Additions and Corrections from the most authentic Writers ; including the Computation of St. Paul, as connecting the Period from the Exode to the Temple. Under the revision of Sir Henry Ellis, K.H., Principal Librarian of the British Museum. Imperial 8vo.31s.6d.half-bound morocco.

BLOOMFIELD. -THE HISTORY OF THE PELOPONNESIAN WAR. By Thucydides. Newly Translated into English, and accompanied with very copious Notes, Philological and Explanatory, Historical and Geographical. By the Rev. S. T. Bloomfield, D.D.F.S.A. 3 vols. 8vo. with Maps and Plates, 2l.5s. boards.

BLOOMFIELD. -THE HISTORY OF THE PELOPONNESIAN WAR.

By Thucydides. A New Recension of the Text, with a carefully amended Punctuation; and copious Notes, Critical, Philological, and Explanatory, almost entirely original, but partly selected and arranged from the best Expositors : accompanied with full Indexes. Illustrated by Maps and Plans. By the Rev. S.T. Bloomfield, D.D. F.S.A. 2 vols. 8vo. 38s. cloth.

\section{BLOOMFIELD. - THE GREEK TESTAMENT :}

With copious English Notes, Critical, Philological, and Explanatory. Formed for the use of advanced Students of Divinity and Candidates for Holy Orders. By the Rev. S. T. Bloomfield, D.D.F.S.A. 6th Edit.improved. 2 vols.8vo, with a Map of Palestine, 40 s. clotli.

BLOOMFIELD. - THE GREEK TESTAMENT FOR COLLEGES AND SCHOOLS; with shorter English Notes, Critical, Philologicul, and Explanatory. By the Rev. S.T. Bloomfield, D.D. Fourth Edition, enlarged and improved, with a New Map of Syria and Palestine, and un Index. Foolscap 8vo.10s.6d. cloth.

BLOOMFIELD.- GREEK AND ENGLISH LEXICON TO THE NEW TESTAMEN'T: especially adapted to the use of Colleges, and the Higher Classes in Public Schools; but also intended as a convenient Manual for Biblical Students in general. By Dr. Bloomfield. 2d Edition, enlaryed, and improved. Foolscap 8vo. 10s. 6d. cloth. 
BOY'S OWN BOOK (THE) :

A Complete Encyclopadia of all the Diversions, Athletic, Scientific, and Recreative, of Boyhood and Youth. 23d Edition. Square 12mo, with many Fngravings on Wood, 6s, boards.

BRANDE --A DICTIONARY OF SCIENCE, LITERATURE, AND ART; Comprising the History, Description, and Scientific Principles of every Branch of Human Knowledge; with the Derivation and Definition of all the Terms in general use. Fdited by W. T. Brande, F.R.S.L. and E.; assisted by J.Cauvin. 8vo. with Woodcuts, $3 l$. cloth.

BRAY (MRS.)-MRS. BRAY'S NOVELS AND ROMANCES,

Revised and corrected by Mrs. Bray. In 10 vols. fcap. 8 vo., uniformly with the "Standard Novels," with Frontispieces and Vignettes. 3l. cloth; or separately 6s. each.

BRAY.-THE PHILOSOPHY OF NECESSITY;

Or, the Law of Consequences as applicable to Mental, Moral, and Social Seience. By Charles Bray. 2 vols. 8 vo. 15 s. cloth.

BRAY.-AN ESSAY UPON THE UNION OF AGRICULTURE WITH MANUFACTURES, AND UPON THE ORGANISATION OF INDUSTRY. BY Charles Bray. 12mo. 18, sewed.

BRAY.-AN OUTLINE OF THE VARIOUS SOCIAL SYSTEMS AND COMMUNITIES WHICH HAVE BEEN FOUNDED ON THE PRINCIPLE OF CO-OPERATION. Preceded by an Essay on the Union of Agriculture with Manufactures, and on the Organisation of Ind ustry. By Charles Bray. Post 8vo. 58. cloth.

BREWSTER.-A TREATISE ON OPTICS.

By Sir David Brewster, LL.D.F.R.S. etc. New Edition. Foolscap 8vo. with vignette title, and $176 \mathrm{IV}$ ood cuts, $6 s$. cloth.

BUCKLER.-A HISTORY OF THE ARCHITECTURE OF THE ABBEY CHURCH of ST. ALBAN, with especial reference to the Norman Structure. By J.C. and C. A. Buckler, Architects. Svo. with numerous Illustrations.

[In the press.

BUDGE (J.)-THE PRACTICAL MINER'S GUIDE :

Comprising a Set of Trigonometrical Tables adapted to all the purposes of Gblique or Diagonal, Vertical, Horizontal, and Traverse Dialling; with their application to the Dial, Exercise of Drifts, Lodes, Slides, Levelling, Inaccessible Distances, Heights, etc. By J. Budge. New Edition, enlarged, 8vo. with Portrait, 12s, cloth.

BULL.-HINTS TO MOTHERS,

For the Management of Health during the Period of Pregnancy and in the Lying-in Room; with an Exposure of Popular Errors in connexion with those subjects. By Thomas Bull, M.D. 4 th Edition, revised and considerably enlarged. Foolscap 8vo.7s. cloth.

\section{BUIL. - THE MATERNAL MANAGEMENT OF CHILDREN,}

In HEALTH and DISEASE. By Thomas Bull, M.D. Physician Accoucheur to the Finsbury Midwifery Institution, etc. 2d Edition, revised and enlarged. Foolscap 8vo.73. cloth.

BURDER. -ORIENTAL CUSTOMS, Applied to the lllustration of the Sacred Seriptures. By Dr. Samuel Burder. Third Edition, with Additious. Frolscap 8vo. 8s. 6d, cloth.

\section{BÜRGER.-THE LEONORA OF BÜRGER.}

Translated by Julia M. Camerou. With Six large Illustrations, drawn on Wood by D. Maclise, R.A. engraved by John Thompson. Crown 4to, 15s. cloth.

\section{BURNS.-THE PRINCIPLES OF CHRISTIAN PHILOSOPHY;}

Containing the Doctrines, Duties, Admonitions, and Consolations of the Cliristian Religion. By John Burns, M.D.F.R.S. 6th Edition. Foolseap 8vo. 6s.6d. cloth.

BURNS.-CHRISTIAN FRAGMENTS;

Or, Remarks on the Nature, Precepts, and Comforts of Religion. By John Burns, M.D. F.R.S. Professor of Surgery in the University of Glasgow, author of "The Principles of Christian Philosophy." Foolscap 8vo. 5s. cloth.

BUTLER.-A SKETCH OF MODERN AND ANCIENT GEOGRAPHY. By Samuel Butler, D.D., late Lord Bishop of Lichfield and Coventry; aud formerly Head Master of Slirewsbury Sehool. New Edition, revised by the Author's Soll. 8vo.9s. boards.

BUTLER. - AN ATLAS OF MODERN GEOGRAPHY.

Cousisting of Twenty-three coloured Maps, from a New Set of Plates; with an Infex of all the Names of Places, referring to the Latitudes and Longitudes. By the late Dr. Butler, Bishop of Lich field. New Edition, corrected. 8vo.12s. half-bound. 


\section{BUTLER.-AN ATLAS OF ANCIENT GEOGRAPHY.}

Consisting of Twenty-three coloured Maps: with an Index of all the Names of Places, referring to the Latitudes and Longitudes. By the late Dr. Butler, Bishop of Liclifield. New Eution, corrected. 8vo. 12s. half-bound.

\section{BUTLER.-A GENERAL ATLAS OF MODERN AND ANCIENT GEOGRAPHY.} Consisting of Forty-five coloured Mups, and copious Indices referring to the Latitudes and Longitudes. By the late Dr. Butler, Bishop of Lichfield. New Edition, from an entirely new and corrected set of Plates. 4to.24s. half-bound.

CALLCOTT.-A SCRIPTURE HERBAL :

With upwards of 120 Wood Engravings. By Lary Callcott. Square crown $8 v 0.12 .58$. cloth.

CARTOONS.-THE PRIZE CARTOONS EXHISITED IN WESTMINSTERHALL, Published under the Sanction and Patronage of Her Majesty's Commissioners on the Fine Arts. The size of the work is large folio. The price of the Eleven Eugravings, in a neat Portfolio, $5 l .5 s . ;$ Proofs before letters, $8 l .88$.

[Early in 1847.

\section{CATLOW.-POPULAR CONCHOLOGY;}

Or, the Shell Cabinet arranged : being an Introduction to the morern System of Conchology: with a sketch of the Natural History of the Animals, an account of the Formation of the Shells, and a complete Descriptive List of the Families and Genera. By Agnes Catlow. Foolscap 8vo. with 312 Woodeuts, 10s. 6d. cloth.

CHALENOR.-WALTER GRAY, A Ballad, and other Poems. By Mary Chalenor. 2d Edition, with Additions, including the Author's Poetical Remains. Fcap. 8vo.6s. cloth.

CLAVERS._FOREST LIFE.

By Mary Clavers, an Actual Settler; author of "A New Home, Who 'll Follow?" 2 vols. feap. 8vo. 12s. cloth.

COCKS (C.)-SORDEAUX, ITS WINES, AND THE CLARET COUNTRY. By C. Cocks, B.L.. Professor of the Living Languages in the Royal Colleges of France; Translator of the Works of Michelet, Mignet, and Quinet. Post 8vo.with View of Bordeaux, 8s. 6d. cloth.

\section{COLLEGIAN'S GUIDE (THE);}

Or, Recollections of Collegc Days; setting forth the Advantages and Temptations of a University Education. By ${ }^{* * * *} * * * * * *$, M.A., C Coll. Oxon. Post Svo.10s,6d.cloth.

\section{COLLIER (J. PAYNE.) - A BOOK OF ROXBURCHE BALLADS.}

Edited by John Payne Collier, Fsq. Fcap. 4to. with Woodeuts, 21s, boards ; morocco, 39 s. (appropriately bound in the best style by Hayday).

\section{COLTON - LACON; OR, MANY THINGS IN FEW WORDS.}

By the Rev. C.C. Colton. New Edition, 8vo.12s.cloth.

CONVERSATIONS ON BOTANY.

9 th Edition, improved. Foolscap 8vo. with 22 Plates, $78.6 d$.clnth; with coloured Plates, $12 s$.

\section{CONVERSATIONS ON MINERALOGY.}

With Plates, engraved by Mr. and Mrs. Lowry, from Original Drawings. Third Edition, enlarged. 2 vols. foolscap 8vo. 14s. cloth.

COOLEY.-THE WORLD SURVEYED IN THE NINETEENTH CENTURY; Or, Recent Narratives of Scientific and Exploring Expeditions (chiefly undertaken b5 command of Foreign Governments). Collected, translated, and, where necessary, abridged, by W. D. Cooley, Fisg., anthor of "The History of Maritime and Inland Discovery," in the Cabinet Cyclopredia, etc.

Tho First Volume contains "The Ascent of Mount Ararat." By Dr. Friedrich Parrot, Professor of Natural Philosophy in the University of Dorpat, Russian Imperial Councillor of State, etc. 8vo. with a Map by Arrowsmith, and Woodcuts, 14s. cloth.

*** Each volume will form, for the most part, a Work complete in itself, and the whole Series will present an accurnte and luminous picture of all the known portions of the earth. The Second Work of the Series, "Erman's Travels through Siberia," is in the press, in 2 vols. $8 v o$.

\section{COOLEY. - THE HISTORY OF MARITIME AND INLAND DISCOVERY.}

By W. D. Cooley, Esq. 3 vols. foolscap 8vo. with Vignette Titles, 18s. cloth. 
COOPER (REV. E.)-SERMONS,

Chiefly designed to elucidate some of the leading Doctrines of the Gospel. To which is added an Appendix, containing Sermons preached on several Public Occasions, and printed by desire. By the Rev. Edward Cooper. 7 th Edition. 2 vols. 12mo. 10s. boards.

\section{COOPER (REV. E.) -PRACTICAL AND FAMILIAR SERMONS,}

Designed for Parochial and Domestic Instruction. By the Rev. Edward Cooper. New Editions. 7 vols. $12 \mathrm{mo} .11$. $18 s$, boards.

$$
* \text { Volo. } 1 \text { to 4, 5s. each; Vols. } 5 \text { to 7, 6s. each. }
$$

\section{COPLAND.-A DICTIONARY OF PRACTICAL MEDICINE;}

Comprising General Pathology, the Nature and Treatment of Diseases, Morbid Structures, and the Disorders especially incidental to Climates, to Sex, and to the different Epochs of Life, with numerous approved Formulæ of the Medicines recommended. By James Copland, M.W., etc. etc. In 3 vols. Vols. 1 and 2,8 vo. $3 l$. cloth; and Part 10, 4s.6d. sewed.

$$
\text { * To be completed in One more Volume. }
$$

COSTELLO (MISS).-THE ROSE GARDEN OF PERSIA. A Series of Translations from the Persian Poets. By Louisa Stuart Costello, author of "Specimens of the Early Poetry of France," etc. Long 8vo. with 12 Illuminated Titles, and Borders printed in Gold and Colours, 18s. boards; or 318. $6 d$. bound in morocco (oriental style), by Hayday.

COSTELLO (MISS) -FALLS, LAKES, AND MOUNTAINS OF NORTH WALES; being a Pictorial Tour through the most interesting parts of the Country. By Louisa Stuart Costello, author of "The Rose Garden of Persia," "Bearn and the Pyrenees," etc. Profusely illustrated with Views, from Original Sketches by D. H. M'Kewan, engraved on wood, and lithographed, by T. aud E. Gilks. Square 8vo. with Map, 14s. cloth.

CRESY (E.) - AN ENCYCLOPAECIA OF CIVIL ENGINEERING, HISTORICAL, THEORETICAL, and PRACTICAL. By Edward Cresy, F.S.A.C.E. Illustrated by many hundred Engravings on Wood, explanatory of the Principles, Machinery, and Constructions which come under the Direction of the Civil Engineer. 8vo. uniform with Messrs. Longman and Co.'s Series of One-Volume Encyclopæedias and Dictionaries.

\section{CROCKER'S ELEMENTS OF LAND SURVEYING.}

Fifth Edition, corrected throughout, and considerably improved and modernised, by T. G. Bunt, Land Surveyor, Bristol. To which are added, TABLES OF SIX.FIGURE LOGARITHMS, etc., superintended by Richard Farley, of the Nautical Almanac Establish. ment. Post 8vo. 12s. cloth.

\section{CROWE-THE HISTORY OF FRANCE,}

From the Earliest Period to the Abdication of Napoleon. By E. F. Crowe, Esq. 3 vols. foolscap 8vo. with Vignette Titles, 18s. cloth.

DALE (THE REV. THOMAS). - THE DOMESTIC LITURGY AND FAMILY CHAPLAIN, in Two Parts: the First Part being Church Services adapted for Domestic Use, with Prayers for every Day of the Week, selected exclusively from the Book of Common Prayer. Part II. comprising an appropriate Sermon for every Sunday in the Year, By the Rev. Thomas Dale, M.A. Canon Residentiary of St. Paul's, and Vicar of St. Pancras, London. Post 4to. handsomely printed, 21s. cloth: or, bound by Hayday, 31s. $6 d$. calf lettered; 50s. morocco, with goffered edges.

DAVY (SIR HUMPHRY), - ELEMENTS OF AGRICULTURAL CHEMISTRY in a Course of Lectures. By Sir Humphry Davy. With Notes by Dr. John Davy. 6 th Edition. 8vo, with 10 Plates, 158 . cloth.

DE BURTIN.-A TREATISE ON THE KNOWLEDGE NECESSARY TO AMATEURS OF PICTURES. Translated and abridged from the French of $M$. Francis Xavier De Burtin, First Stipendiary Member of the Royal Academy of Brussels in the Class of Sciences, etc. By Robert White, Esq. 8vo. with Illustrations, 12s. cloth.

DE CUSTINE.-RUSSIA.

By the Marquis De Custine. Translated from the French. 2d Edition. 3 vols.post 8vo. 31s. 6 d. cloth.

DE LA BECHE.-REPORT ON THE GEOLOGY OF CORNWALL, DEVON, AND WEST SOMERSET. By Henry T. De la Beche, F.R.S. etc., Director of the Ordnance Geological Survey. Published by Order of the Lords Commissioners of H. M. Treasury. 8vo. with Maps, Woodcuts, and 12 large Plates, 148. cloth.

DE MORGAN.-AN ESSAY ON PROBABILITIES, And on their Application to Life Contingencies and Insurance Offices. By Aug. De Morgan, Esq., of Trinity College, Cambridge. Foolscap 8vo, with Vignette Title, 6s, cloth. 


\section{DE SISMONDI.-THE HISTORY OF THE ITALIAN REPUBLICS:}

Or, of the Origin, Progress, and Fall of Freedom in Italy, from A.D. 476 to 1866. By J. C.L. Sismondi. Fcap. 8vo. with Vignette Title, 6s. cloth.

DE SISMONDI.-THE HISTORY OF THE FALL OF THE ROMAN EMPIRE. Comprising a View of the Invasion and Settlement of the Barbarians. By J.C.L. De Sismondi, 2 vols. Fcap. 8vo. with Vignette Titles, 12s. cloth.

DE STRZELECKI (P.E.)-PHYSICAL DESCRIPTION OF NEW SOUTH WALES AND VAN DIEMAN'S LAND. Accompanied by a Geological Map, Sections, and Diagrams, and Figures of the Organic Remains. By P. E. De Strzelecki. 8vo. with coloured Map and numerous Plates, 24s. cloth.

DIBDIN (THE REV. T. F.)-THE SUNDAY LIBRARY:

Containing nearly One hundred Sermons by eminent Divines. With Notes, etc. by the Rev. T.F.Dibdin, D.D. 6 vols. foolscrap 8vo. with 6 Portraits, 30s. cloth; neatly half-bound in morocco, with gilt edges, $2 l .12 s .6 d$.

DODDRII)GE. -THE FAMILY EXPOSITOR;

Or, a Paraphrase and Version of the New Testament: with Critical Notes, and a Practical Improvement of each Section. By P. Doddridge, D.D. To which is prefixed, a Life of the Author, by A. Kippis, D.D. F.R.S. and S.A. New Edition. 4 vols. 8vo.1l. 16s. cloth.

DONOVAN.-A TREATISE ON CHEMISTRY.

By Michael Donovan, Esq. M.R.I.A. 4th Edition. Fcap. 8vo, with Vignette Title, 6s. cloth.

DONOVAN.-A TREATISE ON DOMESTIC ECONOMY.

By M. Donovan, Esq. M.R.I.A., Professor of Chemistry to the Company of Apotbecaries in Ireland. 2 vols. foolscap 8vo. with Vignette Titles, 12s. cloth.

DOUBLEDAY'S BUTTERFLIES. - THE GENERA OF DIURNAL LEPIDOPTEAR ; comprising their Generic Characters-a Notice of the Habits and Transformations - and a Catalogue of the Species of each Genus. By Edward Doubleday, Esq. F.L.S. etc., Assistant in the Zoological Department of the British Museum. Imperial 4to. uniform with Gray and Mitchell's Ornithology; illustrated with 75 coloured Plates, by W. C. Hewitson, Esq. Author of "British Oology.

*.* Publishing in Monthly Parts, 5s. each; each Part consisting of two coloured Plates, with accompanying Letter-press. Part $I V$. will appear on the 1 st of February.

DOVER.-LIFE OF FREDERICK II. KING OF PRUSSIA.

By Lord Dover. 2d Edition. 2 vols. 8vo. with Portrait, 28s. boards.

DRESDEN GALLERY.-THE MOST CELEBRATED PICTURES OF THE ROYAL GALLERY at DRESDEN, drawn on Stone, from the Originals, by Franz Hanfstaengel : with Descriptive and Biographical Notices, in French and German. Nos. I. to XLIV., imperial folio, each containing 3 Plates with accompanying Letter-press, price 20s. to Subscribers; to Non-subscribers, 30s. Single Plates, 12s, each.

"* To be completed in a few nore numbers.

DRUMMOND (DR. J. L.) - LETTERS TO A YOUNG NATURALIST ON THE STUDY OF NATURE AND NATURAL THEOLOGY. By James L. Drummond, M.D. Second Edition. Post 8vo, with Wood Engravings, 7s, 6d. boards.

\section{DRUMMOND.-FIRST STEPS TO BOTANY,}

Intended as popular Illustrations of the Science, leading to its study as a branch of general Education. By J. L. Drummond, M.D. 4th Edit. $12 \mathrm{mo}$. with numerous Woodcuts, 98 . boards.

\section{DUNHAM. - THE HISTORY OF THE GERMANIC EMPIRE.}

By Dr. Dunham. 3 vols. foolscap 8vo. with Vignette Titles, 18s. cloth.

By the same Author.

THE HISTORY OF EUROPE DURING | THE HISTORY OF POLAND. Feap. 8vo.6s. THE MIDDLE AGES. $4 \mathrm{vols}$. $1 l .4 s$.

THE HISTORY OF SPAIN AND PORTUGAL. 5 vols. foolscap $8 \mathrm{vo} .17$. $10 \mathrm{~s}$.

THE HISTORY OF SWEDEN, DENMARK, AND NORWAY. 3 vols. foolscap 8 vo. 18s.

THF LIVES OF THE EARLY WRITERS OF GREAT BRITAIN. Foolscap 8vo, 6s.

THF LIVES OF BRITISH DIRAMATISTS. 2 vols. foolscap 8 vo. $12 s$.

DUNLOP (JOHN).--THE HISTORY OF FICTION :

Being a Critical Account of the most celebrated Prose Works of Fiction, from the earliest Greek Romances to the Novels of the Present Age. By John Dunlop. 3d Edition, complete in One Volume. Medium 8vo. 15s. cloth.

ECCLESTON (JAMES).-A MANUAL OF ENGLISH ANTIQUITIES. By James Eccleston, B.A. H 4 rd Master of Sutton Coldfield Grammar Schnol. 8vo. with numerous Illustrations on Wood.

[ In the press. 


\section{ELLIOTSON.-HUMAN PHYSIOLOGY:}

With which is incorporated much of the Elementary Part of the "Institutiones Physiologica" of J. F. Blumenbach, Professor in the University of Gottingen. By John Elliotson, M.D. Cantab. F.R.S. Fifth Edition, 8vo, with numerous Woudcuts, 2l.2s, cloth.

THE ENGLISHMAN'S GREEK CONCORDANCE OF THE NEW TESTAMEN'T; being an attempt at a Verbal Connexion between the Greek and the English Texts; iucluding a Concordance to the Proper Names, with Indexes, Greek-English aud English. Greek. 2d Edition, carefully revised, with a new Iudex, Greek and English. Royal 8vo. 428.

THE ENCLISHMAN'S HEBREW AND CHALDEE CONCORDANCE OF THE OLD TESTAMENT; being an attempt at a Verbal Connexion between the Original and the English Translations: with Indexes, a List of the Proper Names and their occurrences, etc. etc. 2 vols, royal $8 \mathrm{vo} .3 l$. $13 s .6 d$. cloth; large paper, $4 l$. $148.6 d$.

EPHEMERA.-THE HAND-BOOK OF ANGLING ;

F.mbracing Fly Fishing, Trolling, and Bottom Fishing. With the Natural History of River Fish, and the best Mode of Catehing them. By Ephemera (of Bell's Life in London). With Illustrations.

[ In March.

\section{ESDAILE.-MESMERISM IN INDIA;}

And its Practical Application in Surgery and Medicine. By James Esdaile, M.D. Civil Assistant-Surgeon, E.I.C.S. Bengal. Feap. 8vo. 68.6d. cloth.

ETHERIDGE (J. W.)-THE SYRIAN CHURCHES:

Tueir early History, Liturgies, und Literature, with a Literal Translation of the Four Gospels frum the Peschito, or Canon of Holy Scripture in use anong the Urientul Chistians from the earliest Times. By J. W. Etheridge. 12mo.78.6d. cloth.

\section{FAREY.-A TREATISE ON THE STEAM-ENGINE,} Historical, Practical, aud Descriptive. By John Farey, Engineer. 4to. illustrated by uumerous Woodeuts, and 25 Copper-plates, $5 l$. 5s. in bourds.

FAWN (THE) OF SERTORIUS. 2 vols, post 8vo. 18s. cloth.

"As $a$ work that contains lively and graphic pictures of life and manners, in a distant age, we commend it to the perusul of our readers."-Critic.

\section{FERGUS. - THE HISTORY OF THE UNITED STATES OF AMERICA,}

From the Discovery of America to the Election of General Jackson to the Presidency. By the Rev. H. Fergus. 2 vols. foolscap 8vo. with Vignette Titles, 128. cloth.

FITZROY (LADY). - SCRIPTURAL CONVERSATIONS BETWEEN CilARLES AND HIS MOTHER. By Lady Charles Fitzroy. Foolscap 8vo. 4s.6d, eloth.

FORSTER.-STATESMEN OF THE COMMONWEALTH OF ENGLAND. With an Introductory 'Treatise on the Popular Progress in English History. By John Forster, Esq. 5 vols. foolscap 8vo. with Original Portraits of Pym, Eliot, Hampden, Cromwell, and an Historical Scene after a Picture by Cattermole, 1l. 10s. cloth.

The above 5 vols, form Mr. Forster's Portion of the Lives of Einiuent British Statesmen, by Sir James Mackintosh, the Right Hon. 'T. P. Courtenay, and Jolnn Forster, Esq. 7 vols. foolscap 8vo. with Vignette Titles, 2l. 2s. cloth.

FORSTER (REV. C.)-THE HISTORICAL GEOGRAPHY OF ARABIA; Or, the Patriarchal Evidences of Revealed Religion. A Memoir, with illustrative Maps and an Appendix, containing Translations, with an Alphabet and Glossary of the Hamyaritic Inseriptions recently discovered in Hadramaut." By the Rev. Charles Forster, B.D., Rector of Stisted, Essex, author of "Mahometanism Unveiled." 2 vols. 8vo.308. cloth.

FORSTER (REV. C.)-THE LIFE OF JOHN JEBB, D.D. F.R.S.

Late Bishop of Limerick. With a Selection from his Letters. By the Rev. Charles Forster, B.D., Rector of Stisted, Essex, and one of the Six Preachers in the Cathedral of Christ, Cauterbury, formerly Domestic Chaplain to the Bishop. 2d Edition. 8vo. with Portrait, etc. 16s. cloth.

FOSBROKE.-A TREATISE ON THE ARTS, MANNERS, MANUFACTURES, and INSTITUTIONS of the GREKKS and ROMANS. By the Rev. T. D. Fosbroke, etc. 2 vols. foolscap 8 vo. with Vignette Titles, 128 . cloth.

FROM OXFORD TO RONE: AND, HOW IT FARED WITH SOME WHO MADE THE JOURNEY. By a Companion Traveller. Fuolscap 8vo, with Plate, 6s, cloth.

GERTRUDE.

A Tale. By the author of "Any Herbert." Edited by the Rev. Williain Sewell, B.D., of Exeter College, Oxford. New Kulition, 2 vols. foolscap 8vo. 98. cloth. 
GILBART (J. W.)-THE HISTORY AND PRINCIPLES OF BANKING.

By James William Gilbart, General Manager of the London and Westminster Bank. Third Edition. 8vo. 9s, boards.

\section{GLEIG.-LIVES OF THE MOST EMINENT BRITISH MILITARY COM-} MANDERS. By the Rev. G. R. Glelg. 3 vols, foolscap 8vo. with Vignette Titles, 18s. cloth.

GOLDSMITH-THE POETICAL WORKS OF OLIVER GOLDSMITH.

lllustrated by Wood Engravings, from the Designs of G. W. Cope. A.R.A., Thomas Creswick, A.R.A., J.C. Horsley, R. Redyrave, A.R.A., and Frederick Tayler, Members of the Etching Club. Edited by Bolton Corney, Esq. Square crown 8vo., tuniform with "Thomson's Seasons," 21s, cloth; or 36s, bound in morocco, by Hayday.

"* Une Hundred Copies, 2i.2s. each, printed on prepared paper of great beauty.

GOOD.-THE BOOK OF NATURE.

A Popular Illustration of the General Laws and Phenomena of Creation. By John Mason Good, M.D.F.R.S.etc. 3d Edition, corrected. 3 vols. foolscap 8vo. 24s. cloth.

GOWER.-THE SCIENTIFIC PHENOMENA OF DOMESTIC LIFE FAMILIARLY EXPLAINED. By Charles Foote Gower. New edition. Foolscap 8vo. with Engravings on Wood. 5s. cloth.

GRAHAM.-ENGLISH; OR, THE ART OF COMPOSITION

explained in a Series of Instructions and Examples. By G. F. Graham. 2d Edition, revised and improved. Fuolscap 8vo. 78. cloth.

GRANT (MRS.)-LETTERS FROM THE MOUNTAINS.

Being the Correspondence with her Friends, between the years 1773 and 1803 . By Mrs. Grant, of Laggan. 6th Edition. Edited, with Notes and Additions, by her Son, J. P. Grant, Esq. 2 vols. post 8 vo. 21s. cloth.

GRANT (MRS., OF LAGGAN).- MEMOIR AND CORRESPONDENCE of the late Mrs. Grant, of Laggan, author of "Letters from the Mountains," etc. Fdited by her Son, J. P. Grant, Esq. 2d Edition. 3 vols. post 8vo. Purtrait, 1l. 11s. 6d. cloth.

GRATTAN.-THE HISTORY OF THE NETHERLANDS, From the Invasion by the Romans to the Belgian Revolution in 1830. By T. C. Grattan, Esq. Foolscap 8vo. with Vignette Titles, 6s. cloth.

GRAY (THOMAS).-GRAY'S ELEGY, Written in a Country Churchyard. Illuminated in the Missal style. By Owen Jones, Architect. Imp. 8vo.31s. 6 d. elegantly bound in patent relievo leather.

GRAY.FIGURES OF MOLLUSCOUS ANIMALS, Selected from various Authors. Etched for the Use of Students. By Maria Emma Gray. Vol. I. 8vo. with 78 plates of Figures, 12s. eloth.

GRAY AND MITCHELL'S ORNITHOLOGY.-THE GENERA OF BIRDS ; Comprising their Generic Characters, a Notice of the Habits of each Genus, and an extensive List of Species, referred to their several Genera. By George Robert Gray, Acad. Imp. Georg. Florent. Soc. Corresp. Senior Assistant of the Zoological Department, British Museum; and author of the "List of the Genera of Birds," etc. ete. Imperial 4to. illustrated with 350 Plates, by David William Mitchell, B.A.

* "In course of publication in Monthly Parts, 10s.6d. each; each Part consisting of Four coloured Plates and Three plain, with Letter-press. The Work will not exceed 50 Monthly Parts. No. 33 was published on lst of January.

Order I.--Accipitres has been completed, and may be had separately. Imperial 8vo. with 15 coloured an 12 plain Plates, $2 l .8$ s. boards.

GREENER.-THE GUN;

Or, a Treatise on the various Descriptions of Small Fire Arms. By W. Greener, Inventor of an Improved Method of Firing Cannon by Percussion, ete. 8vo.with Illustrations, 15s.boards.

GRIMBLOT (P.)-LETTERS OF WILLIAM III. AND LOUIS XIV. AND OF THEIR MINISTERS. Illustrating the Domestic and Foreign Policy of England during the period which followed the Revolution of 1688 . Extracted from the Archives of France and England, and frum Family Papers. Edited by P. Grimblot. 8vo. [In the press.

GUEST.-THE MABINOGION,

From the Llyfr Coch o Hergest, or Red Book of Hergest, and other ancient Welsh MSS. with an English Translation and Notes. By Lady Charlotte Guest. Parts 1 to 6. Royal 8 vo. 8s. each sewed. 
GUICCIARDINI (F.)-THE MAXIMS OF FRANCIS GUICCIARDINI, THE HISTORIAN. Translated by Fmma Martin. With Notes, and Parallel Passages from the Works of Machiavelli, Lord Bacon, Pascal, Rochefoucault, Montesquieu, Burke, Prince Talleyrand, Guizot, and others; and a Sketch of the Life of Guicciardini. Square foolscap 8 vo. with Portrait, 7 s. boards; or 14 s. bound in morocco (old style), by Hayday.

\section{GUTCH.-A LYTTELL GESTE OF ROBIN HODE.}

In Eight Fyttes. With other Ancient and Modern Ballads and Songs relative to this celebrated English Yeoman. Edited by J. M. Gutch, F.A.S. 2 vols. 8vo, with Woodcuts by F. W. Fairhult, F.A.S.

[Just ready.

\section{GWILT.-AN ENCYCLOPFDIA OF ARCHITECTURE;}

Historical, Theoretical, and Practical. By Joseph Gwilt, Esq., F.S.A. Illustrated with upwards of 1,000 Engravings on Wood, from Designs by J.S. Gwilt. 8vo.2l. 12s. 6d. cloth.

HALL.-NEW GENERAL LARGE LIBRARY ATLAS OF FIFTY-THREE MAPS, on Colombier Paper; with the Divisions and Bourdaries carefully coloured. Constructed entirely from New Drawings, and engraved by Sidney Hall. New Edition, thoroughly revised and corrected; including all the Alterations rendered necessary by the recent Officia] Surveys, the New Roads on the Continent, and a careful Comparison with the authenticated Discoveries published in the latest Voyages and Travels.- Folded in half, Nine Guineas, halfbound in russia; full size of the Maps, Ten Pounds, half-bound in russia.

\section{HALSTED.-LIFE AND TIMES OF RICHARD THE THIRD,}

as Duke of Gloucester and King of England : in which all the Charges against him are carefully investigated and compared with the Statements of the Cotemporary Authorities. By Caroline A. Halsted, author of "The Life of Margaret Beaufort." 2 vols.8vo.with Portrait and other Illustrations, 11 . 10s. cloth.

HAND-BOOK OF TASTE (THE);

Or, How to Observe Works of Art, especially Cartoons, Pictures, and Statues. By Fabius Pictor. 3d Edition. Foolscap 8vo. 3s. boards.

\section{HANSARD.-TROUT AND SALMON FISHING IN WALES.} By G. A.Hansard, 12mo,68.6d. cloth.

\section{HARRIS.-THE HIGHLANDS OF FETHIOPIA;}

Being the Account of Eighteen Months' Residence of a British Embassy to the Christian Court of Shoa. By Major Sir W. C. Harris, author of "Wild Sports in Southern Africa," etc. 2 d Edition. 3 vols. 8 vo, with Map and 1llustrations, $2 l$. $2 s$. cloth.

HAWES (BARBARA).-TALES OF THE NORTH AMERICAN INDIANS, and Adventures of the Farly Settlers in America; from the Landing of the Pilgrim Fathers in 1620, to the Time of the Declaration of Independence. By Barbara Hawes. Ficap. 8vo.6s.

\section{HAWKER.-INSTRUCTIONS TO YOUNG SPORTSMEN}

In all that relates to Guns and Sho,ting. By Lieut. Col. P. Hawker. 9th edition, corrected, enlarged, and improved, with Eighty-five Plates and Woodcuts, by Adlard and Branston, from Drawings by C. Varley, Dicks, etc. 8vo.21s. cloth.

HAYDON (B. R.)-LECTURES ON PAINTINC AND DESIGN, Delivered at the London Institution, the Royal Institution, Albermarle Street, to the University of Oxford, etc. By B. R. Haydon, Historical Painter. 2 vols. 8vo. with Protraits of the Author and of Sir David Wilkie, and numerous other Illustratiuns, 24s. cloth.

HENSLOW.- THE PRINCIPLES OF DESCRIPTIVE AND PHYSIOLOGICAL BOTANY. ByJ.S. Henslow, M.A. F.L.S. etc. Foolscap 8vo.with Vignette Title, and nearly 70 Woodcuts, 68 . cloth.

HERSCHEL.-A TREATISE ON ASTRONOMY.

By Sir John Herschel. New Edition. Fcap.8vo. with Vignette Title, 6s. cloth.

HERSCHEL, - A PRELIMINARY DISCOURSE ON THE STUDY OF NATURAL PHILOSOPHY. By Sir John Herschel. New Edition. Foolscap 8vo.68.

HIGGINS.-ANACALYPSIS ;

Or, an Attempt to draw aside the Veil of the Saitic Isis : an Inquiy into the Origin of Languages, Nations, aud Religions. By G. Higgins, Esq., F.S.A., F. R. Asiatic Soc., etc. 2 vols, 4 to. $5 l$. cloth.

HIGGINS.-THE CELTIC DRUIDS ;

Or, an Atteinpt to shew that the Druids were the Priests of Oriental Colonics, who emigrated from India, and were the Introducers of the First or Cadmean System of letters, and the Builders of Stonehenge, of Carnac, and of other Cyclopean works in $\lambda$ sia and Europe. By G. Higgins, F.S.A., F.R. Asiatic Soc,, etc. 4to. with numerous Illustrations, $3 l$, cloth. 


\section{HINTS ON ETIQUETTE AND THE USAGES OF SOCIETY:}

With a Glance at Bad Habits. By Arowós. "Manners make the Man." 26th Edition, revised (with additions) by a Lady of Rank. Foolscap 8vo.2s.6d. cloth.

HISTORICAL PICTURES OF THE MIDDLE ACES,

In Black and White. Made on the spot, from Records in the Archives of Switzerland. By a Wandering Artist. 2 vols, post 8vo, 18s, cloth.

HOARE.-A DESCRIPTIVE ACCOUNT OF A NEW METHOD OF PLANTING AND MANAGING THE ROOTS OF GRAPE VINES. By Clement Hoare, author of "A Treatise on the Cultivation of the Grape Vine on Open Walls." 12mo.58. cl.

IIOARE - A PRACTICAL TREATISE ON THE CULTIVATION OF THE GRAPE VINE ON OPEN WALLS. By Clement Huare. 3d Edition, 8vo. 7s.6d. cloth.

\section{HOBBES-THE COMPLETE WORKS OF THOMAS HOBBES,}

Of Malmesbury; now first collected, and edited by Sir William Molesworth, Bart. 16 vols. 8 vo. $8 l$. cloth.

* * Separately, the English Works, in 11 vols. 5 l.10s.; the Latin Works, in 5 vols. 2l. 108.

HOLLAND.-A TREATISE ON THE MANUFACTURES IN METAL. By John Holland, Esq. 3 vols. foolscap 8vo. with about 300 Woodcuts, 18s. cloth.

HOLLAND.-MEDICAL NOTES AND REFLECTIONS.

By Henry Holland, M.D.F.R.S. etc. Fellow of the Royal College of Physicians, Physician Extraordinary to the Queen, and Physician in Ordinary to His Royal Highness Prince Albert. 2d Edition. 8vo. 18s, cloth.

HOOK (DR. W: F.)-THE LAST DAYS OF OUR LORD'S MINISTRY; A Course of Lectures on the principal Events of Passion Week. By Walter Farquhar Hood, D.D., Vicar of Leeds, Prebendary of Lincoln, and Chaplain in Ordinary to the Queen. 4th Edition. Foolscap 8vo. 6s. cloth.

HOOKER.-THE BRITISH FLORA.

In 2 vols.; Vol. I. comprising the Phanogamous or Flowering Plants, and the Ferns. By Sir IVilliam Jackson Hooker, R.H. LL.D. F.R.A. and L.S. etc. etc. etc. 5th Edition, with Additions and Corrections; and 173 ligures, illustrative of the Umbelliferous Plants, the Composite Plants, the Grasses, and the Ferus. Vol. I. 8vo., with 12 Plates, 14s. plain ; with the plates coloured, 248 , cloth.

Vol, II. in Two Parts, comprising the Cryptogamia and the Fungi, completing the British Flora, and forming Vol. V., Parts 1 and 2, of Smith's English Flora, 24s. boarts.

HORNE (THE REV. T. H.) - AN INTRODUCTION TO THE CRITICAL STUUY AND KNOIVLEDGE OF THE HOLY SCRIPTURES. By the Rev. Thomas Hartwell Horne, B.D. of St. John's College, Cambridge. 9th Edition, revised and corrected. 5 vols. 8 vo. with Maps and Fac-similes, $3 l$. 38 . cloth; or $5 l$. bound in calf half-extra, by Hayday.

HORNE (THE REV. T. H.)-A COMPENDIOUS INTRODUCTION TO THE STUUY OF THE BIBLE. By the Rev. Thomas Hartwell Horne, B.D. of St. Joln's College, Cambridge. Being an Analysis of his "Introduction to the Critical Study and Knowledge of the Holy Scriptures." 7th Euition, 12mo. with Maps and Engraviugs, 9s. boards.

HIORSLEY (BISHOP).-BIBLICAL CRITICISM ON THE FIRST FOURTEEN HISTORICAL BOOKS OF THE OLD TESTAMENT; AND ON THE FIIST NINE PROPHETICAL BOOKS. By Samuel Horsley, LL.D. F.R.S. F.A.S. Lord Bishop of St. Asaph. Second Edition, cuntaining Translations by the Author, never before published, together with copious Indexes. 2 vols. 8 vo. 308. cloth. By the same Author,

THE BOOK OF PSALMS ; translated from the Hebrew: with Notes, explanatory and critical. 4th Edition. 8vo. 12s. cloth.

HOWITT.-THE RURAL LIFE OF ENGLAND.

By William Howitt. 'Third Edition, corrected and revised. Medium 8vo, with Engravings on Wood by Bewick and Williams, uniform with "Visits to Remarkable Places," 21s, cloth.

\section{HOWITT.-VISITS TO REMARKABLE PLACES;}

Old Halls, Battle-Ficlds, and Scenes illustrative of Striking Passages in Fnglish History and Poetry. By William Howitt. New Edition. Medium 8vo. with 401 liustrations, 21s. cloth.

SECOND SERIES, chiefy in the Counties of DURHAM and NORTHUMBERLAND, with a stroll along the BORDER. Medium 8vo. with upwards of 40 highly-finished Woodeuts, from Drawings made on the spot, 2ls, cloth. 


\section{HOWITT.-THE RURAL AND DOMESTIC LIFE OF GERMANY:}

With Characteristic Sketches of its chief Cities and Scenery. Collectcd in a General Tour, and during a Residence in that Country in the Years 1840-42. By William Howitt, author of "The Rural Life of England," etc. Medium 8vo,, with above 50 Illustrations, 218. cloth.

\section{HOWITT.-THE STUDENT-LIFE OF GERMANY.}

From the Unpublished MS. of Dr. Cornelius. By William Howitt. 8vo, with 24 WoodEngravings, and 7 Stcel Plates, 21s. cloth.

HOWIT'T.-COLONISATION AND CHRISTIANITY:

A Popular History of the Treatment of the Natives, in all their Colonies, by the Europeans. By William Howitt. Post 8vo. 10s.6d. cloth.

HOWITT.-THE BOY'S COUNTRY BOOK:

Being the real Life of a Country Boy, written by Himself; exhibiting all the Amusements, Pleasures, and Pursuits of Children in the Country. Edited by William Howitt, author of "The Rural Life of England," etc. 2d Edition. Fcap. 8vo. with 40 Woodcuts, 8s. cloth.

\section{HOWITT, (MARY)-BALLADS AND OTHER POEMS*}

By Mary Howitt. Square crown 8vo. with a Portrait from a Picture by Miss Gillies, beautifuliy engraved by W. H. Egleton, 18s. cloth; morocco, 36s. (bound by Hayday).

\section{HUDSON-THE PARENT'S HAND-BOOK;}

Or, Guide to the Choice of Professions, Fmployments, and Situations; containing useful and practical information on the subject of placing out Young Men, and of obtaining their Education with a view to particular oceupations. By J. C. Hudson. Fcap. 8ro. 5s. cloth.

\section{HUDSON.-PLAIN DIRECTIONS FOR MAKING WILLS}

In conformity with the Law, and particnlarly with reference to the Act $7 \mathrm{Wm}$. IV. and 1 Vict. c. 26. To which is added, a clear Exposition of the Law relating to the Distribution of Personal Estate in the case of Intestacy, with two Forms of Wills, and much useful Information, etc. By J. C. Hudson, Esq. 13th Edition, corrected, Fcap.8vo.2s. 6d. cloth.

\section{HUDSON. - THE EXECUTOR'S GUIDE.}

By J. C. Hudson, Esq., of the Iegacy Duty Office, London; author of "Plain Directions for Making Wills," and "The Parent's Hand-Book." 4th Edition. Foolscap 8v0.5s. cloth.

* The above two works may be had in One volune, price 7s. cloth.

\section{HUMBOLDT (BARON).- COSMOS:}

A Sketch of a Physical Description of the Ünivcrse. Translated, with the Author's Sanction and Cooperation, under the superintendence of Lieutenant-Colonel Edward Sabine, F.R.S. For. Sec. R.S. Vols. I, post 8 vo. 12s, cloth.

[Vol. II. is in the press.

\section{HUNT,-RESEARCHES ON LICHT :}

An Examination of all the Phenomena connected with the Chemical and Molecular Changes produced by the Infuence of the Solar Rays; embracing all the known Photographic Processes, and new Discoveries in the Art. By Robert Hunt, Keeper of Mining Records, Museum of Economic Geology. 8vo. with Plate and Woodcuts, 10s.6d.cloth.

JACKSON.-THE PICTORIAL FLORA;

Or, British Botany Delineated, in 1500 Lithographic Drawings of all the Species of Flowering Plants indigenous to Great Britain; illustrating the descriptive works on English Botany of Hooker, Lindley, Smith, etc. By Miss Jackson. 8vo.158. cloth.

JAENISCII.-JAENISCH'S CELEBRATED TREATISE ON CHESS OPENINGS : Translated, with copious Notes, by G. Walker, author of "Chess Studies," etc. 8vo. closely printed.

[In the press.

JAMES.-A HISTORY OF THE LIFE OF EDWARD THE BLACK PRINCE, and of various Events connected therewith, which occurred during the Reign of Edward III. King of England. By G. P. R. James, Esq. 2d Edition. 2 vols. foolscap 8vo. with Map, 15s.

JAMES.-LIVES OF THE MOST EMINENT FOREIGN STATESMEN. By G.P. R. Janes. Esq., and F. E. Crowe, Esq. 5 vols. foolscap 8vo.30s. cloth.

JEBB (BISHOP) AND KNOX (ALEXANDER).-THIRTY YEARS' CORRESPONDF.NCE between John Jebb, D.D.F.R.S., Bishop of Limerick, Ardfert, Aghadoe, Re Al Ferster, B.D. Rector of Stisted, formerly Domestic Cliaplain to Bishop Jebb. 2d Edition. 2 vols. 8vo. 28s, cloth.

JEBB.-A LITERAL TRANSLATION OF THE BOOK OF PSALMS; Iutended to illustratc their Poctical and Moral Structure. To which are added, Disserta. Intended to illustratc their Poctical and Anthorsip, Order, Titles, and Poetical Features of the Psalms. By the Rev. John Jebb, A.M., Rector of Peterstow. 2 rols. 8 vo. 21 s. cloth. 
LORD JEFFREY.- CONTRIBUTIONS TO THE EDINBURGH REVIEW.

By Francis Jeffrey, now one of the Judges in the Court of Session in Scotland. New Edit. 3 vols. 8 vo. $42 s$. cloth.

JOHNSON.-THE FARMER'S ENCYCLOP/EDIA,

And DICTIONARY of RURAL AFFAIRS: embracing all the recent Discoveries in Agricultural Chemistry; adapted to the comprehension of unscientific Readers. By Cuthbert W. Johuson, Esq., F.R.S. Barrister-at-Law, Editor of the "Farmers" Almanack," etc. 8vo. with Wood Engravings, $2 l$. 108 . cloth.

KATER AND LARDNER.-A TREATISE ON MECHANICS. By Captain Kater and Dr. Lardner. New Edition. Foolscap 8vo. with Viguette Title, and 19 Plates, comprising 224 distinct figures, 68 . cloth.

KEIGHTLEY.-OUTLINES OF HISTORY, From the Earliest Period. By Thomas Keightley, Esq. New Edition, corrected and considerably improved. Foolscap 8vo., 6s. cloth; or 6s.6 6 . bound.

KING.-TWENTY-FOUR YEARS IN THE ARGENTINE REPUBLIC.

Embracing the Author's Personal Adventures, with the Civil and Military History of the Country, and an Account of its Political Condition, before and during the administration of Governor Rosas; his course of policy; the causes and character of his interference with the Government of Munte Video, and the circumstances which led to the interposition of Fngland and France. By Col. J. Anthony King, an Officer in the Army of the Republic. 8vo.14s. cl.

KIP.-THE CHRISTMAS HOLYDAYS IN ROME.

By the Rev. W. Ingraham Kip. M.A. Edited"by, the Rev. W. Sewell, B.D., Fellow and Tutor of Exeter College, Oxford. Foolscap 8vo. 5s. cloth.

KIRBY AND SPENCE.-AN INTRODUCTION TO ENTOMOLOGY; Or, Elements of the Natural History of Insects: comprising an account of noxious and useful Insects, of their Metamorphoses, Food, Stratagems, Habitations, Societies, Motions, Noises, Hybernation, Instinct, etc. By W. Kirby, M.A. F.R.S. \& L.S. Rector of Barham; and W. Spence, Esq., F.R.S. \& L.S. 6th Edition, enlarged. 2 vols. 8vo.31s.6d. cloth.

KNOX (ALEXANDER). - REMAINS OF ALEXANDER KNOX, ESQ. Of Dublin, M.R.I.A.; containing Essays, chiefly explanatory, of Christian Doctrine; and Confidential Letters, with Private Papers, illustrative of the Writer's Character, Sentiments, and Life. 3d Edition. 4 vols. 8vo. $2 l$. 8s. cloth.

LAING.-NOTES ON THE SCHISM FROM THE CHURGH OF ROME, called the GERMAN. CATHOLIC CHURCH, instituted by J. Ronge and I. Czerzki, in Oetober 1844, on oceasion of the Pilgrimage to the Holy Coat at Treves. By S.Laing, Esq., author of "Notes of a Traveller," etc. 2d Edition. Foolscap 8vo. 5s. cloth.

LAING.-THE CHRONICLE OF THE KINGS OF NORWAY,

From the Earliest Period of the History of the Northern Sea Kings to the Middle of the Twelfth Century, commonly called the Heimskringla. Translated from the Icelandic of Snorro Sturleson, with Notes, and a Preliminary Discourse, by Samuel Laing, author of "Notes of a Traveller," etc. '3 vols. 8 vo. 368. cloth.

LAING.-A TOUR IN SWEDEN

In 1838; comprising Observations on the Moral, Political,and EconomicalState of the Swedish Nation. By Samuel Laing, Esq. 8vo. 12s, cloth.

LANE (R. I.) - LIFE AT THE WATER CURE : Or, a Month at Malvern. A Diary of Facts and Fancies. To which is added the Sequel. By Richard J. Lane, A.R.A., Lithographer in Ordinary to Her Majesty and His Royal Highness Prince Albert. Post 8vo. with many lllustrations, 14s, cloth.

\section{LANETON PARSONAGE :}

A Tale for Children, on the practical use of a portion of the Church Catechism. By the Author of "A my Herbert," and "Gertrude," Edited by the Rev. W. Sewell, B.D. New Edition. Foolscap 8vo. 5s, cloth.

LAPLACE (THE MARQUIS DE).-THE SYSTEM OF THE WORLD. By M. Le Marquis De Laplace. Translated from the French, and elucidated with Explana tory Notes. By the Rev. Henry H. Harte, F.T.C.D. M.R.I.A. \& vols. 8vo.24s. boards.

\section{LARDNER'S CABINET CYCLOPFEIA;}

Comprising a Series of Original Works on History, Biography, Literature, the Sciences, Arts, and Manufactures. Conducted and edited by Dr. Lardner.

The Series complete in One Hundred and Thirty-three Volumes, 39l. 18s. The Works separately, 6s. per volume.

LARDNER.-A TREATISE ON ARITHMETIC.

By Dr. Lardner, LL.D. F.R.S. Foolscap 8vo, with Vignette Title, 6s. cloth. 


\section{LARDNER.-A TREATISE ON GEOMETRY,}

And its Application to the Arts. By Dr. Lardner. Foolscap 8vo. 6s. cloth.

LARDNER.-A TREATISE ON HEAT.

By Dr. Lardner, LL.D. etc. Fcap. 8vo. with Vignette Title and Woodcuts, 6s.cloth.

LARDNER.-A TREATISE ON HYDROSTATICS AND PNEUMATICS. By Dr. Lardner. New Edition. Foolscap 8vo. with Vignette Title, 6s. cloth.

LARDNER AND WALKER.-A MANUAL ON ELECTRICITY, MAGNETISM, and METEOROLOGY. By Dr. Lardner, LL.D. F.R.S., and C. V. Walker, Secretary of the Electrical Society. 2 vols. foolscap 8 vo. with Vignet te Titles, 12s. cloth.

L. E. L.-THE POETICAL WORKS OF LETITIA ELIZABETH LANDON. New Edition, 4 vols. foolscap 8vo. with lllustrations by Howard, etc. 28s. cloth; or bound in morocco, with gilt edges, $2 l .4 s$.

The following Works separately:-

The IMPROVISATRICF - $108.6 d$. The GOLDEN VIOLET - - $10 \mathrm{~s} .6 \mathrm{~d}$.

The VENETIAN BIACELET: 10s.6d. The TROUBADOUR - : - 10s.6d.

\section{LEE.-TAXIDERMY;}

Or, the Art of Collecting, Preparing, and Mounting Objects of Natural History. For the use of Museums anid Travellers. By Mrs. 1R. Lee (formerly Mrs. T. E. Bowdich), author of "Memoirs of Cuvier," etc. 6th Edition, improved, with an account of a Visit to Walton Hall, and Mr. Waterton's method of Preserving Animals. Fcap. 8vo. with Woodcuts, $7 \mathrm{~s}$.

\section{LEE.-ELEMENTS OF NATURAL HISTORY,}

For the Use of Schools and Young Persons: comprising the Principles of Classification, interspersed with amusing and instructive original Accounts of the most remarkable Animals. By Mrs. R. Lee, author of "Taxidermy," etc. 12mo. with 55 Woodcuts, 7s. $6 d$. bound.

\section{LEMPRIÈRE.-A CLASSICAL DICTIONARY;}

Containing a copious Account of all the Proper Names mentioned in Ancient Authors; with the Value of Coins, Weights, and Measures, used amongst the Greeks and Romans; and a Chronological Table. By T. Lemprière, D.D. 20th Edition, corrected. 8vo. 9s. cloth.

\section{LEREBOURS (N. P.) - A TREATISE ON PHOTOGRAPHY ;}

Containing the latest Discoveries appertaining to the Daguerréotype. Compiled from Communications by M.M. Daguerre and Arago, and other eminent Men of Science. By N. P. Lerebours, Optician to the Observatory, Paris, etc. Translated by J. Egerton. Post 8vo. with Plate, 7s, 6d. cloth.

LESLIE(C.R.)-MEMOIRS OF THE LIFE OF JOHN CONSTABLE, ESQ. R-A. Composed chiefly of his Letters. By C. R. Leslie, R. A. Second Edition, with further Extracts from his Correspondence. Small 4to. with two Portraits (one from a new Sketch, by Mr. Leslie,) and a plate of "Spring," engraved by Lucas, 21s. cloth.

\section{LETTERS TO MY UNKNOWN FRIENDS.} By a Lady. Foolscap 8 vo. 6s. 6 d. cloth.

"The author is no commonplace retailer of cut and dried maxims, but a woman of strong understrinding and culfivated taste, who has read much and thought more. She would have religion to be the beginning and the end of all human actions; but she is not puritanical in her pious zeal, for she acknowledges the worth of poetry und the arts." - Spectator.

\section{LINDLEY.-INTRODUCTION TO BOTANY.}

By Prof.J.Lindley, Ph.D.F.R.S.L.S. etc. 3d Edition, with Corrections and considerable Additions. 8vo. with Six Plates and numerous Woodcuts, 188. cloth.

\section{LINDLEY.-FLORA MEDICA ;}

A Botanical Account of all the most important Plants used in Medicine in different Parts of the World. By John Lindley, Ph.D. F.R.S. etc. 8vo. 18s. cloth.

\section{LIN]LEY.-A SYNOPSIS OF THE BRITISH FLORA,}

Arranged according to the Natural Orders. By Professor John Lindley, Ph. D., F.R.S., etc. Third Edition, with numerous Additions and Improvements. 12mo. 108. 6d. cloth.

\section{LINDLEY.-THE THEORY OF HORTICULTURE :}

Or, an Attempt to Explain the Principal Operations of Gardening upon Physiological Prin. ciples. By John Lindley, Ph.D.F.R.S. 8vo, with Illustrations on Wood, 128. cloth.

\section{LINDLEY.-GUIDE TO THE ORCHARD AND KITCHEN GARDEN ;}

Or, an Account of the most valuable Fruits and Vegetables cultivated in Great Britain : with Kalendars of the Work required in the Orchard and Kitchen Garden during every month in the Year. By George Lindley, C.M.H.S. Edited by Professor Lindley. 8vo. 16s. boards. 


\section{LINWOOD (W.)-ANTHOLOGIA OXONIENSIS ;}

Sive, Florilegiun e Iusibus poeticis diversorum Oxoniensium Graecis et Latinis decerptum.

Curante Gulielmo Linwood, M.A. AEdis Christi Alummo. 8vo. 14s. cloth.

\section{LOUDON (MRS.) - THE AMATEUR CARDENER'S CALENDAR:}

Being a Montlly Guide, as to what should be avoided as well as what should be done in a Garden in each Mouth, with plain Rules how to do what is requisite. By Mrs. Loudon, author of "The Lady's Country Companion," "Gardcuing for Ladies," etc. Fcap. 8vo. with numeruus lllustrations.

[In the press.

\section{LOUDON (MRS.)-THE LADY'S COUNTRY COMPANION;}

Or, How to Enjoy a Country Life Rationally. By Mrs. Loudon, author of "Gardening for Ladics," etc. New Edition. Foolscap 8vo., with Plate and Woodcuts, 7s. 6d. cloth.

\section{I.OUDON (J. C.)-SELF INSTRUCTION}

For Young Gardeners, Foresters, Bailiffs, Land Stewards, and Farmers $;$ in Arithmetic Book-keeping, Geometry, Mensuration, Practical Trigonometry, Mechanics, Land-Surveying, Leveling, Planning and Mapping, Architectural Drawing, and Isometrical Projection and Perspective ; with Examples shewing their applications to Horticultural and Agricultural Purposes. By the late J. C. Loudon, F.L.S. H.S. etc. With a Portrait of Mr.Loudon, and a Memoir by Mrs. Loudon. 8vo, with Wood Engravings, 7s. 6d. cloth.

\section{LOUDON.-AN ENCYCLOPAEDIA OF TREES AND SHRUBS;}

Being the "Arboretum et Fruticetum Britannicum" abridged : containing the Hardy Trees and Shrubs of Great Britain, Native and Foreign, scientifically and popularly described: with their Prnpagation, Culture, and Uses in the Arts. By J.C.Loudou, F.L.S. etc. 8vo. with upwards of 2,000 Engravings on Wood, $2 l$.10s. cloth.

The Original Work; a New Edition, in 8 vols. 8 vo. with above $4008 \mathrm{vo}$. Plates of 'Trees, and upwards of 2,500 Woodeuts, $10 l$. cloth.

\section{LOUDON.-AN ENCYCLOPAEDIA OF GARDENING ;}

Presenting in one systematic view, the History and Present State of Gardening in all Coun. tries, and its Theory and Practice in Grcat Britain: with the Management of the Kitchen Garden, the Flower Garden, Laying-out Grounds, etc. By J. C. Loudon, F.L.S. etc. A new Edition, 8vo, with nearly 1,000 Fngravings on Wood, 2l.10s. cloth.

\section{LOUDON,-AN ENCYCLOPAEIA OF AGRICULTURE;}

Comprising the Theory and Fractice of the Valuation, Transfer, Laying-out, Improvement, and Management of Landed Property, and of the cultivation and economy of the Animal and Vegetable Productions of Agriculture, including all the latest improvements; By J. C. Loudon, F.L.G.Z. and H.S. etc. Fifth Edition. 8vo. with upwards of 1,100 Engravings on Wood, by Branston, $2 l$. 10s. cloth. The Supplement, separately, 5s. sewed.

\section{LOUDON.-AN ENCYCLOPADIA OF PLANTS;}

Including all the Plants which are now found in, or have been introduced into, Great Britain; giving their Natural History, accompanied by such Descriptions, Engraved Figures, and Elementary Details, as may enable a beginner, who is a mere English reader, to discover the name of every Plant which he may find in flower, and acquire all the information respecting it which is nseful and interesting. By J.C. Loudon, F.L.S., etc. The Specific Characters by an Eminent Botanist; the Drawings bv J.D.C. Sowerby,F.L.S. A new Edition, with a new Supplement and a new Index. 8vo. with nearly 10,000 Wood Engravings, 73s. 6d. cloth. * " The last Supplement, separately, 8vo. 158. cloth.

LOUDON.- AN ENCYCLOPADIA OF COTTAGE, FARM, AND VILLA ARCHITECTURE and FURNITURE. Containing Designs for Cottages, Villas, larm Houses, Farmeries, Country Inns, Public Houses, Parochial Schools, etc. ; with the requisite Fittings-up, Fixtures, and Furviture, and appropriate Offices, Gardens, and Garden Scenery: each Design accompanied by Analytical and Critical Remarks. By J. C. Loudon, F.L.S. etc. New Edition, Edited by Mrs. Loudon. 8vo. with more than 2,000 Engravings on Wood, 63s. cloth.-The Supplement, seperately, 8vo.7s. 6d.sewed.

\section{LOUDON.-HORTUS BRITANNICUS :}

A Catalogue of all the Plants indigenous to or introduced into Brituin. The $3 \mathrm{~d}$ Fdition, with a New Supplement, prepared, under the direction of J. C. Loudon, by W. H. Baxter, and revised by George Don, F.L.S. 8vo. 31s.6d. cloth.

\section{LOUDON.-THE SUBURBAN GARDENER AND VILLA COMPANION:}

Comprising the Choice of a Villa or Suburban Residence, or of a situation on which to form one; the Arrangement and Furnishing of the House; and the Laying-out, Planting, and general Management of the Garden and Grounds; the whole adapted for Grounds from one perch to fifty acres and upwards in extent; intended for the instruction of those who know little of Gardening or Rural Affairs, and more particularly for the use of Ladies. By J. C. Loudon, F.L.S., ete. 8ro, with above 300 Wood Engraving s, 20s. cloth.

\section{LOUDON.-HORTUS LIGNOSUS LONDINENSIS:}

Or, a Catalogue of all the Ligneous Plants cultivated in the neighbourhood of London. To which are added their usual Prices in Nurseries. By J.C. Loudon, F.L.S. ete. 8vo. 7s.6d. 
LOW.-ON LANDED PROPERTY, AND THE ECONOMY OF ESTATES;

Comprehendiug the Relatious between Lundlort and 'Penant, and the Principles and'Forms of Leases; of Frrm buildings, Euclosures, Draius, Embankments, Roads, and other Rural Works, Minerals, and Wouds. By David Low, Esq. F.R.S.E. etc., author of "Elements of Practical Agriculture," etc. 8vo. with numerous Wood Engravings, 218. cloth.

LOW.--ON THE DOMESTICATED ANIMALS OF GREAT BRITAIN, comprehending the Natural and Economical History of the Species and Breeds; Illustrations of the Properties of Exterual Form; aul Observations on the Principles and Practice of Breeding. By David Low, Esq., F.R.S.E. Professor of Agriculture in the University of Edinburgh, etc.; suthor of "Elements of Practical Agriculture," etc. 8ro, with Eugravings on Wood, $25 s$. cloth.

LOW.-THE BREEDS OF THE DOMESTICATED ANIMALS OF GREAT BRIYAIN described. By David Low, Hisq, F.R.S.E., Professor of A rriculture in the University of Edinburgh, etc. etc. The Plates from drawings by W. Nicliolson, R.S.A., reduced from a Series of Oil Paintings, exccutcd for the Agricultural Museum of the University of Edinburgh, by W. Shiels, R.S.A. 2 vols, atlas quarto, with 56 Plates of Animals, beautifully coloured after Nature, $161.16 s$. half-bound in morocco. Orin four separate portions, as follow:-

The OX. 1 Vol. atlas quarto, with 22 Plates, | The HORSE. 1 Vol. atlas quarto, with 8 price $6 l$. 16s. $6 d$. half-bound niorocco.

The SHEEP. I Vol. atlas quarto, with 21 Plates, price $6 l .168 .6 d$. half-bound morocco. Plates, price $3 l$. half-bound moroceo. The HOG. 1 Vol. at las quarto, with 5 Plates, price $2 l .2 s$. half-bound morocco.

LOW.-ELEMENTS OF PRACTICAL AGRICULTURE;

Comprehending the Cultivation of Plauts, the Husbandry of the Domestic Animals, and the Economy of the Farm. By David Low, Esq.F.R.S.E., Professor of Agriculture in the University of Ėdinburgh. 4th Edition, with Alterations and Additions. 8vo. with above 200 Woodicuts, 21s, cloth.

MACAULAY. -CRITICAL AND HISTORICAL ESSAYS CONTRIBUTED TO THE EDINBURGH REVIElW. By the Right Hon. Thomas Babington Macaulay, M.P. 4th Edition. 3 vols . 8vo.36s. cloth.

MACAULAY.- LAYS OF ANCIENT ROME. By the Right Honorable Thomas Babington Macaulay, M.P. 8th Edition. Crown 8vo. $10 s .6 d$. cloth.

MACAULAY.-MR. MACAULAY'S LAYS OF ANCIENT ROME. A New Edition. With numerous Illustrations, Original and from the Autiquc, Drawn on Wood by George Scharf, jun.; and Eilgraved by Samue] Williams. Fcp. 4to. [In the press.

MACKAY (CHARLES), - THE SCENERY AND POETRY OF THE ENGLISH LAKES; a Summer Ramble. By Cliarles Mackay, Esq. L.L.D.author of "Legends of the Isles," "The Salamandrine," "The Thames and its Tributaries," etc. Svo. with beautiful Wood Engravings from Original Sketches, 14s. cloth.

MACKINNON.-THE HISTORY OF CIVILISATION. By Wm. Alexander Mackinnon, F.R.S. M.P. for 1,ymington. 2 vols. 8vo. 24s. cloth.

MACKINTOSH (SIR JAMES).-THE LIFE OF SIR THOMAS MORE. By the Right Hou. Sir Jamcs Mackintosh. Reprintcd from the Cabinet Cyclopædia. Foolscap 8vo, with Portrait, 5s. cloth; or bound in vellum gilt (old style), 8 s.

MACKINTOSH'S (SIR JAMES) MISCELLANEOUS WORKS; Including his Contributions to The EDINBURGH REVIEW. Edited by Robert James Mackintosh, Esq. 3 vols. 8 vo. $42 s$. cloth.

MACKINTOSH, ETC.-THE HISTORY OF ENGLAND. By Sir James Mackiutosli; W. Wallace, Esq.; and Robert Bcll, Esq. 10 vols. foolscap Svo. with Vignette' 'Titles, $3 l$, cloth.

M'CULLOCH.-THE LITERATURE OF POLITICAL ECONOMY;

Being a Classified Catalogue of the principal Works in the different departments of Political Economy, interspersed with Historical, Critical, and Biographical Notices. By J. $\mathbf{K}$. M'Culloch, Esq. 8vo. 14s, cloth.

M'CULLOCH (J. R.)-AN ACCOUNT, DESCRIPTIVE, AND STATISTICAL, of the BRITISH EMPIRE; exhibiting its Extent, Physical Capacities, Population, Industry, and Civil and Religious Institutions. By J. R. M.Culloch, Esq. 3d Edition, corrected, enlaryed, and greatly im proved. 2 thick vols. 8 vo.

[In the press.

M'CULLOCH. - A TREATISE ON THE PRINCIPLES AND PRACTICAL INFLULNCE OF TAXATION AND THE FUNDING SYSTEM. BY J.R. M*Culloch, Esq. 8vo. 15s. cloth. 
M'CULLOCH.-A DICTIONARY, GEOGRAPHICAL, STATISTICAL, AND HISTORICAL, of the various Countries, Places, and Principal Natural (objects in the World. By J.R. M'Culloch, Esq. A new Edition. 2 vols. 8vo. with Six large Maps, $4 l$. cloth.

* The new Articles are printed separately as a Supplement to the former Edition. They comprise a full account of the present siate of the United Kingdom, the Oregon Territory, etc. 8vo. 5s. seved.

M'CULLOCH.-A DICTIONARY, PRACTICAL, THEORETICAL, AND HISTORICAL, OF COMMERCE, AND COMMERCIAL NAVIGATION. BY J. R. M'Culloch, Esq. A New Edition, corrected, enlarged, and improved. 8vo. with Maps and Plaus, $50 \mathrm{~s}$. cloth; or 55s. strongly half-bound in russia, with flexible back.

** This Edition, which has been carefully corrected, comprises, besides the Nero Tariff; the new Acts relating to Banking, the Sugar Trade, Navigation and Customs, the hiring of Seamen, elc.; and is further enriched with valuable information from all parts of the woorld.

A SUPPLEMENT, for the use of the purchasers of the last Edition, 8vo, price $3 s .6 d$. sewed.

M'LEOD.-THE GEOGRAPHY OF PALESTINE OR THE HOLY LAND, Including Phoulicia and Philistia. By W. M.Leod, Head Master of the Model School, Royal Military Asylum, Chelsea, late Master of the Model School, Battersen. $12 \mathrm{mo}$. [in the press.

MAITLAND (DR. CHARLES), - THE CHURCH IN THE CATACOMBS: A Description of the primitive Church of Rome, Illustrated by its Sepulchral Remains. By Charles Maitland, M.D. 8vo. with numerous Engravings on Wood. 14s. cloth.

MARCET (MRS.)-CONVERSATIONS ON THE HISTORY OF ENGLAND. For the Use of Children. By Mrs. Marcet, author of "Conversations on Chemistry," etc. 2d Edition, with Additions. $18 \mathrm{mo} .5$ s. cloth.

\section{MARCET-CONVERSATIONS ON CHEMISTRY;}

In which the Elements of that Science are familiarly Explained and Illustrated by Experiments. By Mrs. Marcet. New Edition, corrected. 2 vols. foolscap 8vo. 14s. clot h.

\section{MARCE'T.-CONVERSATIONS ON NATURAL PHILOSOPHY ;}

In which the Elcments of that Science are familiarly explained, and adapted to the comprehension of Young Persons. By Mrs. Marcet. 10th Edition, enlarged and corrected. Feap. 8vo. with 23 Plates, 10 s. 6 d. cloth.

MARCET.-CONVERSATIONS ON POLITICAL ECONOMY; In which the Elements of that Science are familiarly explained. By Mrs. Marcet. 7 th Edition, revised aud enlarged. Foolscap 8vo.7s.6d. cloth.

\section{MARCET.-CONVERSATIONS ON VEGETABLE PHYSIOLOGY;} Comprehending the Elements of Botany, with their application to Agriculture. By Mrs. Marcet. 3d Edition. Foolscap 8vo. with Four Plates, 9s. cloth.

\section{MARCET.-CONVERSATIONS ON LAND AND WATER.} By Mrs. Marcet. 3d Edition revised and corrected. Foolscap 8vo., with coloured Map shewing the comparative Altitude of Mountains, 5s, 6 d. cloth.

\section{MARCET.-CONVERSATIONS ON LANGUAGE,} For Children. By Mrs. Marcet, author of "Mary's Granimar,"etc. 18mo.4s.6d.cloth,

\section{MARGARET PERCIVAL.}

By the author of "Amy Herbert," "Gertrude," and "L Laneton Parsonage." Edited by the Rev. W. Sewell, B.D., Fellow and Tutor of Exeter College, Oxford, 2; vols, foolscap. 8vo. 12s, cloth.

MARRYAT,-THE PRIVATEER'S-MAN ONE HUNDRED YEARS ÀGO. By Captain F. Marryat, C.B. Author of "Peter Simple," "G Masterman Ready," etc. 2 vols. fcap. 8vo. $12 s$. cloth.

MARRYAT (CAPT).-THE MISSION; Or, Scenes in Africa. Written for Young People. By Captain Marryat. C.B., author of "Peter Simple," "Masterman Ready," "The Settlers in Canada," etc. 2 vols. fcap. 8vo. 12s. cloth.

MARRYAT (CAPT.)-THE SETTLERS IN CANADA. Written for Young People. By Captain Marryat, C.B. author of "Peter Simple," "Masterman Ready," etc. New Edition. Fcap. 8vo. with two Illustrations, 7s. 6d. cloth.

MARRYAT (CAPT.)-MASTERMAN READY;

Or, the Wreck of the Pacific. IVritten for Young People. By Captain Marryat, C.B. author of "Peter Simple," etc, 3 vols. fuap. 8vo. with numerous Engravings on Wood, 22s.6d. cloth. 


\section{MAUNDER.-THE TREASURY OF KNOWLEDGE,}

And LIBRARY of REFERENCE. By Samuel Maunder. 16th Editlon, revised throughout and enlarged. Foolscap $8 \mathrm{vo} .10 \mathrm{~s}$. cloth; bound iu roan, $12 \mathrm{~s}$.

* * The principal contents of the present new and thoroughly revised edition of "The Treasury of Knowledge," ane-a new and enlarged English Dicticnary, with a Grammar, Verbal Distinctions, and Exercises; a new Universul Gazetteer; a compendious Classical Dictionury; an Analysis of History aud Chronology; a Dictionary of Law Terms; a new Synopsis of the British Peerage; and various useful tabular Addenda.

\section{MAUNDER. - THE BIOCRAPHICAL TREASURY :}

Consisting of Memoirs, Sketches, and brief Notices of above 12,000 Eminent Persons of all Ages and Nations, from the Earliest Period of History; forming a new and complete Dic. tionary of Universal Biography. By Samuel Maunder. 5th Edition, revised throughout, and containing a copious Supplement; brought down to 1845. Foolscap 8vo. 108. cloth; bound in roan, $12 s$.

\section{MAUNDER - THE SCIENTIFIC AND LITERARY TREASURY:}

A New and Popular Encyclopædia of Science and the Belles Lettres; including all Branches of Science, and every Subject connected with Literature and Art. The whole written in a familiar style, adapted to the comprehension of all persons desirous of acquiring information on the subjects comprised in the work, and also adapted for a Manual of convenient Refer: ence to the more instructed. By Samuel Maunder. 4th Edition. Fcap.8vo.10s, cloth; bound in roan, $12 s$.

\section{MAUNDER.-THE TREASURY OF HISTORY;}

Comprising a General Introductory Outline of Universal History, Ancient and Modern, and a Series of separate Histories of every principal Nation that exists; developing their Rise, Progress, and Present Condition, the Moral and Social Character of their respective Inhabitants, their Religion, Manners, and Customs, etc. etc. By Samuel Maunder. 2d Edit. Feap. 8vo. 10s. cloth; bound in roan, 128.

\section{MAURY.-THE STATESMEN OF AMERICA IN 1846.}

By Sarah Mytton Maury. 8vo, 7s, 6d. cloth.

\section{MENOIRS OF THE GEOLOCICAL SURVEY OF GREAT BRITAIN,}

And of the Museum of Economic Geology in London. Published by order of the Lords Commissioners of Her Majesty's Treasury. Vol. 1, royal 8vo. with Woodcuts and 9 Plates, (seven coloured), 21s. cloth.

\section{MICHELET (J.)-PRIESTS, WOMEN, AND FAMILIES.}

By J. Michelet. Translated from the French (third edition), with the Author's permission, by C. Cocks, B.L. Professor of the Living Languages in the Royal Colleges of France. New Editions. Post 8 vo.9s. cloth. 16mo.1s, $4 d$. sewed.

\section{MICHELET (J.) - THE PEOPLE.}

By M. Michelet, Member of the Institute of France, etc. Translated, with the approbation of the Author, by C. Cocks, B.L. New Edition. Post 8vo.9s. cloth. 16mo. 1s. 6d. sewed.

- * Mr. Cocks's authorised translations of Michelet's "Priests, Women, and Fumilies," and "The People," in one vol. 16 mo. 3s.6d. cloth.

\section{MICHELET AND QUINET. - THE JESUITS.}

By J. Michelet, Member of the Institute of France; and E. Quinet, of the College of France. 'Translated, with the approbation of the Authors by C. Cocks, B.L. New Edition. $16 \mathrm{mo} .1 s, 6 d$. sewed.

- * Mr. Cock's authorised translations of MM. Michelet and Quinet's "The Jesuits," and M. Quinet's "Christianity," in one vol. 16mo. 48. cloth

MILES (W.) - THE HORSE'S FOOT,

And How to Keep it Sound. By William Miles, Esq. New Edition. Royal 8vo. with Engravings, 78. cloth.

MILNER (REVS. J. AND I.) - THE HISTORY OF THE CHURCH OF CHRIST. By the Rev. Joseph Miluer, A.M. With Additions and Corrections by the late Rev. Isaac Milner, D.D. F.R.S. A New Edition. 4 vols. 8 vo.

[Just ready.

$$
\text { A continuation of the above. }
$$

\section{THE HISTORY OF THE CHURCH OF CHRIST,}

irom the Diet of Augsburg, 1530, to the Eighteenth Century; orlginally designed as a Continuation of Milner's "History of the Church of Christ." By the Rev. Henry Stebbing, U.D. 3 vols. 8vo. 36s. cluth.

MOHAN LAL. - LIFE OF THE AMIR DOST MOHAMMED KHAN OF KABUL: with his Political Proceedings towards the English, Russian, and Persian Governments, including the Victory and Disasters of the British Army in Afighanistan. By Mohan Lal, Esq., Knight of the Persian Order of the Liou and Sun; lately attached to the Mission in Kabul.' 2 vols. 8vo, with numerous Portraits, 308. cloth. 
MONTAUBAN (MRS. E.) - A YEAR AND A DAY IN THE EAST;

Or, Wanderings over Land and Sea. By Mrs. Eliot Montauban. Post 8vo. 7s. cloth.

MONTGOMERY'S (JAMES) POETICAL. WORKS.

New and only complete Edition. With some additional Poems and Autobiographical Prefaces. Collected and edited by Mr. Montgomery. 4 vols. foolscap 8vo. with Portrait, and seven other Plates, $20 s$. eloth; bound in morocco, $1 l$. $16 s$.

MOORE.-THE HISTORY OF IRELAND.

From the earliest Kings of that Realm, down to its last Chief. By Thomas Moore, Esq. 4 vols, foolscap 8vo,, with Vignette 'Titles, 248 . clotli.

\section{MOORE'S POETICAL WORKS;}

Containing the Author's recent Introduction and Notes. Complete in one volume, uniform with Lord Byron's Poems. Medium 8vo. with Portrait and Vignette, 1l. 1s. cloth; or $42 s$. bound in morocco, by Hayday.

** Also, an Edition in 10 vols. foolscap 8vo. with Portrait, and 19 Plates, 27.108. clotll; moroeco, $4 l .10 s$.

\section{MOORE'S LALLA ROOKH, AN ORIENTAL ROMANCE.}

New Edition. Medium 8vo, illustrated with 13 fine Engravings, 21s. cloth; morocco, 35s.; with India Proof Plates, $42 s$, eloth.

\section{MOORE'S LALLA ROOKH. AN ORIENTAL ROMANCE.}

New Edition. Foolscap 8vo, with 4 Plates, by IV estall, 10s.6d. cloth; or 14s. bound in moroceo.

\section{MOORE'S IRISH MELODIES.}

Illustrated by D. Maclise, R.A. Imp. 8vo, with 161 Designs, engraved on Steel, $3 l .3 s$. boxrds; or $41.14 s .6 d$. bound in morrocen, by Hayday. Proof Impressions (only 200 eopies printed, of which a few remain), $6 l .6 s$. boards.

** India Proofs before letters of the 161 Designs, on Quarter Colombier, in Portfolio (only 25 copies printed, of which a few remain, 31 l. 10 s.

India Proofs before letters of the 51 Large Designs, on Quarter Colombier, in Portfolio (ouly 25 copies printed, of which a few remain), 181 . 18 s.

MOORE'S IRISH MELODIES.

New Edition. Feap. 8vo, with Vignette Title, 10s. cloth; bound in moroccu, 13s.6 .

\section{MOORE.-THE POWER OF THE SOUL OVER THE BODY,}

Considerled in relation to Health and Morals. By George Moore, M.D. Member of the Royal Colegre of Physicians, London, ete. 2d Edition. Post 8vo.7s.6d. cloth.

\section{MOORE,-THE USE OF THE BODY IN RELATION TO THE MIND.}

By George Moore, M.D. Member of the Royal College of Physicians, London, etc. Post 8vo. 9s. cloth.

\section{MORAL OF FLOWERS (THE).}

3d Edition. Royal 8vo, with 24 beautifully coloured Engravings, 1l. 10s. half-bound.

\section{MOSELEY.-ILLUSTRATIONS OF PRACTICAL MECHANICS.}

13y the Rev. H. Moseley, M.A., Professor of Naturnl Philosophy and Astronomy in King's College, London; being the lirst Volume of the Illustrations of Science by the Professors of King's College. New Edition. Fcap.8vo. with Woodcuts, 8s. cloth.

MOSELEY.-THE MECHANICAL PRINCIPLES OF ENGINEERING AND ARCHITECTURE. By the Rev. H. Moseley, M.A. F.R.S., Professor of Natural Philosophy and Astronomy in King's Colleye, London; and author of " Illustrations of Practical Mechanics," etc. 8 vo, with Woudcuts and Diagranis, $1 l .4 s$. cloth.

\section{MOSHEIM'S ECCLESIASTICAL HISTORY,}

Ancient and Modern. Translated, with cởitus Notes, by James Murdock, D.D. Edited, with Additions, by Henry Soames, M.A. Ne Kdition, revised, and continued. 4 vols. 8 vo. 48s. cloth.

\section{MURRAY.-AN ENCYCLOPAEDIA OF GEOGRAPHY;}

Comprising a complete Description of the Earth: exhibiting its Relation to the Heavenly Bodies, its Physical Strueture, the Natural History of each Country, and the Industry, Commerce, Political Institutions, and Civil and Social State of all Nations. By Hugh Murray, F.R.S.E.: New Edition. 8vo. with 82 Maps, and upwards of 1,000 other Engravings on Wood, $3 l$, cloth.

MY YOUTHFUL COMPANIONS.

By the author of "My School-boy Days." 18mo., with Frontispiece, 2s. 6d. cloth. 
NECKER DE SAUSSURE-PROGRESIVE EDUCATION

Or, Considerations on the Course of Life. Translated and Abridged from the French of Madame Necker De Saussure, by Miss Ifollaud, 3 vols. foolscap 8vo. 19s. 6d. cloth.

**"Separately-vols. I. and II. 12s.; nol. III. 7s.6d.

\section{NESBIT (A.)-A TREATISE ON PRACTICAL MENSURATION;}

Containing the most approved Methods of drawing Geometrical Figures; Mensuration of Superficies; Land-Surveying; Mensuration of Solids; the Use of the Carpeuter's Rule ; Timber Measure, etc. By A. Nesbit. 12th Edition. 12mo. with 300 Woodcuts, 6s. bound.

KEY. 7th Edition. 12mo. 5s, bound.

\section{NEWELL (REV. R. H.) - THE ZOOLOGY OF THE ENGLISH POETS,}

Corrected by the Writings of Modern Naturalists. By the Rev. R.H. Newell, Rector of Little Hormend. Fcap. 8vo, with Engravings on Wood, 5s. 6d. cloth.

\section{NICOLAS.-THE CHRONOLOGY OF HISTORY,}

Containing Tables, Calculations, and Statements indispensable for ascertaining the Dates of Historical Events, and of Public and Private Documents, from the Earlicst Period to the Present Time. By Sir Harris Nicolas, K.C. M.G. 2nd Edition, fcap. 8vo. 6s. cloth.

ORDNANCE MAPS (THE), AND PUBLICATIONS OF THE GEOLOGICAL SURVEY OF THE UNITED KINGDOM.-Messrs. Longman and Co, have been appointed by the Board of Orduance Agents for the sale of the Maps of the Ordnance Survey of Great Britain. Also, sole Agents for the sale of the Maps, Sections, and Books of the Geological Survey of the United Kingdom, and of the Museum of Economic Geology, under the Chief Commissioner of Her Majesty's IWoods, Works, and Land Revenues.

** Complete delailed Catalogues of bath Serics may be had on application.

OWEN. - LECTURES ON THE COMPARATIVE ANATOMY AND PHYSIOLOGY OF THE INVERTEBRATE ANIMALS, delivered at the Royal College of Surzeons in 1843. By Richard Owen, F.R.S. Hunterian Professor to the Collegc. From Notes taken by William White Cooper, M.R.C.S. and revised by Professor Owen. With Glossary and Index. 8vo. with nearly 140 llilustrations on Wood, 14s. cloth.

**" Professor Owen's Lectures on the Vertebratn are in the press, in 2 vols. 8vo. Vol. I. will be published in a few duys.

\section{PARABLES OF OUR LORD.}

Richly Illuminated with appropriate Borders, printed in Colours, and in Black and Gold; with a Design from one of the early German engravers. Square foolscap 8vo., uniform in size with the "Sermon on the Mount," 218 ., in massive carved binding; or 308 . bound in morocco, by Hayday.

\section{PARKES.-DOMESTIC DUTIES :}

Or, Instructions to Young Married Ladies on the Management of their Households and the Regulation of their Conduct in the various Relations and Duties of Married Life. By Mrs. W. Parkes. 5th Edition. Foolscap 8vo.9s. eloth.

\section{PARNELL.-A TREATISE ON ROADS,}

Wherein the Priuciples on which Roads should be made are explained and illustrated by the Plans, Specifications, and Contracts, made use of by Thomas Telford, Esq., on the Ifolyhead Road. By the Rt. Hon. Sir Henry Parnell, Bart. Second Edition, greatly enlarged. 8vo. with Nine large Plates, 21 s. cloth.

PATON (A. A.)-SERVIA, THE YOUNGEST MEMEER OF THE EUROPEAN FAMILY; or, a Residence in Belgrade, and Travels through the Highlands and Woodlands of the Interior, during the years 1843 and 1844. By Andrew Archibald Paton, Esq. Post 8vo. with portrait and plate, 12s. cloth.-By the same Author.

THE MODERN SYRIANS, or, Native Society in Damascus, Aleppu, and the Mountains of the Druses. Post 8vo.10s.6d. cloth.

PEARSON.-AN INTRODUCTION TO PRACTICAL ASTRONOMY: By the Rev. W. Pearson, LL.D.F.R.S. etc. Rector of South Kilworth, Leicestershire, and Treasurer to the Astronomical Society of London. 2 vols. 4 to. with Plates, $7 l$. 7 s. boards.

PEARSON.-PRAYERS FOR FAMII '- $S$ : Consisting of a short but comprehensiv Form for the Morning and Evening of every Day in the Week. Collected by the late Edward Pearsou, D.D. With a Biograplical Memoir of the Author. New Edition. $18 \mathrm{mo} .28 .6 d$, cloth.

PEDESTRIAN AND OTHER REMINISCENCES AT HOME AND ABROAD, WITH SKETCHKS OF COUNTRY LIFE. By Sylvanus. Post 8vo, with Frontispiece and Vignette Title, 10s.6d. cloth.

PEREIRA.-A TREATISE ON FOOD AND DIET: Rigestive With Observations on the Dietetical Regimen suited for Disordered Metropolitan and other Organs; and an Account of the Dietaries of some of the principal Mick, etc. By Jon. Pereira, M.D.F.R.S., author of "Elements of Materia Medica." 8vo. 16s. cloth. 


\section{PERICLES :}

A Tale of Athens in the 83d Olympiad. By the author of "A Brief Sketch of Greek Philosophy." 2 vols. post 8 ro. 18s. cloth.

PERRY (DR. W. C.)-GERMAN UNIVERSITY EDUCATION:

Or, the Professors and Students of Germany. To which is added, a brief account of the Public Schools of Prussia; with Observations on the Influence of Philosophy on the Studies of the German Universities. By Walter C. Perry, Phil. D. of the University of Göttingen. 2nd Edition. $12 \mathrm{mo}, 48,6 d$, cloth.

PESCHEL (C. F.)-ELEMENTS OF PHYSICS, By C. F. Peschel, Principal of the Royal Military College, Dresden, etc. etc. Translated from the German, with Notes, by E. West. 3 vol. fcap. 8vo. with Woodcuts, 21 s. cloth.

Separately $\left\{\begin{array}{c}\text { Part 1. The Physics of Ponderable Bodies. Fcap. 8vo. 7s. 6d. cloth. } \\ \text { Part 2. Imponderable Bodies (Light, Heat, Magnetism, Electricity, } \\ \text { and Electro-Dynamics). 2 vol. fcap. 8vo. 13s. 6d. cloth. }\end{array}\right.$

PHILLIPS. -FIGURES \& DESCRIPTIONS OF THE PALAEOZOIC FOSSILS OF CORNWALL, DEVON, and WFST SOMFRSFT; observed in the course of the Ordnance Geological Survey of that District. By John Phillips, F.R.S. F.G.S. ete. Published by Order of the Lords Commissioners of H. M. Treasury. 8vo. with 60 Plates, comprising very numerous Figures, 9s. cloth.

PHILLIPS. - A CUIDE TO CEOLOCY.

By John Phillips, F.R.S. G.S. etc. Foolscap 8 vo. with Plates, 5s. cloth.

PHILLIPS.-A TREATISE ON GEOLOGY.

By John Phillips, F.R.S. G.S. etc. 2 vols. foulscap $8 v 0$, with Woodcuts. 128, cloth.

PITMAN (REV. J. R.)-SERMONS

On the principal Subjects comprised in the Book of Psalms, abridged from Fminent Divines of the Established Church. By the Rev, J. R. Pitman, A.M. Domestic Chaplain to Her Royal Higliness the Duchess of Kent. 8vo. 1 is. cloth.

\section{PLUNKETT.-THE PAST AHD FUTURE OF THE BRITISH NAVY.} By the Hon, E Plunkett, Commander R.N. 8vo. 7 s. cloth.

PLYMLEY (PETER).-LETTERS ON THE SUB,IECT OF THE CATHOLICS TO MY BROTHFR ABRAHAM, WHO LIVES IN THE COUNTRY. By Peter Plymley. 21 st Edition. Post 8vo. 78. cloth.

POETS' PLEASAUNCE (THE);

Or, Garden of all Sorts of Pleasant Flowers, which our Pleasant Poets have in Past Time (for Pastime) Planted: with the right ordering of then. By Eden Warwick. Square crown 8 vo. with very numerous lllustrations on Wood, engraved in the best manner.

POISSON (S. D.)-A TREATISE ON MECHANICS.

[In the press.

By S.D. Poisson. Second Edition. Translated from the French, and illustrated with Explanatory Notes, by the Rev. Henry H. Harte, late Fellow of Trinity College, Dublin. 2 volumes, 8 vo. $1 l .8$ s. cloth.

POPE (ALEXANDER).-THE WORKS OF ALEXANDER POPE.

Edited by Thomas Roscoe, Esq. With the Author's Life. A New Fdition. 8 vols, 8vo, 4l. $4 s$. cloth.

PORTER.-A TREATISE ON THE MANUFACTURE OF SILK.

By G. R. Porter, Esq. F.R.S., author of "The Progress of the Nation," etc. Fcap.8vo.with Vignette Title, and 39 Engravings on Wood, 68 . cloth.

PORTER.-A TREATISE ON THE MANUFACTURES OF PORCELAIN AND GLASS. By G. R. Porter, Ese. F.R.S. Foolscap 8vo. with 50 Woodcuts, fis. cloth.

PORTLOCK. - REPORT ON THE GEOLOGY OF THE COUNTY OF LONDONDERRY, and of Parts of Tyrone and Fermanagh, examined and described under the Authority of the Master-General and Board of Ordnance. By J.E. Portlock, F.R.S.etc. 8 o. with 48 Plates, 248 , cloth.

POWELL. - THE HISTORY OF NATURAL PHILOSOPHY.

From the Earliest Periods to the Present Time. By Baden Powell, M. A., Savilian Professor of Mathematics in the University of Oxford. Fcap.8vo. with Vignette Title, 6s. cloth.

\section{PYCROFT.-A COURSE OF ENGLISH READING;}

Adapted to every Taste and Capacity. With Anecdotes of Men of Genius. By the Rcv. James Pycroft, B.A., author of "Greek Grammar Practice," and "Latin Grammar Practice ;" Editor of "Virgil, with Marginal References." Foolscap 8vo. 6s. 6d. cloth. 
QUARTERLY JOURNAL OF THE GEOLOGICAL SOCIETY OF LONDON. Edited by David Thomas Ansted, M.A. F.1R.S., Fellow of Jesus College, Cambridre; I'ro: fessor of Geology in Kiug's College, Loudon; Vice-Secretary of the Geological Soclety. 8 vo. 4s, each number, sewed.

* Volume I. 8vo. with Plates and Woodcuts, 17s. 6d. cloth.

\section{QUINET.-CHRISTIANITY IN ITS VARIOUS ASPECTS,}

From the Birth of Christ to the French Revolution. By E. Quinet, of the College of France. Translated with the Author's approbation, by C. Cocks, B.L. 16mo.2s. sewed.

RANKE (PROFESSOR).-RANKE'S HISTORY OF THE REFORMATION. Translated by Sarah Austin, translator of Ranke's "History of the Popes." Vols 1 and 2 , 8 vo. 30 s. cloth.

[Vol. III. is in the press.

READER (THOMAS),-TIME TABLES.

On a New and Simplified Plan; to facilitate the Operation of Discounting Bills, and the Calculation of Interest on Banking and Current Accounts, etc. : shewing, without calculation, the Number of Days from every Day in the Year to any other Day, for any Period not exceeding 365 Days. By Thomas Reader. Post 8vo. 14s. cloth, or 17s. calf lettered.

\section{REECE.-THE MEDICAL GUIDE :}

For the use of the Clergy, Heads of Frmilies, Seminaries, and Junior Practitioners in Medicine; comprising a complete Modern Dispensatory, and a Practical Treatise on the distinguishing Symptoms, Causes, Prevention, Cure, and Palliation of the Disesses incident to the Human Frame. By R. Reece, M.D. 16th Edition, 8vo.128. boards.

\section{REGISTRAR-GENERAL-THE SEVENTH ANNUAL REPORT OF THE} REGISTRAR-GENERAL OF BIRTHS, DEATHS, AND MARRIAGES, IN ENGLAND, 1845. 8vo. 5s. cloth.-Also,

First Repurt (1839), 8vo. 3s. Third Report (184I) 8vo. 4s. Fifth Report (1843) 8vo, 5s.

Second Report (1840), 8vo. 4s. Fourth Report (1842) 8vo.4s. Sixth Report (1844) 8vo. 5s.

\section{REID (DR.)-ILLUSTRATIONS OF THE THEORY AND PRACTICE OF} VFNTILATION : with Remarks on Warming, Exclusive Lighting, and the Communication of Sound. By D. B. Reid, M.D.F.R.S.E. ete. 8vo. with Engravings on Wood, 16s, cloth.

REPTON.-THE LANDSCAPE CARDENING \& LANDSCAPE ARCHITECTURE of the late Humphrey Repton, Esq.; being his entire Works on these subjects. A New Edition, with an Historical and Scientific Introduction, a systematie Analysis, a Biographical Notice, Notes, and a copious Alphabetical Index. By J. C. Loudon, F.L.S., etc. 8vo. with a Portrait and upwards of 250 Engravings, 30s. cloth; with coloured Plates, 3l. 6s. cloth.

\section{REYNARD THE FOX;}

A renowned Apologue of the Middle Age. Reproduced in Rhyme. Embellished throughout with Scroll Capitals, in Colours, from Wood-block Letters made expressly for this work, after Designs of the 12th and 13th Centuries. By Samuel Naylor, late of Queen's College, Oxford. Large square 8 vo. 18s. cloth.

\section{RIDDLE.-A COMPLETE ENGLISH-LATIN AND LATIN-ENGLISH DIC-} TIONARY, from the best sources, chiefly German. By the Rev.J. E. Riddle, M.A. 4th Edition. 8vo. 31s. 6d. cloth.

** Separately-The English-Latin Dictionary, 10s. 6d.; the Latin-English Dictionary, $21 s$.

RIDDLE.-A DIAMOND LATIN-ENGLISH DICTIONARY. A Guide to the Meaning, Quality, and right Accentuation of Latin Classical Words. By the Rev. J. E. Riddle, M.A. New Edition. Royal $32 \mathrm{mo} .4 s$, bound.

RIDDLE.-LETTERS FROM AN ABSENT CODFATHER; Or, a Compendium of Religious Instruction for Young Persons. By the Rev.J.E. Riddle, M.A. Foolscap 8vo.6s. cloth.

\section{RIDDLE.-ECCLESIASTICAL CHRONOLOGY;}

Or, Annals of the Christian Church, from its Foundation to the present Time. Containing a View of General Church History, and the Course of Secular Events ; the Limits of the Church and its Relations to the State; Controversies; Sects and Parties; Rites, Instifutions, and Discipline; Ecclesiastical Writers. By the Rev.J. E. Riddle, M.A. 8vo.15s. cloth.

RITCHIE (ROBERT.)-RAILWAYS: THEIR RISE AND PROGRESS. AND CONSTRUCTION, with Remarks on Railway Accidents, and Proposals for their Prevention. By Robert Ritchie, Esq., F.R.S., S. A., Civil Engineer, Associnte of the Institution of Civil Engineers, etc. Feap. 8vo. with Woodeuts and Diagrams, 9s. cloth. 
RIVERS.-THE ROSE AMATEUR'S CUIDE :

Containing ample Descriptions of all the fine leading varieties of Roses, regularly classed in their respective Families; their History and mode of Culture. By T. Rivers, Jun. Fourth Edition, corrected and improved. Foolscap 8vo.6s. cloth.

ROBERTS.-A COMPREHENSIVE VIEW OF THE CULTURE OF THE VINE UNDER GLASS. By James Roberts, Gardener to Matthew Wilson, Esq., Eshtou Hall, Skipton, Yorkshire. $12 \mathrm{mo}, 5 s, 6 d$, cloth.

ROBINSON (JAMES),-THE WHOLE ART OF CURING, PICKLING, and SMOKING MEAT and FISH, both in the British and Foreign Modes. With many useful Miscellaneous Recipes, and full Directions for the Construction of an Economical Drying.Chimney and Apparatus, on an entirely new Plan. By James Robinson, Eighteell Years a Practical Curer. Fcap. 8vo. 4s,6d. cloth.

\section{ROGERS. - THE VEGETABLE CULTIVATOR;}

Containing a plain and accurate Description of all the different Species of Culinary Vegetables, with the most approved Method of Cultivating them by Natural and Artificial Means, and the best Modes of Cooking them. By John Rogers, author of "The Fruit Cultivator." 2d Edition. Foolscap 8vo.7s. eloth.

\section{ROGET.-THE ECONOMIC CHESS-BOARD;}

Being a Chess-Board, provided with a complete set of Chess-Men, for playing Games in carriages, or out of doors, and for folding up, and carrying in the pocket, without disturbing the Game. Invented by P. M. Roget, M.D. and registered aecording to Act of Parliament. New Edition. In a neat fcap. 8vo. case, price 2s. $6 d$.

ROME.-THE HISTORY OF ROME (IN THE CABINET CYCLOPFDIA). 2 vols. foolscap 8vo. with Vignette Titles, 12s. cloth.

ROSCOE.-LIVES OF EMINENT BRITISH LAWYERS.

By Henry Roscoe, Esq. Foolscap 8vo. with Vignette Title, 6s. cloth.

ROWTON (F.)-THE DEBATER;

Being a Series of complete Debates, Outlines of Debates, and Questions for Discussion. With ample references to the best sources of information upon each particular topic. By Frederic Rowton, Lecturer on General Literature. Foolscap 8vo. 6a. clotb.

SANDFORD (REV. JOHN).-PAROCHIALIA,

or Church, School, and Parish. By the Rev. John 'Sandford, M.A. Vicar of Duuchurch, Chaplain to the Lord Bishop of Worcester, Hon. Canon of Worcester, and Rural Dean 8vo. with numerous Woodents, 16s. cloth.

SANDFORD. - WOMAN IN HER SOCIAL AND DOMESTIC CHARACTER. By Mrs. John Sandford. 6th Edition. Foolscap 8vo.6s. cloth.

SANDFURD.-FEMALE IMPROVEMENT. By Mrs. John Sandford. 2d Edition. Foulscap 8vo.7s.6d. cloth.

SCHLEIDEN (PROF.)-PRINCIPLES OF SCIENTIFIC BOTANY. By M. J. Schleiden, Professor of Botany at Jena. Translated by E. Lankester, M.D. F.L.S. 8vo. with numerous Wood Engraviugs

In the press.

SCOTT.-THE HISTORY OF SCOTLAND.

By Sir Walter Scott, Bart. New Edition. 2 vols. fcap.8vo. with Vignette Titles, 12s.cloth.

SEAWARD. - SIR EDWARD SEAWARD'S NARRATIVE OF HIS SHIPWRECK, and consequent Discovery of certain Islands in the Caribbean Sea: with a Detail of many extraordinary and highly interesting Events in his Life, from 1733 to 1749 , as written in his own Diary. Edited by Miss Jane Porter. 3d Edition. 2 vols. post 8vo. 21s. cloth.

\section{SELECT WORKS OF THE BRITISH POETS :}

From Chaucer to Withers. With Biographical Sketches, by R. Southey, LL.D. Medium 8vo. 30 s. cloth; or, with gilt edges, 31 s. $6 d$.

\section{SELECT WORKS OF THE BRITISH POETS:}

From Ben Johnson to Coleridge. With Biographic land Critical Prefaces by Dr. Aikin. A New Edition, with additional Selections, from more recent Poets, by Lucy Aikin. Medium 8vo. 18s. cloth.

** The peculiar feature of these two works is, that the Poemsincluded are printed entire, vithout mutilation or abridgment. 


\section{SERMON ON THE MOUNT (THE).}

Intended as a Birthday-Present, or Gift-Book for all Seasons. Printed in Gold and Coloura. in the Missal Style, with Ornamental Borders by Owen Jones, Architect, and an Illuminated Frontispiece by W. Boxall, Esq. A new edition. Foolscap 4to. In a rich brocaded silk cover, 21s.; or bound in morocco, by Hayday, 25 s.

\section{SHAKSPEARE, BY BOWDLER.}

THE FAMILY SHAKSPEARE, in which nothing is added to the Original Text ; but thome Words and Expressions are omitted which cannot with propriety be read aloud. By $\mathbf{T}$. Bowdler, Esq. F.R.S. Ninth Edition, 8vo, with 36 Illustrations after Smirke, ete., $21 \mathrm{~s}$. cloth; or, without Illustrations, 8 vols. 8 vo. $4 l$. 14s. $6 d$. boards.

\section{SHELDON (F.)-THE MINSTRELSY OF THE ENGLISH BORDER :}

Being a Collection of Ballads, Ancient, Re-modelled, and Original, founded on well-known Border Legends. With Illustrative Notes, By Frederick Sheldon. Square post 8vo.15s. cloth; morocco, 30s. (bound by Hayday).

\section{SHELLEY, ETC.-LIVES OF THE MOST EMINENT LITERARY MEN OF} ITALY, SPAIN and PORTUGAL. By Mrs. Shelley, Sir D. Brewster, J. Montgomery, etc. 3 vols. foolscap 8 vo. with Vignette Titles, 18s. cloth.

\section{SHELLEY.-LIVES OF THE MOST EMINENT FRENCH WRITERS.}

By Mrs. Shelley and others. 2 vols. foolscap 8vo. with Vignette Titles, 12, cloth.

\section{SHEPHERD (REV. W.)-HORE APOSTOLICFE;}

Or, a Digested Narrative of the Acts, Lives, and Writings of the Apostles. Arranged according to Townsend. By the Rev. William Shepherd, B.D. Rector of Margaret Roding, Essex, and Rural Dean. Fcap.8vo.5s.6d. cloth.

\section{SHORT WHIST :}

Its Rise, Progress, and Laws; with the recent Decisions of the Clubs, and Observations to make any one a Whist Player. Containing als o the Laws of Piquet, Cassino, Ecarte, Cribbage, Backgammon. By Major A * * . 9th Edition. To which are added, Precepts for'Tyros. By Mrs. B * * Foolscap 8vo.3s, cloth, gilt edges.

\section{SINNETT.-THE BY-WAYS OF HISTORY.}

By Mrs. Percy Sinnett. 2 vols, post 8vo.

[ust ready.

\section{SMITH (GEORGE).-THE RELIGION OF ANCIENT BRITAIN HISTORICALLY}

CONSIDERED: Or, a Succinct Account of the several Religious Systems which have obtained in this Island from the Earliest Times to the Norman Conquest: including an Investigation into the Early Progress of Error in the Christian Church, the Introduction of the Gospel into Britain, and the State of Religion in England till Popery had gained the Ascendency. By George Smith, F.A.S. 2d Edition. 8vo.78.6d. cloth.

\section{SMITH (GEORGE),-PERILOUS TIMES:}

Or, the Agressions of Anti-Christian Error on Scriptural Christianity : considered in reference to the Dangers and Duties of Protestants. By George Smith, F.A.S. Member of the Royal Asiatic Society, and of the Royal Society of Literature. Foolscap 8vo. 6s. cloth.

SMITH (MRS. H.) - THE FEMALE DISCIPLE OF THE FIRST THREE CENTURIES OF THE CHRISTIAN ERA : Her Trials and Her Mission. By Mrs. Henry Smith. Foolscap 8vo. 68. cloth.

\section{SMITH.-AN INTRODUCTION TO THE STUDY OF BOTANY.}

By SirJ. E. Smith, late President of the Linnaean Society. 7th Edition, corrected ; in which the object of Smith's "Grammar of Botany" is combined with that of the "Introduction." By Sir William Jackson Hooker, K.H. LL.D. etc. 8vo. with 36 Steel Plates, 16s. cloth, with coloured Plates, 2l.12s.6d. cloth.

\section{SMITH.-COMPENDIUM OF THE ENGLISH FLORA.}

By Sir J. E. Smith. 2d Edition, with Additions and Corrections. By Sir W.J.Hooker. $12 \mathrm{mo} .78,6 d$. cloth. THE SAME IN LATIN. 5th Edition, $12 \mathrm{mo} .7 \% .6 d$.

\section{SMITH.-THE ENGLISH FLORA.}

By Sir James Edward Smith, M.D. F.R.S., late President of the Linnean Society, etc. 6 vols. 8vo. $3 l .12 s$. boards. 
SMITH (SYDNEY).-SERMONS PREACHED AT ST. PAUL'S CATHEDRAL, the Foundling Hospital, and several Churches in London; together with others addressed to a Country Cungregation. By the late Rev. Sydney Smith, Canon Residentiary of St. Paul's Cathedral. 8vo. 12s. cloth.

SMITH.-THE WORKS OF THE REV. SYDNEY SMITH.

$3 d$ Edition, with additions. 3 vols.8vo. with Portrait, 368 . cloth.

SOPHOCLES, BY LINWOOD.

SOPHOCLIS TRAGOEDIA SUPERSTITES. Recensuit, et brevi adnotatione instruxit Gulielmus Linwood, A.M. Adis Christi apud Oxonienses Alumnus. 8vo. 16s, cloth.

SOUTHEY (ROBERT). - THE LATE MR. SOUTHEY'S COMMONPLACE BOOK; comprising his Readings and Collections in History, Biography, Manners and Literature, Voyages and Travels, etc. etc.; systematically arranged. [In the press.

SOUTHEY (ROBERT) -THE DOCTOR, ETC: VOL. VI.

From the Papers of the late Robert Southey. Edited by his Son-in-Law, the Rev. John Wood Warter. Post 8vo.108,6d. cloth.

\section{SOUTHEY.-THE LIFE OF WESLEY,}

And Rise and Prugress of Methodism. By Robert Southey, Esq. LL.D. 3rd Edition, with Notes by the late Samuel Taylor Coleridge, Esq., and Remarks on the Life and Character of John Wesley, by the late Alexander Knox, Esq. Edited by the Rev. Charles Cuthbert Southey, A.M. Curate of Cockermouth. 2 vols. 8 vo. with two Portraits, 1l. 8 , cloth.

SOUTHEY, ETC.-LIVES OF THE BRITISH ADMIRALS;

With an Introductory View of the Naval History of England. By R. Southey, Esq. and R. Bell, Esq. 5 vols. foolscap 8vo., with Vignette Titles, 1l. 10s. cloth.

\section{SOUTHEY'S (ROBERT) COMPLETE POETICAL WORKS :}

Containing all the Author's last Introductions and Notes. Complete in one volume, medium 8vo. with Portrait and Vignette, uniform with Byron's and Moore's Poetical Works, 21s.; or 42s. bound in moroceo, by Hayday.

Also, an Edition in 10 vols. foolscap 8vo, with Portrait and 19 Plates, 2l.108.; morocco, $4 l .108$.

\section{SPIRIT OF THE WOODS (THE).}

By the author of "The Moral of Flowers." 2d Edition. Royal 8vo. with 23 benutifully coloured Engravings of the Forest Trees of Great Britain, $1 l .11 s .6 d$. cloth.

STABLE TALK AND TABLE TALK; OR, SPECTACLES FOR YOUNG SPORTSMEN. By Harry Hieover. 2 vols, 8vo, with Portrait, 12s. cloth.

\section{STEBBING.-THE HISTORY OF THE CHRISTIAN CHURCH,}

From its Foundation to A.D. 1492. By the Rev, H. Stebbing, M.A., etc. 2 vols. foolscap 8vo. with Vignette Titles, 12s. cloth.

STEBBING.-THE HISTORY OF THE REFORMATION.

By the Rev. H. Stebbing. 2 vols. foolscap 8vo. with Vignette Titles, 12s,cloth.

\section{STEEL'S SHIPMASTER'S ASSISTANT.}

Compiled for the use of Merchants, Owners and Masters of Ships, Officers of Customs, and all Persons connected with Shipping or Commerce; containing the Law and Local Regulations affecting the Ownership, Charge, and Management of Ships and their Cargoes ; together with Notices of other Matters, and all necessary Information for Mariners. New Edition, rewritten throughout. Edited by Graham Willmore, Esq. M.A. Barrister-at-Law; the Customs and Shipping Department by George Clements, of the Custems, London, compiler of "The Customs Guide;" The Exchanges, etc. and Naval Book-keeping, by William 'Tate, author of "The Modern Cambist." 8vo.28s. cloth ; or 29s. bound.

\section{STEEPLETON}

Or, High Church and Low Church. Being the present Tendencies of Parties in the Church, exhibited in the History of Frank Faithful. By a Clergyman. Foolseap 8ro.

[In Junuary.

\section{STEPHENS. - A MANUAL OF BRITISH COLEOPTERA;}

Or, BEETLES : containing a Description of all the species of Beetles hitherto ascertained to inhabit Great Britain and Ireland, etc. With a complete Index of the Genera. By J. F. Stephens, F.L.S., author of "Il'ustrations of Entomology." Post 8vo. 14s, cloth.

SWITZERLAND.-THE HISTORY OF SWITZERLAND.

(In the Cabinet Cyclopædia.) Foolscap 8vo. with Vignette Title, 6s. cloth. 
SWAINSON.-A PRELIMINARY DISCOURSE ON THE STUDY OF NATURAL HISTORY. By W. Swainson, Esq. Foolscap 8vo.68. cloth.-By the same Author.

A TREATISE ON THF NATURAI, HIS. TORY \& CLASSIFICATION OF ANIMALS. Fcap. 8vo. 6s.

NATURAL HISTORY AND CLASSIFICATION OF QUADRUPEDS. Fcap. 8vo.6s. NATURAL HISTORY AND CLASSIFICA. TION OF BIRDS. 2 vols. fcap. $8 v 0.12 s$.

HABITS AND INSTINCT OF ANIMALS. Feap. 8vo. 6s.

ANIMALS IN MENAGERIES. Fcap. 8vo.6s.
NATURAL HISTORY ETC. OF FISH, AMPHIBIA, \& RE.PTILFS. 2 vols, fcap. 8vo. 12n.

A TREATISE ON MALACOLOGY; Or, the Natural Classification of Sliells and ShellFish. Feap. 8vo.68.

HISTORY AND NATURAL ARRANGEMEN'T OF INSECTS. Feap.8vo.6s.

A TREATISE ON TAXIDERMY; with the Biography of Zoologists, and Notices of their Works. Fcap. 8vo,6s.

\section{SYMONDS.-THE LAW RELATING TO MERCHANT SEAMEN,}

Arranged chietly for the use of Masters and Officers in the Merchant Service. With an Appendix, contuining the Act $7 \& 8$ Vic. c. 112 ; the Regulations under which Lascars may be employed; and some forms of Proceedings before Magistrates. By E. W. Symonds, Esq. Chief Clerk of the Thames Police Court. Third Edition. 12mo. 5s. cloth.

\section{TATE.-HORATIUS RESTITUTUS:}

Or, the Books of Horace arranged in Chronological Order, according to the Scheme of Dr. Bentley, from the Text of Gesuer, corrected and improved. With a Preliminary Dissertation, very much enlarged, on the Chronology of the Works, on the Localities, and on the Life and Character of that Poet. By James Tate, M.A. Second Edition. 8vo. 12s. cloth.

TATE.-THE CONTINUOUS HISTORY OF THE LIFE AND WRITINGS OF ST. PAUL, on the basis of the Acts; with Intercalary Matter of Sacred Narrative, supplied from the Epistles, and elucidated in occasional Dissertations: with the Horæ Paulinz of Dr. Paley, in a more correct edition, subjoined. By James Tate, M.A. 8vo. Map, 13s. cloth.

TAYLER (REV, CHARLES B.)-MARGARET; Or, the Pearl. By the Rev. Charles B. Tayler, M.A. Rector of St. Peter's, Chester, author of "Lady Mary; or, Not of the World;" etc. 2d Edition. Foolscap 8vo.6s. cloth.

TAYLER (REV.CHARLES B.)-LADY MARY; OR, NOT OF THE WORLD. By the Rev. Charles B. Tayler, Rector of St. Peter's, Chester; author of "Margaret, or the Pearl," etc. Foolscap 8vo.6s.6d. cloth.

\section{TAYLER (REV. CHARLES B.)-TRACTARIANISM NOT OF COD.}

Sermons. By the Rev. C.B. Tayler, Rector of St. Peter's, and Evening Lecturer at St. Mary's, Chester; author of "6 Lady Mary ; or, Not of the World," etc. Fcap.8vo.68. cloth.

\section{TAYLER (REV. CHARLES B.)-DORA MELDER :}

A Story of Alsace. By Meta Sander. A Translation. Edited by the Rev. C. B. Tayler, author of "Margaret; or, the Pearl," etc. Fcap. 8vo., with two Illustrations, 7s. cloth.

\section{TAYLOR (JEREMY).-BISHOP JEREMY TAYLOR'S WORKS.}

With the References verified. A New and thoroughly revised Edition.

* This Work is in the hands of a competent Editor at Oxford, and will be published in volumes, price $10 s .6 d$. each; to be completed in 12 volumes, each of 600 closely printed pages, published at intervals of two months. The first volume vill be published early in 1847. Subscribers' names received by the Proprietors, and all Booksellers.

\section{THIRLWALL.-THE HISTORY OF GREECE.}

By the Right Rev. the Lord Bishop of St. David's. A new Edition, revised; with Notes. Vols. I. to III. demy 8 vo. with Maps, 12s. each cloth. To be completed in 8 volumes.

[Vol. IV. is in the press.

** Also, an Edition in 8 vols. fcap. 8vo. with Vignette Titles, 2l. 8s. cloth.

\section{THOMSON'S SEASONS.}

Edited by Bolton Corney, Esq. Illustrated with Seventy-seven Designs drawn on Wood by the Members of the Etching Club. Engraved by Thompson and other emineut Engravers. Square crown 8vo. uniform with "Goldsmith's Poems," 21s. cloth; bound in morocco, by Hayday, $36 s$.

THOMSON.-EXPERIMENTAL RESEARCHES ON THE FOOD OF ANIMALS, AND THE FATTENING OF CATTLE: with Remarks on the Food of Man. By Robert Dundas Thomson, M.D. of the University of Glasgow. Feap. 8v0. 5s. cloth.

"The question of the origin of the fat of animals appears to be completely resolved by these beautiful and elaborate eaperiments."-Baron Liebig. 
THOMSON (JOHN).-TABLES OF INTEREST,

At Three, Four, Four-and-a-half, and Five per Cent., from One Pound to Ten Thousand, and from One to Three Hundred and Sixty-five Days, in a regular progression of Single Days; with Interest at all the above Rates, from One to Twelve Months, and from One to Ten Years. Also, Tables shewing the Exchange on Bills, ete.etc.etc. By John Thomson, Accountant in Edinburgh. 12mo. 8s. bound.

THOMSON. - THE DOMESTIC MANAGEMENT OF THE SICK ROOM, Necessary, in Aid of Medical Treatment, for the Cure of Diseases. By Anthony Todd Thomson, M.D. F.L.S. etc. 2d Edition. Post 8v0.10s.6d. cloth.

\section{THORNTON -OVER POPULATION AND ITS REMEDY:}

Or, an Enquiry into the Extent and Causes of the Distress prevailing among the Labouring Classes of the British Islinds, and iuto the means of remedying it. By William Thomas Thornton. 8vo.10s. 6d. cloth.

TISCHENDORF-CONSTANTINE TISCHENDORF'S TRAVELS IN THE EAST. Translated from the German. $16 \mathrm{mo}$. uniform with the cheap authorised English Translations of the works of Michelet and Quinet.

[In the press.

TOMLINE (BISHOP).-AN INTRODUCTION TO THE STUDY OF THE BIBLE: Being the First Volume of the Elements of Christian Theology; containing Proofs of the Authenticity and Inspiration of the Holy Scriptures; a Summary of the History of the Jews; an Account of the Jewish Sects; and a brief Statement of the Contents of the several Books of the Old Testament. By the late George Tomlin, D.D.F.R.S. 20th Edition. Foolscap 8vo. 58. 6d. cloth.

TOMLINS. - A POPULAR LAW DICTIONARY;

Familiarly explaining the Terms and Nature of English Law; adapted to the comprehension of Persons not educated for the Legal Profession, and affording Information peculiarly useful to Magistrates, Merchants, ParochialOfficers, and others. By Thomas Edlyne Tomlins, Attorney and Solicitor. Post 8vo.18s. cloth.

TOOKE.-A HISTORY OF PRICES ;

With reference to the Causes of their principal Variations, from 1792 to the Present Time. Preceded by a Sketch of the History of the Corn Trade in the last Two Centuries. By Thomas Tooke, Esq. F.R.S. 3 vols. 8 vo. $2 l$. 8 s. cloth.

". Separately, Vols. I. and II. 36s.; Vol. III. I2s.

TOPHAM.-CHEMISTRY MADE EASY,

For the Use of Agriculturists. By John Topham, A.M. Rector of St. Andrew, St. Mary Witton, and St. Nicholas, Droitwich. Third Edition. 16mo.2s. sewed.

TOWNSEND (CHARLES).-THE LIVES OF TWELVE EMINENT JUDGES. OF THE LAST AND OF THE PRESENT CENTURY. By W. Charles Townsend, Esq. A.M. Recorder of Macclesfield, author of "Memoirs of the House of Commons." 2 vols. 8vo. 28s. cloth.

TREVOR ;

Or, The New St. Francis. A Tale of the Times. Foolscap 8 ro.

[In January.

TROLLOPE (REV. W.)-ANALECTA THEOLOGICA :

A Critical, Philological, and Exegetical Commentary on the New Testament, adapted to the Greek Text ; compiled and digested from the most approved sources, British and Foreign, and so arranged as to exhibit the comparative weight of the differeut Opinious on Disputed Texts. By the Rev. William Trollope, M.A. New Edition. 2 vols.8vo.11. 12s, cloth.

TURNER.-THE SACRED HISTORY OF THE WORLD,

Philosophically considered. By S. Turner, F.S.A. R.A.S.L. New Edit. 3 vols.8vo.42s. bds.

TURNER.-THE HISTORY OF ENGLAND,

From the Earliest Period to the Death of Elizabeth. By SharonTurner, Esq.F.A.S.R.A.S.L. New Editions. 12 vols. 8vo. $8 l$. 3s. cloth; or, separately-

THE HISTORY of the ANGLO-SAXONS. 3 vols. $8 \mathrm{vo} .22 .5 \mathrm{~s}$.

THE HISTORY of ENGLAND during the MIDDLE AGES. 5 vols. 8 vo. $3 l$.

THE HISTORY of the REIGN of HENRY VIII. 2 vols. 8vo.268.

THE REIGNS of EDWARD VI., MARY, and ELIZABETH. 2 vols. 8vo.32s. 
TURNER.-A TREATISE ON THE FOOT OF THE HORSE,

And a New System of Shoeing, by Une-sided Naillng; and on the Nature, Origln, and Symptoms of the Navicular Joint Lameness, with Preventive and Curative Treatment. By James Turner, M.R.V.C. Royal 8vo. 7s.6d. boards.

TURTON'S (DR.) MANUAL OF THE LAND AND FRESHWATER SHELLS OF THE BRITISH ISLANDS. A new Edition, thoroughly revised, and with considerabie Additions. By Joln Edward Gray, Keeper of the Zoological Coilection in the British Museum. Post 8vo. with Woodcuts, and 12 coloured Plates, 15s. cloth.

TYTLER (PROFESSOR). - PROFESSOR TYTLER'S ELEMENTS OF GENERAL HISTORY, Ancient and Modern, with Dr. Nares'Continuation. A new Edition, revised and continued to the Deati of Wiliam IV. 8vo. with 7 Maps, 14s. cloth.

URE.-DICTIONARY OF ARTS, MANUFACTURES, AND MINES

Containing a clear Exposition of their Principles und Practice. By Andrew Ure, M.D. F.R.S. M.G.S.M.A.S. Lond.; M. Acad. N.S. Philad.; S. Ph. Soc. N. Germ. Hanov. i Mullii, etc. etc. Third Edition, corrected. 8vo. with 1240 Woodcuts, 50s. cloth.

By the same Author,

SUPPLEMENT OF RECENT IMPROVEMENTS. 2d Edition. 8vo. 14s. cloth.

VON ORLICH (CAPT.)-TRAVELS IN INDIA,

And the adjacent Countries, in 1842 and 1843. By Capt. Leopold Von Orlich. Translated from the German by H. Fvans Lloyd, E'sq. 2 vols. 8vo. with coloured Frontispieces, and uumerous Illustratious on Wood, 258. cluth.

\section{WALFORD (J. E.) - THE LAWS OF THE CUSTOMS,}

Compiled by Direction of the Lords Commissioners of Her Majesty's Treasury, and published under the Sanction of the Commissioners of Her Majesty's Customs; with Notes and a General Index. Edited by J.G. Walford, Esq. Solicitor for the Customs. Printed for Her Majesty's Stationery Office, and published by Authority. 8vo. 10s. 6d. cloth.

WALKER'S PRONOUNCING DICTIONARY OF THE ENGLISH LANGUAGE, adapted to the Present State of Literature and Science. By B. H. Smart, Author of "Theory and Practice of Elocution," etc. 2nd Edition. To which are now added, an enlarged Etymological Index; and a Supplement, containiug nearly 3,000 words not included in the previous Edition of the Dictionary. 8vo.15s. cloth.

* The Supplement, with the Etymological Index, may be had separately, price 3s. 6d. sewed.

WALKER'S PRONOUNCING DICTIONARY, Epitomised by Smart. New Edition. $16 \mathrm{mo.}$ 7s. 6d. cloth.

WÁLKER (GEO.)-CHESS STUDIES :

Comprising 1000 Games actually Played during the last Half Century ; presenting a nnique Collection of Classical and Brilliant Specimens of Chess skili in every stage of the Game, and forming an Encyclopæedia of Refercnce. By George Walker. Medium 8vo. 10s. 6d. sewed.

WARDLAW.-DISCOURSES ON THE PRINCIPAL POINTS OF THE SOCINIAN CONTROVERSY - the Unity of God, and the Trinity of Persons in the Godhead-the Supreme Divinity of Jesus Christ-the Doctrine of the Atonement-the Christian Character, etc. By Ralph Wardlaw, D.D. 5th Edition. 8vo.15s. cloth.

WATERTON.-ESSAYS ON NATURAL HISTORY, Chiefly Ornithology. By Charles Waterton, Esq., author of "'Wanderings in South America." With an Autobiography of the Author, and.a View of Walton Hall. New Edition, foolscap 8 ro. 8s. cloth.

SECOND SERIES. With Continuation of Mr. Waterton's Autoblography. New Edition, feap. 8vo. with Vignette by T. Creswick, A.R.A. 6s.6d. cloth.

WATTS (A. A.) - LYRICS OF THE HEART,

With other Poems. By Alaric A. Watts. Illustrated by 40 highly-finished Line Engravings, from the Designs of many of the eminent modern Palnters, by the best Kugravers of the age. from the Designs of many of the eminent modern Painters, by the wished "Italy" and "Poems," Square crown 8vo. printed and embellished uniformly with $31 s, 6 d$. boards; or proof impressions, $63 s$. boards; proofs before letters, on 4to. coloster.
India paper (only 50 copies printed), price $5 \mathbf{l} .58$.
[At Baster.

WEBSTER.-AN ENCYCLOPAEDIA OF DOMESTIC ECONOMY;

Comprising such subjects as are most immediately connected with Housekeeping $;$ as, Comprising stich sibjects as are most ith the modes of Warming, Ventilating, and The Construction of Domestic Edifices, with the modes of Lighting them-A description of the various articles of Furniture, with the nature or tered Materials-Duties of Servants, etc. etc. etc. By Thomas Webster,
by the late Mrs. Parkes. 8vo, with nearly i,000Woodeuts, 50s. cloth. 
WEIL (DR.)-THE BIBLE, THE KORAN, AND THE TALMUD;

Or, Biblical Legends of the Mussulmans, compiled from Arabic Sources, and compared with Jewish Traditions. By Dr. G. Weil, Librarian of the University of Heidelberg, etc Translated from the German, with occasional Notes. Post 8vo. 7s. 6d: cloth.

WESTWOOD (J.O). - AN INTRODUCTION TO THE MODERN CLASSIFICATION OF INSECTS; founded on the Natural Habits and compounding Organisation of the different Families. By J. O. Westwood, F. L.S. ete. etc. etc. 2 vols. 8 vo. with numerous Illustrations, $2 l .7 s$, cloth.

\section{WHITLEY.-THE APPLICATION OF GEOLOGY TO AGRICULTURE,}

And to jthe Improvement and Valuation of Land; with the Nature and Properties of Soils, and the Principles of Cultivation. By Nicholas Whitley, Land-Surveyor. 8vo. 7s. 6 d. cloth.

WILBERFORCE (W.) - A PRACTICAL VIEW OF THE PREVAILING RELIGIOUS SYSTEMS OF PROFESSED CHRISTIANS, in the Higher and Middle Classes in this Country, contrasted with Real Christianity. By William Wilberforce, Esq. M.P. for the County of York. New Editions. 8vo. 8s, boards. 12mo, 4s, 6d, cloth:

WILKINSON.-A CATECHISM OF CHURCH HISTORY IN GENERAL, From the Apostolic Age to the Present Time. To which is added, a Catechism of Envlish Church History; with a Summary of principal Events, in Chronological Order. By the Rev. W. F. Wilkinson, A.M. Theological Tutor of Cheltenham College. Foolscap 8vo. 6s, cloth.

\section{WILKINSON (H.)-ENGINES OF WAR :}

Or, Historical and Experimental Observations on Ancient and Modern Warlike Machines and Implements, including the Manufacture of Guns, Gunpowder, and Swords. With Remarks on Bronze, Iron, and Steel. By Henry Wilkinson, M.R.A.S. etc. 8vo.9s. çloth.

WILLIS (N.P.)-DASHES AT LIFE. WITH A FREE PENCIL.

By N.P. Willis, Esq., author of "Pencillings by the Way," "Inklings of Adventure," etc. 8 vols, post 8 vo. 31s.6d. boards.

\section{WILLOUGHBY (LADY) - A DIARY}

Purporting to be by the LAUY WILLOUGHBY of the Reign of Charles I., embracing some Passages of her Domestic History from 1635 to 1648. 3d edition. Square foolscap 8vo. 8s. boards; or 18s. bound in morocco (old style).

* This volume is printed and bound in the style of the period to which The Diary rejers.

WINTER (J. W.)-THE HORSE IN HEALTH AND DISEASE:

Or, Suggestions on his Natural and General History, Varieties, Conformation, Paces, Age, Soundness, Stabling, Condition, Training, and Shoeing. With a Digest of Veterinary Practice. By James W. Winter, M.R.C.V.S.L. 8vo. 10s.6d, cloth,

\section{WOOD.-A PRACTICAL TREATISE ON RAILROADS,}

And Interior Communication in General; containing numerous Experiments on the Powers of the Improved Locomotive Engines, and Tables of the comparative Cost of Conveyance on Canals, Railways, and Turnpike Roads. By Nicholas Wood, Memb. Inst. Civ. Eng. etc. Third Edition. 8vo, with Plates and Woodcuts, 31s. 6d. cloth.

\section{WOODWARD.-ESSAYS, SERMONS, ETC.}

By the Rev. Henry Woodward, A.M. formerly of Corpus Christi College, Oxford; Rector of Fethard, in the Diocese of Cashel. Fourth Edition. 2 vols. 12mo. 148. cloth.

By the same Author,

THE SHUNAMMITE: a Series of Lectures and Reflections on 2 Kings, iv, 2 vols. I2mo. 12s. cloth. Vol. 2, separately, 6s. cloth.

\section{ZOOLOGY OF THE VOYAGE OF H.M.SS' EREBUS AND TERROR.}

Under the Command of Capt. Sir James Clark Ross, R.N. F.R.S. during the years 1839 , $40,41,42,43$. Published by Authority of the Lords Commissioners of the Admiralty. Edited by John Richardson, M.D. F.R.S. etc.; and John Edward Gray, Esq. F.R.S. Parts I. to XV. Royal 4to. with numerous coloured and plain Plates, 10s. each, sewed.

$$
\text { ** To be completed in tun or three more parts. }
$$

\section{ZUMPT (PROF.)-A GRAMMAR OF THE LATIN LANGUAGE.}

By C. G. Zumpt, Ph. D. Professor in the University, and Member of the Royal Academy of Berlin. Translated from the 9th Edition of the original, and adapted to the use of English Students, by Leonhard Schmitz, Ph. D., Rector of the High School of Edinburgh; with numerous Additions and Corrections by the Author. 8vo.14s. cloth. 

RETURN TO the circulation desk of any University of California Library

or to the

NORTHERN REGIONAL LIBRARY FACILITY

Bldg. 400, Richmond Field Station

University of California

Richmond, CA 94804-4698

ALL BOOKS MAY BE RECALLED AFTER 7 DAYS

- 2-month loans may be renewed by calling

(510) 642-6753

- 1 -year loans may be recharged by bringing books to NRLF

- Renewals and recharges may be made 4 days prior to due date.

DUE AS STAMPED BELOW

JUN -81999 
$3 \quad \therefore$ 
